City University of New York (CUNY) CUNY Academic Works

9-2017

\title{
Toxic Gas Sensing on Nanoporous Carbons
}

Nikolina-Eleni Travlou

The Graduate Center, City University of New York

\section{How does access to this work benefit you? Let us know!}

More information about this work at: https://academicworks.cuny.edu/gc_etds/2256

Discover additional works at: https://academicworks.cuny.edu

This work is made publicly available by the City University of New York (CUNY).

Contact: AcademicWorks@cuny.edu 

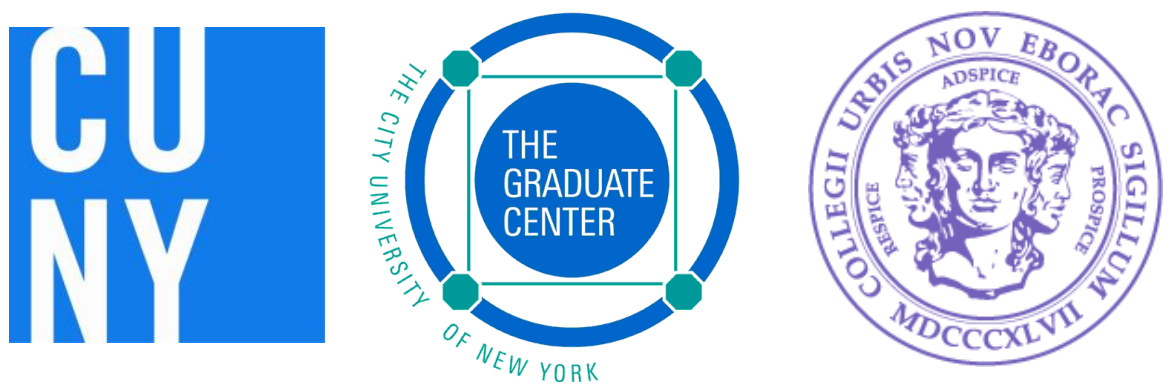

Toxic gas sensing on nanoporous carbons

by Nikolina-Eleni Travlou

A dissertation submitted to the Graduate Faculty in Chemistry in partial fulfillment of the requirements for the degree of Doctor of Philosophy, The City University of New York 2017 
(C) 2017

Nikolina-Eleni Travlou

All Rights Reserved 
Toxic gas sensing on nanoporous carbons

by

Nikolina-Eleni Travlou

This manuscript has been read and accepted for the Graduate Faculty in Chemistry in satisfaction of the dissertation requirement for the degree of Doctor of Philosophy.

Date

Date

\author{
Teresa J. Bandosz \\ Chair of Examining Committee
}

Brian Gibney

Executive Officer

Supervisory Committee:

Charles Michael Drain

Maria Tamargo

Stephen O'Brien 


\section{ABSTRACT \\ Toxic gas sensing on nanoporous carbons \\ by \\ Nikolina-Eleni Travlou}

Advisor: Teresa J. Bandosz

Activated carbons, either synthetic, developed in our laboratory, or commercial, were prepared or further modified, in order to introduce specific heteroatoms such as oxygen, nitrogen and sulfur to their matrices. Chips coated with thin layers of the carbon samples were used for the sensing of gaseous ammonia. They were exposed to continuous cycles of various ammonia concentrations (10-500 ppm), and changes in normalized resistance were analyzed. In all cases linear responses were recorded and the chips reached sensitivities as high as $31 \%$, which are comparable to those of modified graphene-based sensors. The applied specific surface chemical modifications were an effective means to control the type of the charge carriers (electrons or holes), and thus the electronic and transport properties. The mechanism of the reversible sensing was governed by several processes including specific interactions between the surface functional groups and the molecules of the target gas, pore-filling with ammonia (especially of pores smaller than $0.7 \mathrm{~nm}$ ), electron-hole conductivity, and charge transport through ionic conductivity. Strongly acidic carboxylic and sulfonic groups played an important role in ammonia sensing by promoting charge transport via ionic conductivity, due to the formation of $\mathrm{NH}_{4}{ }^{+}$. Among all $\mathrm{N}$-containing groups, nitrogen located in six-membered rings (pyridines and quaternary nitrogen), rather than nitrogen on the periphery (amines, amides) played the most important role in sensing. An important aspect was the conversion of the conduction type from predominantly $p$ - to predominantly $n$ - upon 
oxidation of the carbon surface due to introduction of electron withdrawing nitro groups to the matrix. Owing to the high porosity of the oxidized carbon and the polarity of the formed $-\mathrm{NO}_{2}$ groups present in the pore system, opposite signal changes compared to the initial counterpart were recorded (decrease instead of increase in the normalized resistance). Interesting changes in the electrical response were noticed for S- and N-dual-doped carbons. Their ability to activate oxygen and generate superoxide ions resulted in oxidation of ammonia to nitrogen dioxide. $\mathrm{NO}_{2}$ adsorbed in the pore system caused an increase in the population of holes $\left(h^{+}\right)$as charge carriers in the matrix, which led to a conductivity increase upon ammonia exposure. The surface chemical and structural features of the carbons acted either synergistically or competitively. When the chips were exposed to $\mathrm{H}_{2} \mathrm{~S}$, they showed a very low sensitivity to this gas. A high surface acidity of the carbons enhanced their affinity towards $\mathrm{NH}_{3}$ adsorption, contributing to a selective ammonia detection. The role of the specific chemical arrangement of the heteroatoms on ammonia sensing is extensively examined and analyzed. 


\section{ACKNOWLEDGEMENTS}

A few years back, after a 12 hour flight from the city of Thessaloniki, Greece, I found myself standing on the electrifying pavements of New York, USA. It was a beautiful New York day and I was about to embark into one of the most precious and exciting experiences of my life. The opportunity to do my doctorate will forever be a heaven sent gift, because it came at a time of my life when I became really aware of my personal insecurities and hesitations. I will forever be thankful to the people who made it possible for me to enjoy this breathtaking ride.

I will forever be grateful to Professor Bandosz for being a powerhouse of knowledge, guidance and support on a scientific level as well as a personal level through the continuous encouragement and motivation she has provided me with. Professor Bandosz is the first person who believed in me and my abilities in science, and planted confidence into me. What a force to be reckoned with! To me Professor Teresa presents the perfect role model of an innovative, smart professional scientist, as well as of a strong, creative and beautiful woman. I am deeply inspired by her mesmerizing personality and will always consider her one of the most important people of my life. Professor Teresa Bandosz thank you for everything!

My deepest gratitude and appreciation go to Professors Maria Tamargo, Charles Michael Drain, and Stephen O'Brien for serving on my Dissertation Committee, helping me so openhandedly in every step of my Doctoral journey, and for offering me invaluable expertise, advice and encouragement over the last four years. It is an honor to meet people that not only are tremendous scientists, but also beautiful and special human beings.

I would like to wholeheartedly thank my colleagues and collaborators. It has been a truly amazing experience to scientifically grow around and with such bright and charismatic scientists. Karifala Kante, Wanlu Li, Dimitrios Giannakoudakis, Kavindra Singh, Svetlana Bashkova, Marc Florent, 
Rajiv Wallace, Jimmy Escalada, Finola Fung-Khee, Lilja Nelson, Amani Ebrahim, Mykola Seredych, Dr. Javier Arcibar-Orozco, Mariusz Barczak, Lucie Laritte, Ren Tiezhen, Yuping Hu, Anmol Jadvani, William Stephens, Carla Bastos Vidal, Barbara Herkt, Jeff Secor, Manuel Algarra, Andrea Cardenas, Jorge Morales, Prof. Anuradha Janakiraman, and Prof. Enrique Rodriguez Castellon, thank you! You have made this experience so beautiful and fun. Special thanks to Karifala Kante, Wanlu Li, and Marc Florent, for being not just great colleagues but also true friends! Many thanks to Kavindra Singh who helped me take my first steps in the exciting world of gas sensing.

I would also like to thank Dimitrios Giannakoudakis with whom I started and ended this beautiful journey. He has always been supportive through this $\mathrm{PhD}$. He is a very bright scientist and I am very happy for his professional achievements.

With gratitude, I would also like to acknowledge the financial support from the Graduate Center of CUNY, and Onassis Foundation. Moreover, the travel grants from NSF, Gerondelis Foundation, and Quantachrome Instruments. This research was possible owing to the support from US Army Research Office (Grant W911NF-13-1-0225) and NSF collaborative CBET (Grant no. 1133112). I would like to express my gratitude and deepest love to my father Athanasios Travlos and mother Maarit-Katriina Kukkoaho who are the most unique human beings to step on this planet. I am grateful for their seemingly unlimited reserves of love, human sacrifice and support, through thick and thin since day 1 . I would also like to thank my three sisters, Christina, Valentini and Iliana, who are the greatest gifts my heart will ever know, and who love me unconditionally, as well as Kiriako whom I consider a brother.

My heartiest gratitude goes to certain people who crossed my life as guardian Angels! I cannot thank you enough. 
I reserve my deepest gratitude to God for blessing me much more than I deserve. We should never forget that our goals in life are completed through His allowance and blessings. 
This PhD thesis is dedicated to my beloved parents, Athanasios Travlos and Maarit-Katriina Kukkoaho 


\section{Contents}

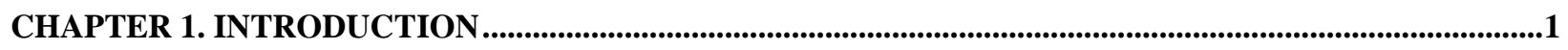

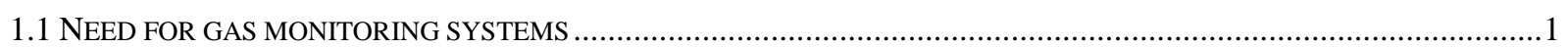

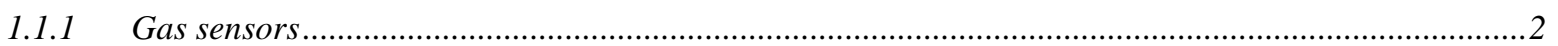

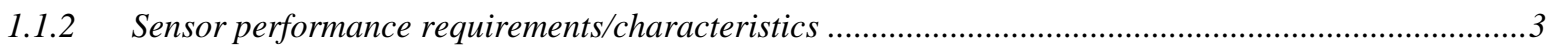

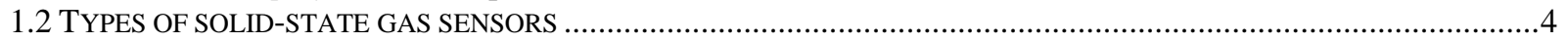

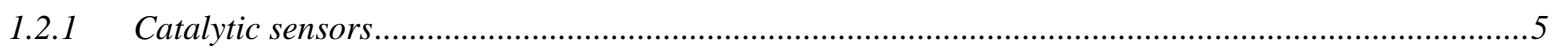

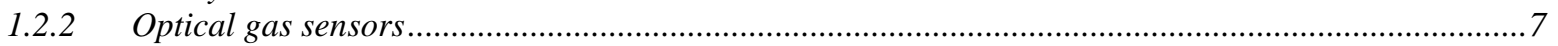

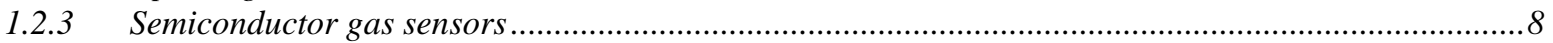

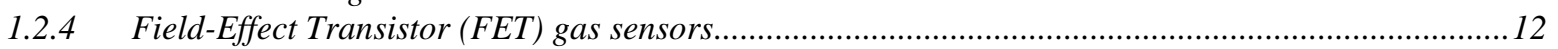

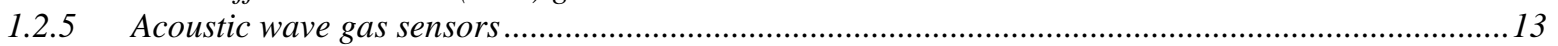

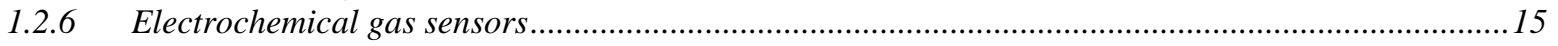

1.3 ADVANTAGES AND DISADVANTAGES OF SOLID-STATE GAS SENSORS …….............................................19

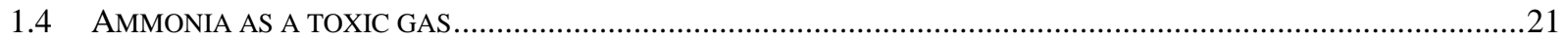

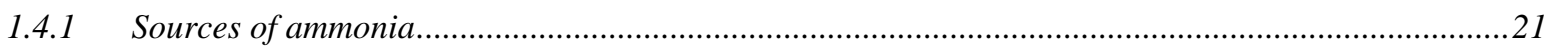

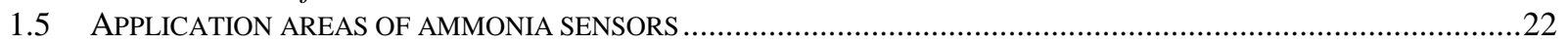

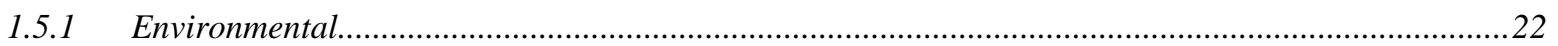

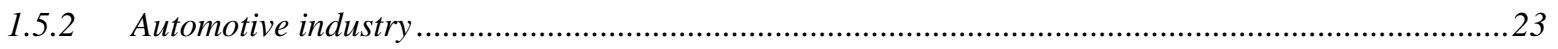

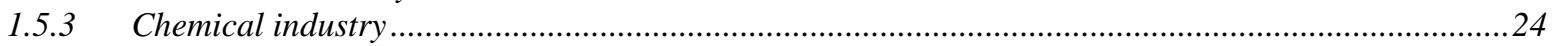

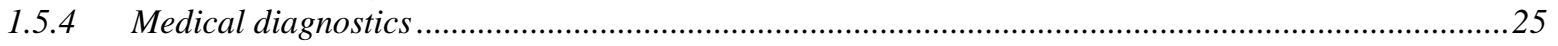

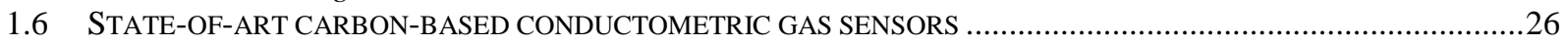

CHAPTER 2. OBJECTIVES AND RESEARCH APPROACH .................................................................34

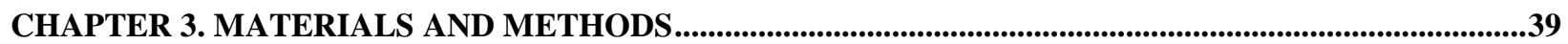

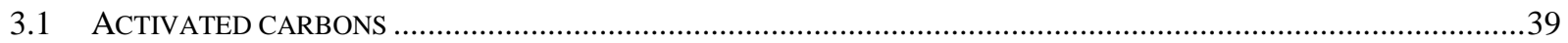

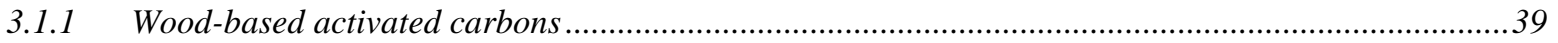

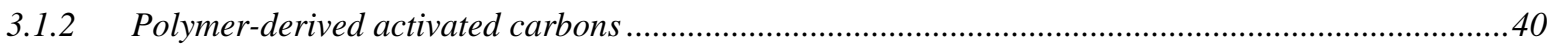

3.1.3 Wood-based/polymer derived-carbon composites …....................................................................42

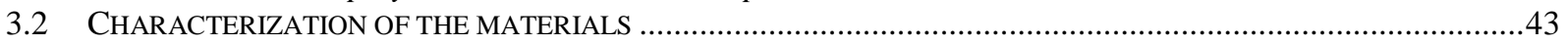

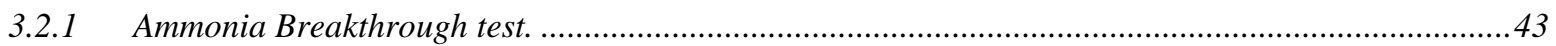

3.2.2 Characterization of structural and morphological features ..................................................................4

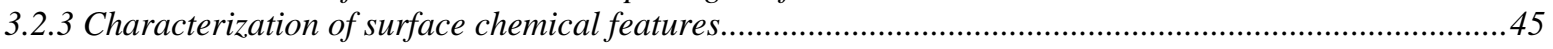

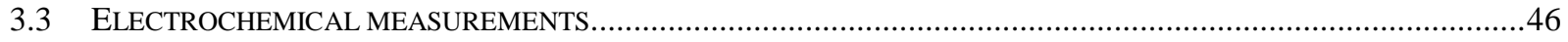

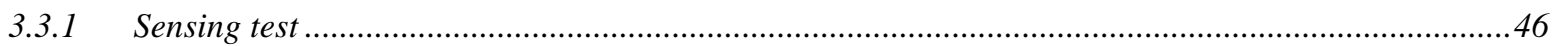

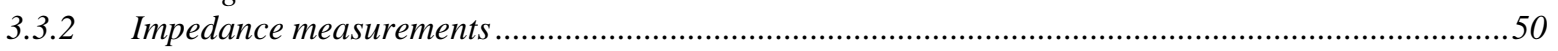

CHAPTER 4. COMMERCIAL WOOD-BASED ACTIVATED CARBONS ......................................................51

4.1 INITIAL SENSOR STABILIZATION- FIRST ESTIMATION OF PREDOMINANT INTERACTIONS IN THE SENSING

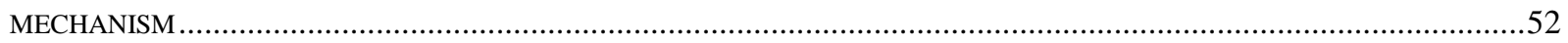

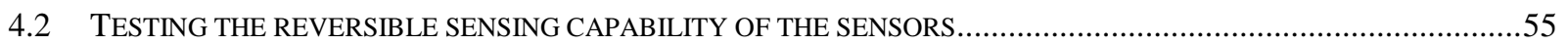

4.3 EVALUATION OF THE CONDUCTION TYPE OF THE MATERIALS ……........................................................61

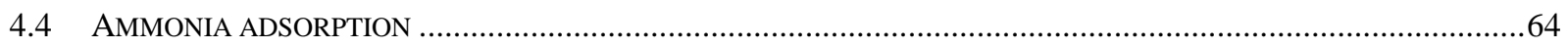

4.5 EFFECT OF OXYGEN AND NITROGEN INCORPORATED TO THE CARBON MATRIX ON THE ELECTRONIC

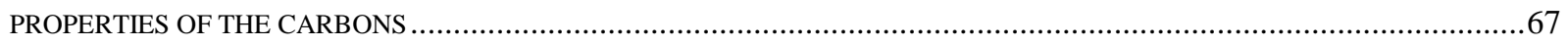

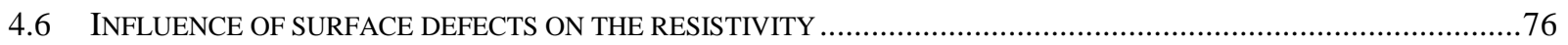

4.7 DEPENDENCE OF SENSOR SENSITIVITY ON SURFACE ACIDITY ……..........................................................

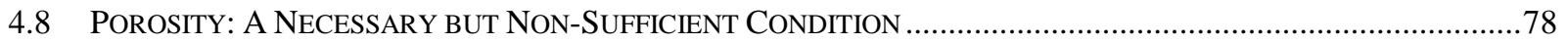

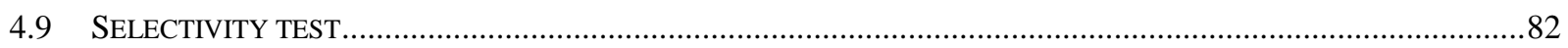

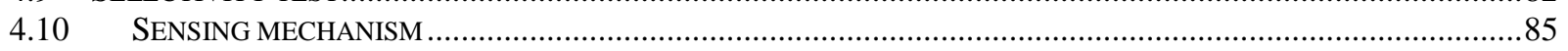

4.10.1. Conduction type-role of specific surface chemistry ........................................................................ 85

4.10.2. Alteration of conduction type during ammonia exposure ……….....................................................8 87

4.10.3. Role of specific adsorption forces and porosity on the ammonia sensing mechanism ..........................87

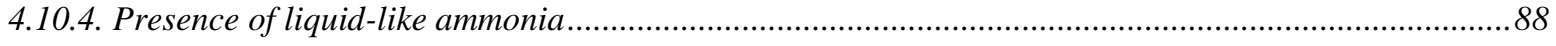


5.1 ESTIMATION OF PREDOMINANT AMMONIA INTERACTION TYPE BASED ON THE INITIAL SENSOR RESPONSE.....90

5.2 TESTING THE REVERSIBLE SENSING CAPABILITY OF THE SENSORS.........................................................

5.2.1 Reversible sensing capability of $S$-containing carbons ....................................................................91

5.2.2 Reversible sensing capability of $\mathrm{N}$-doped polymeric resin-derived carbons .........................................93

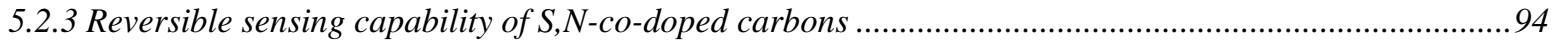

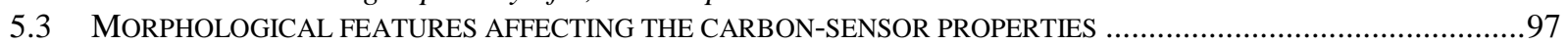

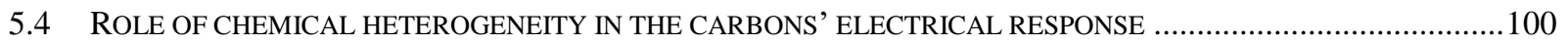

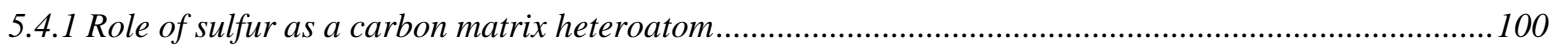

5.4.2. Role of nitrogen as a carbon matrix heteroatom.............................................................................. 105

5.4.3 Role of sulfur and nitrogen as combined carbon matrix co-dopants.............................................110

5.5 Dependence of sensitivity on surface heterogeneity and porosity of nanoporous carbons ....................114

5.6 RELATIONSHIP BETWEEN THE SENSITIVITY AND THE NUMBER OF ACIDIC GROUPS .................................117

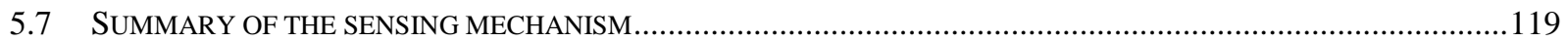

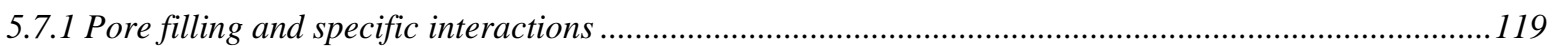

5.7.2 Hole depletion/accumulation in the matrix upon the contact with $\mathrm{NH}_{3}$ and/or $\mathrm{NO}_{2} \ldots \ldots \ldots \ldots \ldots \ldots \ldots . . . . . . . . . .120$

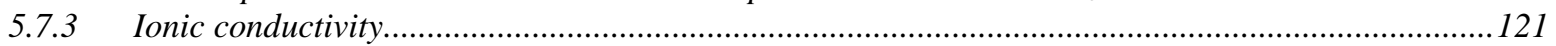

5.7.4. The effect of the Degree of graphitization/conductivity .......................................................121

CHAPTER 6. WOOD-BASED/POLYMER-DERIVED NANOPOROUS CARBON COMPOSITES ............122

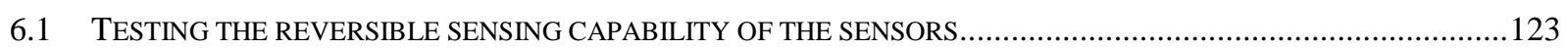

6.2 EFFECT OF THE POLYMER-DERIVED CARBON PHASE ON THE SENSOR SENSITIVITY …................................126

6.3 SYNERGISTIC EFFECT ON POROSITY AFFECTING THE ELECTRICAL RESPONSE OF THE CARBON COMPOSITES .127

6.4 PRIORITY ORDER OF VARIOUS CHEMICAL GROUPS ON THE $\mathrm{NH}_{3}$ SENSING CAPABILITY OF NANOPOROUS

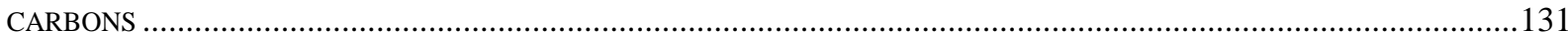

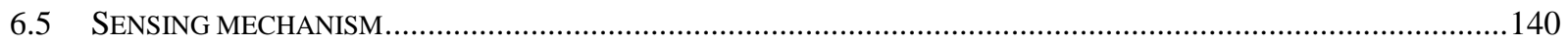

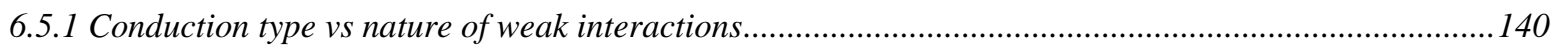

6.5.2 Importance of surface features: Role of surface chemistry vs porosity...............................................142

6.5.3 Importance of ionic conductivity as an ammonia sensing mechanism.............................................143

\section{CHAPTER 7. ROLE OF WATER ON THE SENSING PERFORMANCE OF NANOPOROUS CARBONS}

\begin{tabular}{|c|c|}
\hline 7.1 & 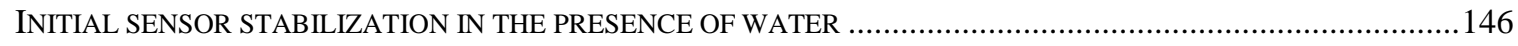 \\
\hline 7.2 & 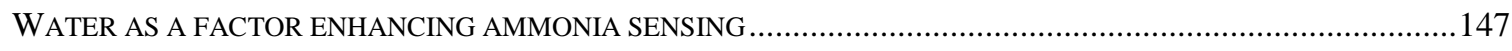 \\
\hline 7.3 & 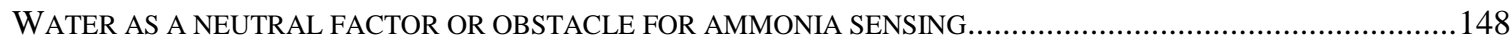 \\
\hline 7.4 & 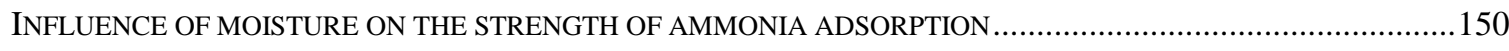 \\
\hline 7.5 & 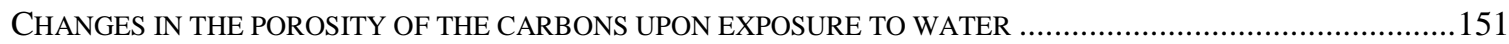 \\
\hline 7.6 & INFLUENCE OF MOISTURE ON THE SURFACE CHEMICAL FEATURES OF THE CARBONS.............................153 \\
\hline 7.7 IN & INFLUENCE OF WATER ON THE SENSING MECHANISM \\
\hline 7.7.1 & $1 \quad$ Competition between ammonia and water molecules... \\
\hline 7.7 .2 & Ammonia diffusion and weak interactions .................. \\
\hline 7.7 .3 & Depletion of charge carriers by $\mathrm{NH}_{3} / \mathrm{H}_{2} \mathrm{O} \ldots \ldots \ldots \ldots$ \\
\hline 7.7.4 & Ammonia dissolution in water .............................. \\
\hline 7.7 .5 & Ionic conductivity through proton transport.... \\
\hline 7.7.6 & Hydrophilicity as an important factor. \\
\hline & NFLUENCE OF DIFFERENT HUMIDITY LEVELS...... \\
\hline
\end{tabular}

CHAPTER 8. SUMMARY OF MECHANISMS THAT GOVERN THE AMMONIA SENSING CAPABILITY OF NANOPOROUS CARBONS AND CONCLUSIONS ....................................................166

CHAPTER 9. OUTLOOK FOR FUTURE RESEARCH TO ADVANCE THE SENSING FIELD ...............175

APPENDIX

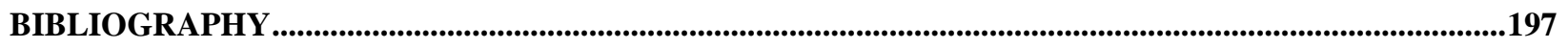


Chapter 4 is a slightly revised version of the following article, with permission from ACS publications, Copyright 2016, reported in Reference 83:

Travlou, N. A.; Ushay, C.; Seredych, M.; Rodríguez-Castellón, E.; Bandosz, T. J. Nitrogen-Doped Activated Carbon-Based Ammonia Sensors: Effect of Specific Surface Functional Groups on Carbon Electronic Properties. ACS Sensors 2016, 1, 591-599.

Chapter 5 is a slightly revised version of the following articles, with permission from Elsevier, Copyright 2014, 2016, and 2017, reported in References 84, 5, and 86, respectively:

Singh, K.; Travlou, N. A.; Bashkova, S.; Rodríguez-Castellón, E.; Bandosz, T. J. Nanoporous Carbons as Gas Sensors: Exploring the Surface Sensitivity. Carbon 2014, 80, 183-192

Travlou, N. A.; Seredych, M.; Rodríguez-Castellón, E.; Bandosz, T. J. Insight into Ammonia Sensing on Heterogeneous S- and N- Co-Doped Nanoporous Carbons. Carbon 2016, 96, 10141021.

Travlou, N. A.; Bandosz, T. J. N-Doped Polymeric Resin-Derived Porous Carbons as Efficient Ammonia Removal and Detection Media. Carbon 2017, 117, 228-239.

Chapter 6 is a slightly revised version of the following article, with permission from Elsevier, Copyright 2017, reported in Reference 127:

Travlou, N. A.; Bandosz, T. J. Nanoporous Carbon-Composites as Gas Sensors: Importance of the Specific Adsorption Forces for Ammonia Sensing Mechanism. Carbon, 2017, 121, 114-126.

Chapter 7 is a slightly revised version of the following article, with permission from Elsevier, Copyright 2016, reported in Reference 132:

Travlou, N. A.; Rodríguez-Castellón, E.; Bandosz, T. J. Sensing of $\mathrm{NH}_{3}$ on Heterogeneous Nanoporous Carbons in the Presence of Humidity. Carbon 2016, 100, 64-73. 


\section{Chapter 1}

Figure 1.1. Graphical illustration of the operating principles of solid-state gas sensors.

Figure 1.2. Pellistor-type catalytic sensor.

Figure 1.3. A schematic diagram of optical gas sensor

Figure 1.4 Schematic model of oxygen ionosorption on the $\mathrm{SnO}_{2}$ surface in a) In pure air, the adsorbed oxygen species trap electrons from $\mathrm{SnO}_{2}$ forming ions that scatter electrons within the Debye length $\delta$ of the oxide. This decreases the electron concentration and mobility resulting in a reduction of the $\mathrm{SnO}_{2}$ conductivity. b) The reaction between ethanol and the ionosorbed oxygen decreases the concentration of these scattering centers $\left(\mathrm{O}^{-}\right)$and releases the trapped electrons thereby increasing the $\mathrm{SnO}_{2}$ conductivity. Copyright 2017, with permission from AIP Publishing LLC.

Figure 1.5. Layout of a FET with CNTs acting as the conducting channel.

Figure 1.6. Schematic illustration of a typical SAW sensor.

Figure 1.7. A typical conductometric thin film gas sensor.

Figure 1.8. Schematic illustration of the synthesis of phosphorus doped graphene nanosheets (PGNS) through high temperature annealing of the graphene oxide and triphenylphosphine (GOTPP) mixture. Copyright 2017, with permission from Royal Society of Chemistry.

\section{Chapter 3}

Figure 3.1. Polymer precursors used for the preparation of activated carbons.

Figure 3.2. Schematic illustration of the treatments applied to the activated carbon samples.

Figure 3.3. Illustration of the experimental set-up. 
Figure 3.4. Illustration of a sensing chip.

Figure 3.5. Illustration of the gas chamber.

Figure 3.6. Typical sensor response curve.

\section{Chapter 4}

Figure 4.1. Changes in the normalized resistance for the activated carbon samples upon their initial exposure to NH3 and subsequent air purging (after the signal stabilization) (A) for BAX and BAX$\mathrm{O}$, (B) for BAX-M, (C) for BAXMO1 and BAX-MO2, (D) for BAX-O1-M and BAX-O2-M, and (E) for BAX-O1-M[O1] and BAX-O2-M[O2]. Copyright 2017, with permission from American Chemical Society.

Figure 4.2. Response curve for BAX (A) and BAX-O (B) at 10 and 20 ppm of ammonia gas.

Figure 4.3. Response curves for $\mathrm{BAX}(\mathrm{A}, \mathrm{B})$ and $\mathrm{BAX}-\mathrm{O}(\mathrm{C}, \mathrm{D})$, and linear response $(\mathrm{E})$, of the tested carbon samples upon exposure to various ammonia concentrations.

Figure 4.4. Response curves for the best performing carbons (A, B, C, D). Dependence of $\Delta R /$ Ro (\%) of the chips on various $\mathrm{NH}_{3}$ concentrations (error bars indicate $\sigma$ ) (E). Copyright 2017, with permission from American Chemical Society.

Figure 4.5. Comparison of the normalized resistance changes of BAX, BAX-O and all melamine treated carbon samples tested upon exposure to $500 \mathrm{ppm}$ of $\mathrm{NH}_{3}$. Copyright 2017, with permission from American Chemical Society.

Figure 4.6. The Mott-Schottky plot for BAX (A) and BAX-O (B). E $E_{F n}$ and $E_{F p}$ represent the Fermi levels of $n$ and $p$ type materials.

Figure 4.7. The Mott-Schottky plot for BAX-M, BAX-M-O2, BAX-O2-M, and BAX-O1-M[O1]. Copyright 2017, with permission from American Chemical Society. 
Figure 4.8. Ammonia breakthrough and desorption curves for BAX and BAX-O (A), the series treated with melamine (B). (B): Copyright 2017, with permission from American Chemical Society.

Figure 4.9. The deconvolution of $\mathrm{N} 1 s$ core energy levels for the initial and exposed to ammonia BAX and BAX-O.

Figure 4.10. A) Content of elements; B-D) Concentration of the specific carbon, oxygen, and nitrogen groups, on the surface of the melamine treated carbon samples. Copyright 2017, with permission from American Chemical Society.

Figure 4.11. The distributions of the $\mathrm{pK}_{\mathrm{a}}$ for the species present on the surfaces of BAX and BAXO, before and after ammonia adsorption.

Figure 4.12. A) Content of elements; B-D) Concentration of the specific carbon, oxygen, and nitrogen groups, on the surface of the melamine treated carbon samples. Copyright 2017, with permission from American Chemical Society

Figure 4.13. Response curve for $\mathrm{BAX}(\mathrm{A})$ and $\mathrm{BAX}-\mathrm{O}(\mathrm{B})$ at $500 \mathrm{ppm}$ of $\mathrm{H}_{2} \mathrm{~S}$.

Figure 4.14. Comparison of the selectivity of the melamine treated carbon sensors: (A) in terms of the changes of their normalized resistance (sensitivity of the sensors), and (B) in terms of the response time of the sensors toward $\mathrm{NH}_{3}$ sensing. Copyright 2017, with permission from American Chemical Society. 


\section{Chapter 5}

Figure 5.1. Changes in the normalized resistance for the activated carbon samples upon their initial exposure to $\mathrm{NH}_{3}$ and subsequent air purging (after the signal stabilization) (A) for $\mathrm{C} 1$, (B) for C2, (C) for $\mathrm{C}-\mathrm{AO}$ and $\mathrm{C}-\mathrm{BO}$, and (D) for PFM-AO, RFM-AO and PFU-AO.

Figure 5.2. (A) Response curve for both carbons at various ammonia concentrations. (B) The dependence of the change in normalized resistance of the C-1 and C-2 carbons on the ammonia concentration in the challenge gas.

Figure 5.3. (A, B, C): Change in the normalized resistance for PFM-AO, RFM-AO and PFU-AO samples, upon testing their reversible sensing capability at $\mathrm{NH}_{3}$ concentrations varying between 45-500 ppm. (D): Dependence of $\Delta \mathrm{R} / \mathrm{R}_{\mathrm{o}}(\%)$ of the air-oxidized samples on various $\mathrm{NH}_{3}$ concentrations.

Figure 5.4. Response curves for $\mathrm{C}-\mathrm{B}$ (A), C-AO and C-BO (B) exposed to various ammonia concentrations. (C) Dependence of $\Delta \mathrm{R} / \mathrm{R}_{\mathrm{o}}$ of the oxidized samples on $\mathrm{NH}_{3}$ concentration. The error bars are similar or smaller than the size of the data points used.

Figure 5.5. TEM images of C-1 and C-2 samples. Copyright 2017, with permission from Elsevier.

Figure 5.6. TEM images of $\mathrm{C}-\mathrm{AO}$ and $\mathrm{C}-\mathrm{BO}$ samples.

Figure 5.7. TEM images of the PFM, RFM and PFU samples.

Figure 5.8. The deconvolution of $S 2 p$ core energy levels for the initial and exposed to ammonia C-1 and C-2 carbons.

Figure 5.9. The deconvolution of $\mathrm{N} 1 \mathrm{~s}$ core energy levels for $\mathrm{C}-1$ and $\mathrm{C}-1$ carbons exposed to ammonia. 
Figure 5.10. The distribution of the functional groups on $\mathrm{C}-1$ and $\mathrm{C}-2$, with $\mathrm{pK}_{\mathrm{a}}$ values between 4 and 11, determined from the potentiometric titration, before (A) and after (B) ammonia adsorption. For the exhausted samples after ammonia adsorption, the suffix $-\mathrm{E}$ is added to their names.

Figure 5.11. (A) Content of elements; (B-E) Surface concentration of the specific carbon, oxygen, nitrogen and sulfur groups on $\mathrm{C}-\mathrm{A}, \mathrm{C}-\mathrm{B}, \mathrm{C}-\mathrm{AO}$, and $\mathrm{C}-\mathrm{BO}$ before and after ammonia exposure. For the exhausted samples after ammonia adsorption, the suffix $-\mathrm{E}$ is added to their name

Figure 5.12. Comparative graph of the chip normalized resistance changes (\%) (at $500 \mathrm{ppm}$ of ammonia) and surface area of the nanoporous carbons addressed in this work and a previously studied S-doped nanoporous carbon.

Figure 5.13. Dependence of $\Delta \mathrm{R} / \mathrm{R}_{\mathrm{o}}(\%)$ of the air-oxidized samples (PFM-AO, RFM-AO, and PFU-AO) on the number of strongly acidic groups $\left(\mathrm{pK}_{\mathrm{a}}<7\right)$, weakly acidic groups $\left(\mathrm{pK}_{\mathrm{a}}>7\right)$, and total number of functional groups.

Figure 5.14. Visualization of the working principles of the nanoporous-carbon based sensor (only sulfur-containing groups active in adsorption of $\mathrm{NH}_{3}$ are present on the surface of the $\mathrm{C}$ - 1 carbon).

\section{Chapter 6}

Figure 6.1. (A, B): Response curves for the BAX-CS and BAX-CSN composite series. (C): Dependence of $\Delta R / R_{0}(\%)$ of the two best performing materials from each composite series, on various $\mathrm{NH}_{3}$ concentrations.

Figure 6.2. (A): Comparison of the response time required time for the electrical signal to reach the plateau of the two composite series upon the exposure to various ammonia concentrations, (B): Response curves for the BAX-CS-1\% and BAX-CSN-1\% composite series. 
Figure 6.3. Comparison of the normalized resistance changes of BAX-CS and BAX-CSN composite series tested upon exposure to $500 \mathrm{ppm}$ of $\mathrm{NH}_{3}$.

Figure 6.4. Pore size distributions for the BAX-CS and BAX-CSN composite series.

Figure 6.5. Comparison of the hypothetical and measured surface areas, volumes of mesopores, micropores and ultramicropores $(\mathrm{V}<0.7 \mathrm{~nm})$ for BAX-CS and BAX-CSN composite series (calculated using the NLDFT method).

Figure 6.6. Content of elements and contributions of the specific carbon, oxygen, nitrogen and sulfur groups on the initial and exhausted BAX-AO, BAX-CS-1\%, BAX-CSN-1\%, BAX-CS-5\%, ans BAX-CSN-5\% .

Figure 6.7. Deconvolutions C $1 s, \mathrm{O} 1 s$, and N $1 s$ core energy level spectra for BAX-CS-1\% and BAXCSN-1\%, initial and exposed to ammonia.

Figure 6.8. Deconvolutions S $2 p$ core energy level spectra for BAX-CS-5\% and BAX-CSN-5\%, initial and exposed to ammonia.

Figure 6.9. The distributions of the $\mathrm{pK}_{\mathrm{a}}$ for the species present on the surface of BAX-AO, BAXCS (1\% and 5\%) and BAX-CSN (1\% and 5\%), initial and exposed to ammonia.

Figure 6.10. The Mott-Schottky plots for BAX-AO, BAX-CS-1\%, BAX-CSN-1\%, BAX-CS-5\%, and BAC-CSN-5\%.

\section{Chapter 7}

Figure 7.1. Normalized change in a resistance for $\mathrm{C}-\mathrm{AO}$ and $\mathrm{C}-\mathrm{BO}$ upon their initial exposure to a humid gas stream (A) and a humid gas stream with $2 \mathrm{~h}$ prehumidification (B and $\mathrm{C}$ ). For the exhausted samples after ammonia adsorption, the suffix -EM is added when they were directly exposed to a humid $\mathrm{NH}_{3}$ stream, and the suffix -EPM is added after their prehumification. 
Figure 7.2. (A) Response curve for $\mathrm{C}-\mathrm{AO}$ upon the direct exposure to $\mathrm{NH}_{3} /$ moist air cycles, and (B) dependence of the normalized resistance change on the various ammonia concentrations.

Figure 7.3. Response curve for (A): C-BO upon the direct exposure to $\mathrm{NH}_{3} /$ moist air cycles, (B, $\mathrm{C})$ : $\mathrm{C}-\mathrm{AO}$ and $\mathrm{C}-\mathrm{BO}$ after a $2 \mathrm{~h}$ prehumidification, and dependence of the normalized resistance change on the various ammonia concentrations for (D): C-BO without prehumidification, and (E): $\mathrm{C}-\mathrm{AO}$ and $\mathrm{C}-\mathrm{BO}$ with prehumidification.

Figure 7.4. Ammonia breakthrough and desorption curves for $\mathrm{C}-\mathrm{AO}$ and $\mathrm{C}-\mathrm{BO}$.

Figure 7.5. The $\mathrm{pK}_{\mathrm{a}}$ distributions of the species present on the surfaces of the initial and exhausted C-AO and C-BO carbons, in both dry and humid conditions

Figure. 7.6 A) Content of elements; B-E) Surface concentration of the specific carbon, oxygen, nitrogen and sulfur groups on the initial and exhausted $\mathrm{C}-\mathrm{AO}$ and $\mathrm{C}-\mathrm{BO}$ carbons, in both dry and humid conditions. Due to the complexity of the species, the components of the $\mathrm{N} 1 s$ core energy level spectra are referred to as $\mathrm{N}-1$ (pyridines), N-2 (pyrroles/ammonia/amines/amides), N-3 (quaternary nitrogen and/or protonated amines) and N-4 ( $\mathrm{NH}_{4}{ }^{+}$and/or $\mathrm{NO}_{\mathrm{x}}$ species).

Figure 7.7. (A): Typical response curves for both carbons, during an $\mathrm{NH}_{3} /$ air cycle, without prehumidification (B): Typical response curve for $\mathrm{C}-\mathrm{AO}$, during an $\mathrm{NH}_{3} /$ air cycle, with water being preadsorbed on its surface. (C): Sensing mechanisms that correspond to the electrical outcome of Figure 6A. (6C-1: hole formation due to the electron withdrawing character of $\mathrm{NO}_{2}$, 6C-2: hole deletion by electrons donated by ammonia, 6C-3: proton transport mechanism) (D): Sensing mechanisms that corresponds to the electrical outcome of Figure $6 \mathrm{~B}-\mathrm{A}$ high surface coverage of water molecules "blocks" those sites on the carbon's surface, which would be 
otherwise available for weak interactions with ammonia, therefore leading to a limited charge hopping mechanism.

Figure 7.8. Changes in the normalized resistance for the best performing carbon-composite chips from both series tested (BAX-CS-1\% and BAX-CSN-1\%), upon exposure to $500 \mathrm{ppm}$ of ammonia, at different humidity levels.

\section{Chapter 8}

Figure 8.1. A visualization of the specific interactions (hydrogen bonding, dipole/dipole interactions, dispersive interactions) that take place upon ammonia exposure.

Figure 8.2. Schematic illustration of the different factors that govern the electrical response of nanoporous carbons.

\section{Chapter 9}

Figure 9.1. Possible dopant-elements to examine

Figure 9.2. Figure 9.2. Changes in the normalized resistance for all P-modified samples before (BP-C-1, 30, 60, 85\%) and after air-oxidation (BP-CAO-1, 30, 60, 85\%) upon exposure to 500 ppm of ammonia, (B): linear response of the best performing carbon (BP-CAO-1).

Figure 9.3. Possible configurations of $-\mathrm{P}$ in the carbon matrix (phosphate-carbon complexes) as described in the literature. 


\section{List of Tables}

\section{Chapter 1}

Table 1.1 Long- and short-term exposure limits of the most common toxic gases.

Table 1.2. Comparison of gas detection sensor technologies.

\section{Chapter 4}

Table 4.1. Change in the normalized resistance $\Delta \mathrm{R} / \mathrm{R}_{\mathrm{o}}[\%]$ of $\mathrm{BAX}$ and $\mathrm{BAX}-\mathrm{O}$ after exposure to various ammonia concentrations.

Table 4.2. Content of elements on the surface of the melamine treated samples (in at. \% from XPS analysis). Copyright 2017, with permission from American Chemical Society.

Table 4.3. The results of deconvolution of C $1 s, \mathrm{O} 1 s$ and $\mathrm{N} 1 s$ core energy levels for BAX and BAX-O.

Table 4.4. Parameters of the porous structure for all wood-based nanoporous carbons, calculated from the nitrogen adsorption isotherms. Copyright 2017, with permission from American Chemical Society.

\section{Chapter 5}

Table 5.1. Content of elements on the surface (in at \%; from XPS analysis) for the initial and exhausted C-1 and C-2 carbons.

Table 5.2. The results of deconvolution of $\mathrm{C} 1 s, \mathrm{O} 1 s$ and $\mathrm{N} 1 s$ core energy levels for the initial and exhausted C-1 and C-2 carbons.

Table 5.3. Content of elements on the surface (in at \%; from XPS analysis) for the initial and exhausted PFM-AO, RFM-AO, and PFU-AO. 
Table 5.4. Parameters of the porous structure for the initial and exhausted C-1, C-2, C-A, C-B, C$\mathrm{AO}$, and $\mathrm{C}-\mathrm{BO}$ carbons, calculated from the nitrogen adsorption isotherms.

Table 5.5. The surface $\mathrm{pH}$ values and the amounts of strong acidic $\left(\mathrm{pK}_{\mathrm{a}}<7\right)$, weakly acidic $\left(\mathrm{pK}_{\mathrm{a}}\right.$ > 7) and total number of acidic groups, on PFM-AO, RFM-AO, and PFU-AO.

\section{Chapter 6}

Table 6.1. Parameters of the porous structure calculated from the nitrogen adsorption isotherms, for the BAX-CS and BAX-CSN composite series.

\section{Chapter 7}

Table 7.1. Change of normalized resistance $\Delta R / R_{0}(\%)$ of the $C-A O$ and $C-B O$ carbon chips upon exposure to various ammonia concentrations in the moist conditions. ${ }^{1}$

Table 7.2. Parameters of the porous structure calculated from the nitrogen adsorption isotherms, for $\mathrm{C}-\mathrm{AO}$ and $\mathrm{C}-\mathrm{BO}$ before and after ammonia exposure, in both dry and humid conditions.

\section{Chapter 8}

Table 8.1. Changes in the normalized resistance (sensitivity), and response time of the carbons tested in this study, at $500 \mathrm{ppm}$ of $\mathrm{NH}_{3}$, in dry conditions.

\section{Chapter 9}

Table 9.1. Change in the normalized resistance $\left(\Delta \mathrm{R} / \mathrm{R}_{\mathrm{o}}\right) * 100$ of the P-doped carbon samples before and after air-oxidation, upon their exposure to $500 \mathrm{ppm}$ of ammonia. 
Peer-reviewed papers published during the $\mathrm{PhD}$ study

14. Escalade, J.; Savaram, K.; Travlou, N. A.; Li, W.; Delgado-Sánchez, C.; Fierro, V.; Alain, Celzard, A.; He, H.; Bandosz, T. J. Combined Effect of Porosity and Surface Chemistry on the Electrochemical Reduction of Oxygen on Cellular Vitreous Carbon Foam Catalyst. ACS Catalysis, 2017, submitted.

13. Travlou, N. A.; Cardenas Arevalo, A. L.; Giannakoudakis, D. A.; Algarra, M.; Janakiraman, A.; Rodríguez-Castellón, E.; Bandosz, T. J. S- and N-doped Carbon Quantum Dots: Surface Chemistry Dependent Bactericidal Activity. Carbon, 2017, submitted.

12. Travlou, N. A.; Bandosz, T. J. Nanoporous Carbon-Composites as Gas Sensors: Importance of the Specific Adsorption Forces for Ammonia Sensing Mechanism. Carbon, 2017, 121, 114126.

11. Travlou, N. A.; Bandosz, T. J. N-Doped Polymeric Resin-Derived Porous Carbons as Efficient Ammonia Removal and Detection Media. Carbon 2017, 117, 228-239.

10. Travlou, N. A.; Seredych, M.; Rodríguez-Castellón, E.; Bandosz, T. J. Toxic gas sensing on nanoporous carbons. Adsorption 2017, 23, 271-280.

9. Travlou, N. A.; Secor, J.; Bandosz, T. J. Highly Luminescent S-doped Carbon Dots for the Selective Detection of Ammonia. Carbon 2016, 114, 544-556.

8. Giannakoudakis, D. A.; Travlou, N. A.; Secor, J.; Bandosz. T. J. Oxidized g-C $\mathrm{C}_{3} \mathrm{~N}_{4}$ Nanospheres as Photoactive Linkers in $\mathrm{MOF} / \mathrm{g}-\mathrm{C}_{3} \mathrm{~N}_{4}$ Composite of Hierarchical Pore Structure. Small 2016 DOI: $10.1002 /$ smll.201601758 
7. Travlou, N. A.; Ushay, C.; Seredych, M.; Rodríguez-Castellón, E.; Bandosz, T. J. NitrogenDoped Activated Carbon-Based Ammonia Sensors: Effect of Specific Surface Functional Groups on Carbon Electronic Properties. ACS Sensors 2016, 1, 591-599.

6. Travlou, N. A.; Rodríguez-Castellón, E.; Bandosz, T. J. Sensing of $\mathrm{NH}_{3}$ on Heterogeneous Nanoporous Carbons in the Presence of Humidity. Carbon 2016, 100, 64-73.

5. Travlou, N. A.; Seredych, M.; Rodríguez-Castellón, E.; Bandosz, T. J. Insight into Ammonia Sensing on Heterogeneous S- and N- Co-Doped Nanoporous Carbons. Carbon 2016, 96, 10141021.

4. Travlou, N. A.; Singh, K.; Rodríguez-Castellón, E.; Bandosz, T. J. Cu-BTC MOF / Graphenebased hybrid materials as low concentration ammonia sensors. J. Mater. Chem. A 2015, 3, 1141711429.

3. Travlou, N. A.; Seredych, M.; Rodríguez-Castellón, E.; Bandosz, T. J. Activated Carbon-Based Gas Sensors: Effects of Surface Features on the Sensing Mechanism. J. Mater. Chem. A 2015, 3, $3821-3831$.

2. Singh, K.; Travlou, N. A.; Bashkova, S.; Rodríguez-Castellón, E.; Bandosz, T. J. Nanoporous Carbons as Gas Sensors: Exploring the Surface Sensitivity. Carbon 2014, 80, 183-192.

1. Jurow, M.; Varotto, A.; Manichev, V.; Travlou, N.A.; , Giannakoudakis, D.; Drain, C.M. Selforganized Nanostructured Materials of Alkylated Phthalocyanines and Underivatized C60 on ITO. RSC Advances 2013, 3, 21360-21364. 


\section{Chapter 1. Introduction}

\subsection{Need for gas monitoring systems}

A continuous development of industrial activities, aiming to meet the human demands and improve our daily life, caused a dramatic increase in air pollution over the last decades. The consequences of it, and the release of poisonous gases can pose a threat to both human health and the environment. Hazardous industrial gases can be generally classified in three main categories: combustible, toxic, and asphyxiates. ${ }^{1}$ Methane, ethane, hydrogen, and acetylene are the most common gases of the first category (combustible), which can easily burn and are explosive. Toxic gases, being even more hazardous than combustible, can lead to serious ailments or even cause death, depending on their concentration and the exposure time. Ammonia, $\left(\mathrm{NH}_{3}\right)$, hydrogen sulfide $\left(\mathrm{H}_{2} \mathrm{~S}\right)$, nitrogen monoxide $(\mathrm{NO})$, nitrogen dioxide $\left(\mathrm{NO}_{2}\right)$, carbon monoxide $(\mathrm{CO})$, and carbon dioxide $\left(\mathrm{CO}_{2}\right)$, are some of the most hazardous toxic gases. The last category, asphyxiates, are non-toxic gases which displace oxygen in the atmosphere causing oxygen deprivation. Exposure to them can cause unconsciousness and death. Nitrogen, helium, krypton, neon, argon, and xenon are the most common examples of asphyxiants. The emergence of concern over environmental pollution and human health and the need to monitor and detect hazardous gases, has led to the necessity of developing toxic gas sensors. Such sensors/detectors can be used in various application areas such as industry (e.g. detection of methane in mines), environmental monitoring (e.g. air pollution caused by exhaust gases from automobiles) ${ }^{2}$, agriculture, medical diagnosis (e.g. gas analysis of human expiration), ${ }^{3}$ and indoor air quality supervision (e.g. detection of CO or formaldehyde). ${ }^{4}$ Table 1.1 illustrates the long- and short-term exposure limits of the most common toxic gases. 
Table 1.1 Long- and short-term exposure limits of the most common toxic gases. ${ }^{5}$

\begin{tabular}{lcc}
\hline Gas & $\begin{array}{c}\text { Long term exposure limit, 8 } \\
(\mathrm{ppm})\end{array}$ & $\begin{array}{c}\text { Short-term exposure limit, 10 min } \\
(\mathrm{ppm})\end{array}$ \\
\hline $\mathrm{H} 2 \mathrm{~S}$ & 10 & 15 \\
$\mathrm{CO}$ & 50 & 300 \\
$\mathrm{NO}_{\mathrm{x}}$ & 3 & 5 \\
$\mathrm{SO}_{2}$ & 2 & 5 \\
$\mathrm{PH}_{3}$ & - & 0.3 \\
$\mathrm{CH}_{3} \mathrm{OH}$ & 200 & 250 \\
$\mathrm{Cl}_{2}$ & 0.5 & 1 \\
$\mathrm{NH}_{3}$ & 25 & 35 \\
$\mathrm{HCl}$ & - & 5 \\
\hline
\end{tabular}

\subsubsection{Gas sensors}

A sensor in general is a device whose purpose is to recognize and detect changes in certain environmental parameters, and convert them to analytically useful signals. ${ }^{6-8}$ Such environmental parameters may be the temperature or molecules of target species, which can affect certain properties of the sensor material such as its conductivity, mass or other measurable physical properties. ${ }^{8}$ A broad division of the gas sensing technologies based on the employed sensing mechanism, includes two sensor categories: a) solid state gas sensors, where the detection capability of the sensor is based on the variation of the electrical properties, and b) sensors whose operation is based on the usage of traditional analytical methods such as gas chromatography, mass spectrometer, and nuclear magnetic resonance (NMR). ${ }^{9}$ Compared to the second sensor category (analytical sensors), solid state sensors are more advantageous in having a smaller size, lower detection limits, higher sensitivities, and real-time detection capability. These features make them very good candidates in a wide application range including environmental monitoring, industrial production, medical diagnosis, safety military, and aerospace. ${ }^{10}$ 


\subsubsection{Sensor performance requirements/characteristics}

As aforementioned, gas sensors can be characterized as "transducers" that transform the chemical interactions of analyte gasses into electrical signals. The requirements and nature of a particular sensing application make designing/fabrication of a sensor exhibiting certain operating characteristics a necessity. Thus, an ideal sensor that operates in a real-time should exhibit a following set of parameters ${ }^{10}$ :

- High sensitivity, which is the capability of the gas sensor to provide measurable electrical signal changes at low gas concentrations. It is defined as $R_{a} / R_{g}$ or $R_{g} / R_{a}$ for reducing or oxidizing gasses, respectively, where $\mathrm{R}_{\mathrm{a}}$ stands for the sensor resistance in the reference gas, usually air, and $\mathrm{R}_{\mathrm{g}}$ stands for the resistance of the sensor when exposed to the carrier gas containing the target gasses. ${ }^{11}$

- High selectivity, which is the capability of a gas sensor to selectively detect a particular gas species from a mixture of gasses.

- A continuous, fast and reversible response, without affecting/disturbing the nature or properties of the sensing material.

- A repeatable response, which is a prerequisite for commercial sensors which need to operate for several thousands of cycles, and show reproducible readings for a certain period of time.

- A fast response and recovery time. The former is defined as the required time for the electrical signal to reach the $90 \%$ of its maximum magnitude upon the exposure to a target gas. Similarly, the recovery time is defined as the duration of time between the moment that the target gas is turned off and the point when the electrical signal has recovered by $90 \%$. 
- An excellent long-term stability.

- Low-cost, simple, and reliable operation, humidity and temperature insensitivity, contamination/poisoning resistance, having self-calibration capabilities, and small-size characteristics. ${ }^{6}$

\subsection{Types of solid-state gas sensors}

The main principle behind solid-state gas sensors lies on the adsorption, desorption or chemical reaction of gas species on the surface or in the film of the sensing materials (Figure 1.1). ${ }^{12}$ Such reactions/interactions by causing physical changes (e.g. changes in the conductivity, mass, temperature etc.) can be detected by the sensors. ${ }^{12}$ Solid-state gas sensors exhibit certain advantages that make them good candidates in a variety of applications in the scientific and industrial world. ${ }^{12}$ These include their small sizes, high sensitivities, low detection limits (in ppm or ppb level), detection capability of various gas species, low cost and real-time application. ${ }^{13}$ Traditional analytical instruments, on the other hand (mass spectrometer, chromatography or NMR), except of suffering from high costs are also complex, and large in size. Moreover, the analysis usually requires the preparation of the sample which makes their application in real-time difficult or even non feasible. ${ }^{13}$ 


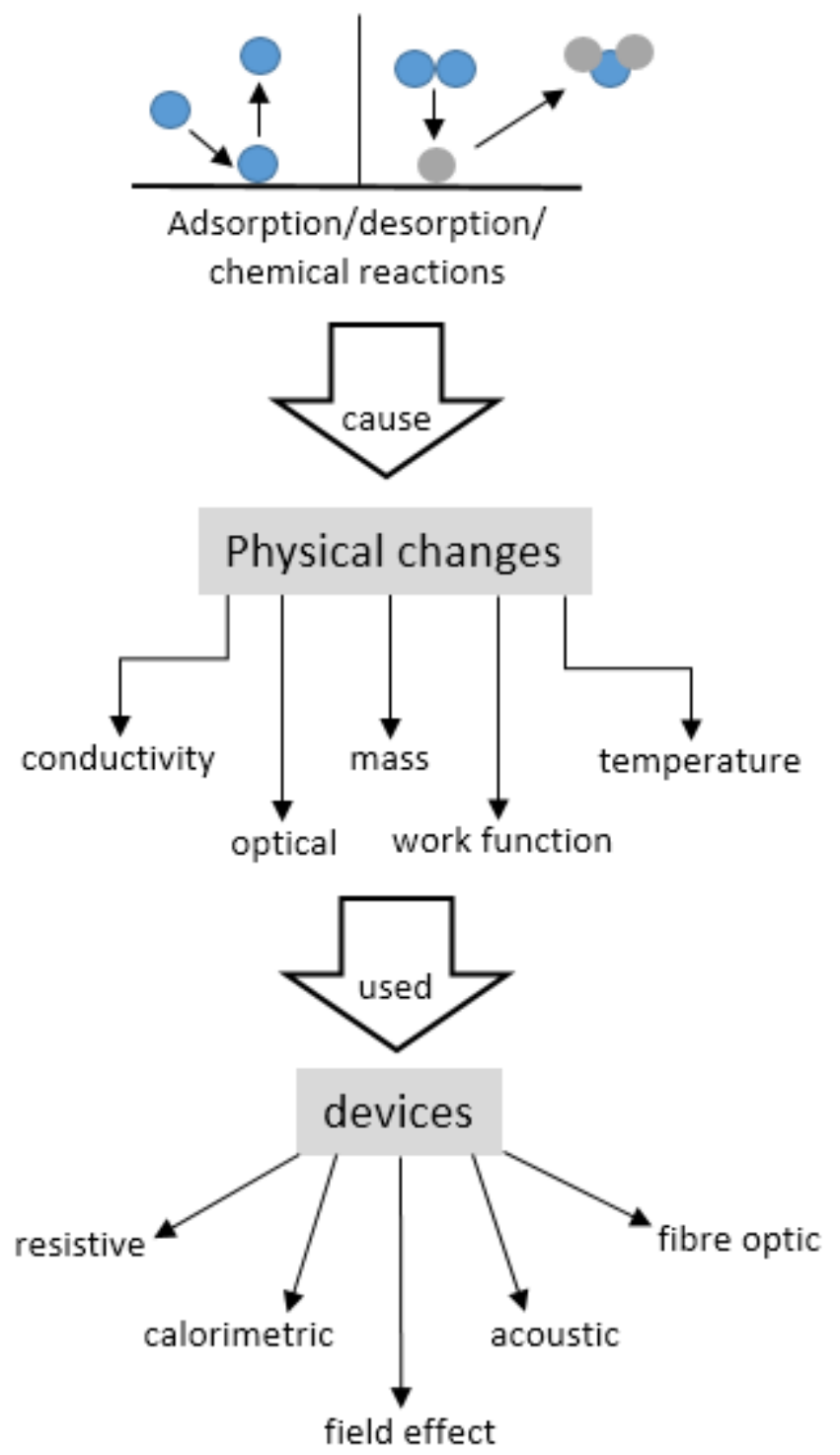

Figure 1.1. Graphical illustration of the operating principles of solid-state gas sensors. ${ }^{12}$

\subsubsection{Catalytic sensors}

Catalytic sensors are the most commonly used for the detection of combustible gases in oil and gas. ${ }^{4,14}$ The working principle of this type of sensors is based on the conversion of the heat that is produced by the catalytic oxidation of a gas on the surface of the sensor coated with an active material (catalyst), to a signal, which is expressed as the percentage of change per a degree change in a temperature. This conversion is done through a standard Wheatstone Bridge-type device, and 
is proportional to the concentration of the combustible gas. Two main types of catalytic sensors are the pellistor and thermoelectric type. ${ }^{4}$ Combustible gas mixtures usually do not burn unless they reach an ignition temperature. In the presence of specific chemical media/species the ignition temperature lowers. Metal oxides and their compounds, platinum, palladium, and thoria are most frequently used as the media promoting such a catalytic combustion process.

The pellistor-type gas sensor is the most common type of catalytic sensors (Figure 1.2). It consists of two platinum coils serving as a heater and a resistance thermometer. ${ }^{4}$ The coils are embedded in both an active and an inactive bead. The former one is activated with a catalyst and thus promotes oxidation, while the latter one which lacks the catalyst, prevents the oxidation process. Upon the application of a certain voltage, the coils heats causing the temperature of the beads to increase. The reached temperature usually ranges from $300^{\circ} \mathrm{C}$ to $500^{\circ} \mathrm{C}$, and in the presence of oxygen the oxidation of the target gas at the active bead of the pellistor takes place. In the case of methane for instance, the combustion reaction is the following:

$$
\mathrm{CH}_{4}+2 \mathrm{O}_{2}+8 \mathrm{~N}_{2} \rightarrow \mathrm{CO}_{2}+2 \mathrm{H}_{2} \mathrm{O}+8 \mathrm{~N}_{2}
$$

The heat generated by this catalytic process causes an increase in the coil resistance, which in turn causes an imbalance in the Wheatstone Bridge circuit, related to the concentration of the target gas present. 


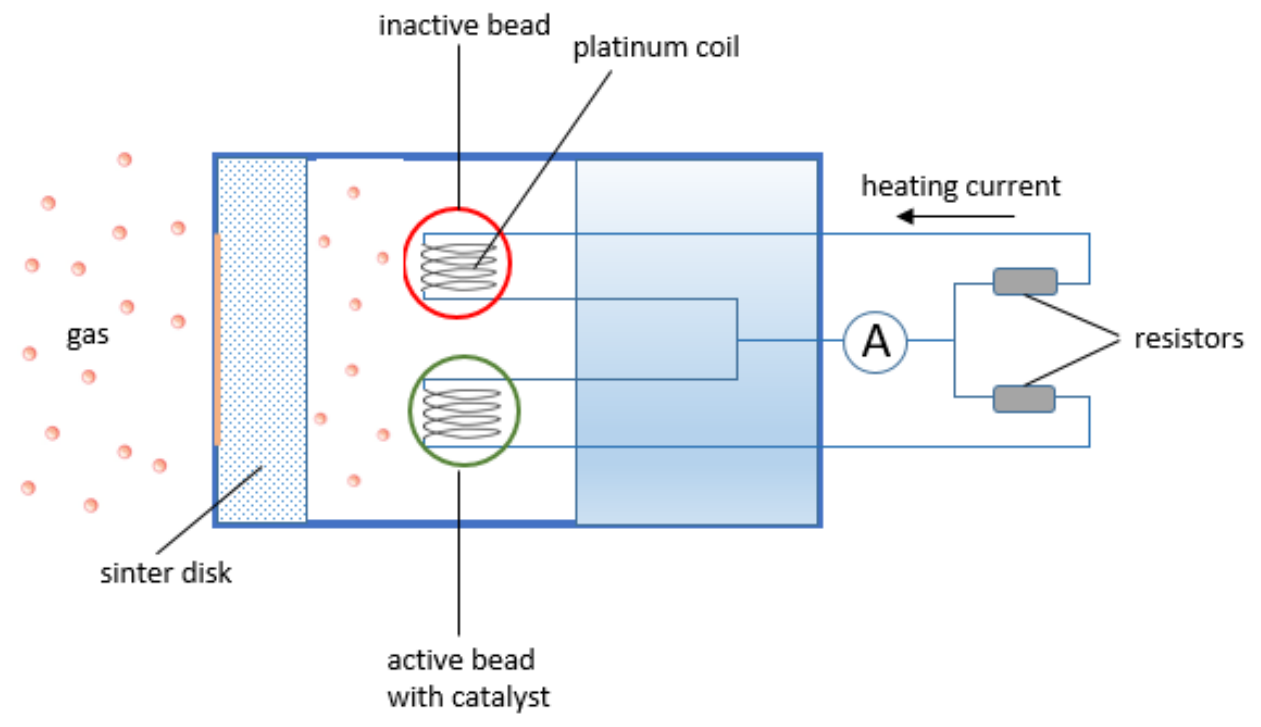

Figure 1.2. Pellistor-type catalytic sensor. ${ }^{4}$

\subsubsection{Optical gas sensors}

Optical gas sensors use spectroscopic optical methods to monitor the absorption/emission/scattering of target gasses, at defined optical wavelengths. ${ }^{15}$ Using this type of gas sensors, real-time measurements can be conducted offering high sensitivities (in ppb levels) and selectivities, with fast response times that can be even less than 1 sec. Furthermore, optical sensors exhibit a longer lifetime compared to most of other detection methods.

The typical optical sensor set-up consists of a light source, which is most often an IR laser diode, and a detector (Figure 1.3). ${ }^{16}$ The light source serves as a transmitter of the light through a gas environment towards the detector. Based on the physical properties of the gas molecules, they absorb light at certain wavelengths, and can thus be easily identified. Furthermore, their absorption/emission/scattering intensity information, provides data about their concentration, upon calibration of these signals. 


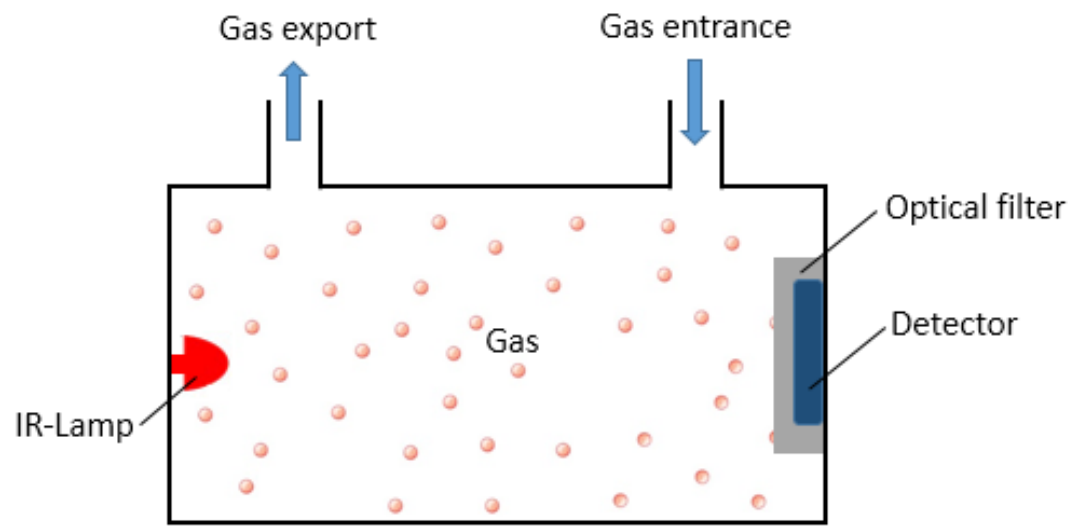

Figure 1.3. A schematic diagram of optical gas sensor. ${ }^{16}$

\subsubsection{Semiconductor gas sensors}

Semiconductor gas sensors consist of metal oxide semiconductor (e.g. $\mathrm{SnO}_{2}, \mathrm{TiO}_{2}, \mathrm{In}_{2} \mathrm{O}_{3}, \mathrm{WO}_{3}$, $\mathrm{NiO}$, etc.). The gas sensing property/capability of metal oxides, which is the ability of a gas to cause changes in their conductivity, has been known since $1962 .{ }^{17}$ Their operation principle is based on a change in the concentration of the charge carriers of the material upon its interaction with a target gas, usually through the adsorbed surface oxygen ions. This leads to a change in the conductivity of the material which is caused by the electron trapping by adsorbed oxygen species and thus the band bending of the metal oxide energy levels. ${ }^{11}$ These adsorbed oxygen species are considered as free oxygen ions (such as $\mathrm{O}_{2}^{-}, \mathrm{O}^{2-}$ and $\mathrm{O}^{-}$) which are stabilized on the metal oxide surface through electrostatic forces. ${ }^{18}$ The predominant form of the oxygen ions depends on the applied temperature. Thus, below $150^{\circ} \mathrm{C}$ oxygen is present as $\mathrm{O}_{2}{ }^{-}$, while above $150^{\circ} \mathrm{C}$ it is present as chemisorbed oxygen $\left(\mathrm{O}^{-}\right.$or $\left.\mathrm{O}^{2-}\right) \cdot{ }^{19,20}$ For a gas sensor operating at ambient conditions, chemisorbed oxygen species are the predominant oxygen forms on the surface. ${ }^{19}$ 
The main principle of the change in the conductivity of a semiconductor upon its exposure to combustible gases is a consequence of an adsorption and reaction of gas molecules on the surface of the metal oxide. This mechanism strongly depends on the chemical state of the adsorbed oxygen species. ${ }^{19}$ Thus, combustible gases may not directly interact with the metal oxide, but their presence controls the concentration of the adsorbed oxygen species. This in turn controls the surface charge and thus the conductivity of the gas sensor. Exposure of a semiconductor-based sensor to combustible gases causes charge transfer (electron extraction) from the conduction band of the metal oxide to the iono- or chemisorbed oxygen species. This process produces a band bending and forms a net surface charge, which induces a space charge region on the surface of the metal oxide.

Summarizing, the operation principles of metal oxide gas sensors can be described by two models, a) the oxygen-vacancy model (reduction-reoxidation mechanism) and b) the ionosorption model (Figure 1.4). ${ }^{18}$ In both models the sensing mechanism relies on a change in the concentration of the charge carriers of the material upon its interaction with a target gas, usually through the adsorbed surface oxygen species (ions). This leads to a change in the conductivity of the material. In the case of the oxygen-vacancy model, the interaction of a gas with a metal oxide causes the partial reduction and reoxidation of the metal oxide surface. In the case of a typical $n$-type semiconductor $\left(\mathrm{SnO}_{2}\right)$ oxygen vacancies act as $\mathrm{e}^{-}$donors. Upon its exposure to reducing gas (e.g. ethanol, $\mathrm{CO}$ ), the surface of the metal oxide is partially reduced, which leads to an increase in the concentration of the oxygen vacancies. This process injects free electrons to the conduction band, and thus an increase in the conductivity occurs. Upon the removal of the analyte, the surface is reoxidized (upon the presence of oxygen), filling the vacancies and thus causing a decrease in the conductivity. In the case of oxidizing gas species (e.g. $\mathrm{NO}_{\mathrm{x}}$ ), the mechanism is the opposite. 
In the case of the ionosorption model, oxygen in the form of free ions plays an important role. Initially physisorbed oxygen gets charged and thus ionosorbed due to the metal oxide-oxygen $e^{-}$ transfer. ${ }^{21}$ Such ionized oxygen species include $\mathrm{O}_{2}^{-}$(molecular), $\mathrm{O}, \mathrm{O}^{2-}$ (atomic). These oxygen ions scatter electrons within the Debye length $\delta$ of the metal oxide forming a space-charge layer (electron depleted region), with a reduced mobility of $e^{-}$near the surface of the metal oxide (Figure 1.3). ${ }^{21}$ Exposure of the metal oxides to reducing gases $\left(\mathrm{CO}, \mathrm{H}_{2}\right.$, ethanol) oxidizes the ionic oxygen, and thus its concentration decreases. Such surface reactions are illustrated below:

$$
\begin{gathered}
\mathrm{C}_{2} \mathrm{H}_{5} \mathrm{OH}_{(\mathrm{g})}+\mathrm{O}_{(\mathrm{ad})}{ }^{-} \rightleftharpoons \mathrm{CH}_{3} \mathrm{CHO}_{(\mathrm{g} / \mathrm{ad})}+\mathrm{e}^{-} \\
\mathrm{H}_{2(\mathrm{~g})}+\mathrm{O}_{(\mathrm{ad})}{ }^{-} \rightleftharpoons \mathrm{H}_{2} \mathrm{O}_{(\mathrm{g})}+\mathrm{e}^{-} \\
\mathrm{CO}_{(\mathrm{g})}+\mathrm{O}_{(\mathrm{ad})}{ }^{-} \rightleftharpoons \mathrm{CO}_{2(\mathrm{~g})}+\mathrm{e}^{-}
\end{gathered}
$$

This process releases the trapped $e^{-}$, increasing the electron mobility in the oxides, and as a result an increase in the conductivity occurs. Once again, in the case of oxidizing gas species (e.g. $\mathrm{NO}_{\mathrm{x}}$ ) an opposite effect is observed due to the increase in the concentration of ionosorbed oxygen. It is important to mention that $300-450{ }^{\circ} \mathrm{C}$ is the working temperature range for most metal oxides, since at this range $\mathrm{O}^{-}$is known to be the dominant species. 
a)

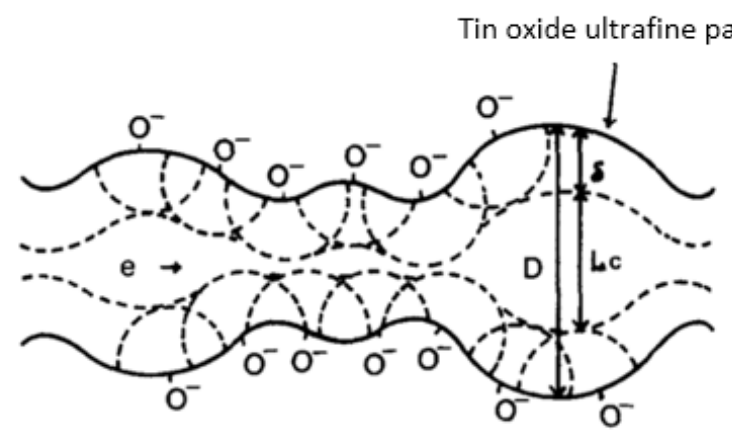

b)

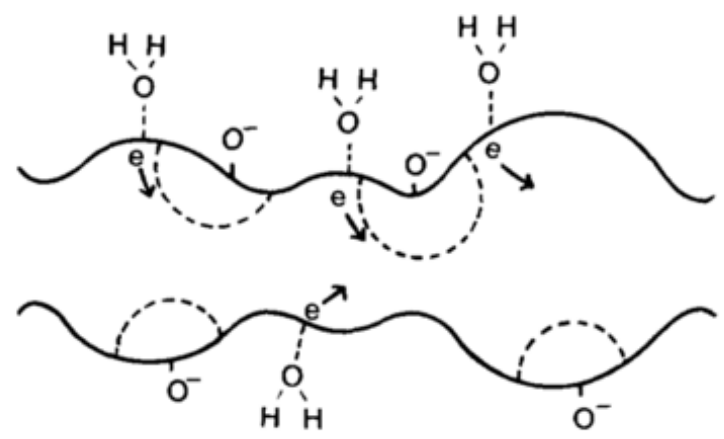

Figure 1.4 Schematic model of oxygen ionosorption on the $\mathrm{SnO}_{2}$ surface in a) In pure air, the adsorbed oxygen species trap electrons from $\mathrm{SnO}_{2}$ forming ions that scatter electrons within the Debye length $\delta$ of the oxide. This decreases the electron concentration and mobility resulting in a reduction of the $\mathrm{SnO}_{2}$ conductivity. b) The reaction between ethanol and the ionosorbed oxygen decreases the concentration of these scattering centers $\left(\mathrm{O}^{-}\right)$and releases the trapped electrons thereby increasing the $\mathrm{SnO}_{2}$ conductivity. ${ }^{18}$ Copyright 2017, with permission from AIP Publishing LLC. $^{21}$

Numerous metal oxides have been explored as active layers in gas sensing devices, and they are divided in three main categories; pre-transition metal oxides, transition metal oxides and posttransition metal oxides. The first category contains elements that have only one oxidation state and are wide band gap insulators. Due to their large band gap, such metal oxides are rather inert, meaning that they cannot get reduced or oxidized. Due to their difficulties they possess in 
conductivity measurements, they are considered as poor candidates in gas sensor devices. Alkaline-earth oxides and $\mathrm{Al}_{2} \mathrm{O}_{3}$ belong to this category. Transition-metal oxides behave differently than pre-transition metal oxides and are more sensitive to environmental changes. This property is based on multivalent cations that can be oxidized or reduced, which is related to the rather small difference between the cation $d^{n}$ configuration and either the $d^{n+1}$ or $d^{n-1}$ configurations. ${ }^{11}$ Their structural instability and non-optimality of other features that play a crucial role in a sensor device based on conductivity measurements, limits their application. The most common representatives of this category are $\mathrm{TiO}_{2}, \mathrm{~V}_{2} \mathrm{O}_{5}$, and $\mathrm{WO}_{3}$ which are metal oxides with $\mathrm{d}^{0}$ electronic configuration, and $\mathrm{ZnO}$ or $\mathrm{SnO}_{2}$, which are metal oxides with $\mathrm{d}^{10}$ electronic configuration. Post-transition metals, which are the third category, include metal oxides with $\mathrm{d}^{10}$ electronic configuration, which can be reduced. They are the most sensitive and stable candidates

for sensing applications. $\mathrm{ZnO}, \mathrm{In}_{2} \mathrm{O}_{3}$ and $\mathrm{SnO}_{2}$ are the most common examples of this category. ${ }^{17}$

\subsubsection{Field-Effect Transistor (FET) gas sensors}

The operation principle of the Field-Effect Transistor (FET) gas sensors is based on the introduction of a field effect as a result of the exposure of the sensing channels to the target gas. Unlike in the case of conductometric gas sensors, whose detection capability is based on changes in the resistance, in the case of the FET gas sensors, multiple transistor parameters, such as the bulk conductivity, the mobility and the threshold voltage, govern their detection capability. This category of gas sensors is considered to be very advantageous for several reasons, including their operation at room temperature, while conductometric sensors usually function at the temperature range $200-400{ }^{\circ} \mathrm{C}$, the usage of various sensing materials, and their small dimensions that allow them to be made into sensor arrays. ${ }^{4,22}$ 
Figure 1.5 illustrates the basic layout of a FET sensor. The device contains a source, drain, and a semiconductor layer which is contacted by two electrodes. An additional insulating oxide layer is placed between a third electrode, gate, and the semiconductor layer. The semiconductor layer can consist of various materials such as carbon nanotubes, polymers, metal oxides, semiconducting nanowires etc. When a gate bias is applied with respect to the source, accumulation or depletion of the charge carriers occurs at the semiconductor-insulator interface. This field-effect causes the variation of the charge carrier density in the semiconductor. As a result, the semiconductor resistivity, and thus the current through the semiconductor can be altered over orders of magnitude. $^{8}$

Upon the exposure of the transistor to target gases, its electrical characteristics change. In the case of n- and p-type semiconductors, current decreases or increases occur, depending on the nature of the gas (electron donating or withdrawing). These current changes are in agreement with a threshold voltage shift towards positive or negative gate biases.

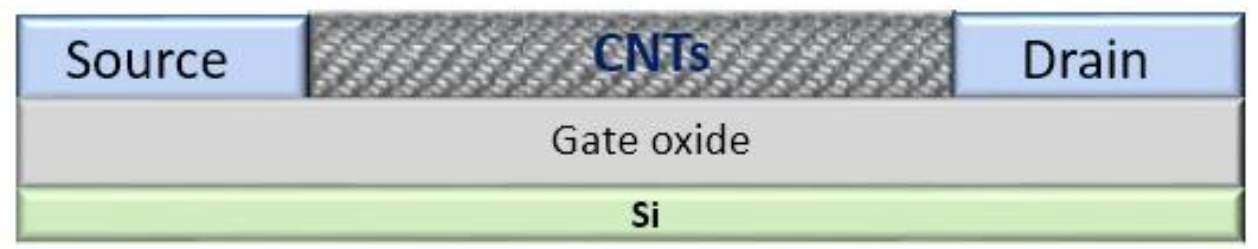

Figure 1.5. Layout of a FET with CNTs acting as the conducting channel. ${ }^{8}$

\subsubsection{Acoustic wave gas sensors}

The main operation principle of acoustic wave gas sensors is a high-frequency mechanical vibration. ${ }^{23}$ Their detection capability relies on the modulation of surface acoustic waves. ${ }^{24}$ In a typical surface acoustic wave gas sensor (SAW), a piezoelectric substrate is used for the generation of an acoustic wave, on the top of which a thin layer of an active material is deposited. The sensing capability of such sensors relies on their sensitivity towards perturbations that occur on the surface 
of the active material. ${ }^{25}$ Thus, during the propagation of an acoustic wave on the surface or through the active material, changes of the propagation wave path influence the amplitude and velocity of the wave. In the presence of a certain gas species for example, the adsorption of the gas molecules on the active material, causes the perturbation of the velocity and attenuation of the surface waves. These changes in the wave properties can be detected by electronic systems (mainly oscillators) that measure the frequency or phase characteristics of the detector, and can be correlated to the concentration of the target gases. ${ }^{26}$

Based on their acoustic and electrical features/characteristics, acoustic gas sensors are classified in two categories: the surface acoustic wave sensors (SAW), and the bulk acoustic wave sensors (BAW). ${ }^{25,27}$ In the case of BAW sensors, the wave propagation occurs through the interior of the substrate. In the case of SAW sensors, on the other hand, the wave propagation occurs on the surface of the substrate. ${ }^{28}$ The main advantage of SAW sensors over BAW is that higher frequencies and sensitivities can be achieved using the former ones. ${ }^{27}$

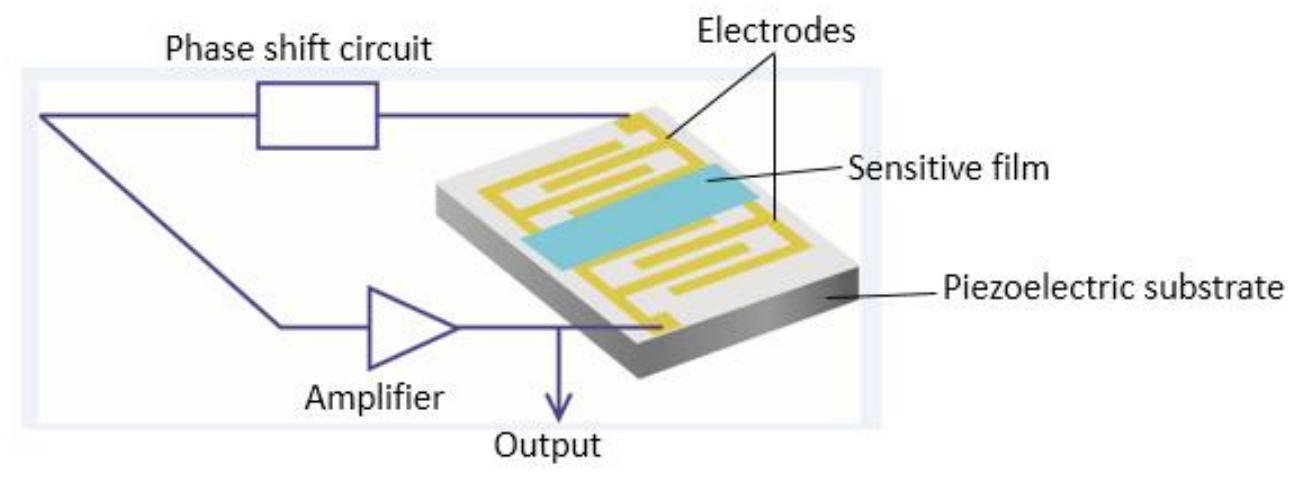

Figure 1.6. Schematic illustration of a typical SAW sensor. 


\subsubsection{Electrochemical gas sensors}

The operation principle behind this category of gas sensing devices is the measurement of current, voltage or conductivity as a result of the chemical reactions or strong physical interactions occurring between the molecules of the target gas and the sensing electrode. The corresponding sensors are called amperometric, potentiometric and conductometric, respectively.

Amperometric sensors are usually used in various applications including safety applications. The main operation principle of such devices is an electron transfer to or from the analyte. ${ }^{29} \mathrm{~A}$ typical amperometric instrument consists of a sensor cell, an electrolyte, and three electrodes, a counter electrode, reference electrode (e.g.; $\mathrm{Ag} / \mathrm{AgCl}, \mathrm{Hg} / \mathrm{Hg}_{2} \mathrm{Cl}_{2}$ ) and working electrode. The working electrode usually consists of platinum, palladium or carbon, coated with an active material. This is the "sensing" electrode where oxidation/ reduction of target gas takes place. ${ }^{30}$ For the recording of measurable signal changes in the current flow, a certain potential bias is applied to the electrode. The sensitivity of such a detector is dependent on the rate that gas molecules diffuse into the active material. Thus, one disadvantage of this technology is a slightly delayed sensor response time, related to a slow diffusion time. The main advantages of such sensors however, is their high sensitivity and low fabrication costs.

Unlike in the case of amperometric sensors where the measured signal is an electric current, in the case of potentiometric sensors, an electromotive force is the measured parameter. A typical potentiometric sensing cell consists of a solid electrolyte where the target gas is converted to its mobile components, and two electronically conducting electrodes deposited on the two sides of a solid electrolyte; an ion selective electrode, and a reference electrode. ${ }^{31}$ The former electrode type, which is also the "sensing electrode", is capable of selectively measuring the activity of a specific ionic species. As a result of the equilibrium of the electrochemical reactions, chemical potentials 
are formed at the electrolyte-electrode interfaces. In the case of an potentiometric oxygen sensor for instance, the chemical potential of oxygen at the electrode/electrolyte interface is defined by the equilibrium of the chemical reactions at the gas-electrode-electrolyte triple phase boundary. ${ }^{32}$ Potentiometric gas sensors are widely used in automotive industry.

Conductometric (resistive) semiconductor gas sensors are one of the most widely studied groups of gas sensors. Compared to other senor types they exhibit certain advantages. ${ }^{33,34}$ These are: a) thin-film electrodes allow the large scale production using inexpensive technology, b) a reference electrode is not required, d) a low applied/driving voltage is sufficient, which decrease significantly the power consumption, e) a variety of analytes (gases) can be detected based on various reactions and mechanisms, f) they can be used in a distributed environment for an on-line or remote sensing.

The structure of conductometric (resistive) semiconductor gas sensors is very simple and their operating principle is based on changes in the resistance as a result of the exposure of the sensing substrate to chemical species. The resistance changes occur as a result of various processes/reactions that take place on the surface of an active material (sensing layer). Such reactions can be chemical reactions, adsorption, catalysis, diffusion or swelling.

Among advantages of the conductometric sensors, low fabrication costs and flexibility in production, simplicity of usage, high sensitivity, good reproducibility and the detection capability of a variety of target gases, are the most striking ones. Altering several parameters such as a substrate, thickness of an active material layer or an operating temperature, can greatly affect the performance of such gas sensors. Their main disadvantage is a sensitivity to humidity and in some cases a rather low selectivity towards gases with similar chemical characteristics. ${ }^{11}$ A metal oxide 
conductometric gas sensor is the most common type of this category, which is used to detect trace amounts of various gas species $\left(\mathrm{NH}_{3}, \mathrm{CH}_{4}, \mathrm{H}_{2}\right.$ etc. $) .{ }^{11}$ Conductometric gas sensors find usage in various industrial applications including automotive, environmental monitoring, public security, and public air-conditioning. ${ }^{35}$

Materials with a chemical/gas transduction capabilities (i.e. gas adsorption followed by an electrical property modification) are considered as good active materials in the conductometric sensors. ${ }^{36}$ This is not, however, the only requirement of a good/suitable sensing material. Other features such as the robustness and stability or the kinetics of interactions between the target gas and the surface of the substrate need also to be considered. ${ }^{36}$ The most widely studied active material in such a sensor type (conductometric) are metal oxides ${ }^{37}$ and various carbonaceous materials. ${ }^{38}$ The latter include, carbon nanotubes, carbon black, carbon nanofibers, graphene, graphene oxide or graphene/metal oxides composites. ${ }^{38}$ The usage of carbon allotropes in gas sensing is analyzed in Section 1.6. A typical conductormetric sensing set-up consists of a gas mixing unit, a gas chamber, a substrate/substrate holder (chips), and an electrical monitor (measurement electronics). Usually the gas flow is constant.

Conductometric gas sensors/chips consist mainly of two elements; an insulated substrate (e.g. alumina or silica) and contact electrodes (e.g. Au or Pt interdigitated electrode fingers). The electrodes are embedded in the conducting sensing layer. Figure 1.7 illustrates a typical thin film gas sensor. During the sensing measurement, a DC voltage is applied to the device, and an electrical monitor records the current flow. This is called the sensor response. Since $300-450{ }^{\circ} \mathrm{C}$ is the working temperature range for most metal oxides, in the case of metal oxide conductometric gas sensors, a heater is also included in the device to reach these temperatures. 


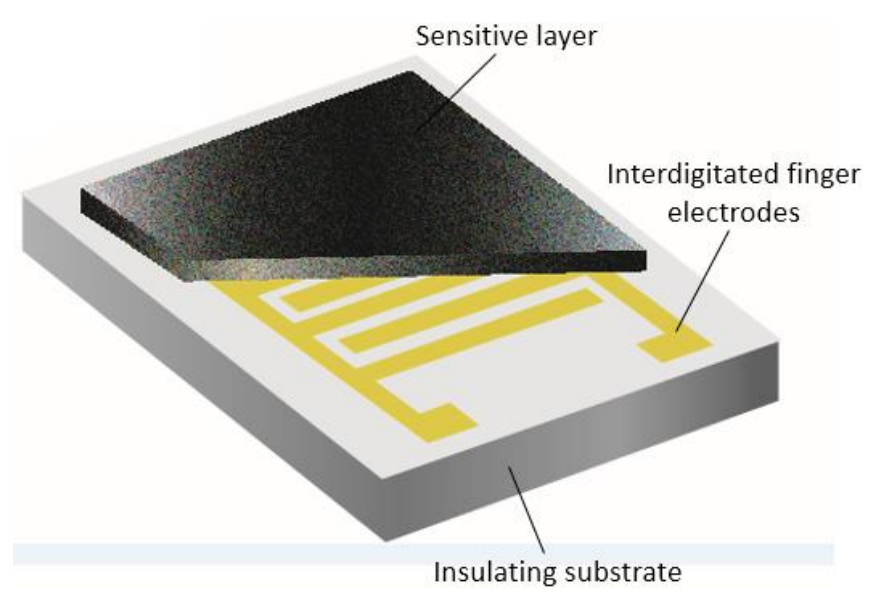

Figure 1.7. A typical conductometric thin film gas sensor.

\subsubsection{Gas sensors based on conducting polymer nanofibers}

The usage of conducting polymers, such as polyaniline (PANI), polypyrrole (PPy), polythiophene (PTh) and their derivatives, has received great attention because of their improved features compared to other commercial toxic gas sensors. They are easily prepared through electrochemical and chemical processes, show highly sensitive responses, short response times, good mechanical properties, and high conductivity. Moreover, they can be further modified by copolymerization or structural deviations of their molecular chain. ${ }^{39}$ Conducting polymer nanofibers are promising sensing materials in chemiresistors, due to the above mentioned features as well as their high specific surface area, and low fabrication cost. ${ }^{40}$ PANI is one of the most commonly studied and used conducting polymers in gas sensing applications, which offers the capability of further modification. PANI nanofibers with diameters in the order of tens of nanometers are usually prepared using elecrospinning method, which is considered as one of the most suitable ones for their mass production. ${ }^{40,41}$ The most common disadvantages of polymer-based gas sensors are the irreversibility in their response, poor selectivity, and long-time instability. Moreover, their performance may be affected by the working environment. ${ }^{42}$ 


\subsection{Advantages and disadvantages of solid-state gas sensors}

An optimal sensing technology should be considered in the context of a sensor's operating and environmental conditions, as well as its production cost. Therefore, it is important for one to be aware of the most important advantages and disadvantages of each solid-state gas sensing technology, which are presented in Table 2 . 
Table 1.2. Comparison of gas detection sensor technologies.

\begin{tabular}{|c|c|c|}
\hline Sensor type & Advantages & Disadvantages \\
\hline Catalytic & $\begin{array}{l}\text { Simple operation, robust. } \\
\text { Long life and low technology and } \\
\text { replacement cost. } \\
\text { Measures flammability of gasses. } \\
\text { Detects most combustible. hydrocarbon }\end{array}$ & $\begin{array}{l}\text { Air or oxygen is required for their operation. } \\
\text { Can become poisoned or inactive by } \\
\text { contamination from chlorinated \& silicone } \\
\text { compounds, prolonged exposure to } \mathrm{H}_{2} \mathrm{~S} \text { and } \\
\text { other sulfur and corrosive compounds. }\end{array}$ \\
\hline Optical & $\begin{array}{l}\text { High sensor life cycle } \\
\text { Wide monitoring area } \\
\text { Easy operation in absence of oxygen }\end{array}$ & $\begin{array}{l}\text { High installation expenses. } \\
\text { Optics contamination over time. } \\
\text { Operation affected by ambient light } \\
\text { interference. }\end{array}$ \\
\hline Semiconductors & $\begin{array}{l}\text { Good operation at high humidity. } \\
\text { Flexibility of sensor design for specific } \\
\text { applications. } \\
\text { Inexpensive to manufacture due to their } \\
\text { simplicity. }\end{array}$ & $\begin{array}{l}\text { False measurements by the absorption of } \\
\text { non-target gases (ozone, water, organic } \\
\text { compounds). } \\
\text { Non-linear response requires consistent } \\
\text { calibration of the sensors leading to } \\
\text { increased sensor costs associated with } \\
\text { resources and labor time. }\end{array}$ \\
\hline $\begin{array}{c}\text { Field-Effect } \\
\text { Transistors (FET) }\end{array}$ & $\begin{array}{l}\text { Robustness. } \\
\text { Enable application of various sensing } \\
\text { materials. } \\
\text { Compatible with micro-fabrication } \\
\text { technology, due to their small size, can } \\
\text { be made into sensor arrays }\end{array}$ & $\begin{array}{l}\text { Very poor linearity. } \\
\text { Poor frequency response due to its high input } \\
\text { capacitance. } \\
\text { Can be damaged due to the static electricity. }\end{array}$ \\
\hline Acoustic & $\begin{array}{l}\text { Long lifetime. } \\
\text { Secondary pollution is avoided. } \\
\text { Short response time. } \\
\text { Low power consumption, size, } \\
\text { robustness }\end{array}$ & $\begin{array}{l}\text { Low sensitivity. } \\
\text { Temperature and humidity dependence. } \\
\text { Difficulty of senor replacement. } \\
\text { Poor reproducibility in the deposition of the } \\
\text { coating material. } \\
\text { Certain level of noise. }\end{array}$ \\
\hline Electrochemical & $\begin{array}{l}\text { Measures toxic gases in relatively low } \\
\text { concentrations. } \\
\text { Can be specific to a particular gas or } \\
\text { vapor in the parts-per-million range. } \\
\text { Wide range of gases can be detected. } \\
\text { Linear output, low power requirements } \\
\text { and good resolution. } \\
\text { Excellent repeatability and accuracy. } \\
\text { Does not get poisoned by other gases. } \\
\text { Less expensive than most other gas } \\
\text { detection technologies. }\end{array}$ & $\begin{array}{l}\text { Narrow or limited temperature range. } \\
\text { Cross-sensitivity of other gases. } \\
\text { Short or limited shelf life. } \\
\text { Failures modes are unrevealed unless } \\
\text { advanced monitoring technique used. }\end{array}$ \\
\hline $\begin{array}{l}\text { Conducting } \\
\text { polymers }\end{array}$ & $\begin{array}{l}\text { Mechanical flexibility, high specific } \\
\text { surface area, low cost fabrication, and } \\
\text { high conductivity. }\end{array}$ & $\begin{array}{l}\text { Irreversibility in their response, poor } \\
\text { selectivity, and long-time instability. }\end{array}$ \\
\hline
\end{tabular}




\subsection{Ammonia as a toxic gas}

Ammonia is a colorless toxic gas that poses a serious threat to air quality. It has a strong irritating and pungent odor and can be smelt only at a concentration higher than $50 \mathrm{ppm}$ (parts per million). This means that it is natural for everybody to be regularly exposed to low levels of $\mathrm{NH}_{3}$ present in air, food, soil, and water, without even realizing it. It has a diameter of about $3 \AA$, and due to its polarity and ability to form hydrogen bonds it has a high solubility in water. Short term exposures to ammonia gas (less than $8 \mathrm{~h}$ ) may cause injuries to the respiratory tract, eyes and skin, while prolonged exposures to concentrations higher than $300 \mathrm{ppm}$ can lead to serious ailments or even death. ${ }^{43}$ Therefore, it is a necessity to develop highly sensitive and selective ammonia sensors.

\subsubsection{Sources of ammonia}

The three most common sources of ammonia are given below ${ }^{44}$ :

The first ammonia source is related to processes contributing to a nitrogen fixation by plants. Even though the atmosphere consists of $80 \%$ nitrogen, a very small part of it is available to plants. Nitrogen is known to enter the ecosystem through a process which is called nitrification. One path of nitrification is an activity of nitrogen-fixing bacteria, which can transform atmospheric nitrogen to inorganic compounds, usable by plants. These bacteria release $\mathrm{NH}_{3}$, which, due to the acidity of the soils, is usually converted to ammonium ions. The second path of nitrification involves the deposition of ammonium and nitrate salts on the vegetation and soil. The removal of such $\mathrm{N}$ compounds from the atmosphere can be done through both dry and wet deposition. ${ }^{45}$ The former type involves the rapid deposition of ammonia in ecosystems. This pathway also includes the ammonia removal though the formation of aerosol particles by its interaction with atmospheric $\mathrm{HNO}_{3}$ and $\mathrm{H}_{2} \mathrm{SO}_{4}$. Wet deposition involves ammonia removal with the rainwater. An excess of 
ammonium, however, can cause ecosystem acidification or eutrophication, and results in an increase of the ammonia concentration in the atmosphere.

The second ammonia source is related to nitrogen cycle in soils, and more precisely to a process called ammonification, which is the production of ammonia from organic compounds. The process includes a series of metabolic activities by bacteria called ammonifying, and results in the existence of ammonia and ammonium ions $\left(\mathrm{NH}_{4}{ }^{+}\right)$, due to the dissolution of the former (ammonia) in soil water. ${ }^{46}$

The third source are ammonia emissions owing to a direct or indirect human activity. This includes ammonia production by chemical industries and motor vehicles or its usage in refrigeration systems. In chemical industries ammonia is used for the production of liquid fertilizer solutions consisting of ammonia, ammonium nitrate, urea and aqua ammonia. In fertilizer industry ammonia is used for the production of ammonium and nitrate salts.

\subsection{Application areas of ammonia sensors}

Environmental, automotive, chemical industry and medical diagnostics are the main areas where the exact ammonia concentration is crucial to be known and thus $\mathrm{NH}_{3}$ sensors are required.

\subsubsection{Environmental}

Ammonia emissions in farming areas or emissions from manure spread onto farmland are considered as a public health issue because of their unpleasant odor and their effect on air quality. This is the case when the concentration of the gas is higher than the permissible exposure limit. In such areas the ammonia exposure limit is $\sim 20 \mathrm{ppm} .{ }^{47} \mathrm{The}^{\mathrm{NH}} 3$ concentrations are usually the highest inside the stables. This causes unhealthy living conditions to both the farmers and the animals. 
Another dangerous aspect of ammonia emissions is related to the capability of a gaseous $\mathrm{NH}_{3}$ to react with sulfuric and nitric acid to form the corresponding ammonium salts. ${ }^{48}$ These salts can act as condensation nuclei for the formation of aerosol particles, which eventually lead to the formation of clouds of smog, especially above industrial areas or larger cities. Due to their sunblocking effect, the formed aerosols cause the cooling of the atmosphere, which however is not easily noticeable since it competes with more intense global warming as a results of the greenhouse effect.

The design of the appropriate ammonia detectors is a necessity while the accuracy of their concentration limit depends on their actual application. Thus, $\mathrm{NH}_{3}$ sensors with a detection limit as low as $1 \mathrm{ppb}$ or even lower are required for ammonia monitoring/detection in natural atmosphere (e.g. above the oceans). ${ }^{44}$ In farming areas, ammonia sensors should be able to detect gas concentrations of about $10 \mathrm{ppm}$ or less. ${ }^{44}$ In dairy wastewater lagoons for instance the $\mathrm{NH}_{3}$ concentration should be less than $10 \mathrm{~nm} \cdot{ }^{49}$ In poultry houses, on the other hand, the permissible concentration limit is $150 \mathrm{ppm} .{ }^{49}$ Even though ammonia monitoring systems in environmental areas do not demand extremely fast sensors/analyzers, their response time should be approximately

1 min. ${ }^{44,49}$ Furthermore, agricultural detectors need to withstand heavy dust loading conditions and operate in humid conditions (e.g. rain or condensation). ${ }^{49}$

\subsubsection{Automotive industry}

The detection of ammonia gas in automotive industry becomes an important objective mainly for the following three reasons: ${ }^{50}$

It is a necessary to control the vehicle exhaust gases that cause atmospheric pollution, and more precisely those in gasoline vehicles that are equipped with three-way catalysts (TWC). In that case 
ammonia is formed by the reaction of nitrogen monoxide with molecular hydrogen, which $\left(\mathrm{H}_{2}\right)$ is produced by the reaction of $\mathrm{CO}$ with water according to the following reactions:

$$
\begin{gathered}
\mathrm{CO}+\mathrm{H}_{2} \mathrm{O} \rightarrow \mathrm{CO}_{2}+\mathrm{H}_{2} \\
2 \mathrm{NO}+2 \mathrm{CO}+3 \mathrm{H}_{2} \rightarrow 2 \mathrm{NH}_{3}+2 \mathrm{CO}_{2} \\
2 \mathrm{NO}+5 \mathrm{H}_{2} \rightarrow 2 \mathrm{NH}_{3}+2 \mathrm{H}_{2} \mathrm{O}
\end{gathered}
$$

There is a need to control the air quality in the passenger compartment, which means that cars should be equipped with gas sensors. In the case of a low quality air outside the car (e.g. near farms and meadows), the detection limit of such indoor sensors should be $\sim 50 \mathrm{ppm}$. Moreover, a response time in the order of seconds is an additional necessity.

The third reason concerns diesel and lean-burn engines, which operate at high air-to-fuel ratios, resulting to an excess of oxygen in the exhaust gas, and thus high concentrations/levels of $\mathrm{NO}_{\mathrm{x}}$ emissions. ${ }^{51}$ The produced $\mathrm{NO}_{\mathrm{x}}$ can be reduced by adding ammonia to the exhaust gas, through a process that is called "selective catalytic reduction (SCR)". 52 The reduction occurs according to the following equation ${ }^{53}$ :

$$
4 \mathrm{NO}+4 \mathrm{NH}_{3}+\mathrm{O}_{2} \rightarrow 4 \mathrm{~N}_{2}+6 \mathrm{H}_{2} \mathrm{O}
$$

In this case the amount of the injected ammonia to the exhaust gas needs to be controlled to avoid atmospheric pollution. The detectors should be able to detect gas concentrations of only few ppm and have response times as fast as maximum 1 minute. Moreover, considering that the monitoring occurs at the exhaust pipes, the sensors should be able to operate at elevated temperatures.

\subsubsection{Chemical industry}

The demand of ammonia detectors in chemical industry concerns mainly the production of ammonia, and its usage as a refrigerant. Ammonia was first synthesized by the German scientist Fritz Haber in $1904,{ }^{54}$ by a process that is known as a Haber process. Its production involves the 
reaction of atmospheric gaseous nitrogen with hydrogen at elevated temperature $\left(\sim 500{ }^{\circ} \mathrm{C}\right)$, high pressure (150-200atm), and using a porous metal catalyst (iron). This process was industrially scaled-up by Carl Bosch, and therefore it is usually referred to as the Haber-Bosch process. The initial purpose of ammonia production was the demand for an economical source of nitrogen for the production of $\mathrm{HNO}_{3}$ as an explosive component. Nowadays, the main purpose of ammonia usage in chemical industry is for fertilizers containing ammonium salts, and the production of chemicals. Another common usage of ammonia is in refrigerators because of its ability to freeze at temperatures below $0 \circ \mathrm{C} .^{44,43,54,55}$ In the above mentioned applications ammonia leaks can cause life-threatening situations if the exposure limits is higher than $20 \mathrm{ppm}$. Ammonia detectors at such application areas can have a response time of a few minutes, and withstand high temperatures.

\subsubsection{Medical diagnostics}

In human body, ammonia is a natural product that yields from the metabolism of proteins and nucleic acids. It is excreted from it (the body) in the form of ammonium salts in urine. $50 \mathrm{ppm}$ is the lowest limit of $\mathrm{NH}_{3}$ that can be sensed by perception of smell. Considering that concentrations even lower than $50 \mathrm{ppm}$ can irritate the respiratory tract, the eyes and skin, ${ }^{56,57}$ a long term exposure limit as set to be $20 \mathrm{ppm}$. Exposure to $500 \mathrm{ppm}$ can cause an immediate irritation of the throat and nose, while even higher concentrations (1000 ppm) may lead to pulmonary oedema. ${ }^{43,57}$ Prolonged exposures to concentrations higher than $300 \mathrm{ppm}$ or exposures to very high concentrations (5000-10000 ppm) can cause serious ailments or even death.

Since ammonia is produced by the human body and is involved in various physiological processes, its elevated levels in the body (e.g. in blood) can be a biomarker of various dysfunctions (e.g. kidney disorder, metabolism disorders, such as urea cycle disorders etc.). ${ }^{58}$ Considering that blood ammonia is in gaseous equilibrium with the lungs, using breath ammonia analyzers/detectors is an 
effective means to detect and even prevent such body dysfunctions. ${ }^{58}$ Such a diagnostic method however requires ammonia detectors with a response time as fast as a only few minutes, for gas concentrations as low as $50 \mathrm{ppb}$, which is the level of ammonia in healthy individuals..$^{58,59}$

\subsection{State-of-art carbon-based conductometric gas sensors}

Based on the above discussion, solid state gas sensors are very advantageous due to their small sizes, low power consumption, high sensitivity and selectivity, and low operation costs. Their limited measurement accuracy and stability over time are however two of the main limitations. The recent development of nanotechnology, has provided the potential to develop sensors with enhanced sensing performances, by utilizing novel nanostructures as the detection elements. Considering that the performance of a gas sensor depends on the exposed surface area, one of the most important parameters determining its sensitive operation is its specific surface to volume ratio. Compared to conventional microsensors, carbon-based nanostructured materials as gas sensing substrates exhibit higher detection areas. This allows the greater adsorption of the target gas species which markedly enhances their efficiency as gas sensors. ${ }^{10}$ Furthermore, by applying simple chemical treatments, their sensitivity can be further enhanced. The most widely investigated carbon-based nanostructured materials for gas sensing applications are carbon nanotubes (CNTs), as well as graphene and its derivatives, such as pure graphene, graphene oxide, and reduced graphene oxide. The main principle behind the sensing mechanism of such $p$-type carbon-based materials is a decrease in their conductivity upon their exposure to reducing gases, or an increase in the same parameter upon their exposure to oxidizing gases. Their $p$-type conductivity means that under ambient conditions, positively charged holes $\left(h^{+}\right)$are the majority charge carriers. Thus, a decrease in the conductivity upon exposure to electron donating gases is 
related to the depletion of the carriers, while an increase in the same parameter upon exposure to electron accepting gases is related to the opposite phenomenon.

Carbon nanotubes (CNTs) are members of the family of fullerene structures, and can be classified to single-walled and multi-walled carbon nanotubes (SWCNTs and MWCNTs, respectively). In the case of SWCNTs, a one-atom-thick layer of graphite is wrapped into a seamless cylinder, with a diameter of only several nanometers, while in the case of MWCNTs, multiple layers of graphite are rolled in on themselves to form a tube shape (interlayer spacing of $3.4 \AA$ ). Due to their structural features, CNTs possess unique geometry, a large surface area, and excellent electronic, charge transport, mechanical and thermal properties. These features make them great candidates for the sensitive detection of low gas concentrations (e.g. $\mathrm{NH}_{3}, \mathrm{CO}, \mathrm{NO}_{2}$ etc). CNTs can reach detection limits as low as few tens of parts-perbillion (ppb). The main principle of their sensitive detection capability is based on a change in their electrical conductivity, caused by electron exchange processes during the adsorption of the gas molecules. Moreover, the ballistic electron transport (electrons travel through CNTs experiencing no or negligible scattering) that takes place through the CNTs allows the direct transmission of the electrical signals to the external contacts. Finally, due to their chemically robust graphitic surface, they show a stable long-term operation. ${ }^{8}$

Even though pristine CNTs have been reported to be great candidates as gas sensors, a relatively low sensitivity, and the lack of a selective detection of different analytes are their main limitations. Aiming to improve the operation of gas sensors based on CNTs the efforts have been focused on CNTs' functionalization with polymers or metals and metal oxides. Among other organic polymers, conducting polymers exhibiting the optical and magnetic properties of semiconductors while simultaneously retaining the mechanical properties of polymers, have been reported as promising materials for gas sensing. Even higher sensor performances have been reported when 
conducting polymers, such as polyaniline, polypyrrole or polythiophene are combined with SWCNTs. Zhang and coworkers fabricated a chemical ammonia gas sensor using SWCNTs, electrochemically functionalized with polyaniline (PANI). The detection limit of the sensor was as low as only $50 \mathrm{ppb}$, while a sensitivity of about $14.26 \%$ was recorded upon the exposure to 10 ppm of the target gas. ${ }^{60}$ In another study by Zhang and coworkers ${ }^{61}$ it was demonstrated that when poly(m-aminobenzene sulfonic acid) (PABS) was covalently attached SWCNTs, the sensor exhibited a high sensitivity with a detection limit of $100 \mathrm{ppb}$ for $\mathrm{NH}_{3}$ and $20 \mathrm{ppb}$ for $\mathrm{NO}_{2}$. Upon exposure to $\mathrm{NH}_{3}$ or $\mathrm{NO}_{2}$ an enhanced sensor response, compared to simple carboxylated SWNTs, was linked to the protonation/deprotonation of the polymeric phase (PABS). These processes by affecting the concentration of the charge carriers in the SWCNTs, caused dramatic changes to their resistivity. ${ }^{61}$ Kang and coworkers ${ }^{62}$ fabricated metallophthalocyanines- multiwalled carbon nanotube hybrids MPc-3/MWCNTs $(\mathrm{M}=\mathrm{Cu}, \mathrm{Pb}$ and $\mathrm{Ni})$ and used them as efficient ammonia gas sensors. The so-obtained hybrids showed good sensing characteristics, including a high sensitivity of about $40.5 \%$ upon exposure to $80 \mathrm{ppm} \mathrm{NH}_{3}$, excellent stability/reproducibility, and fast response/recovery times. An improved performance of the hybrids was linked to the strong interaction/binding ability of the metal centers with ammonia, and the high electrical mobility provided by the MWCNTs. ${ }^{62}$

Compared to polymer-based sensors, metal sensors can operate at more elevated temperatures, and under harsher environments. This is related to their chemical and mechanical robustness and their electronic and physical properties. Thus, metal or metal oxide functionalized CNT-based gas sensors have also demonstrated enhanced gas sensing performances. Abdelhalim and coworkers studied CNT-based gas sensor functionalized with $\mathrm{Au}$ nanoparticles as $\mathrm{NH}_{3}$ gas sensors. They reported that the sensors' normalized responses reached values of $25 \%$ and $92 \%$ when exposed to 
$10 \mathrm{ppm}$ and $100 \mathrm{ppm}$ of the target gas, respectively. ${ }^{63}$ In another study by Penza and coworkers, it was demonstrated that when Au and Pt nanoclusters were sputtered on the surface of MWCNT, enhanced sensor sensitivities were recorder, which were improved by a factor up to one order of magnitude compared to pure MWCNTs. ${ }^{64}$

Graphene and its derivatives including pristine graphene, graphene oxide, and reduced graphene oxide have also been reported to show distinct gas sensing capabilities. Their suitability in gas sensing applications is related to exceptional properties of graphene, including a high mechanical strength and carrier mobility, good thermal stability, and low electrical noise. In its pristine form, graphene is a perfect $2 \mathrm{D}$ crystalline structure. Its two dimensional structure makes the electron transport through its structure highly sensitive to adsorbed gas molecules. Based on the ability of the target gases to either donate or withdraw electrons upon their adsorption on graphene's surface, they cause changes in the concentration of the local charge carriers (electrons or holes), thus affecting its electrical conductivity.

One of the most common ways to synthesize graphene is the chemical oxidation of graphite, and the simultaneous reduction of the obtained graphite oxide (GO). ${ }^{65}$ The latter one (GO) has a similar to graphite layered structure but is functionalized with oxygen-containing groups such as carboxylic, lactonic, epoxy and hydroxyls. ${ }^{66}$ These groups except of expanding the interlayer spacing, also increase the hydrophility level of the material allowing its exfoliation when sonicated or stirred in aqueous media. Because of its rich surface chemistry, in some cases GO can have better sensing properties than pure graphene towards certain gas species (e.g. ammonia). ${ }^{67,68}$ This is attributed to its surface defects (oxygen-containing functional groups), which promote/enhance the interactions with the molecules of the target gasses. Moreover, Tang and coworkers demonstrated, based on first-principle calculations, ${ }^{69}$ that when the target species are nitrogen 
oxides, carbonyl and hydroxyl groups on GO, as well as their neighboring carbon atoms enhance charge transfer from $\mathrm{NO}_{\mathrm{x}}$ to $\mathrm{GO}$, enhancing the chemical adsorption of the gas molecules.

By removing some oxygen containing functional groups, graphite oxide can be reduced to graphene-like sheets. Because of its similar to graphene structure, and the presence of oxygencontaining functional groups, reduced graphene oxide $(\mathrm{rGO})$ has also great potential as a gas sensing material. In fact, rGO has been also reported to be even more advantageous than pure graphene in gas sensing because of its lower production cost, the capability to tune its conductivity and structure, its dispersibility in water and capability for further modifications ${ }^{67}$ Recently, $\mathrm{Hu}$ and coworkers, fabricated ultrafast and sensitive ammonia gas sensors, based on chemically reduced graphene oxide (rGO). The sensor response was reported as high as $2.4 \%$ upon its exposure to only $1 \mathrm{ppb}$ of ammonia. ${ }^{70}$

Similarly to CNTs, chemical modifications of graphene-based materials greatly enhance their sensing performance, by allowing the manipulation of their physiochemical properties. Such modifications involve the functionalization with metals/metal oxides, the introduction of defects/dopants or the coating with polymers. Graphene doping, for example, with different heteroatoms (such as $-\mathrm{S},-\mathrm{B},-\mathrm{Si}$ ) has been proven to greatly enhance the sensing performance, owing to the heteroatom induced band-gap alterations, which in turn affect the electronic properties of graphene. Niu and coworkers ${ }^{71}$ reported the ammonia sensing capability of phosphorus doped graphene, which they prepared by annealing a mixture of triphenylphosphine and GO (P-GNS) (Figure 1.8). The modified P-GNSs sensors exhibited an improved sensor response ( $1.7 \%$ for $1 \mathrm{ppm}$ of $\mathrm{NH}_{3}$ ) compared to the pure thermally reduced graphene. ${ }^{71}$ In a recent study, ${ }^{72}$ Seekaew and coworkers fabricated a graphene-poly(3,4-ethylenedioxythiophene):poly(styrenesulfonate) (PEDOT:PSS) composite film for an ammonia sensing. An 
enhancement in the sensitivity of the sensor compared to pristine PEDOT:PSS or graphene was observed and linked to an increase in a specific surface area of graphene, and $\pi-\pi$ interactions in graphene-PEDOT:PSS.

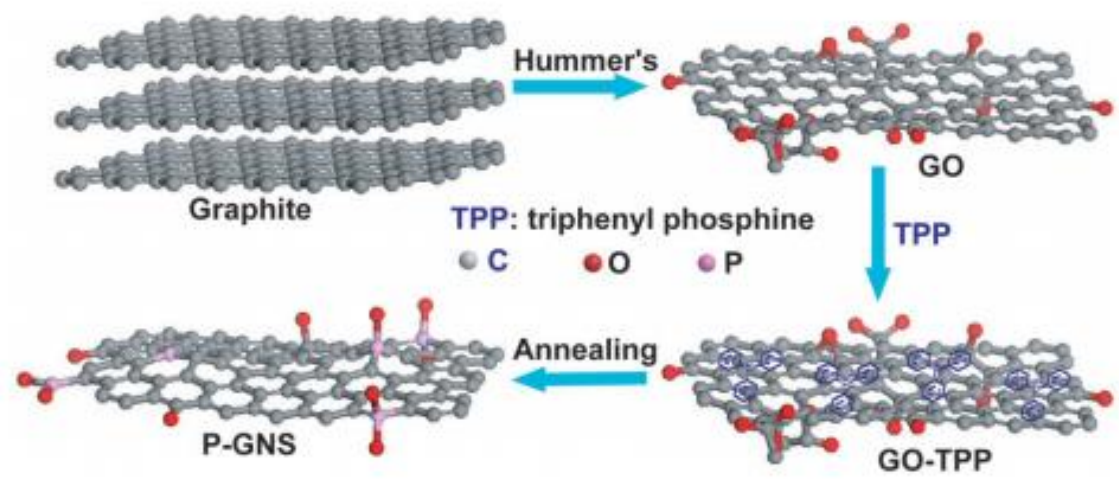

Figure 1.8. Schematic illustration of the synthesis of phosphorus doped graphene nanosheets (PGNS) through high temperature annealing of the graphene oxide and triphenylphosphine (GOTPP) mixture. Copyright 2017, with permission from Royal Society of Chemistry. ${ }^{71}$

The influence of modifications on the sensing capability of reduced GO has been also studied. Huang and co-workers showed that when polyaniline (PANI) nanoparticles were anchored on the surface of reduced graphene oxide sheets (RGO), the RGO-PANI hybrids exhibited a response of $59.2 \%$ upon exposure to $50 \mathrm{ppm}$ of $\mathrm{NH}_{3}$, when the response of the unmodified RGO-based sensor was only $5.2 \% .^{73}$ Another example is given by the data reported by Wang and co-workers, who fabricated an $\mathrm{NH}_{3}$ gas sensor based on chemically reduced graphene oxide with pyrrole vapor (PyrGO). ${ }^{74}$ The sensor exhibited responses as high $4.2 \%$ and $22 \%$ when exposed to gas concentrations as low as $5 \mathrm{ppb}$ and $100 \mathrm{ppm}$, respectively.

As aforementioned, metal decoration of graphene-based materials is an additional means for enhancing their sensing characteristics. Xiang and coworkers fabricated gas sensors based on a composite of polypyrrole (PPy) and graphene nanoplatelets (GNs) decorated with titanium dioxide 
(TiO2) nanoparticles (TiO2@PPy-GN). ${ }^{75}$ The sensor exhibited a sensitivity as high as $102.2 \%$ when exposed to $50 \mathrm{ppm}$ of $\mathrm{NH}_{3}$.

The sensing performance of the state-of-art carbon-based conductometric gas sensors is summarized in Table 3. 
Table 1.3. Table summarizing the sensing performance of the state-of-art carbon-based conductometric gas sensors

\begin{tabular}{|c|c|c|c|c|}
\hline $\begin{array}{l}\text { Carbon-based } \\
\text { ammonia sensors }\end{array}$ & Name & $\begin{array}{c}\mathrm{NH}_{3} \\
\text { concentration } \\
\text { (ppm or ppb) } \\
\end{array}$ & $\begin{array}{l}\text { Response of } \\
\text { the sensor } \\
(\%)\end{array}$ & Ref. \\
\hline SWCNTs-PANI & $\begin{array}{l}\text { Single-walled carbon } \\
\text { nanotubes functionalized } \\
\text { with polyaniline }\end{array}$ & $\begin{array}{c}100 \mathrm{ppm} \\
50 \mathrm{ppb}-3 \mathrm{ppm}\end{array}$ & $\begin{array}{c}14.26 \\
2.44 \\
\text { (superior) }\end{array}$ & 60 \\
\hline SWNT-PABS & $\begin{array}{l}\text { Poly }(\mathrm{m} \text {-aminobenzene } \\
\text { sulfonic acid }) \\
\text { functionalized single- } \\
\text { walled carbon nanotubes }\end{array}$ & $100 \mathrm{ppb}$ & $\sim 1.7$ & 61 \\
\hline $\begin{array}{l}\text { MPc- 3/MWCNTs }(\mathrm{M} \\
=\mathrm{Cu}, \mathrm{Ni} \text {, and } \mathrm{Pb})\end{array}$ & $\begin{array}{l}\text { Metallophthalocyanines- } \\
\text { multiwalled carbon } \\
\text { nanotube hybrids }\end{array}$ & $80 \mathrm{ppm}$ & 40.5 & 62 \\
\hline CNT-Au & $\begin{array}{l}\text { Carbon nanotubes } \\
\text { functionalized with } 1.0 \mathrm{~nm} \\
\text { of } \mathrm{Au}\end{array}$ & $\begin{array}{l}10 \mathrm{ppm} \\
100 \mathrm{ppm}\end{array}$ & $\begin{array}{l}25 \\
92\end{array}$ & 63 \\
\hline SWCNTs & $\begin{array}{l}\text { Single-walled carbon } \\
\text { nanotubes }\end{array}$ & 500 ppm & 27.3 & 76 \\
\hline Ag NC-MWCNTs & $\begin{array}{l}\text { Ag nanocrystal- } \\
\text { functionalized multiwalled } \\
\text { carbon nanotubes }\end{array}$ & $10,000 \mathrm{ppm}$ & 9 & 77 \\
\hline VA-MWCNTs & $\begin{array}{l}\text { Vertically aligned multi- } \\
\text { walled carbon nanotubes }\end{array}$ & $500 \mathrm{ppm}$ & 1.9 & 78 \\
\hline rGO & $\begin{array}{l}\text { Chemically reduced } \\
\text { graphene oxide }\end{array}$ & $1 \mathrm{ppb}$ & 2.4 & 70 \\
\hline P-GNS-400 & $\begin{array}{l}\text { Phosphorus doped } \\
\text { graphene nano-sheets } \\
\text { annealed at } 400^{\circ} \mathrm{C}\end{array}$ & $\begin{array}{c}1 \mathrm{ppm} \\
100 \mathrm{ppm}\end{array}$ & $\begin{array}{c}1.7 \\
5.4 \pm 0.2 \\
\end{array}$ & 71 \\
\hline RGO-PANI & $\begin{array}{l}\text { Reduced graphene oxide- } \\
\text { polyaniline hybrid }\end{array}$ & $50 \mathrm{ppm}$ & 59.2 & 73 \\
\hline Py-rGO & $\begin{array}{l}\text { Chemically reduced } \\
\text { graphene oxide with } \\
\text { pyrrole vapor }\end{array}$ & $\begin{array}{c}5 \mathrm{ppb} \\
100 \mathrm{ppm}\end{array}$ & $\begin{array}{l}4.2 \\
22\end{array}$ & 74 \\
\hline $\mathrm{TiO}_{2} @ \mathrm{PPy}-\mathrm{GN}$ & $\begin{array}{l}\text { Polypyrrole (PPy) and } \\
\text { graphene nanoplatelets } \\
\text { (GNs) decorated with } \\
\text { titanium dioxide }\left(\mathrm{TiO}_{2}\right) \\
\text { nanoparticles }\end{array}$ & $50 \mathrm{ppm}$ & 102.2 & 75 \\
\hline Graphene-PtNPs & $\begin{array}{l}\text { Graphene films decorated } \\
\text { with platinum NPs }\end{array}$ & $58 \mathrm{ppm}$ & 12 & 79 \\
\hline $\mathrm{SnO}_{2} / \mathrm{GN}$ & $\begin{array}{l}\text { Tin oxide/graphene } \\
\text { nanocomposite }\end{array}$ & $50 \mathrm{ppm}$ & 15.9 & 80 \\
\hline
\end{tabular}




\section{Chapter 2. Objectives and research approach}

The application of various carbon-based nanostructured materials such as exfoliated graphene sheets, reduced graphene oxide and carbon nanotubes as gas sensors has been extensively addressed in the literature and are addressed in Chapter 1 . The most important advantages of such materials for gas sensing are: their relatively low cost, semiconducting electrical properties, potential for modifications and ability to operate at room temperature. Furthermore, they exhibit a sufficient sensitivity towards specific gas species. This feature can be further enhanced through the application of simple chemical treatments. The main disadvantage of nanocarbon-based sensors however is the lack of selectivity. To improve the latter feature (selectivity) functionalization processes with metals, metal oxides and conducting polymers are usually required. The complexity of such surface functionalization processes, however, increases the production costs. This directed our attention to the application of nanoporous (microporous) carbons for the first time as toxic gas sensors.

Nanoporous carbons may have a limited conductivity compared to the above-mentioned carbonbased nanomaterials, however, they exhibit a great number of desirable features that make them very good candidates in gas sensing devices. These include an extensive surface area, highly developed internal porous structure, rich surface chemistry, and high degree of surface reactivity. Such features affect the physical and chemical adsorption of the gas molecules and they are expected to have a great influence also on the electrical response of nanoporous carbons upon their exposure to target gases. Moreover, the rich surface chemistry of nanoporous carbons and the potential to modify it, opens a possibility to achieve a better selectivity towards certain gas species than the above-mentioned nanoforms of carbon materials. Doing this further costly functionalization/doping processes can be eliminated. 
The objective of our study is to examine the ammonia sensing capability of nanoporous carbons, either synthetic, developed in our laboratory, or commercial, and identify the key parameters that enhance/improve their sensitivity and selectivity as gas sensors. The two latter sensing features (sensitivity and selectivity) must be comparable or improved compared to those reported in the literature for other graphene-based ammonia sensors. Furthermore, unlike in the case of the above mentioned modified graphene-based gas sensors, where costly functionalization processes are applied aiming to improve their operation, in this study, the carbonaceous ammonia sensors are prepared using the most simple and economical possible approach.

Considering that chemical gas sensors monitor reactions that involve chemisorption, physisorption and surface defects, and that the operation of a reliable gas sensor relies on reversible changes, ${ }^{81}$ in our study, three features/parameters need to be considered, aiming to meet these requirements and fabricate efficient ammonia gas sensors. The first one is the pore structure of the carbon-based sensors. This is related to the physisorption of the $\mathrm{NH}_{3}$ gas molecules, and implies the usage of a micro/ultaramicroporous material/adsorbent. The second one is the surface chemical features of the carbon samples, and more precisely their specific surface chemistry (specific configuration of the heteroatoms). This is related to the ability of the gas molecules to interact with the surface functional groups through both weak interactions, which govern the reversible sensing, and stronger interactions (reactive chemical adsorption), which govern the irreversible sensing. The last important feature is the conduction type of the carbonaceous gas sensors, which is also linked to the specific surface chemistry, and thus surface defects, which control the predominant type of charge carriers (electrons or holes). 
To accomplish our objective the following research approach has been adapted:

a) Preparation or further modification of nanoporous carbons that are either synthetic, developed in our laboratory, or commercial ones. The aim was to introduce specific heteroatoms to their matrices. Such heteroatoms include oxygen, nitrogen, and sulfur. The main goal of such modifications is to examine how the specific configurations of various heteroatoms interact with the target gas and thus affect the electrical sensitivity and selectivity of the carbons as gas (ammonia) sensors.

b) Further activation/modifications of the obtained carbons by applying either chemical or a thermal treatments, aiming to i) modify their pore structure, ii) enhance the surface reactivity towards ammonia, and iii) determine the role of chemisorption and physisorption on ammonia sensing.

c) Extensive characterization of the surface chemical and structural features of the prepared carbons (adsorbents) before and after exposure to the target gas, using various techniques.

d) Testing the ammonia sensing capability of the carbons at various gas concentrations, at room temperature, in dry conditions.

e) Testing the selective sensing capability of the carbons using both hydrogen sulfide and ammonia as probes.

f) Testing the influence of moisture on the ammonia sensing capability of the carbons.

g) Identification of factors (surface chemical and structural) that affect the electrical performance of the carbons and govern the mechanism through which they act as gas sensors.

h) Proposing of a sensing mechanism. 
The results of the above mentioned research approach are presented and analyzed throughout this Thesis. A brief description of the content of each Chapter is provided below:

Chapter 3 describes the preparation of the materials tested as gas sensors, and the various techniques used for their characterization and the testing of their sensing performance. Based on the origin/precursors of the carbon samples, they are classified in three categories; wood-based activated carbons, polymer-derived activated carbons, and wood-based/polymer derived-carbon composites, each of which is analyzed in Chapters 4, 5 and 6, respectively.

Chapter 4 describes the gas sensing performance of wood-based nanoporous carbons either commercial as received or further modified in our lab. The chapter focuses on the role of oxygen and nitrogen heteroatoms on the ammonia sensing capability of the samples. The content of oxygen/nitrogen, their specific chemical configuration, the surface acidity, and pore accessibility are among other factors that are extensively examined. The type, concentration and distribution of the $\mathrm{N}$ and $\mathrm{O}$ defects in the carbon matrix are also studied in the context of the electronic and transport properties of nanoporous carbons.

Chapter 5 describes the ammonia sensing capability of a series of polymer-derived nanoporous carbons, doped with $\mathrm{S}$ and $\mathrm{N}$ heteroatoms, either separately or as co-dopants. The Chapter examines the role of surface heterogeneity on sensing, and whether porosity or surface chemistry plays a more important role on the electrical performance of nanoporous carbons.

Chapter 6 describes the ammonia sensing capability of wood-based/polymer-derived nanoporous carbon composites. It focuses on the role of the synergy between the components of the composites on their electrical response as gas sensors, and examines whether the nature of the weak interactions between the various surface functional groups and ammonia or the electronic nature 
of the carbon matrix itself plays a more important role on their electrical performance. It also proposes a priority order of the various surface functional groups on ammonia sensing.

Chapter 7 examines the role of humidity on the $\mathrm{NH}_{3}$ sensing capability of nanoporous carbons. The samples used for this test are polymer-derived carbons and wood-based/polymer-derived carbon composites. The Chapter proposes a complex mechanism that governs the ammonia sensing capability of nanoporous carbons at various humidity levels.

Chapter 8 summarizes the mechanisms that govern the overall sensing capability of nanoporous carbons. The conclusions of this research are also presented there.

Chapter 9 suggests an outlook for future research to advance the sensing field. 


\section{Chapter 3. Materials and methods}

\subsection{Activated carbons}

Activated carbons, either synthetic, developed in our laboratory, or commercial were prepared or further modified, aiming to introduce specific heteroatoms to their matrix, including oxygen, nitrogen and sulfur. Based on the origin of the carbons, three series of carbon samples were prepared and further tested as ammonia gas sensors.

Briefly, the first sample series was prepared by nitric acid oxidation of a commercial wood-based activated carbon. The so-obtained carbon along with the initial one were impregnated with melamine, and then heated at $450^{\circ} \mathrm{C}$ under inert atmosphere. The second carbon series were prepared by the carbonization of several $\mathrm{S}$ and $\mathrm{N}$-containing polymer precursors. Aiming to modify their structural and surface chemical features, the so-obtained carbons were further airoxidized. Finally, the last carbon series, consists of nanoporous carbon-composites which were prepared by mixing a wood-based activated carbon with two polymer precursors. A detailed description of the materials' preparations is provided below.

\subsubsection{Wood-based activated carbons}

A commercial activated carbon of wood origin BAX-1500 (Mead-Westvaco) was used. The carbon was oxidized with $20 \%$ and $50 \%$ nitric acid for 5 hours and then washed in a Soxhlet apparatus until constant $\mathrm{pH}$ of the leachate, to remove the excess of the oxidizing agent and watersoluble compounds. The samples obtained by this procedure are referred to as BAX-O1 and BAX$\mathrm{O} 2$, respectively. ${ }^{82,83}$

Aiming to further modify the surface chemistry of the samples, $30 \mathrm{~g}$ of the initial and oxidized carbons were further mixed with a melamine suspension ( $20 \mathrm{~g}$ of melamine in $100 \mathrm{~mL}$ of ethanol) 
which was followed by a $5 \mathrm{~h}$ stirring at a room temperature. This led to the series of samples referred to as BAX-M and BAX-O-M, respectively. To evaporate ethanol, the mixture was then boiled and finally dried in the oven at $120^{\circ} \mathrm{C}$. The samples were then heated under $\mathrm{N}_{2}$, in a horizontal furnace at $450^{\circ} \mathrm{C}$ for $30 \mathrm{~min}$, with a heating rate of $50^{\circ} \mathrm{C} / \mathrm{min}$. The letter " $\mathrm{M}$ " which is added to the names of the modified carbons refers to melamine. The obtained carbons were then further oxidized with nitric acid (20\% and $50 \%$ of $\left.\mathrm{HNO}_{3}\right)$ to receive BAX-M-O and BAX-O-M[O] series. In total, the samples received are the following: BAX-M, BAX-M-O1, BAX-M-O2, BAXO1-M, BAX-O2-M, BAX-O1-M[O1] and BAX-O2-M[O1] ${ }^{83}$ A schematic illustration of the treatments applied is given below: ${ }^{83}$
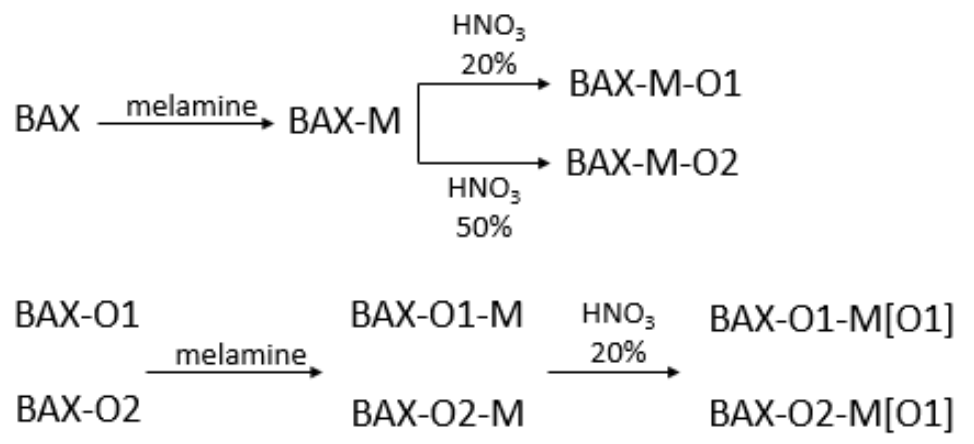

\subsubsection{Polymer-derived activated carbons}

Three sets of polymer-derived carbons were prepared. The polymer precursors for the two carbon series are poly (sodium 4-styrene sulfonate), poly (4-ammonium styrene-sulfonic acid) and poly (4-styrenesulfonic acid-co-maleic acid) (Figure 1). The third series consists of carbons derived from N-containing polymeric resins, synthesized in our lab.To obtain the first polymer-derived carbon series, poly (sodium 4-styrene sulfonate) was carbonized in a horizontal furnace, at $800{ }^{\circ} \mathrm{C}$ for $40 \mathrm{~min}$, with a heating rate of $50{ }^{\circ} \mathrm{C} / \mathrm{min}$. The flow rate of $\mathrm{N}_{2}$ was $300 \mathrm{~mL} / \mathrm{min}$. The obtained sample was then washed in a Soxhlet extractor with deionized water to remove the excess of water soluble species. Finally it was dried in the oven at $120^{\circ} \mathrm{C}$ for $24 \mathrm{~h}$. The obtained carbon is referred 
to as $\mathrm{C}-1 .{ }^{84} \mathrm{C}-1$ carbon was then air-oxidized by heating at $350^{\circ} \mathrm{C}$ in air for 3 hours inside a horizontal furnace (heating rate of $50{ }^{\circ} \mathrm{C} / \mathrm{min}$ ). The resulting material is referred to as $\mathrm{C}-2 .{ }^{84}$

The second polymer-derived carbon series were obtained by the carbonization of poly (4ammonium styrene-sulfonic acid) and a 1:1 mixture of $30 \%$ solution of poly (4-ammonium styrene-sulfonic acid) and Poly(4-styrenesulfonic acid-co-maleic acid) sodium salt, at $800{ }^{\circ} \mathrm{C}$ for $40 \mathrm{~min}$. The flow of $\mathrm{N}_{2}$ was $300 \mathrm{~mL} / \mathrm{min}$ and a heating rate $-50{ }^{\circ} \mathrm{C} / \mathrm{min}$. The carbons are referred to as $\mathrm{C}-\mathrm{A}$ and $\mathrm{C}-\mathrm{B}$, respectively. These two carbons were then oxidized in air at $350{ }^{\circ} \mathrm{C}$ for $3 \mathrm{~h}$. The resulting materials are referred to as $\mathrm{C}-\mathrm{AO}$ and $\mathrm{C}-\mathrm{BO}$ following the names of the parent carbons. ${ }^{85}$
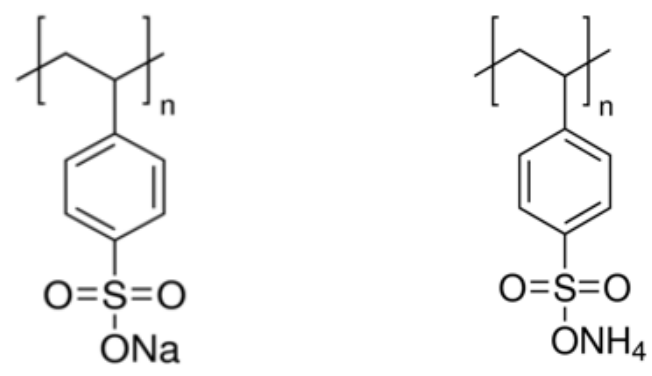

Poly (sodium 4-styrene sulfonate)
Poly (4-ammonium styrene-sulfonic acid)

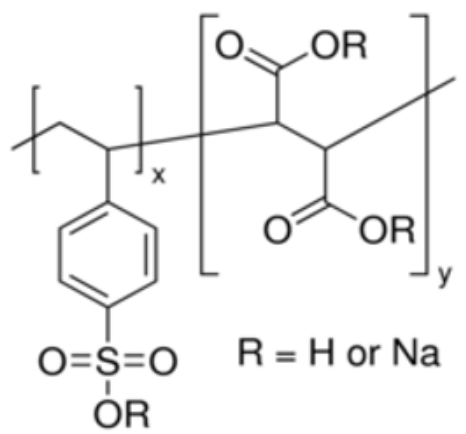

Poly(4-styrenesulfonic acid-co-maleic acid)

Figure 3.1. Polymer precursors used for the preparation of activated carbons.

The third series consists of carbons derived from $\mathrm{N}$-containing polymeric resins. Nanoporous polymeric resins were synthesized by the polymerization of three different combinations of melamine/urea and phenol/resorcinol/formaldehyde precursors, where $\mathrm{H}_{2} \mathrm{SO}_{4}$ was used as a chemical activation agent. ${ }^{86}$ The three precursor combinations were the following: i) phenol (1.5g), formaldehyde $(5 \mathrm{~mL})$, melamine $(1 \mathrm{~g})$, ii) resorcinol $(1.5 \mathrm{~g})$, formaldehyde $(5 \mathrm{~mL})$, melamine, and iii) phenol $(1.5 \mathrm{~g})$, formaldehyde $(5 \mathrm{~mL})$, urea $(1 \mathrm{~g})$. They were first mixed using magnetic stirring, 
and then the activation agent was rapidly added $\left(10 \mathrm{~mL}\right.$ of $\left.\mathrm{H}_{2} \mathrm{SO}_{4}\right)$. The obtained polymeric resins were washed with water and ethanol, and then were dried in the oven at $60^{\circ} \mathrm{C}$ for 24 hours. The products were then heated in a horizontal furnace under nitrogen, at $800^{\circ} \mathrm{C}$ for 40 minutes, to obtain activated carbons. The flow of $\mathrm{N}_{2}$ was $300 \mathrm{~mL} / \mathrm{min}$ and a heating rate $-50{ }^{\circ} \mathrm{C} / \mathrm{min}$. As a next step the carbons were washed in a Soxhlet apparatus until the stabilization of the solution $\mathrm{pH}$. The soobtained carbons are referred to as PFM, RFM and PFU according to the initial letter of the precursors used. To further modify the structural and surface chemical features of the carbons, they were oxidized in air at $350{ }^{\circ} \mathrm{C}$ for 3 hours. The suffix-AO is added to the names of the airoxidized carbon samples. Thus, the obtained carbons after air-oxidation at $350^{\circ} \mathrm{C}$ are referred to as PFM-AO, RFM-AO and PFU-AO. ${ }^{86}$

\subsubsection{Wood-based/polymer derived-carbon composites}

For the carbon-composite preparation, two polymers; poly (sodium 4-styrene sulfonate) (SigmaAldrich, MW 70,000) and poly (4-ammonium styrene-sulfonic acid) ammonium salt solution, and a wood-based commercial activated carbon (BAX-1500) (MeadWestvaco) were used. For the composites consisting of a polymer-derived carbon content of 1, 5, 10 and $20 \%$ in the final material, BAX was initially mixed with the predetermined amounts of the two polymers, dissolved in water. The amounts of the polymers were determined based on their yield after carbonization and air-oxidation. The mixtures were then dried in the oven at $120^{\circ} \mathrm{C}$ for 24 hours. The dry products were carbonized in a horizontal furnace for $40 \mathrm{~min}$, at $800{ }^{\circ} \mathrm{C}\left(\mathrm{N}_{2}\right.$ flow rate of $300 \mathrm{~mL} / \mathrm{min}$, heating rate of $50{ }^{\circ} \mathrm{C} / \mathrm{min}$ ). To modify the structure and chemistry of the obtained carbons they were further air-oxidized at $350{ }^{\circ} \mathrm{C}$ for 3 hours. The resulting materials are referred to as BAX-CS-X\% or BAXCSN-X\% where X-represents $1,5,10$ and $25 \%$ of the polymer-derived carbon phase. CS refers to the sulfur containing carbon that was obtained from poly (sodium 4-styrene sulfonate), and CSN 
refers to the sulfur and nitrogen dual-doped carbon obtained from poly (4-ammonium styrenesulfonic acid). The same treatment (heating at $800^{\circ} \mathrm{C}$ followed by air oxidation at $350^{\circ} \mathrm{C}$ ) was also applied to the as-received BAX sample. The treated carbon is referred to as BAX-AO. A brief schematic illustration of the treatments applied is provided below:

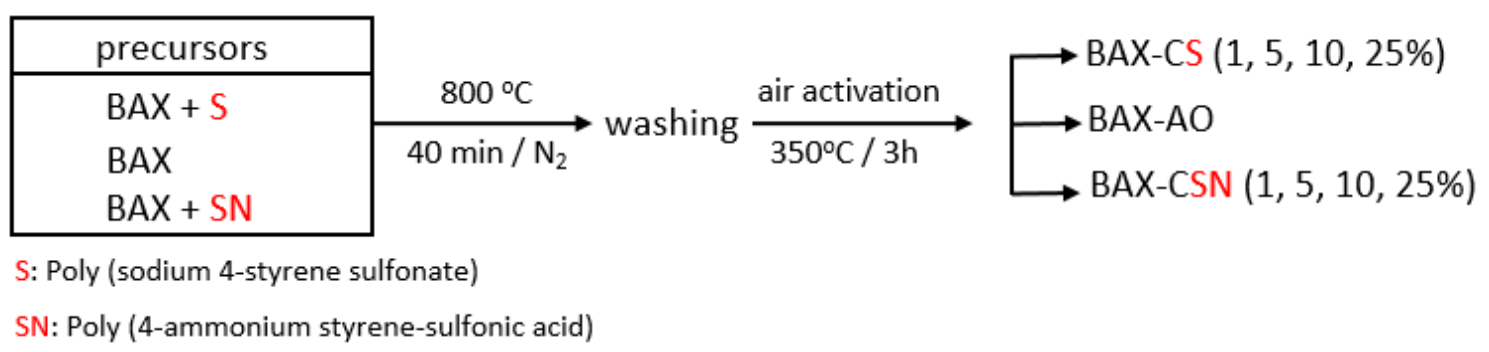

Figure 3.2. Schematic illustration of the treatments applied to the activated carbon samples.

\subsection{Characterization of the materials}

\subsubsection{Ammonia Breakthrough test.}

The ammonia breakthough capability of the carbon samples was evaluated using a laboratory designed dynamic test, at room temperature. In this test, an ammonia stream diluted in air passed through a fixed bed of the carbon sample (bed volume $2 \mathrm{~cm}^{3}$ ), which was packed into a glass column (length $370 \mathrm{~mm}$, internal diameter $9 \mathrm{~mm}$ ). The carbon samples with a particle size of about 0.425-0.6 mm were packed into the column. The concentration of ammonia in the inlet stream was $1000 \mathrm{ppm}$, having a total flow rate of $225 \mathrm{~mL} \mathrm{~min}^{-1}$. The concentration of the same gas in the outlet stream was measured using an electrochemical sensor (Multi-Gas Monitor ITX system). The test was arbitrarily stopped at the breakthrough concentration of $100 \mathrm{ppm}$, which is the limit of the sensor reading. Subsequent desorption tests followed, during which, an adsorbent bed was purged solely with air. After these steps the suffix -ED was added to the name of the resulting exhausted samples after exposure to ammonia in dry conditions. To evaluate the role of moisture, the ammonia stream was diluted with a moist air stream (70\% humidity). The same test was also 
performed after applying a $2 \mathrm{~h}$ prehumification of the carbons. The suffixes -ED,-EM and -EPM were added to the name of the resulting exhausted samples, respectively.

\subsubsection{Characterization of structural and morphological features}

Nitrogen sorption. Nitrogen sorption measurements were carried out for the evaluation of the surface area and porosity of the carbon samples. ASAP 2020 Surface Area and Porosity Analyzer (Micromeritics) was used. Prior to the analysis, the samples were outgassed at $120^{\circ} \mathrm{C}$ to constant vacuum $\left(10^{-4} \mathrm{kPa}\right)$. At these conditions physically adsorbed species were removed without altering the surface chemistry. From the $\mathrm{N}_{2}$ adsorption isotherms, the surface areas (BET method), total pore volumes, $V_{\mathrm{t}}$ (from the last point of isotherm at a relative pressure equal to 0.99), and the volumes of micropores $\left(V_{\text {mic }}\right)$ and mesopores $\left(V_{\text {mes }}\right)$ were determined. The pore size distributions were calculated using the Density Functional Theory (NLDFT) (free download at WWW.nldft.com). ${ }^{87,88}$

Scanning electron microscopy (SEM). SEM images were obtained with a Zeiss Supra 55 VP. The accelerating voltage was $5.00 \mathrm{kV}$. Scanning was performed in situ on sample powders previously dried. In some cases, in order to avoid charging, a sputter coating of the samples with a thin layer of gold was performed.

Transmission Electron Microscopy (TEM). High resolution transmission electron microscopy (HRTEM) was performed on a JEOL 2100F instrument (accelerating voltage of $200 \mathrm{kV}$ ). The analyses were conducted on the powdered samples previously dispersed in isopropanol and then deposited on copper grids. 


\subsubsection{Characterization of surface chemical features}

X-ray Diffraction Spectroscopy. XPS studies were performed either on a Physical Electronic PHI 5700 spectrometer or on a Physical Electronics PHI 5000 VersaProbe II spectrometer using non-monochromatic $\mathrm{Mg}-\mathrm{K}_{\square}$ radiation $(300 \mathrm{~W}, 15 \mathrm{kV}$ and $1253.6 \mathrm{eV})$ or $\mathrm{Al} \mathrm{Ka} \mathrm{X}$-ray radiation source $(50 \mathrm{~W}, 15 \mathrm{kV}, 1486.6 \mathrm{eV})$, respectively, to analyze the core-level signals of the elements of interest with a hemispherical multichannel detector. The sample spectra were recorded with a constant pass energy value at $29.35 \mathrm{eV}$, using a $720 \mu \mathrm{m}$ or $200 \mu \mathrm{m}$ diameter circular analysis area. The X-ray photoelectron spectra obtained were analyzed using PHI ACESS ESCA-V6.0F software and processed using MultiPak 8.2B package. The binding energy values were referenced to adventitious carbon C $1 s$ signal $(284.8 \mathrm{eV})$. Shirley-type background and Gauss-Lorentz curves were used to determine the binding energies.

Potentiometric titration. Potentiometric titration measurements were performed using a Titrando 888 automatic titrator (Metrohm). $50 \mathrm{mg}$ of the carbon samples were placed in a container, where $25 \mathrm{~mL}$ of $\mathrm{NaNO}_{3}(0.01 \mathrm{M})$ were added. The dispersion equilibrated overnight, under continuous stirring, at room temperature. To eliminate the influence of $\mathrm{CO}_{2}$, the suspension was purged with $\mathrm{N}_{2}$, throughout the entire experiment. The titration was performed in the $\mathrm{pH}$ range 3-10. Volumetric standard $\mathrm{NaOH}(0.1 \mathrm{M})$ was used as a titrant. Prior to the titration with $\mathrm{NaOH}(0.1$ $\mathrm{M})$, the $\mathrm{pH}$ of the suspension was adjusted to $\sim 3.20$, adding $\mathrm{HCl}(0.1 \mathrm{M})$.

To evaluate the surface properties, it was assumed that the population sites can be described by a continuous $\mathrm{pK}_{\mathrm{a}}$ distribution, $\mathrm{f}\left(\mathrm{pK}_{\mathrm{a}}\right)$. The experimental data was transformed into a proton binding isotherm, $\mathrm{Q}$, representing the total amount of protonated sites. From them, the $\mathrm{pK}_{\mathrm{a}}$ distributions

and the numbers of groups represented by certain $\mathrm{pK}_{\mathrm{a}}$ values were calculated, ${ }^{89,90}$ using the following integral equation: 


$$
\mathrm{Q}(\mathrm{pH})=\int_{-\infty}^{\infty} \mathrm{q}\left(\mathrm{pH}, \mathrm{pK}_{a}\right) f\left(\mathrm{pK}_{a}\right) \mathrm{dpK}_{a}
$$

\subsection{Electrochemical measurements}

\subsubsection{Sensing test}

Experimental set-up. A typical sensing set-up consists of a gas mixing unit, a gas chamber, a substrate/substrate holder (chips), and an electrical monitor (measurement electronics). A general illustration of the experimental set-up is provided in Figure 3.3.

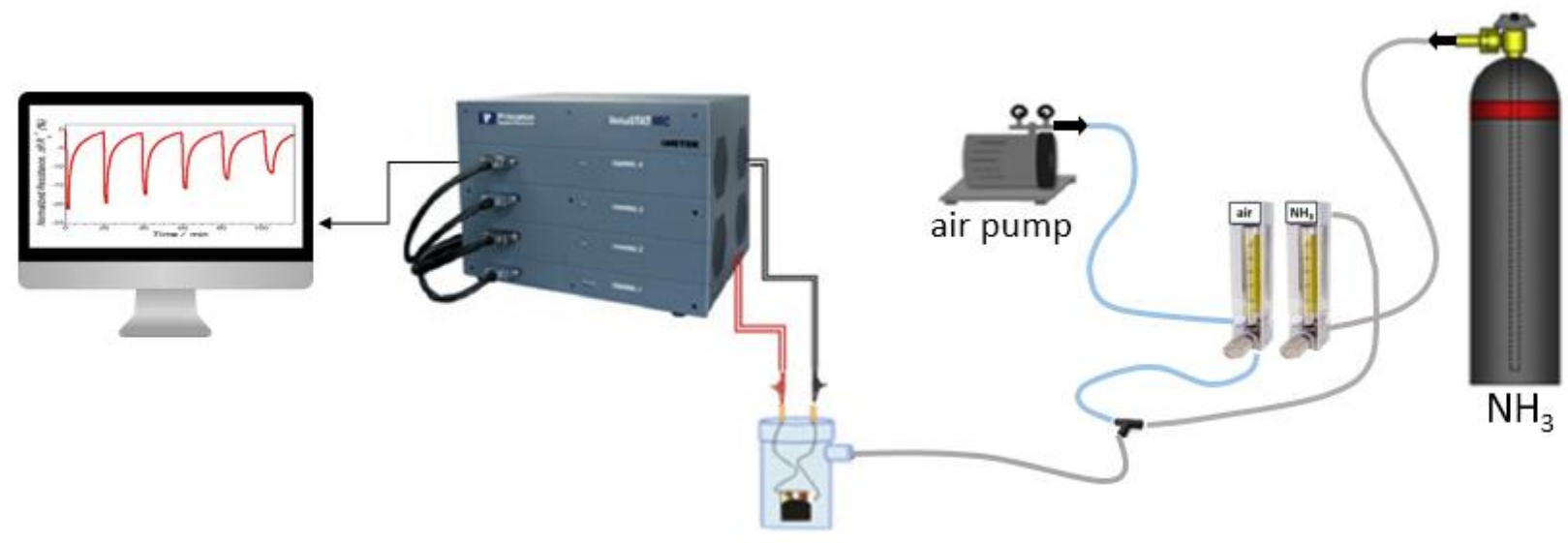

Figure 3.3. Illustration of the experimental set-up.

Coating of the chips. Prior the sensing test, the active materials are first finely grounded and made into a slurry using N-methyl-2-pyrrolidinone as the solvent because of its good solvency properties. The slurry is then spread/coated on the surface of the sensing substrates/chips using a blade. These substrates/chips are made of an alumina substrate equipped with $8 \mathrm{~mm} \times 8 \mathrm{~mm}$ thinfilm gold interdigitated finger electrodes, with $50 \mu \mathrm{m}$ lines/spaces, and without insulation layer (Electronic Design Center, Case Western Reserve University, Cleveland, OH). After coating the chips with the active material, they are placed in the oven, and dried at $120{ }^{\circ} \mathrm{C}$ for $24 \mathrm{~h}$. The thickness of the obtained film varied from $10-15 \mu \mathrm{m}$. 


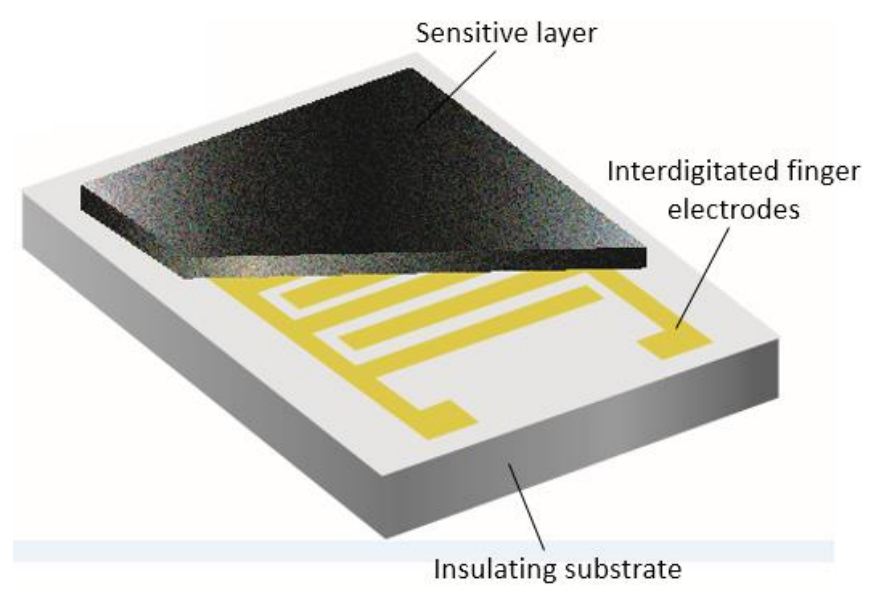

Figure 3.4. Illustration of a sensing chip.

Gas chamber. For the sensing test, the dried coated chips were placed into a gas chamber. The gas chamber is one of the most important parts of the sensing system, since it needs to a) provide a uniform distribution of the target gas, and b) allow a fast ammonia/air exchange for the accurate evaluation of the time-dependent sensor parameters (sensor response and recovery). The geometry of the gas chamber pays a crucial role in controlling the correct operation of the sensor since it can affect both the accuracy and the repeatability of the electrical measurements. In our laboratory we use a home-made gas chamber $\left(20 \mathrm{~cm}^{3}\right)$, of a circular shape. An opposite placement of the inlet tube and coated chips was planned to ensure the uniform gas distribution on the surface of the active material and to minimize the time-dependent sensor parameters. Two nickel wires were used to keep the terminal pins/electrodes of the chips connected to the upper part of the chamber. 


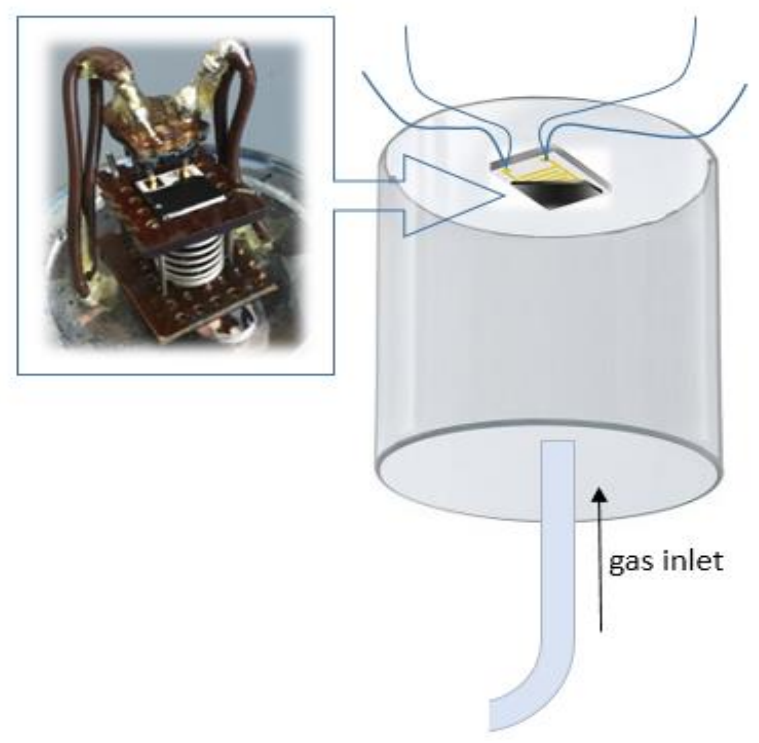

Figure 3.5. Illustration of the gas chamber.

Electrical monitor. The chamber is connected through four wires to a VersaSTAT MC electrical monitor (AMETEK, Princeton Applied Research). For the sensing test a potential in the range of 0.5-1 Volt is applied. Since the initial resistivity of the carbons used varied from $\Omega-\mathrm{M} \Omega$, to be able to make accurate comparisons of the sensor response between different materials and different sensing devices, the changes in resistance were normalized to the initial resistance of each carbon chip:

$$
\left(\Delta \mathrm{R} / \mathrm{R}_{\mathrm{o}}\right)=\left(\mathrm{R}_{\mathrm{t}}-\mathrm{R}_{\mathrm{o}}\right) / \mathrm{R}_{\mathrm{o}}
$$

where $R_{0}$ is the resistance of the sensor before exposure to $\mathrm{NH}_{3}$, and $\mathrm{R}_{t}$ is the resistance at any time, $t$.

Figure 3.6 presents a typical sensor response curve upon the exposure of an active material to the target gas and its subsequent air purging. The definition of the sensor response time is also clarified/illustrated in Figure 3.6. It is the duration between the moment that the sensor is exposed to the target gas and the point when the electrical signal reaches the $90 \%$ of its maximum magnitude. 


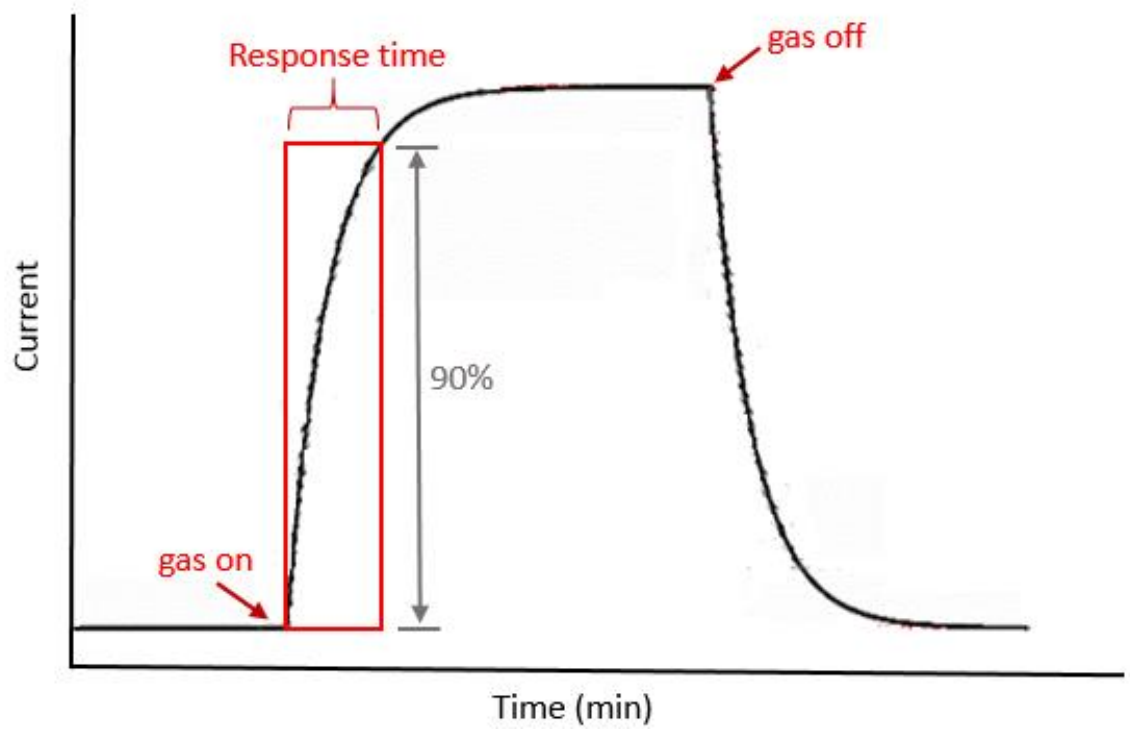

Figure 3.6. Typical sensor response curve.

Sensing test. The sensing tests were carried out at room temperature $\left(22^{\circ} \mathrm{C}\right)$ by exposing the coated chips to ammonia mixed with air (dry or humid), at concentrations $10-500 \mathrm{ppm}$, with a constant gas flow rate of $500 \mathrm{~mL} / \mathrm{min}$. By maintaining a constant gas flow the distortion of the electrical measurements upon changing time constants for the target gas/air exchange can be avoided and the stabilization of the sensor baseline can be also achieved easier. The desired gas concentrations was produced by mixing ammonia with air. To establish such dry conditions air passed through a column packed with Drierite. To establish controlled humid conditions air was introduced into the main chamber after passing through a water container. To establish different humidity levels (50$67 \% \mathrm{RH}$ ), prior the sensing test, the system was prehumidified (air was passing through water) for $30 \mathrm{~min}-2 \mathrm{~h}$. The RH level inside the chamber was measured using a traceable hygrometer recorder (VWR, Traceable Calibration Control Company). 


\subsubsection{Impedance measurements}

Impedance spectroscopy was carried out in $0.5 \mathrm{M} \mathrm{Na}_{2} \mathrm{SO}_{4}$, in a three-electrode cell, using $\mathrm{Ag}$ / $\mathrm{AgCl}(3 \mathrm{M} \mathrm{KCl})$ as the reference electrode, the active material as the working electrode, and a platinum rod as a counter electrode. The working electrode was prepared by coating a Ti foil collector of active area of $1 \mathrm{~cm}^{2}$, with the well-grounded slurry of the activated carbon and polyvinylidene fuoride (PVDF) (ratio 90 : 10) in N-methyl-2-pyrrolidinone (NMP). The electrodes were dried at $120{ }^{\circ} \mathrm{C}$ for 24 hours. Potentiostatic electrochemical impedance spectroscopy (EIS) measurements were performed using VersaSTAT MC (AMETEK, Princeton Applied Research) in the frequency range of $0.05 \mathrm{~Hz}$ to $100 \mathrm{kHz}$ with a $10 \mathrm{mV} \mathrm{AC}$ amplitude, at various potentials vs. the reference electrode, ranging from $0.2 \mathrm{~V}$ to $1.0 \mathrm{~V} .^{82}$ 


\section{Chapter 4. Commercial wood-based activated carbons}

This chapter describes the gas sensing performance of wood-based nanoporous carbons to various ammonia concentrations. As already mentioned in Chapter 3, the first sample series were prepared by the oxidation of commercial wood-based activated carbon (BAX) with nitric acid. Further modifications of the oxidized carbons were also applied aiming to alter their surface chemical and structural features.This chapter focuses on the role of the specific surface chemistry, and more precisely the role of oxygen and nitrogen as heteroatoms, and the role of their structural features in the sensing performance. It links the porosity and surface chemistry of the carbons' tested to the nature of their interactions with ammonia/ mechanism and thus to the electrical response of the sensors. The content of nitrogen, its configuration, chemical environment/ acidity, and pore accessibility are among the factors that are extensively examined. The type, concentration and distribution of nitrogen defects in the carbon matrix are also studied in the context of the electron transport properties of nanoporous carbons.

Chapter 4 is a slightly revised version of the following article, with permission from ACS publications, Copyright 2016, reported in Reference 83:

Travlou, N. A.; Ushay, C.; Seredych, M.; Rodríguez-Castellón, E.; Bandosz, T. J. Nitrogen-Doped Activated Carbon-Based Ammonia Sensors: Effect of Specific Surface Functional Groups on Carbon Electronic Properties. ACS Sensors 2016, 1, 591-599. 


\subsection{Initial sensor stabilization- First estimation of predominant interactions in the sensing mechanism}

The sensing chips was initially exposed to $500 \mathrm{ppm}$ of ammonia till the electrical signal reached a plateau (Figure 4.1) ${ }^{82,83,91}$ This initial stabilization step was carried out assuming in order to exhaust of all chemically reactive sites, surface functional groups, which could undergo reactions with ammonia. After signal stabilization, ammonia was turned off and the chamber was purged with air. This caused the removal of the physically adsorbed gas molecules. Judging from the percentage change (increase or decrease) of the electrical signal during this stabilization step, we were able to estimate whether physisorption or chemisorption was a predominant interaction type. Based on the results presented in Figure 4.1A, a greater change in the normalized resistance for BAX-O (20\%) compared to that for BAX (12\%), upon air purging, indicates that interactions generating an irreversible signal must be stronger in the case of the initial carbon, while physisorption as an interaction type should be more pronounced for the oxidized counterpart. This hypothesis was be further verified by the analyses of the surface chemistry and porosity. Their results are addressed below in this chapter. It is worth mentioning that a slow sensor recovery during the air purging stage is related to the complexity of the reactive and physical adsorption processes occurring simultaneously during the initial exposure of the chips to ammonia.

Another interesting trend seen in Figure 4.1A is the opposite direction of the electrical signals measured on both chips. More precisely, while in the case of BAX the normalized resistance increases upon ammonia exposure, in the case of BAX-O it decreases. This suggests that oxidation with nitric acid altered the electrical properties of the BAX carbon matrix. This aspect is addressed in details below in this chapter. 
It is worth to mention that oxidation with nitric acid led to an increase in the overall resistivity of the materials. More precisely, the resistivity of the coated chips was found to be $68 \mathrm{k} \Omega, 1.04 \mathrm{M} \Omega$, $7 \mathrm{k} \Omega, 16 \mathrm{k} \Omega$, and $29 \mathrm{k} \Omega$, for BAX, BAX-O, BAX-M, BAX-M-O1, and BAX-M-O2, respectively. ${ }^{82,83}$ Even though these values are high, the materials have provide measurable signal changes. 

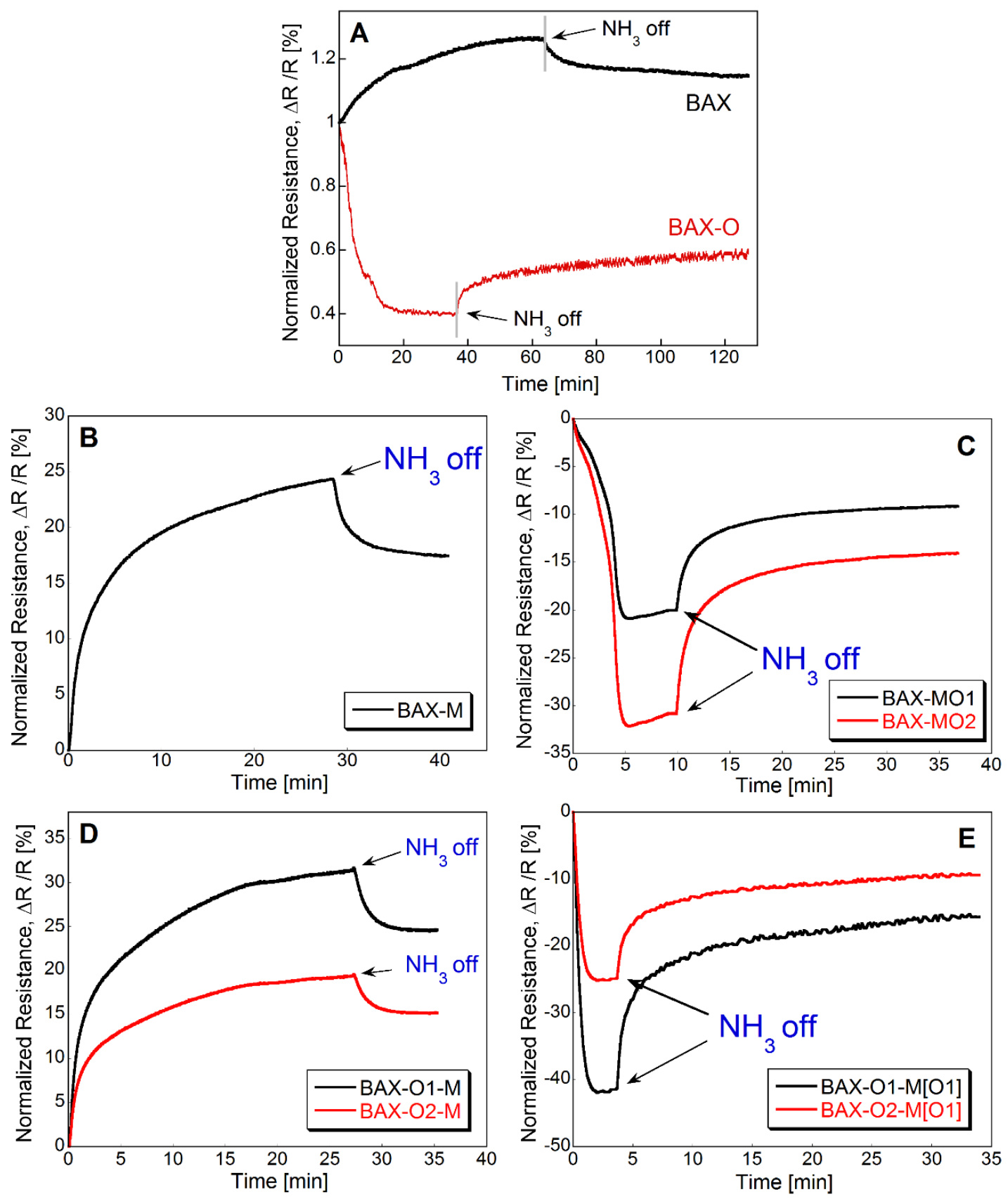

Figure 4.1. Changes in the normalized resistance for the activated carbon samples upon their initial exposure to NH3 and subsequent air purging (after the signal stabilization) (A) for BAX and BAXO, (B) for BAX-M, (C) for BAXMO1 and BAX-MO2, (D) for BAX-O1-M and BAX-O2-M, and (E) for BAX-O1-M[O1] and BAX-O2-M[O2]. Copyright 2017, with permission from American Chemical Society. ${ }^{83}$ 


\subsection{Testing the reversible sensing capability of the sensors}

The initial stabilization of the carbons was followed by their exposure to various concentrations of ammonia ranging from $45-500 \mathrm{ppm}$. This was done aiming to test their reversible sensing capability, which is an important feature of a gas sensor. At this sensing stage, only the weak interactions of the target gas molecules with the carbons' surface were supposed to generate reversible signal changes, and they are responsible for a fast sensor recovery upon air purging, between the consecutive cycles. ${ }^{83}$

Table 4.1 and Figures 4.2 and 4.3 present the changes in the normalized resistance for our samples tested upon exposure to ammonia concentrations varying from $10-500 \mathrm{ppm} \cdot{ }^{82,91}$ The response of our sensors to ammonia concentrations as low as 10 and $20 \mathrm{ppm}$ are illustrated in Figures 4.2A and $4.2 \mathrm{~B}$ for $\mathrm{BAX}$ and $\mathrm{BAX}-\mathrm{O}$, respectively. ${ }^{82}$ Figures $4.3 \mathrm{~A}$ and $4.3 \mathrm{C}$ illustrate the response of the coated chips to ammonia concentrations varying from 100-500 ppm, for BAX and BAX-AO, respectively. ${ }^{82,91}$ We also tried to evaluate the sensors, based on their response time, which, as mentioned in Chapter 1, is the required time for a sensor to reach the $90 \%$ of the maximum value of the normalized resistance change, upon its exposure to the target gas. This we have shorten the exposure time of the chips to ammonia, aiming to find the minimum period that a signal equilibrium could be reached. This is illustrated in Figure 4.3, which shows that while for BAXO a sensing cycle could be completed within 4 minutes (Figure 4.3B), for BAX, on the other hand, it took 45 minutes for the completion of a cycle (Figure 4.2A). ${ }^{82,91}$ This clearly indicates that the kinetics of ammonia adsorption/desorption are much faster on BAX-O than those on BAX.

Overall, Figures 4.2 and 4.3 indicate that the exposure of both samples to continuous adsorption/desorption $\mathrm{NH}_{3}$ cycles, indicates the good consistency (repeatability) and reversibility of the response. A good reversibility of the response indicates that upon purging the system with 
dry air, ammonia is apparentlyremoved. Thus, those sites that participated in the reversible adsorption during the $\mathrm{NH}_{3}$ exposure become available again to interact with the target gas. This causes a change in the electrical property of the carbons. Even at this reversible sensing stage $\mathrm{i}$ both samples exhibit opposite signal trends.

Figure 4.3E shows that for both carbon chips, the normalized resistance increases linearly with the increasing t ammonia concentration, which is a desirable feature of a gas sensor. ${ }^{82,91}$ This linearity also indicates that sensing mechanism does not change with increasing the gas concentrations. For gas concentration below $100 \mathrm{ppm}$, a larger deviation from linearity is linked to the larger error on these concentrations, due to dilution, than for those over $100 \mathrm{ppm}^{82}$
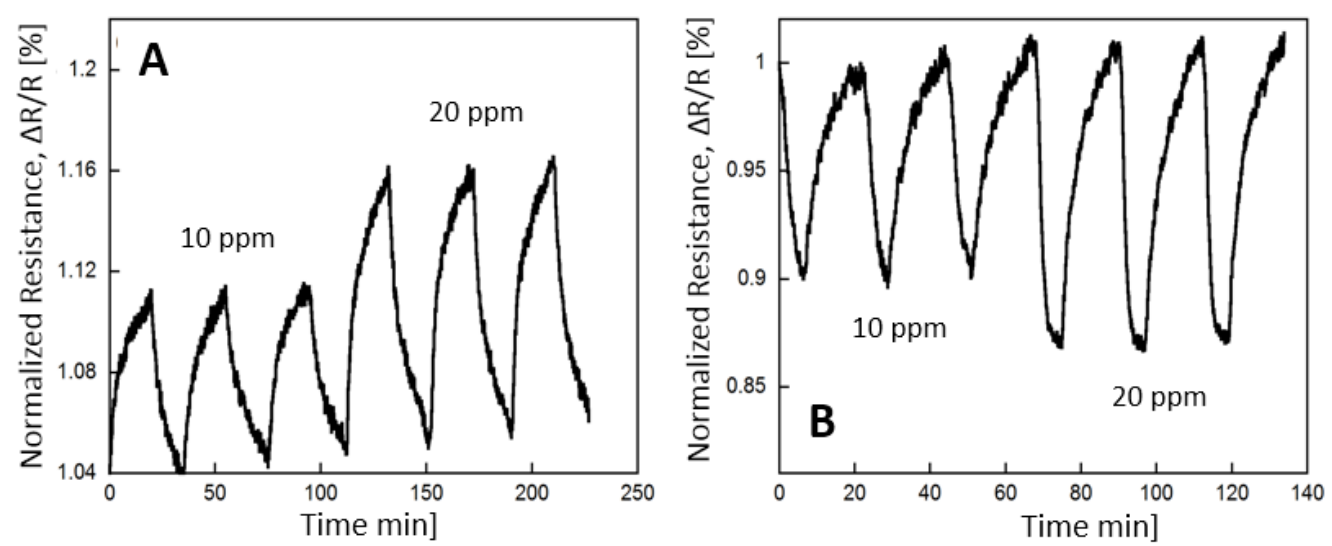

Figure 4.2. Response curve for BAX (A) and BAX-O (B) at 10 and 20 ppm of ammonia gas. ${ }^{82}$ 
Table 4.1. Change in the normalized resistance $\Delta \mathrm{R} / \mathrm{R}_{\mathrm{o}}[\%]$ of BAX and BAX-O after exposure to various ammonia concentrations. ${ }^{82}$

\begin{tabular}{ccc}
\hline \multirow{2}{*}{$\begin{array}{c}\mathrm{NH}_{3} \text { concentration } \\
(\mathrm{ppm})\end{array}$} & \multicolumn{2}{c}{$\Delta \mathrm{R} / \mathrm{R}_{\mathrm{o}}[\%]$} \\
\cline { 2 - 3 } & $\mathrm{BAX}$ & $\mathrm{BAX}-\mathrm{O}$ \\
\hline 10 & 8.5 & 11.0 \\
20 & 11.0 & 13.8 \\
100 & 15.7 & 14.2 \\
175 & 19.9 & 16.8 \\
250 & 22.2 & 19.7 \\
375 & 27.2 & 22.5 \\
500 & 29.2 & 24.9 \\
\hline
\end{tabular}



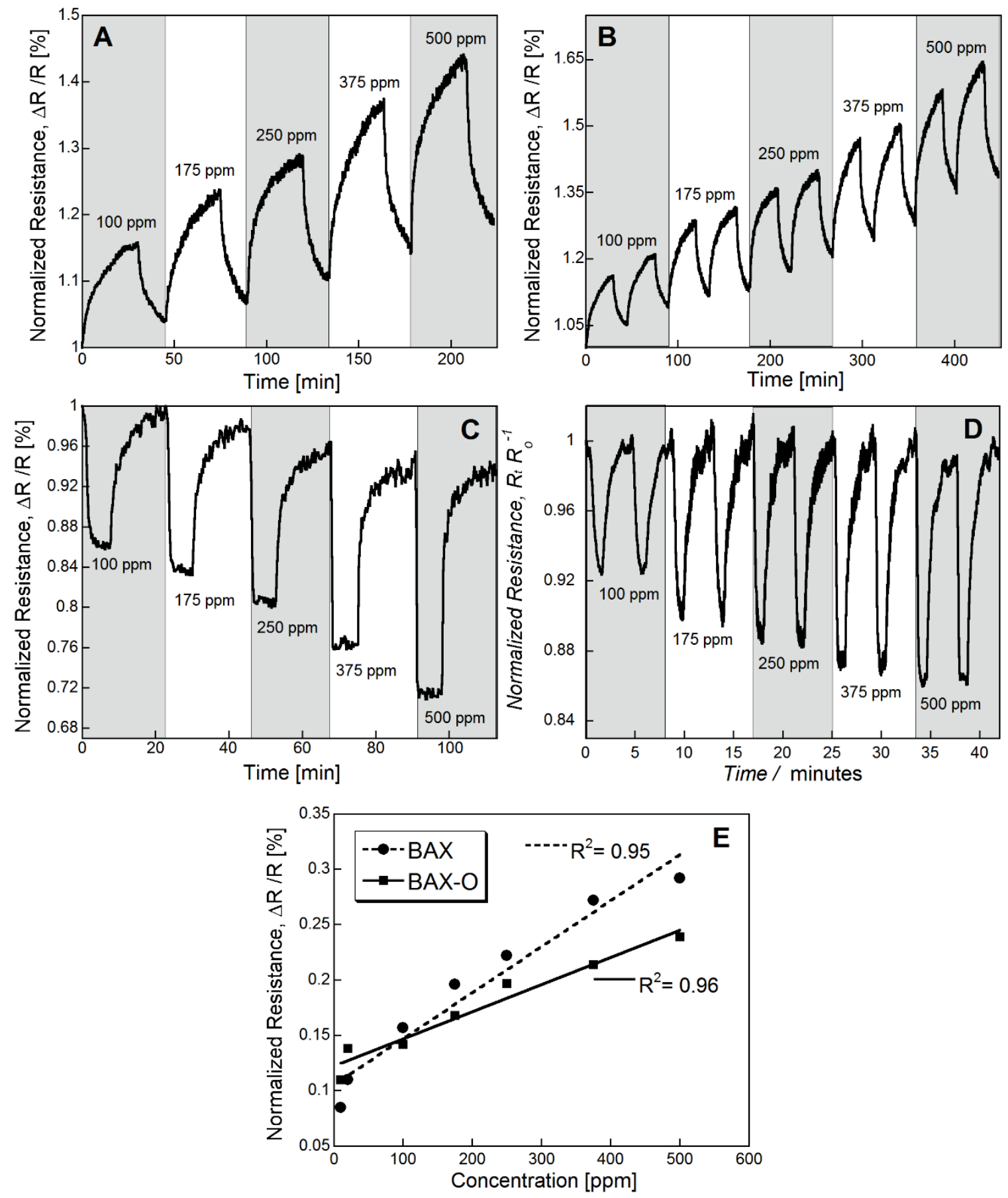

Figure 4.3. Response curves for $\mathrm{BAX}(\mathrm{A}, \mathrm{B})$ and $\mathrm{BAX}-\mathrm{O}(\mathrm{C}, \mathrm{D})$, and linear response $(\mathrm{E})$, of the tested carbon samples upon exposure to various ammonia concentrations. ${ }^{82}$ 
The reversible sensing capability of the carbons impregnated with melamine, at ammonia concentrations ranging from 45 to $500 \mathrm{ppm}$, is illustrated in Figure $4.4{ }^{83}$ The samples tested as ammonia sensors are the following: BAX-M, BAX-M-O1, BAX-M-O2, BAX-O1-M, BAX-O2$\mathrm{M}, \mathrm{BAX}-\mathrm{O} 1-\mathrm{M}[\mathrm{O} 1]$ and $\mathrm{BAX}-\mathrm{O} 2-\mathrm{M}[\mathrm{O} 1]$. A schematic illustration of the treatments applied to obtain these samples is provided in section 3.1.1 of Chapter 3 .

Among all carbon pairs, whose difference is in the concentration of the oxidizing agent $\left(\mathrm{HNO}_{3}\right)$ $20 \%$ and $50 \%$ of $\mathrm{HNO}_{3}$ (BAX-MO1/BAX-MO2, BAX-O1-M/BAX-O2-M, and BAX-O1$\mathrm{M}[\mathrm{O} 1] / \mathrm{BAX}-\mathrm{O} 2-\mathrm{M}[\mathrm{O} 1])$ which were described earlier in Chapter 3, the changes in the normalized resistance of the counterpart with the optimal electrical response (highest sensitivity) are presented in this Figure. As seen, all carbon-chips show an excellent repeatability and reversibility of the electrical response, and there is a linear relationship between the latter parameter and the concentrations of the target gas. The relative $\sigma(\% \mathrm{RSD})$ was also calculated, and found to be between $3.3 \%$ and $10.5 \%{ }^{83}$ Finally, the effective response time for BAX-M series, BAX-M-O series, BAX-O-M series, and BAX-O-M[O] series, was found to be $6,2,8$, and 2 min, respectively. ${ }^{83}$

Figure 4.5 compares the electrical responses of all wood-based nanoporous carbons tested as ammonia gas sensors ${ }^{83}$ From the data collected, two conclusions can be drawn a) the melamine treated samples show an increase in their electrical response while the samples where oxidation with $\mathrm{NHO}_{3}$ was the last treatment step showed a decrease in the signal response, and (b) the carbons for which oxidation with $\mathrm{HNO}_{3}$ was the last treatment step (BAX-M-O1, BAX-M-O2, BAX-O1-M[O1], BAX-O2-M[O2]) the signal changes are larger than for their initial counterparts (BAXM, BAX-O1-M, BAX-O2-M). This suggests that melamine treatment at $450{ }^{\circ} \mathrm{C}$ followed by 
the subsequent oxidation with $\mathrm{HNO}_{3}$ affected the electronic properties of the carbons and altered the type and distribution of $\mathrm{N}$-type defects in the carbon matrix.

A

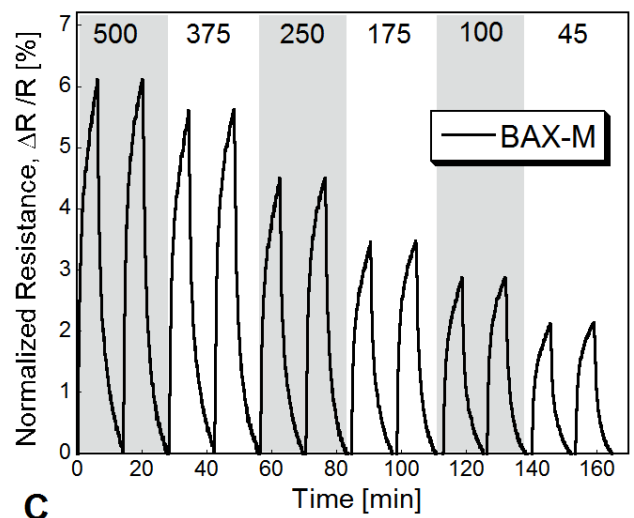$$
\text { C }
$$
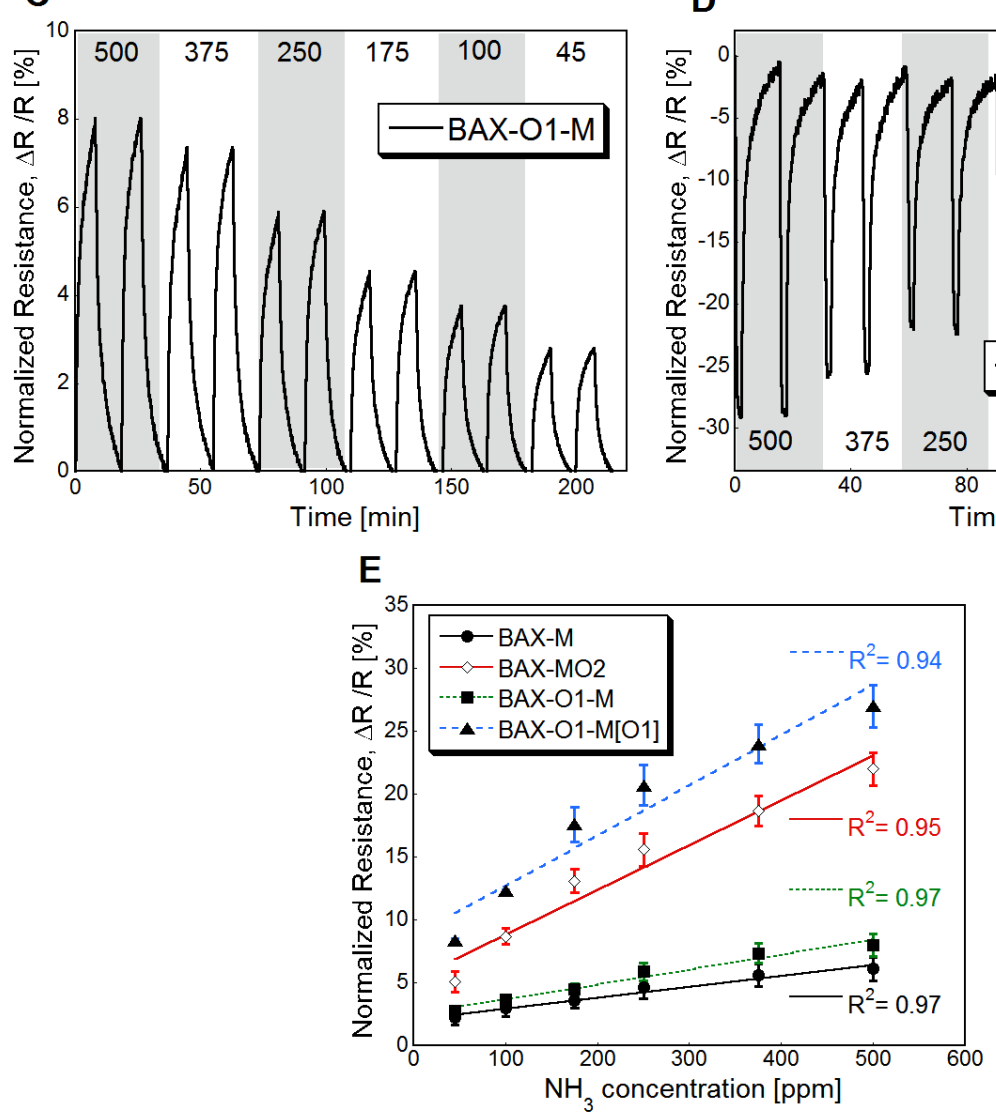
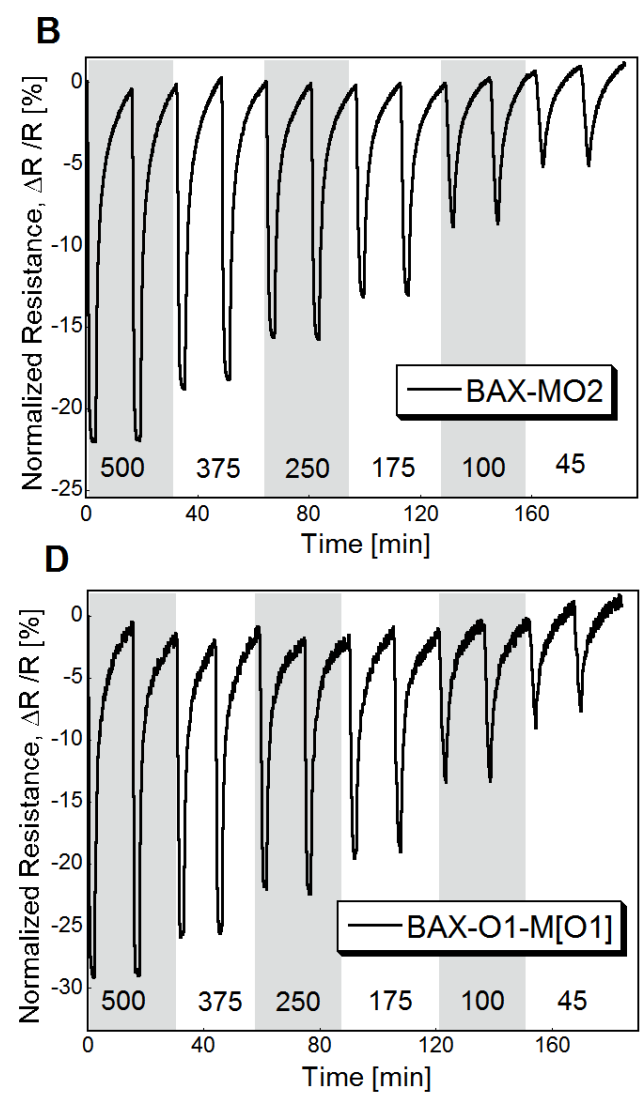


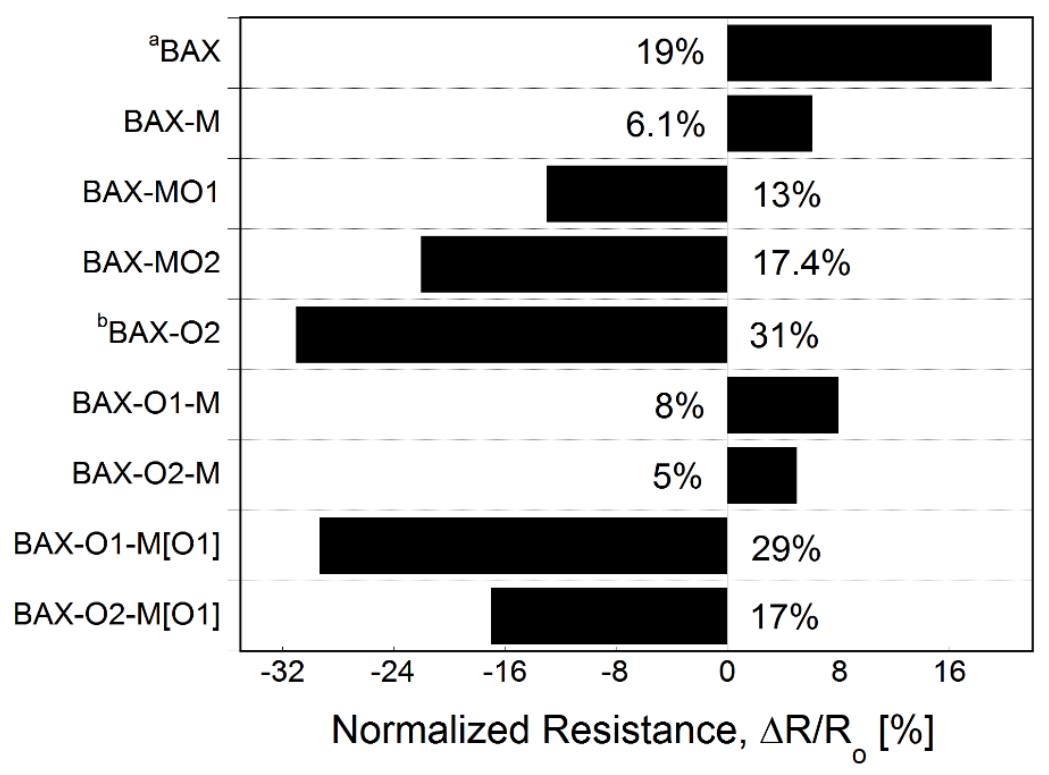

Figure 4.5.Comparison of the normalized resistance changes of BAX, BAX-O and all melamine treated carbon samples tested upon exposure to 500 ppm of $\mathrm{NH}_{3}$. Copyright 2017, with permission from American Chemical Society. ${ }^{83}$

\subsection{Evaluation of the conduction type of the materials}

Since our carbons are sensors that record resistivity changes, the type of the charge carriers is crucial and need to be examined. To determine the conduction type of our materials, we decided to treat them as semiconductors and apply the Mott-Schottky approach based on the impedance measurements. ${ }^{92,93}$ The conduction type of a material can be identified based on the slopes of the $1 \mathrm{C}^{-2}$ vs $\mathrm{E}$ plots (I $1 \mathrm{C}^{-2-}$ nverse square of space charge layer capacitance, $\mathrm{E}=$ semiconductor electrode potential (Mott-Schottky plots). ${ }^{94}$ More precisely, linear trends with positive slopes indicate the existence of $n$-type conductivity, while linear trends with negative slopes - $p$-type conductivity. In the case of the former conduction type ( $n$-type) electrons $\left(e^{-}\right)$are the main charge carriers, while in the case of the latter one ( $p$-type) positively charged holes $\left(h^{+}\right)$are the major 
charge carriers. The Mott-Schottky plots for our materials tested, are presented in Figures 4.6 and $7 .^{82,83}$

From the Mott-Schottky plots of BAX and BAX-O, the x-intercept was used to determine the flat band potential and from the slope of the curve the carrier density was calculated. ${ }^{82,92,93}$ The capacitance values of the space-charge regions were defined from the crossing point of the lines. In the Mott-Schottky equation the following dependence is presented:

$$
\frac{1}{C^{2}}=\frac{2}{N_{d} e \varepsilon_{0} \varepsilon}\left(E-E_{F B}-\frac{k T}{e}\right)
$$

where, $C$ represents the capacitance of the space-charge region, $E$ and $E_{F B}$ represent the applied potential and Fermi level respectively, $\varepsilon$ the dielectric constant of the activated carbon, $\varepsilon_{o}$ the vacuum permittivity, $e$ the elementary charge for electrons, $N_{d}$ the acceptor or donor density, $k$ the Bolzmann constant and $T$ the absolute temperature. Due to the small value of the temperature term, it can be neglected.

Using the above equation, the acceptor $\left(N_{A}\right)$ and donor $\left(N_{D}\right)$ density values for BAX were calculated $N_{A}=4.86 * 10^{21}$ and $N_{D}=3.38 * 10^{21}$. Since our samples are activated carbons, we used the dielectric constant that corresponds to them, which is $e=12 .{ }^{95}$ The higher value of $N_{A}$ for BAX indiates that the $p$-type conductivity is predominant for it. For BAX-O on the other hand, $N_{A}=$ $1.19^{*} 10^{21}$ and $N_{D}=2.16^{*} 10^{21}$ and thus, a higher value of $N_{D}$ indicates that BAX-O exhibits a predominantly $n$-type conductivity.

The Mott-Schottky plots for BAX and BAX-O are presented in Figure 4.6. The extents of the slopes for BAX show that it exhibits predominantly $p$-type conductivity, while BAX-O shows predominantly $n$-type conductivity. This suggests that oxidation of BAX with nitric acid clearly 
altered the electronic properties of the carbon matrix, leading to the conversion of its conduction type.
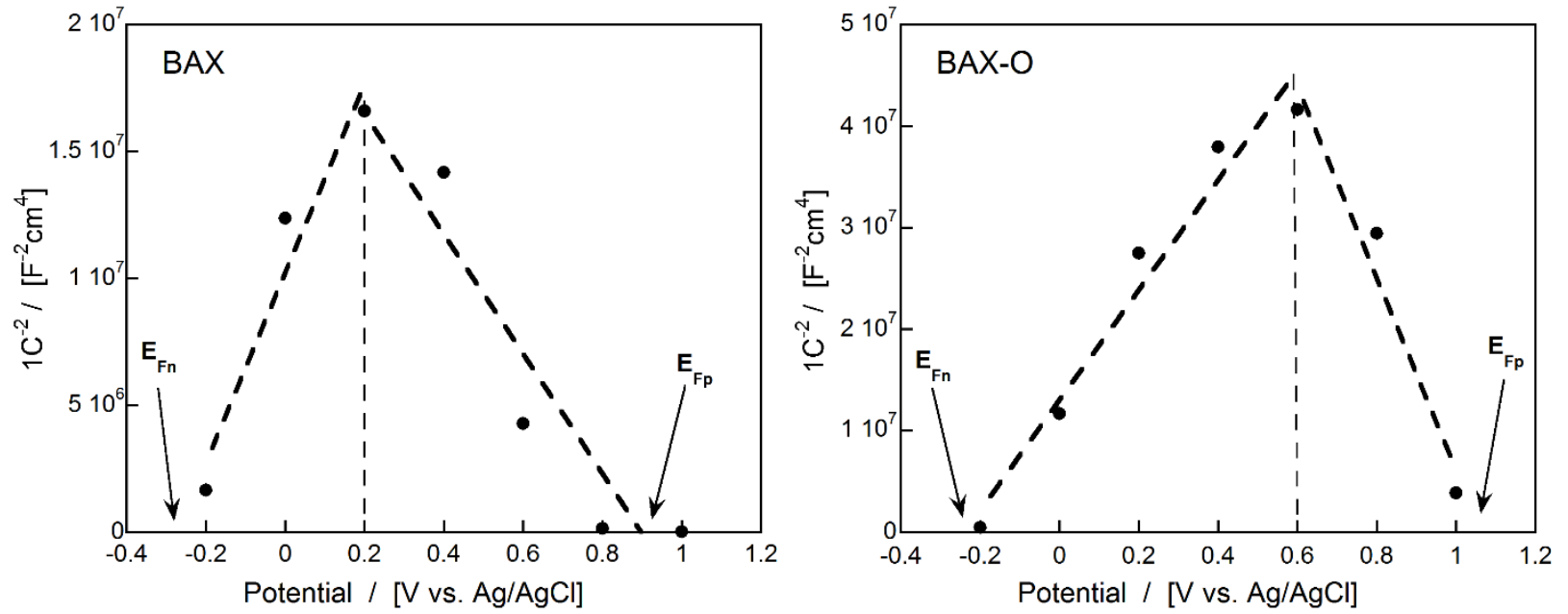

Figure 4.6. The Mott-Schottky plot for BAX (A) and BAX-O (B). $E_{F n}$ and $E_{F p}$ represent the Fermi levels of $n$ and $p$ type materials. ${ }^{82}$

In the case of the carbon series treated with melamine, since each pair of the oxidized carbons (oxidized with $20 \%$ and $50 \%$ of $\mathrm{HNO}_{3}$ ) shows similar electrical behaviors, we applied the MottSchottky approach only to the best performing samples. As seen in Figure 4.7, all four carbons exhibit a predominantly $p$-conduction type indicating that positively charged holes are the main charge carriers. Interestingly, even though $\mathrm{HNO}_{3}$ was used as the oxidizing agent, it didn't have the same effect on the electrical properties of the BAX and BAX-M carbons. In fact it did not cause any conversion in the conduction type, which was observed for BAX and BAX-O. ${ }^{83}$ 

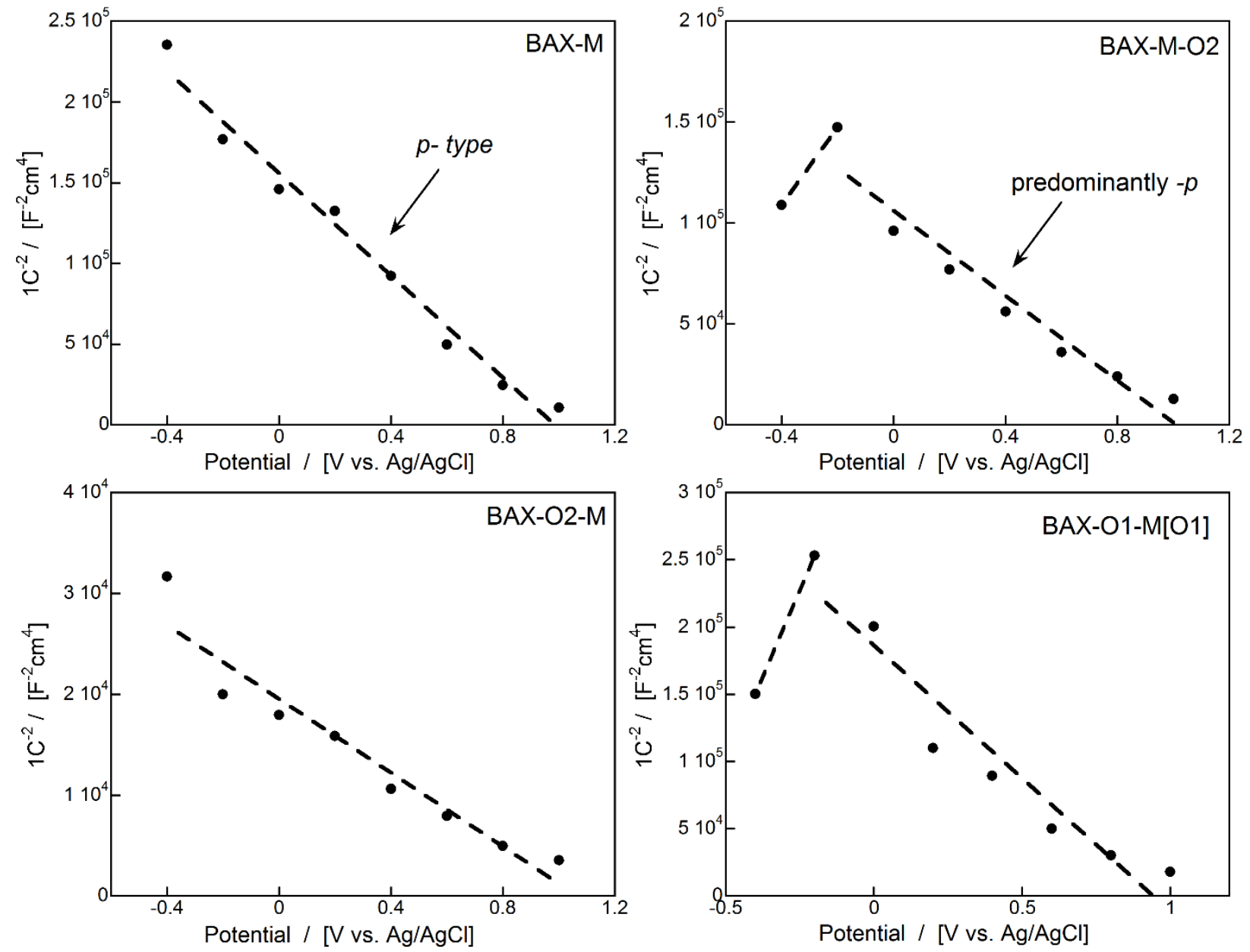

Figure 4.7. The Mott-Schottky plot for BAX-M, BAX-M-O2, BAX-O2-M, and BAX-O1-M[O1]. Copyright 2017, with permission from American Chemical Society. ${ }^{83}$

\subsection{Ammonia adsorption}

Since the electronic and transport properties of carbonaceous materials strongly depend on the specific surface chemistry, the type and distribution of heteroatoms in the carbon matrix, and their structural features, the initial and exhausted samples after $\mathrm{NH}_{3}$ adsorption were extensively characterized. The surface chemical features of the exhausted samples exposed to ammonia, are of a great importance, since they are responsible for a reversible sensing. 
To collect a sufficient quantity of exhausted samples for the further characterization of their surface chemical and structural features, $\mathrm{NH}_{3}$ breakthrough tests were run. The suffix $-\mathrm{ED}$ was added to the name of the exhausted samples.

The ammonia breakthrough curves of all wood-based activated carbons along with the calculated breakthrough capacities are presented in Figure 4.8..$^{82,83}$ The comparison of the performance of the two carbons indicates that BAX exhibits a shorter breakthrough time than does BAX-O. The calculated breakthrough capacities are $11.5 \mathrm{mg} / \mathrm{g}$ and $30.7 \mathrm{mg} / \mathrm{g}$ for BAX and BAX-O, respectively. Thus the chemical oxidization resulted in an almost threefold increase the amount of ammonia retained on the surface of the carbons.

Figure 4.8B presents the adsorption and desorption curves for the melamine treated carbon series. ${ }^{3}$ A qualitative analysis of the adsorption strength can be made based on the shape of the adsorption/desorption curves. ${ }^{96}$ The slopes of the desorption curves are indicative of the adsorption strength. Considering that the area under the desorption curves is related to the amount of the gas that desorbs during the air purging step, the stronger the interactions between the target molecules and the surface of the adsorbent, the steeper the desorption curve. When ammonia is strongly retained on the surface of an adsorbent, it is not expected to desorb from the sample upon air purging. Thus a steep desorption curve reaching fast a zero ammonia concentration represents a strong adsorption process. Another indicator of the extent of the adsorption strength is the appearance of a "gaps" between the adsorption and desorption. Such "gaps" are linked to the limit of the sensor detection. Since our sensor limit is $100 \mathrm{ppm}$, an ammonia concentration during the air purging step higher than that $\left(\mathrm{NH}_{3}\right.$ released from the surface) cannot be recorded. This explains the missing part of the desorption curve which appears as the above mentioned "gap" in the measurements. The larger is the gap between the breakthrough and desorption curves, the weaker 
is the nature of the interactions of the target gas with the adsorbents' surface. In the case of our carbons, such gaps are observed for BAX-M-O2, BAX-O1-M[O1] and BAX-O2-M [O1], and they suggest the weak nature of the interactions between ammonia and the carbons' surface. ${ }^{9}$ For BAXM, BAX-O1-M and BAX-O2-M, on the other hand, steep adsorption/desorption curves and much smaller gaps for BAX-M, BAX-O1-M and BAX-O2-M indicate faster adsorption kinetics and a strong ammonia retention. ${ }^{97}$

It is worth to mention that even though the breakthrough capacities of all carbons are not very high compared to those of modified carbons reported in the literature, 97 chemical oxidation enhanced their performance. This trend agrees with those reported for the majority of carbons, where a large number of oxygen-containing acidic groups and a higher porosity, as features beneficial to the ammonia retention..$^{82,98}$
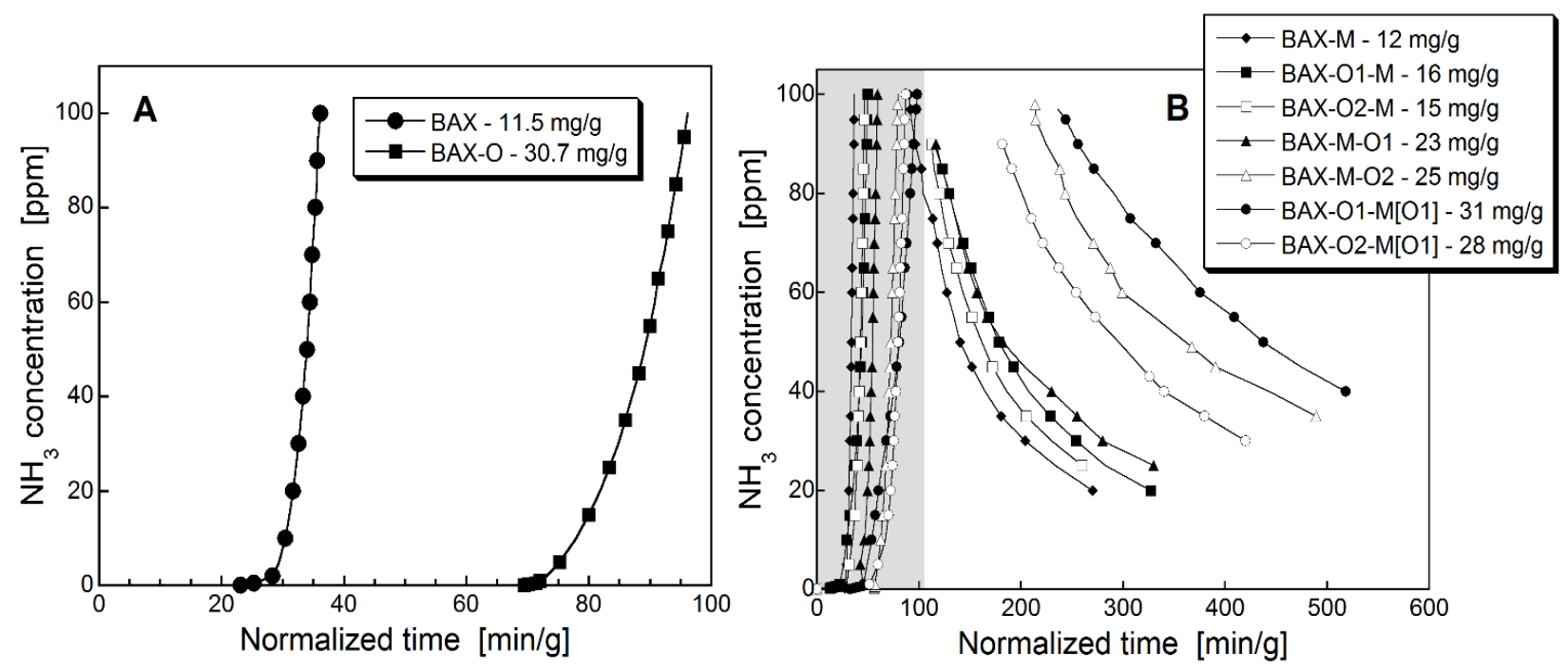

Figure 4.8. Ammonia breakthrough and desorption curves for $\mathrm{BAX}$ and $\mathrm{BAX}-\mathrm{O}(\mathrm{A})$, the series treated with melamine (B). (B):Copyright 2017, with permission from American Chemical Society. ${ }^{83}$ 


\subsection{Effect of oxygen and nitrogen incorporated to the carbon matrix on the electronic properties of the carbons}

To understand the role of the specific surface chemistry on the sensing capability of the carbons tested, the surface chemistry of the initial and exhausted after ammonia adsorption samples was extensively characterized. This characterization is an important tool to derive a sensing mechanism and to determine the role of specific heteroatoms, and more precisely of $-\mathrm{O}$ and $-\mathrm{N}$ on the sensing capability of nanoporous carbons.

The nature of the surface functional groups was examined by the XPS analysis. The content of

elements in atomic $\%$ for all carbons addressed in this chapter are presented in Table 4.2. ${ }^{82,83}$ As expected oxidation with $\mathrm{NHO}_{3}$ led to an increase in the total content of oxygen. This increase was even larger for those samples where chemical oxidation was their last treatment step (BAX-O, BAX-M-O1, BAX-M-O2, BAX-O1-M[O1], and BAX-O2-M[O1]). Interestingly, oxidation of BAX and BAX-O $\mathrm{HNO}_{3}$ besides an increase in the total content of oxygen, also to an increase in the total content of nitrogen (Table 4.2). 
Table 4.2. Content of elements on the surface of the melamine treated samples (in at. \% from XPS analysis). Copyright 2017, with permission from American Chemical Society. ${ }^{83}$

\begin{tabular}{llllll}
\hline Sample & $\mathrm{C}$ & $\mathrm{O}$ & $\mathrm{N}$ & $\mathrm{P}$ & $\mathrm{Na}$ \\
\hline BAX & 89.2 & 9.1 & 0.6 & 0.9 & 0.24 \\
BAX-O & 79.8 & 17.3 & 2.6 & 0.3 & $\mathrm{ND}$ \\
BAX-M & 86.8 & 4.6 & 8.2 & 0.3 & $\mathrm{ND}$ \\
BAX-M-O1 & 84.8 & 8.3 & 6.9 & $\mathrm{ND}$ & $\mathrm{ND}$ \\
BAX-M-O2 & 80.1 & 10.4 & 9.5 & $\mathrm{ND}$ & $\mathrm{ND}$ \\
BAX-O1-M & 87.5 & 6.4 & 5.6 & 0.5 & $\mathrm{ND}$ \\
BAX-O2-M & 83.7 & 5.6 & 10.6 & $\mathrm{ND}$ & $\mathrm{ND}$ \\
BAX-O1-M[O1] & 83.6 & 11.2 & 5.3 & $\mathrm{ND}$ & $\mathrm{ND}$ \\
BAX-O2-M[O1] & 81.0 & 8.8 & 10.2 & $\mathrm{ND}$ & $\mathrm{ND}$ \\
\hline BAX-ED & 92.5 & 6.4 & 0.6 & 0.5 & $\mathrm{ND}$ \\
BAX-O-ED & 79.9 & 16.9 & 2.7 & 0.4 & $\mathrm{ND}$ \\
BAX-M-ED & 86.2 & 4.8 & 8.7 & 0.3 & $\mathrm{ND}$ \\
BAX-M-O1-ED & 83.9 & 8.7 & 7.4 & $\mathrm{ND}$ & $\mathrm{ND}$ \\
BAX-M-O2-ED & 80.7 & 11.0 & 8.2 & 0.14 & $\mathrm{ND}$ \\
BAX-O1-M-ED & 88.0 & 6.1 & 5.7 & 0.2 & $\mathrm{ND}$ \\
BAX-O2-M-ED & 83.5 & 5.0 & 11.5 & $\mathrm{ND}$ & $\mathrm{ND}$ \\
BAX-O1-M[O1]-ED & 85.6 & 11.0 & 3.4 & $\mathrm{ND}$ & $\mathrm{ND}$ \\
BAX-O2-M[O1]-ED & 80.9 & 8.6 & 10.5 & $\mathrm{ND}$ & $\mathrm{ND}$ \\
\hline
\end{tabular}

For BAX and BAX-O, the results of the deconvolution of C $1 s, \mathrm{O} 1 s$ and $\mathrm{N} 1 s$ core energy levels are given in Table 4.3. Figure 4.9 presents the deconvolution results for an $\mathrm{N} 1 s$ core energy level, while Figures A1 and A2 of Appendix present the deconvolution results for $\mathrm{C} 1 s$ and $\mathrm{O} 1 s$. For the BAX series treated with melamine, due to the number of samples, and for the clarity of the discussion, the deconvolution results are summarized in the form of a bar graph (Figure 4.10). ${ }^{83}$ For these samples (treated with melamine) detailed results of core energy level deconvolutions are provided in Tables A1-A4 of Appendix. Due to the variety of species existing at each of the six distinguished energies in the $\mathrm{N} 1 s$ core energy level spectra of the melamine treated samples, the species at 398.7, 400.2, 401.3, 402.6, and $405.9 \mathrm{eV}$ are referred to as N1, N2, N3, N4, and N5, 
respectively. In N1 we include pyridines, in N2- pyrroles/amines/amides, in N3-quaternary nitrogen and/or protonated amines, in $\mathrm{N} 5$-pyridine- $\mathrm{N}$-oxides, and in $\mathrm{N} 5-\mathrm{C}-\mathrm{N}^{+} \mathrm{O}-\mathrm{C}, \mathrm{NO}_{\mathrm{x}}$ species.

Based on the deconvolution of the N $1 s$ core energy level spectra (Figure 4.9) and the surface atomic composition (Table 4.2), BAX contains 0.6 at.\% nitrogen in the form of pyridines, amines, amides and pyrroles. BAX-O on the other hand contains 2.57 at. \% nitrogen, mainly in the form of nitro-type complexes with high binding energies between 405.3 and $405.9 \mathrm{eV}$. BAX-O also contains a small amount of nitrogen in the form of pyrroles and amides with binding energies between 400.1 and $400.6 \mathrm{eV}$, pyridines between 398.2 and $399 \mathrm{eV}$ and $\mathrm{N}-\mathrm{Q}$ in quaternary and/or protonated amines between 401.6 and $402.2 \mathrm{eV}$.

In the BAX carbon series treated with melamine (BAX-M, BAX-OM), nitrogen is incorporated to the carbon matrix mainly in the form of pyridines ( $\mathrm{N}-1)$ and amides/amines ( $\mathrm{N}-2)$. Pyridines, having localized electrons at the nitrogen atoms bring defects to the carbon matrix, resulting in an increase in the population of holes. ${ }^{83,99}$ This contributes to their dominant $p$-type conductivity. ${ }^{83,100-}$ 103 Nitrogen in BAX-M-O1 and BAX-M-O2 is in the form of nitro-type complexes (N-5) owing to $\mathrm{HNO}_{3}$ treatment Table 4.3 and Figure 4.10). For these two carbons, a decreased contribution of pyridines (N-1) is also observed, compared to BAX-M. This might be linked to their conversion to nitropyridines after oxidation with $\mathrm{HNO}_{3}{ }^{83}$ Similarly to pyridines, nitropyridines, are also responsible for inducing a $p$-type conductivity. ${ }^{83}$ This is consistent with the impedance results for those samples for which oxidation with nitric acid was the last treatment step (BAX-M-O2 and BAX-O1-M[O1] (Figure 4.7). Nitropiridines enhance the $p$-electrical conduction type due to the strong electron accepting nature of the nitro groups. ${ }^{83}$

Even though BAX-O was obtained using the same oxidizing agent $\left(\mathrm{HNO}_{3}\right)$, and nitro-type complexes were formed, their effect on the electrical properties was different than that for BAX. 
In fact it caused the conversion in the conduction type from predominantly $-p$ for $\mathrm{BAX}$ to predominantly $-n$ for BAX-O. In this case such a behavior is linked to the decrease of the $s p^{2}$ carbon contribution (Table 3) after oxidation, caused by the formation of electron acceptor defects $\left(-\mathrm{NO}_{2}\right){ }^{83}$

The results discussed above suggest that the electronic and transport properties of nanoporous carbons depend not only on the type of nitrogen defects but also their concentration and distribution in the carbon matrix. Figure 4.10 and Tables A1-A4 indicate a high contribution of amines and pyridines for the melamine impregnated samples that were further oxidized with $\mathrm{HNO}_{3}$ (BAX-MO1 and BAX-MO2). As aforementioned these groups are the contributors to $p$-type conduction. Interestingly, when pure BAX was oxidized with $\mathrm{HNO}_{3}$ the contribution of amines and pyridines, and thus of $p$-type conduction on BAX-O, was rather very low (Table 4.3). Indeed, BAX-O was found to exhibit predominantly $n$-type conductivity (Figure 4.6). A different effect of surface oxidation on the type of surface defects, which determine the electronic properties of the carbons, is likely linked to the different surface compositions of BAX and BAX-M. In the case of the melamine impregnated carbon, heat treatment at $450{ }^{\circ} \mathrm{C}$ led to the formation of pyridines and protonated amines. Their contribution was either negligible or much smaller on the BAX surface. Oxidation of BAX-M, transformed pyridines to nitropyridines which induce a $p$-type conduction. Apparently, heat treatment at $450^{\circ} \mathrm{C}$, played a crucial role in the formation of $p$-type contributors (pyridines). In general, it is well-known that the distribution and type of N-defects can be easily altered during the treatment of carbonaceous materials at elevated temperatures. ${ }^{104-106}$

Considering that during the initial stabilization chip step (Figure 4.1 ) the active surface sites chemically reacted with ammonia and got exhausted, the reversible sensing process (Figures 4.3 and 4.4) strongly depends on the new surface chemical features of the exhausted /stablized 
samples. Thus, the results of the characterization of the carbons after $\mathrm{NH}_{3}$ exposure, are of a great importance to comprehend the role of the specific surface chemistry on reversible sensing. Figure 4.9 shows that after ammonia adsorption the relative concentration of nitrogen in amides increased for BAX-ED. These groups can be formed by the reaction of $\mathrm{NH}_{3}$ with carbonyl (such as ketones) and epoxy groups. ${ }^{82}$ The deconvolution of O 1s core energy level spectra (Table 4.3 and Figure A2) shows that a decrease in the content of $\mathrm{C}=\mathrm{O}$ groups after ammonia adsorption/stabilization which indicates their involvement in a chemical reaction with $\mathrm{NH}_{3}$. The chemical reaction of ammonia with epoxy groups led to the opening of the epoxide ring and the formation of $-\mathrm{NH}_{2}$ and -OH groups. ${ }^{82}$ This is verified not only by the deconvolution of $\mathrm{O} 1 \mathrm{~s}$ which shows an increase in the relative concentration of oxygen in $\mathrm{C}-\mathrm{O}$ groups, but also by the deconvolution of $\mathrm{N} 1 s$, where an increase in the content of nitrogen in amine groups is found.

Interestingly, after ammonia adsorption, the contribution of pyridines on BAX-O decreased, compared to BAX, which suggests the partial conversion of pyridines to aminopyridines and/or the reaction of some surface anhydrides with ammonia. ${ }^{82}$ Such a reaction results in the protonation of pyridines (pyridinium), deprotonation of acetic acid and formation of amide groups. An increased contribution of amide groups on BAX-ED, further supports the latter reaction. Finally, the nitrogen in the form of $\mathrm{NH}_{4}{ }^{+}$is associated to the chemical reaction of ammonia through acidbase reactions with surface carboxylic groups. ${ }^{97}$ All of these discussed reactions are in agreement with our hypothesis about the higher contribution of chemisorption in the case of BAX compared to BAX-O, based on Figure 1A.

The deconvolutions of $\mathrm{N} 1 s$ core energy level spectra of the exhausted BAX-O, BAX-M-O2 and BAX-O2- M[O1] after $\mathrm{NH}_{3}$ adsorption, show an increase in the relative concentration of $\mathrm{NO}_{\mathrm{x}}$ species $\left(\mathrm{R}-\mathrm{NO}_{2}\right.$ and $\mathrm{Ph}-\mathrm{NO}_{2}$ groups) (Table 4.3 and Figure 4.10). This suggests that further 
oxidation took place on the carbons' surfaces while exposed to ammonia. ${ }^{83}$ In the case of the melamine treated samples, this increase is most visible for BAX-O2- M[O1] which also shows the highest contribution of superoxide ions $\left(\mathrm{O}_{2}^{-}\right)$, based on the $\mathrm{O} 1 s$ core energy level spectra. The superoxides can partially oxidize of $\mathrm{NH}_{3}$ to $\mathrm{NO}_{2} \cdot{ }^{85}$ Upon the reaction of ammonia with chemisorbed oxygen species $\left(\mathrm{O}_{2}^{-}\right)$, NO and $\mathrm{N}_{2} \mathrm{O}$ are formed. In the presence of $\mathrm{O}_{2}^{-}$, the relatively unreactive $\mathrm{NO}$ can be transformed to $\mathrm{NO}_{2}{ }^{97}$ which, as a strong oxidant, can further oxidize the carbon's surface. ${ }^{107}$ This can results in the removal of carbon atoms or previously deposited bulky surface functionalities.

Such a surface oxidation is supported by the decomposition O $1 s$ core energy level spectra, which shows a decrease in the contribution of oxygen in carboxyl/carbonyl groups for the exhausted BAX M-O2 and BAX-O2-M[O1] (Figure 4.10). While for BAX-M-O2-ED and BAX-O2-M[O1]-ED a decrease in the contribution of pyridines (N-1) is found, BAX-M-O1-ED and BAX-O2-M[O1]ED show a decrease in the contribution of pyrroles/amides/amines (N-2). The removal/decomposition of these groups might results in an increase in the pore volume upon $\mathrm{NH}_{3}$ exposure. For the exhausted BAX-M-O2 a decrease in the contribution of pyridinic groups is accompanied by an increase in the contribution of $-\mathrm{NH}_{2}$ groups. This suggests the oxidative amination of nitropyridines to form amino-nitropyridines, during the reactive adsorption of ammonia, in the presence of $\mathrm{O}_{2}{ }^{-3}$ 

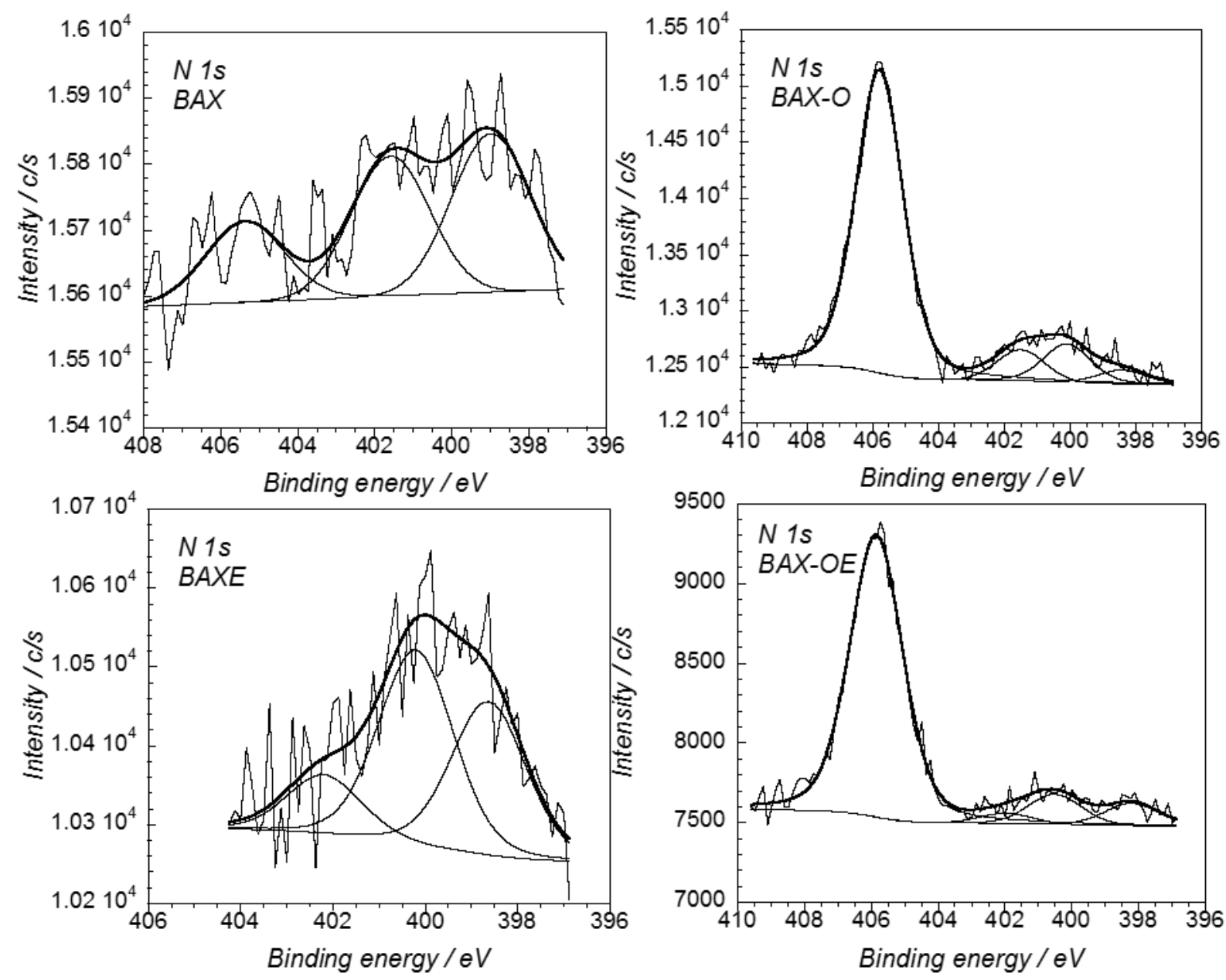

Figure 4.9. The deconvolution of $\mathrm{N} 1 s$ core energy levels for the initial and exposed to ammonia $\mathrm{BAX}$ and $\mathrm{BAX}-\mathrm{O} .^{82}$ 
Table 4.3. The results of deconvolution of C $1 s, \mathrm{O} 1 s$ and $\mathrm{N} 1 s$ core energy levels for BAX and $\mathrm{BAX}-\mathrm{O} .^{82}$

\begin{tabular}{|c|c|c|c|c|c|}
\hline $\begin{array}{c}\text { Binding } \\
\text { energy, } \\
\mathrm{eV}\end{array}$ & Bond assignment & $\mathrm{BAX}$ & BAX-ED & $\mathrm{BAX}-\mathrm{O}$ & BAX-O-ED \\
\hline \multicolumn{6}{|l|}{ C 1s } \\
\hline 284.8 & $\begin{array}{l}\mathrm{C}-\mathrm{C}\left(\mathrm{sp}^{2} \text { carbon }\right) \text { or in nitro } \\
\text { compounds }\end{array}$ & 77.86 & 78.86 & 68.67 & 73.75 \\
\hline 286.2 & $\begin{array}{l}\mathrm{C}-\mathrm{O}, \mathrm{C}-\mathrm{H} \text { (phenolic, alcoholic, } \\
\text { etheric) or } \mathrm{C}-\mathrm{N}, \mathrm{C}-\mathrm{NH}_{2}\end{array}$ & 12.06 & 12.07 & 17.40 & 14.13 \\
\hline 287.3 & $\begin{array}{l}\mathrm{C}=\mathrm{O} \text { (carbonyl or quinone }) \text { or } \\
\mathrm{C}=\mathrm{N}\end{array}$ & 4.94 & 4.71 & 6.98 & 6.33 \\
\hline 288.9 & $\mathrm{O}-\mathrm{C}=\mathrm{O}$ (carboxyl or ester) & 3.42 & 2.78 & 5.53 & 4.64 \\
\hline 290.2 & $\pi-\pi^{*}$ & 1.72 & 1.58 & 1.41 & 1.15 \\
\hline \multicolumn{6}{|l|}{ O 1s } \\
\hline 531.6 & $\begin{array}{l}\mathrm{O}=\mathrm{C} / \text { (in carboxyl/carbonyl or } \\
\mathrm{N}-\mathrm{C}-\mathrm{O} \text { ) }\end{array}$ & 44.43 & 39.60 & 16.51 & 26.82 \\
\hline 533.4 & $\mathrm{O}-\mathrm{C} /$ (in phenol/epoxy or NOx.) & 55.57 & 60.40 & 83.49 & 73.18 \\
\hline \multicolumn{6}{|l|}{$\mathbf{N} 1 s$} \\
\hline $\begin{array}{l}398.2- \\
399\end{array}$ & N-6 in Pyridines & 41.34 & 37.68 & 3.46 & 6.31 \\
\hline $\begin{array}{l}400.1- \\
400.6\end{array}$ & $\begin{array}{l}\mathrm{N}-5 \text { in Pyrrolic, } \mathrm{NH} \text { amides,C- } \\
\mathrm{NH}_{2}\end{array}$ & 36.56 & 47.69 & 9.67 & 8.01 \\
\hline $\begin{array}{l}401.6- \\
402.2\end{array}$ & $\begin{array}{l}\mathrm{N}-\mathrm{Q} \text { in quaternary, } \mathrm{NH}_{4}^{+}, \\
\text {pyridinium }\end{array}$ & & 14.63 & 7.13 & 2.58 \\
\hline 405.3 & $\begin{array}{l}\text { Oxidized nitrogen } \\
\text { functionalities in } \mathrm{C}-\mathrm{N}^{+} \mathrm{O}-\mathrm{C}, \mathrm{Ph}- \\
\mathrm{NO}_{2}, \mathrm{R}-\mathrm{NO}_{2} \text { and } \mathrm{NO}_{3}{ }^{-1}\end{array}$ & 22.10 & & 79.74 & 83.09 \\
\hline
\end{tabular}



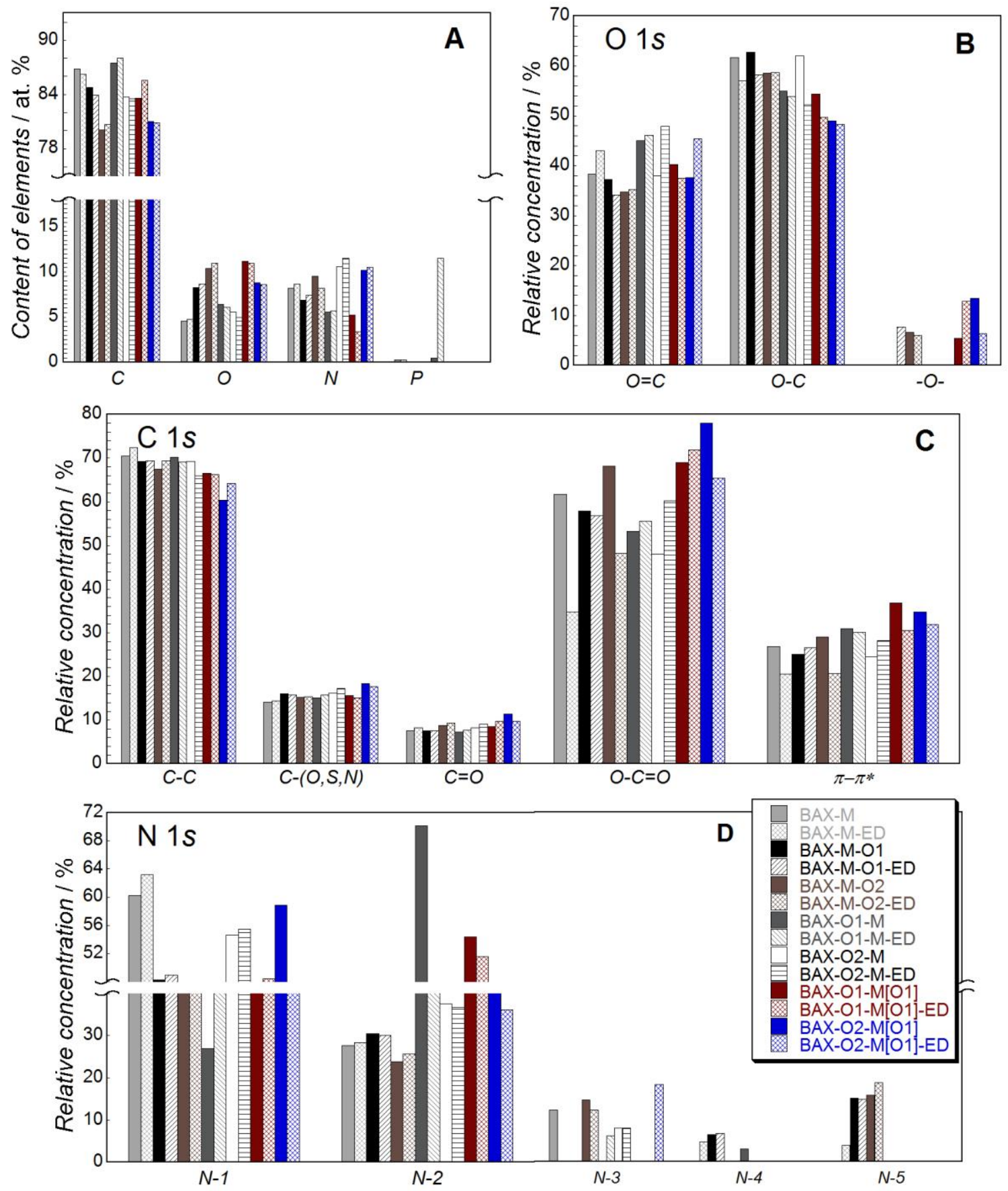

Figure 4.10 A) Content of elements; B-D) Concentration of the specific carbon, oxygen, and nitrogen groups, on the surface of the melamine treated carbon samples. Copyright 2017, with permission from American Chemical Society. ${ }^{83}$ 


\subsection{Influence of surface defects on the resistivity}

As mentioned in section 4.1, oxidation of the initial BAX and BAX-M samples, caused an increase in their overall resistivity. More precisely, in the case of the BAX/BAX-O series, the resistivity increased from $68 \mathrm{k} \Omega$ to $1.04 \mathrm{M} \Omega$, while in the case of the BAX-M, BAX-M-O1 and BAX-M-O2 series, an increase from $7 \mathrm{k} \Omega$ to $16 \mathrm{k} \Omega$ and $29 \mathrm{k} \Omega$, respectively, was found. Based on the deconvolution of $\mathrm{N}$ 1s oxidation of BAX and BAX-M with nitric acid led to the functionalization

of the carbon matrices with nitro-type complexes (Table 4.3 and Figure 4.10). An increased amount of the latter species is directly related to an increase in the number of surface defects, which causes resistance to the electron flow. ${ }^{83}$ The presence of surface defects is reflected in the decreased contribution of $s p^{2} \mathrm{C}-\mathrm{C}$, as evidenced from $\mathrm{C} 1 \mathrm{~s}$ core energy level spectra, for both carbon series.

\subsection{Dependence of sensor sensitivity on surface acidity}

Surface acidity is among other surface features that contribute to the extent of ammonia reactivity with the surface of the carbons. ${ }^{108,109}$ Figures 4.11 and 4.12 summarize the distribution of the acidity constants of the species detected on the carbon surfaces, along with the $\mathrm{pH}$ values of the initial and exhausted samples, after ammonia adsorption. For the BAX series treated with melamine, due to the number of samples, and for the clarity of the discussion, the $\mathrm{pK}_{\mathrm{a}}$ distributions are summarized in the form of a bar graph (Figure 4.12). As expected, an increase in the extent of oxidation is accompanied by an increase in the surface acidity. Moreover, the exposure of all samples to ammonia led to a decrease in their surface acidity. This decrease is small in the case of BAX and the carbons for which melamine impregnation was their last treatment step (BAX-M, BAX-O1-M, and BAX-O2-M). This is related to the small amount of ammonia adsorbed. For the carbons for which chemical oxidation was the last treatment step, on the other hand (BAX-O, 
BAX-M-O1, BAXM-O2, BAX-O1-M[O1] and BAX-O2-M[O1]), this effect is more pronounced. After ammonia adsorption, an increase in the number of groups at $\mathrm{pK}_{\mathrm{a}} 9-10$ is assigned to the formation of ammonium salts $\left(\mathrm{NH}_{4}+\right) \cdot{ }^{97}$ They are formed in the acid-base reactions of $\mathrm{NH}_{3}$ with acidic oxygen-containing groups, such as carboxylic acids (at $\left.\mathrm{pK}_{\mathrm{a}} 4-5\right)$.
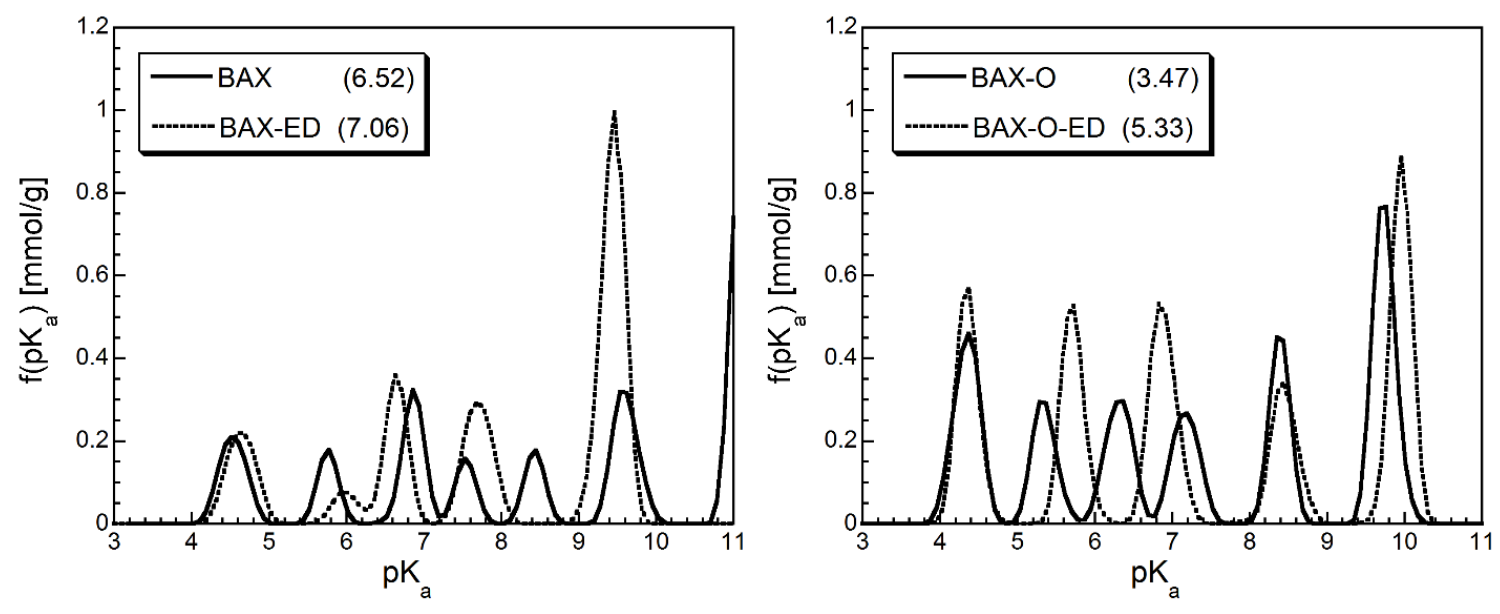

Figure 4.11. The distributions of the $\mathrm{pK}_{\mathrm{a}}$ for the species present on the surfaces of $\mathrm{BAX}$ and $\mathrm{BAX}$ $\mathrm{O}$, before and after ammonia adsorption. ${ }^{82}$ 

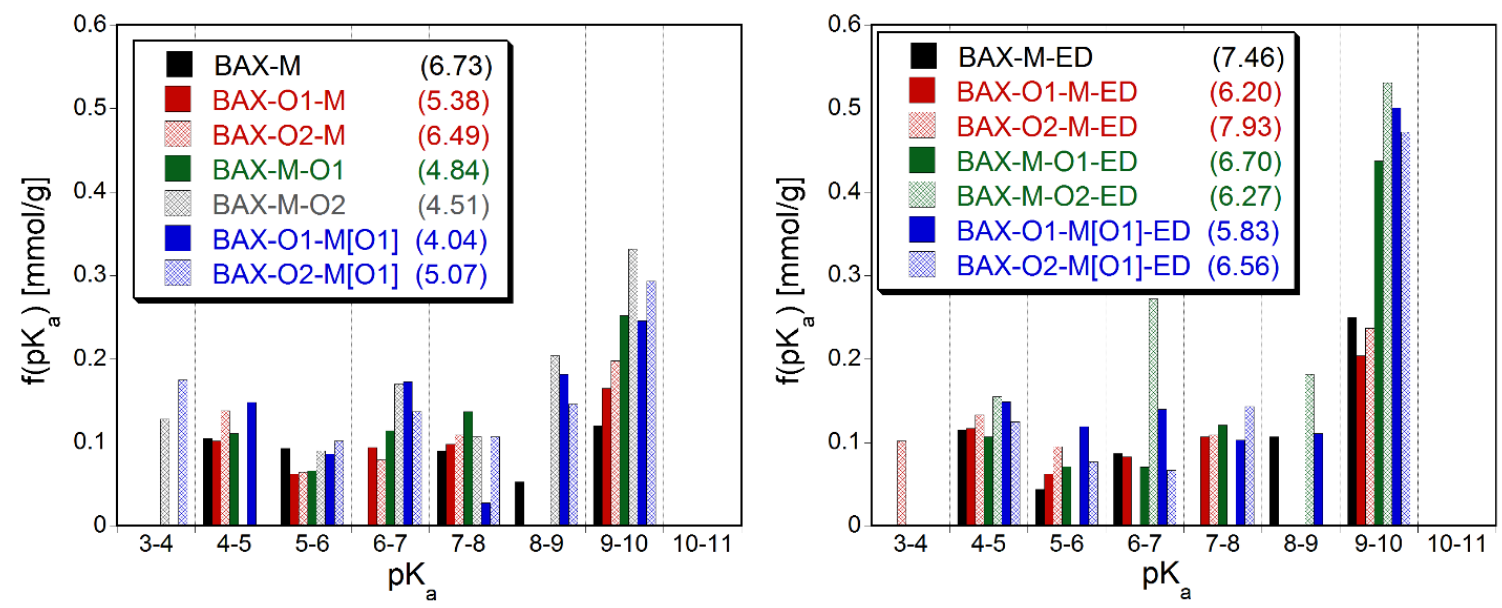

Figure 4.12. A) Content of elements; B-D) Concentration of the specific carbon, oxygen, and nitrogen groups, on the surface of the melamine treated carbon samples. Copyright 2017, with permission from American Chemical Society. ${ }^{83}$

The results of XPS and Potentiometric Titration analyses indicate the crucial role of surface chemistry on the ammonia sensing capability of nanoporous carbons, which strongly depends on both the type and amount of surface functionalities, and on the acidity of the adsorbents. Surface acidity was found as not only affecting the extent of ammonia adsorption, but also the sensitivity of the carbons to the target gas. Figures 4.5 and 4.11 show that the sensitivity order (BAX-O > BAX-O1-M[O1] > BAX-M-O2 > BAX-O1-M > BAX-M) of the melamine treated carbons is in agreement with their corresponding surface $\mathrm{pH}$ values). ${ }^{83}$

\subsection{Porosity: A Necessary but Non-Sufficient Condition}

The parameters of the porous structure for all carbons, initial and exposed to ammonia, are collected in Table 4.4. For BAX the contribution of micropores ( $41.4 \%$ of the total pore volume) and mesopores (59\% of the total pore volume) is significant. After the treatment of BAX with melamine, a decreased volume of these pores and ultramicropores $(\mathrm{V}<1 \mathrm{~nm})$ is observed as a result of the deposition of bulky melamine resins at their entrances. ${ }^{110}$ Upon the chemical oxidation of 
BAX and the melamine treated samples, the volume of ultramicropores increased. This increase is most pronounced for those ultramicropores that are smaller than $0.7 \mathrm{~nm}$, and where physical adsorption of ammonia is expected to be the strongest. ${ }^{97}$ An increase in the ultramicropore volume can be explained by the removal of some carbon atoms and previously deposited bulky groups from the pore walls and/or entrances, due to the surface oxidation.

When the oxidized samples were treated with melamine (BAX-O1M, BAX-O2M), the pore volumes decreased. Unlike in the case of $\mathrm{BAX}$ and $\mathrm{BAX}-\mathrm{M}$, where oxidation with $\mathrm{HNO}_{3}$ increased the micro- and ultramicropore volumes, for BAX-O1-M and BAX-O2-M further chemical oxidation with $\mathrm{HNO}_{3}$ (to obtain BAX-O1-M[O1] and BAX-O2-M[O1]) decreased the volumes of those pores. This decrease might be linked to the formation of new bulky surface functional groups as a result of the chemical reaction of $\mathrm{HNO}_{3}$ with the carbon surface. Such groups are most likely nitro-type complexes, whose presence and nature was discussed in section 4.5 (XPS analysis).

Ammonia exposure had a different influence on the initial and oxidized BAX samples. In the case of BAX-O, no significant changes in the volume of micro- and ultramicropores were observed after ammonia adsorption. This suggests that physisorption rather than a chemisorption is the predominant mechanism for the retention of the target gas. In the case of chemisorption) the chemical reaction of $\mathrm{NH}_{3}$ with the carbon surface would lead to the formation of new stable surface compounds which would cause a decrease in the pore volumes. For BAX, on the other hand, small changes in the volumes of the above-mentioned pores upon ammonia exposure are linked to some degree of chemisorption that took place. These observations are in agreement with our first estimation about the predominant interaction mechanism of our carbon samples with ammonia, based on their electrical behavior during the initial stabilization step (Figure 4.1). SEM images 
showing a highly porous structures of $\mathrm{BAX}$ and $\mathrm{BAX}-\mathrm{O}$ are presented in Figure $\mathrm{A} 3$ of the Appendix. No significant differences in their texture were however found.

In the case of the melamine treated samples where oxidation with $\mathrm{HNO}_{3}$ was their last treatment step, ammonia exposure caused an increase in their pore volume. Interestingly they also showed an increase in the conductivity when exposed to ammonia (Figure 4.3). The observed pore volume increase suggests that during ammonia exposure, some oxidation of the target gas took place. ${ }^{85}$ Formed in this process nitrogen oxide could react with carbon and thus lead to the removal of some carbon atoms from the pore-walls. On the other hand, carbons treated solely with melamine (BAXM, BAX-O1M, BAX-O2M), showed a decrease in both the pore volume (especially micro- and ultramicropore volume) and electrical conductivity upon exposure to ammonia.

Comparison of the parameters of the pore structure of the carbons tested and the extent of their signal changes shows an interesting pattern. For the BAX and BAX-O samples there is a direct relationship between the sensitivity of the carbons and the volume of micro/ultramicropores. ${ }^{1}$ Thus BAX-O that exhibits a higher volume of those pores compared to BAX, also exhibits more pronounced signal changes upon the $\mathrm{NH}_{3}$ exposure. Such a trend is expected considering that micropores, and especially ultramicropores, are the most energetically favorable site for the adsorption of small gas molecules such as ammonia $(3 \AA),{ }^{97}$ and therefore also play an important role in the electrical performance of the carbons. Unlike in the case of BAX and BAX-O, the melamine treated sample series show an indirect relationship between the volume of micro/ultramicropores and the chip sensitivity. More precisely, the analysis of the dependence of the sensitivity of BAXO1-M, BAX-O2-M, BAX-M-O2, and BAX-O2-M-[O1] on their micro/ultramicropore volume, shows that even though BAX-O1-M and BAX-O2-M have a higher volume of those pores, they are less sensitive to ammonia than are BAX-M-O2, and BAX-O2-M- 
[O1]. This suggests that even though porosity and especially ultramicroporosity is a necessity in ammonia sensing, it is not always a sufficient condition for a good sensor performance.

Table 4.4. Parameters of the porous structure for all wood-based nanoporous carbons, calculated from the nitrogen adsorption isotherms. ${ }^{82,83}$ Copyright 2017, with permission from American Chemical Society. ${ }^{83}$

\begin{tabular}{lllllll}
\hline Sample & $\begin{array}{l}\mathrm{S}_{\mathrm{NLDFT}} \\
\left(\mathrm{m}^{2} \mathrm{~g}^{-1}\right)\end{array}$ & $\begin{array}{l}\mathrm{V}_{\mathrm{t}} \\
\left(\mathrm{cm}^{3} \mathrm{~g}^{-1}\right)\end{array}$ & $\begin{array}{l}\mathrm{V}_{\text {meso }} \\
\left(\mathrm{cm}^{3} \mathrm{~g}^{-1}\right)\end{array}$ & $\begin{array}{l}\mathrm{V}_{\text {mic }} \\
\left(\mathrm{cm}^{3} \mathrm{~g}^{-1}\right)\end{array}$ & $\begin{array}{l}\mathrm{V}_{<0.7 \mathrm{~nm}} \\
\left(\mathrm{~cm}^{3} \mathrm{~g}^{-1}\right)\end{array}$ & $\begin{array}{l}\mathrm{V}_{<1 \mathrm{~nm}} \\
\left(\mathrm{~cm}^{3} \mathrm{~g}^{-1}\right)\end{array}$ \\
\hline BAX & 1549 & 1.489 & 0.872 & 0.617 & 0.086 & 0.225 \\
BAX-ED & 1616 & 1.441 & 0.793 & 0.648 & 0.090 & 0.232 \\
BAX-M & 874 & 0.835 & 0.513 & 0.322 & 0.059 & 0.128 \\
BAX-M-ED & 870 & 0.848 & 0.531 & 0.317 & 0.062 & 0.124 \\
BAX-M-O1 & 1050 & 0.957 & 0.554 & 0.403 & 0.102 & 0.174 \\
BAX-MO1-ED & 1115 & 1.035 & 0.608 & 0.427 & 0.103 & 0.179 \\
BAX-M-O2 & 900 & 0.786 & 0.450 & 0.336 & 0.086 & 0.152 \\
BAX-M-O2-ED & 990 & 0.869 & 0.499 & 0.370 & 0.093 & 0.168 \\
BAX-O & 1408 & 1.082 & 0.531 & 0.551 & 0.147 & 0.252 \\
BAX-O-ED & 1427 & 1.088 & 0.532 & 0.556 & 0.137 & 0.259 \\
BAX-O1-M & 1384 & 1.199 & 0.673 & 0.526 & 0.139 & 0.239 \\
BAX-O1-M-ED & 1363 & 1.186 & 0.651 & 0.535 & 0.140 & 0.233 \\
BAX-O2-M & 1156 & 0.910 & 0.474 & 0.436 & 0.157 & 0.221 \\
BAX-O2-M-ED & 1013 & 0.823 & 0.444 & 0.379 & 0.132 & 0.187 \\
BAX-O2-M[O1] & 969 & 0.759 & 0.403 & 0.359 & 0.139 & 0.185 \\
BAX-O2-M[O1]-ED & 985 & 0.781 & 0.413 & 0.368 & 0.139 & 0.186 \\
BAX-O1-M[O1] & 1307 & 1.122 & 0.615 & 0.507 & 0.138 & 0.229 \\
BAX-O1-M[O1]-ED & 1341 & 1.148 & 0.629 & 0.519 & 0.145 & 0.236 \\
\hline
\end{tabular}

For the exhausted samples after ammonia adsorption, the suffix -ED is added to their name. 


\subsection{Selectivity test}

To evaluate the selectivity of the materials towards ammonia, the carbon chips were exposed to $500 \mathrm{ppm}$ of $\mathrm{H}_{2} \mathrm{~S}$ in dry air. ${ }^{82}$ Similarly to ammonia the latter gas is a reducing gas (electron donating), but of a different chemistry (acidic instead of basic). Figure 4.13 summarizes the results for BAX and BAX-O. As seen small changes in the normalized resistance are recorded for both carbons when exposed to $500 \mathrm{ppm}$ of $\mathrm{H}_{2} \mathrm{~S}$. These are $4 \%$ for $\mathrm{BAX}$ and $9 \%$ for $\mathrm{BAX}-\mathrm{O}$. The small sensitivity of the two carbons towards the acidic gas is likely related to the expected small adsorption capacities of these carbons ${ }^{111}$ because of their acidic surface properties. ${ }^{112}$

The results of the selectivity test for all carbon samples are summarized in Figure $4.14 . .^{82,83}$ The results are presented in terms of: (a) the changes in the normalized resistance, which is the sensor sensitivity, and (b) the response time, which indicates how fast a sensor can respond to an environmental change. Figure 4.15A shows that all carbon samples show a much slower response to $\mathrm{H}_{2} \mathrm{~S}$ than that to $\mathrm{NH}_{3}$. For $\mathrm{BAX}-\mathrm{O}$ for instance, it took only 2 min for the electrical signal to reach the maximum of normalized resistance and to stabilize upon ammonia exposure. Upon the exposure of BAX-O to $\mathrm{H}_{2} \mathrm{~S}$ on the other hand, it took almost $1 \mathrm{~h}$ for the same parameter (normalized resistance) to reach the plateau and stabilize. Since the carbons show much higher sensitivities to ammonia than to hydrogen sulfide, the same parameter (sensitivity) was also evaluated based on the response time of the sensors to $\mathrm{NH}_{3}$. This is illustrated in Figure 4.14B. As seen, same exposure times to both reducing gases led once again to greater signal changes for ammonia than those for hydrogen sulfide.

Since $\mathrm{NH}_{3}$ and $\mathrm{H}_{2} \mathrm{~S}$ are molecules of similar sizes, and thus have similar accessibility to the carbons' pore-network, a higher selectivity to $\mathrm{NH}_{3}$ is linked to the presence of certain surface functional groups and their surface acidity that enhance the affinity towards $\mathrm{NH}_{3}$ adsorption. Even 
though, N-type basic groups are expected to attract $\mathrm{H}_{2} \mathrm{~S}$, the kinetics of adsorption/reactive adsorption are apparently slow.
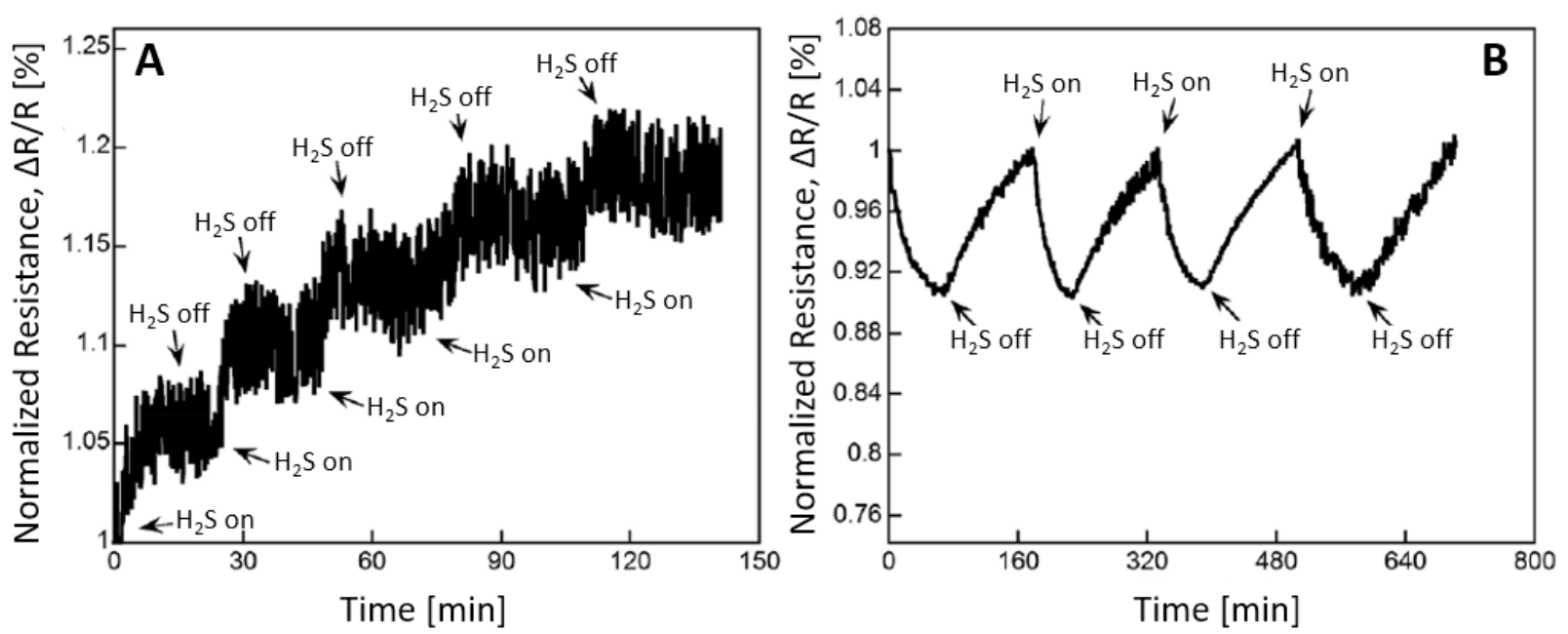

Figure 4.13. Response curve for BAX (A) and BAX-O (B) at 500 ppm of $\mathrm{H}_{2} \mathrm{~S} .{ }^{82}$ 


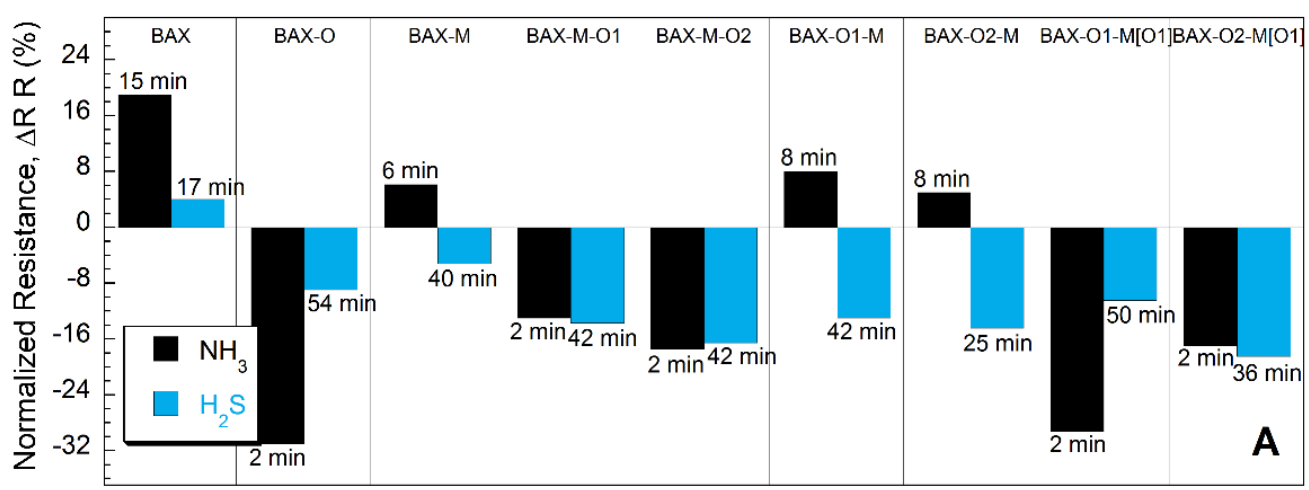

Carbon samples

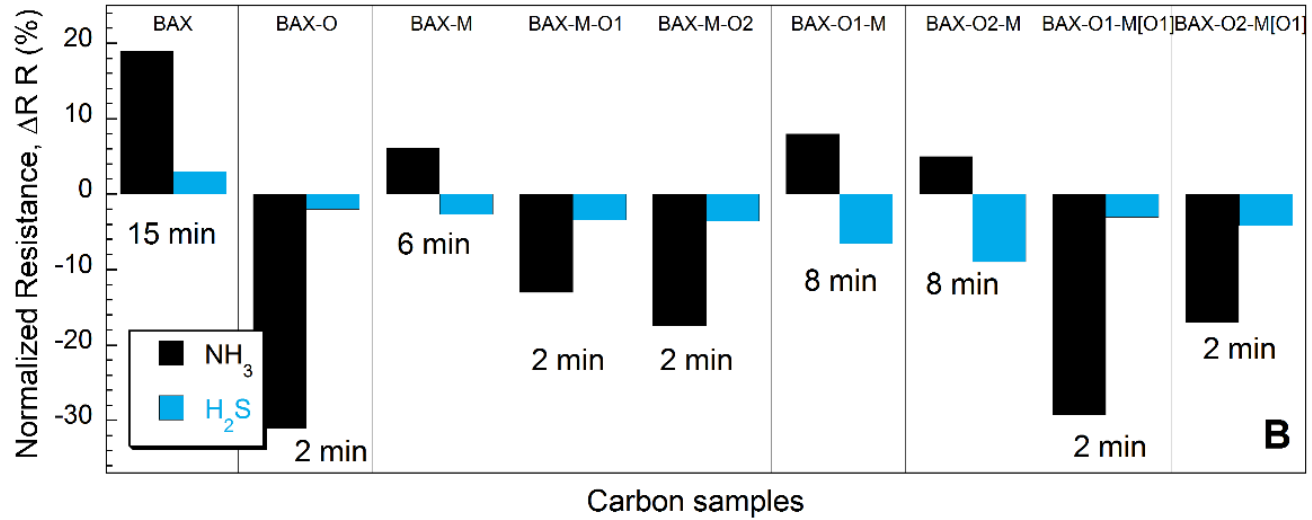

Figure 4.14. Comparison of the selectivity of the melamine treated carbon sensors: (A) in terms of the changes of their normalized resistance (sensitivity of the sensors), and (B) in terms of the response time of the sensors toward $\mathrm{NH}_{3}$ sensing. Copyright 2017, with permission from American Chemical Society. ${ }^{83}$

The carbon series for which melamine impregnation was their last treatment step (BAX-M, BAX$\mathrm{O} 1-\mathrm{M}$, and $\mathrm{BAX}-\mathrm{O} 2-\mathrm{M}$ ), shows a very interesting trend in its electrical changes (increase or decrease of normalized resistance) upon exposure to $\mathrm{NH}_{3}$ and $\mathrm{H}_{2} \mathrm{~S}$. Even though both gas are electron donating species, the samples showed opposite electrical responses when exposed to them. This is clearly linked to the combined effect of the surface chemistry of these carbons and the chemistry of the gases. XPS revealed an increases in the contribution of pyridine-like nitrogen in the case of those samples. Such groups are known to increase the carbon surface polarity and thus the adsorption of water molecules. ${ }^{12,113}$ Even though the sensing tests were conducted in dry 
conditions, $\mathrm{H}_{2} \mathrm{O}$ molecules can still be present in the very small pores of the carbons. In the presence of $\mathrm{H}_{2} \mathrm{O}$, and in the vicinity of basic groups, $\mathrm{H}_{2} \mathrm{~S}$ dissociates into $\mathrm{H}^{+}$and $\mathrm{HS}^{-}$ions. Pyridines facilitate the direct contact of $\mathrm{HS}^{-}$ions with the carbon matrix, where they can be further oxidized to $\mathrm{SO}_{2} \cdot{ }^{112,114}$ Unlike $\mathrm{H}_{2} \mathrm{~S}, \mathrm{SO}_{2}$ has electron withdrawing properties, and thus causes the normalized resistance to decrease. A similar electrical outcome can be also linked to the dissociation of $\mathrm{HS}^{-}$ions, which promote ionic conductivity across the carbon matrix.

\subsection{Sensing mechanism}

Based on the extensive analysis of the surface chemical and structural features of the carbons addressed in this chapter, their electrical response as gas sensors, and their conduction type according to the impedance measurements, a sensing mechanism is proposed. This mechanism involves various processes.

\subsubsection{Conduction type-role of specific surface chemistry}

The specific surface chemistry, which is related to the particular configuration of $\mathrm{O}$ - and $\mathrm{N}$ heteroatoms (surface defects), is one of the main features governing the electrical performance of these carbons as the ammonia gas sensors. Based on the impedance measurements, BAX exhibits the predominantly $p$ - conduction type and in its matrix positively charged holes $\left(h^{+}\right)$are the main

charge carriers. The $p$-type behavior of this sample is linked to some degree of disappearance of the $\pi$-state, because of the bonding between the $\pi$ - and oxygen-related states. This causes electrons to transfer from the carbon phase to oxygen. ${ }^{115}$

The p-conduction type was also observed in the case of the carbons for which impregnation with melamine was their last treatment step (BAX-M and BAX-O2-M). In this case pyridines were responsible this kind of conductivity, which is related to the localized electrons at the N-atoms. 
They bring defects to the carbon matrix, resulting in an increase in the population of the positively charged carriers (holes) ${ }^{99}$ For the samples where oxidation with $\mathrm{HNO}_{3}$ was their last treatment step, the p-conduction type was attributed to both pyridines and nitropyridines owing to the strong electron accepting nature of the nitro moiety. Considering that ammonia is an electron donating gas, when such $p$-type materials are exposed to it, an increase in the normalized resistance (or increase in the conductivity) can be explained by the decrease in the concentration of the positively charge carriers (holes), by $e^{-}$donated by the target gas.

In the case of BAX-O the impedance measurements showed that oxidation with nitric acid altered the electronic properties of the carbon matrix, converting it from predominantly $p$ - to predominantly $n$-type. This is likely related to the decrease in the concentration of positively charged holes $\left(h^{+}\right)$, and is in agreement with a previously reported study which showed that treatment of carbon black which is a $p$-type material with $\mathrm{HNO}_{3}$ caused a depletion in the population of holes. ${ }^{116} \mathrm{~A}$ decrease in the concentration of $h^{+}$, left electrons $\left(e^{-}\right)$as the main charge carriers. When an $n$-type material, such as BAX-O, is exposed to an electron donating gas (such as $\mathrm{NH}_{3}$ ), the decrease in the normalized resistance (or increase in the conductivity) results from an increase in the concentration of the charge carriers (electrons), by $e^{-}$donated by $\mathrm{NH}_{3}$. In the case of the melamine treated oxidized carbon series [BAX-M-O and BAX-O- MO], a mechanism responsible for the decrease in the normalized resistance upon ammonia exposure, involves the oxidation of the target gas to $\mathrm{NO}_{2}$ in the presence of superoxide ions $\left(\mathrm{O}_{2}{ }^{-}\right)$. The XPS analysis detected such species on the surface of the samples based on XPS analysis. Unlike $\mathrm{NH}_{3}, \mathrm{NO}_{2}$ has electron withdrawing properties and thus causes an increase rather than a decrease in the concentration of the positively charged holes of a p-type material. This mechanism is analyzed more extensively in Chapter 5 . 


\subsubsection{Alteration of conduction type during ammonia exposure}

It is important to mention that the oxidized melamine treated samples (BAX-M-O2 and BAX-O1$\mathrm{M}[\mathrm{O} 1])$, even though they exhibit $p$-type conductivity, they do not show the typical behavior of $\mathrm{p}$ type materials during ammonia exposure. More precisely, during the reversible ammonia exposure they show a decrease in the normalized resistance rather than an increase. This trend/observation suggests that during the initial stabilization of the samples in ammonia, their surface chemical features that induce a $p$-type conduction likely changed, affecting their electronic characteristics. This could be a result of a chemical reaction of the target gas with the surface functional groups of the initial samples (before $\mathrm{NH}_{3}$ exposure). Indeed, the XPS analysis revealed that the BAX-M-O2 and BAX-O2-M[O1] exhausted samples after ammonia exposure showed a decreased contribution of pyridinic groups, accompanied by an increase in the contribution of $-\mathrm{NO}_{\mathrm{x}}$ and $-\mathrm{NH}_{2}$ groups The appearance of such species suggests the formation of amino-nitropyridines. In these configurations the amino moiety induces electron charge density to the aromatic ring while the nitro group acts as an electron acceptor. Exposure of the above samples to ammonia, by enhancing the distribution/delocalization of the $e^{-}$charge density, causes the conductivity to increase. Such a behavior is expected based previously reported results which showed that pyridinic defects are sensitive to adsorbates such as $\mathrm{NH}_{3}$ and $\mathrm{H}_{2}$, which cause a transition in the carrier type (from ptype to n-type) upon their adsorption. ${ }^{17-119}$ Thus, a decrease in the normalized resistance in the case of the initially $p$-type materials is linked to the conversion of the conduction type (from predominantly $-p$ to predominantly $-n$ ) during $\mathrm{NH}_{3}$ exposure.

\subsubsection{Role of specific adsorption forces and porosity on the ammonia sensing mechanism}

The sensing performance of the oxidized carbons can be also explained on the basis of physical interactions (specific and non-specific) that govern the physical adsorption of the target gases. 
Such interactions include hydrogen bonding or dipole-dipole interactions, between the O- and Ncontaining surface functional groups and the $\mathrm{NH}_{3}$ and/or $\mathrm{NO}_{2}$ molecules. ${ }^{82}$ Species that can participate in hydrogen bonding with ammonia include, hydroxyl, carboxylic and phenol groups. Highly polar $\mathrm{NO}_{2}$ and amino-nitropyridines also participate in such weak interactions, increasing simultaneously the overall polarity of the carbon surface. This greatly enhances the physical adsorption of ammonia in the pore system. Such weak interactions, provide alternate paths for current conduction across the ultramicropores through charge hopping mechanisms, ${ }^{120}$ which leads to a decrease in the resistance of the chips (or increase in the conductivity) upon exposure to the $\mathrm{NH}_{3}$.

\subsubsection{Presence of liquid-like ammonia}

Besides the above mentioned mechanisms, the contribution of liquid-like ammonia on sensing also need to be considered. ${ }^{1}$ Even though the sensing tests were performed in all cases in dry conditions, liquid-like ammonia can still be present in the very small pores that lack functional groups and thus specific interactions cannot take place. Ammonia in this state (liquid-like), contributes to an increase in the DC conductivity, because of its higher conductivity compared to that of air. ${ }^{121}$ 


\section{Chapter 5. Polymer derived nanoporous carbons}

This chapter describes the ammonia sensing capability of polymer-derived nanoporous carbons. Three sets of materials are examined. The polymer precursors for the two first carbon series are -

$\mathrm{S}$ and $-\mathrm{N}$ and are Poly (sodium 4-styrene sulfonate), Poly (4-ammonium styrene-sulfonic acid) and Poly (4-styrenesulfonic acid-co-maleic acid). The third series consists of carbons derived from $\mathrm{N}$-containing polymeric resins. More precisely the carbons tested in this Chapter are the following:

C-1: derived by the carbonization of Poly (sodium 4-styrene sulfonate)

C-2: obtained by the air-oxidation of C-1

C-AO: derived by the carbonization and further air-oxidation of Poly (4-ammonium styrene-sulfonic acid)

C-BO: derived by the carbonization and further air-oxidation of a 1:1 mixture of $30 \%$ solution of Poly (4-ammonium styrene-sulfonic acid) and Poly(4-styrenesulfonic acid-co-maleic acid) sodium salt

PFM-AO, RFM-AO, and PFU-AO: derived by the carbonization and further airoxidation of combinations: i) Phenol-Formaldehyde-Melamine, ii) ResorcinolFormaldehyde- Melamine, and iii) Phenol-Formaldehyde-Urea combinations.

Details of the carbons' preparation are described in Chapter 3.

This chapter focuses on the role of sulfur and nitrogen as dopants (either separately or as codopants), in the sensing response of nanoporous carbons. It also extensively examines the role of porosity in sensing and elucidates which pores play the most important role. 
Chapter 5 is a slightly revised version of the following articles, with permission from Elsevier, Copyright 2014, 2016, and 2017, reported in References 84, 5, and 86, respectively:

Singh, K.; Travlou, N. A.; Bashkova, S.; Rodríguez-Castellón, E.; Bandosz, T. J. Nanoporous Carbons as Gas Sensors: Exploring the Surface Sensitivity. Carbon 2014, 80, 183-192

Travlou, N. A.; Seredych, M.; Rodríguez-Castellón, E.; Bandosz, T. J. Insight into Ammonia Sensing on Heterogeneous S- and N- Co-Doped Nanoporous Carbons. Carbon 2016, 96, 10141021.

Travlou, N. A.; Bandosz, T. J. N-Doped Polymeric Resin-Derived Porous Carbons as Efficient Ammonia Removal and Detection Media. Carbon 2017, 117, 228-239.

\subsection{Estimation of predominant ammonia interaction type based on the initial sensor response}

Figure 5.1 presents the electrical response of the carbons during their initial stabilization at 500

ppm of ammonia followed by air-purging. ${ }^{84-86}$ As mentioned in Chapter 4, during this stage ammonia reacts both physically and chemically with the carbons' surface causing their exhaustion. More precisely, a stabilization of the electrical signal indicates the complete occupation of the active sites of the carbons by ammonia molecules. Based on the percentage change of the electrical signal during this sensing stage we can conclude that: a) in the case of $\mathrm{C} 1$ and $\mathrm{C} 2$ carbon series physisorption is more pronounced for the latter sample, while chemisorption seems to be the main interaction type for $\mathrm{C} 1, \mathrm{~b}$ ) for $\mathrm{C}-\mathrm{AO}$ and $\mathrm{C}-\mathrm{BO}$ series, chemisorption seems to predominate as an interaction type for both carbons, and finally c) for the last carbons series (PFM-AO, RFM-AO, and PFU-AO), physisorption is more pronounced for RFM-AO and PFU-AO, and less pronounced for PFM-AO. 

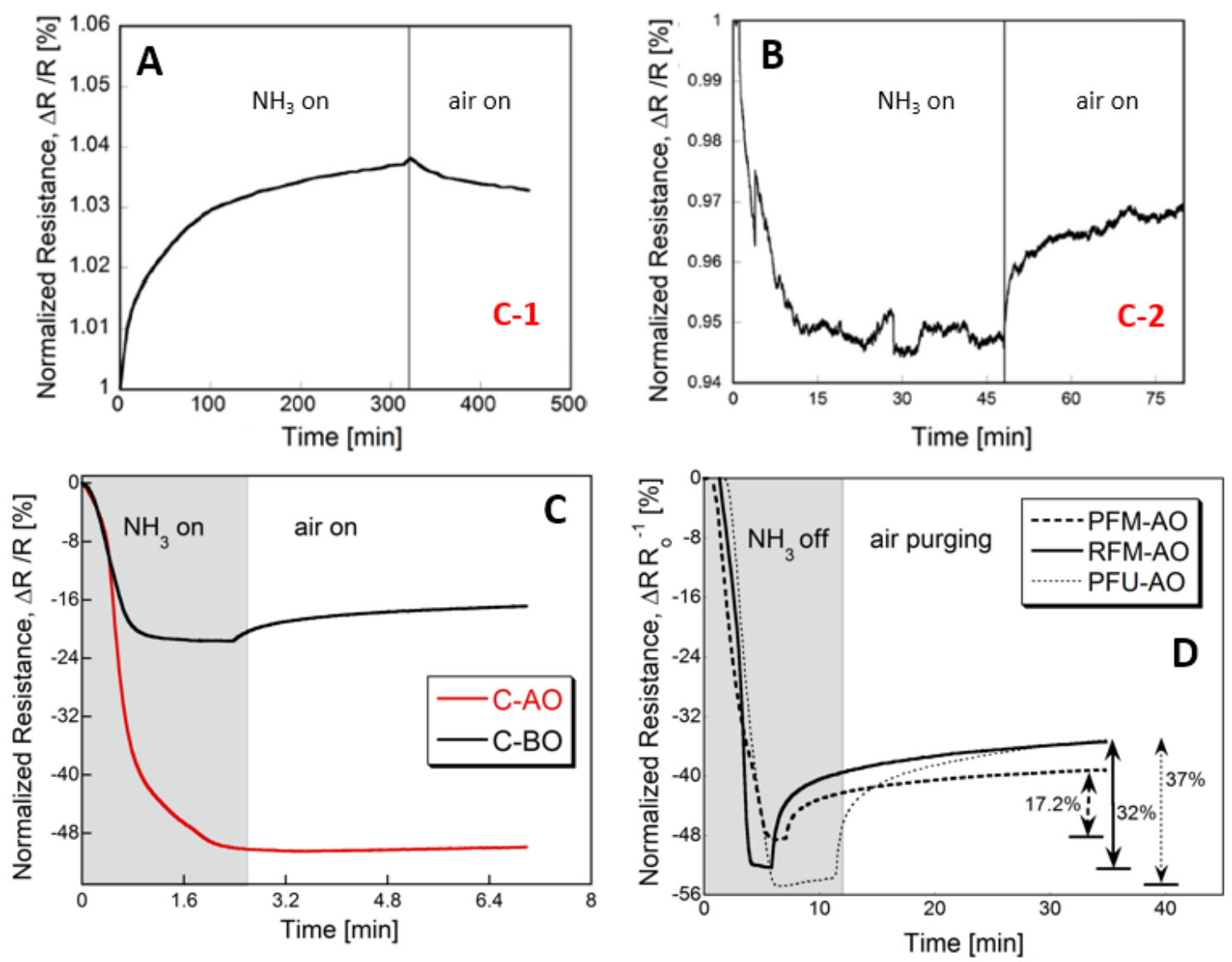

Figure 5.1. Changes in the normalized resistance for the activated carbon samples upon their initial exposure to $\mathrm{NH}_{3}$ and subsequent air purging (after the signal stabilization) (A) for $\mathrm{C} 1$, (B) for C2, (C) for C-AO and C-BO, and (D) for PFM-AO, RFM-AO and PFU-AO. ${ }^{84-86}$

\subsection{Testing the reversible sensing capability of the sensors}

\subsubsection{Reversible sensing capability of S-containing carbons}

To evaluate the reversible sensing capability of the S-containing nanoporous carbons, the carbon chips were exposed to ammonia concentrations in dry air, ranging between 100 and $500 \mathrm{ppm}$. The resistivities of the chips were $10 \Omega$ and $19 \Omega$ for $\mathrm{C} 1$ and for $\mathrm{C} 2$, respectively. ${ }^{84}$ Such resistivity values can provide measurable electrical signal changes, which are presented in Figure 5.2. ${ }^{84}$ For both carbons the normalized resistance decreases upon ammonia exposure. The sensitivity for C2 is nine times greater than that for $\mathrm{C}-1$ (Figure 5.2A). Figure 5.2B illustrates the linear trend of 
the dependence of the electrical sensor response on the ammonia concentrations, which is a desired feature of a gas sensor. ${ }^{84}$

The results of the initial stabilization stage and the reversible sensing curves (Figures 5.1 and 5.2, respectively) leads to the following findings:

a) While the $\mathrm{C}-2$ carbon shows a similar trend in its electrical response during the initial sensor stabilization stage and the reversible sensing stage (decrease in the normalized resistance upon $\mathrm{NH}_{3}$ exposure), the opposite trend is observed for the $\mathrm{C}-1$ carbon. More precisely, $\mathrm{C}$ 1 shows an increase in the resistance upon ammonia exposure during the initial stabilization stage, and a decrease in the resistance during the reversible sensing stage. This is likely related to the changes in surface chemical features of the sample before and after its exhaustion, which affect its sensing mechanism accordingly.

b) The signal changes (sensitivity) for C-2 are nine times greater than those for C- 1 . Considering that C-2 carbon was obtained by the air-oxidation of $\mathrm{C}-1$ at $350^{\circ} \mathrm{C}$, its greater sensitivity suggests that the formation of new surface chemical and structural features (as a results of air-oxidation) are likely responsible for an enhanced sensor response. 

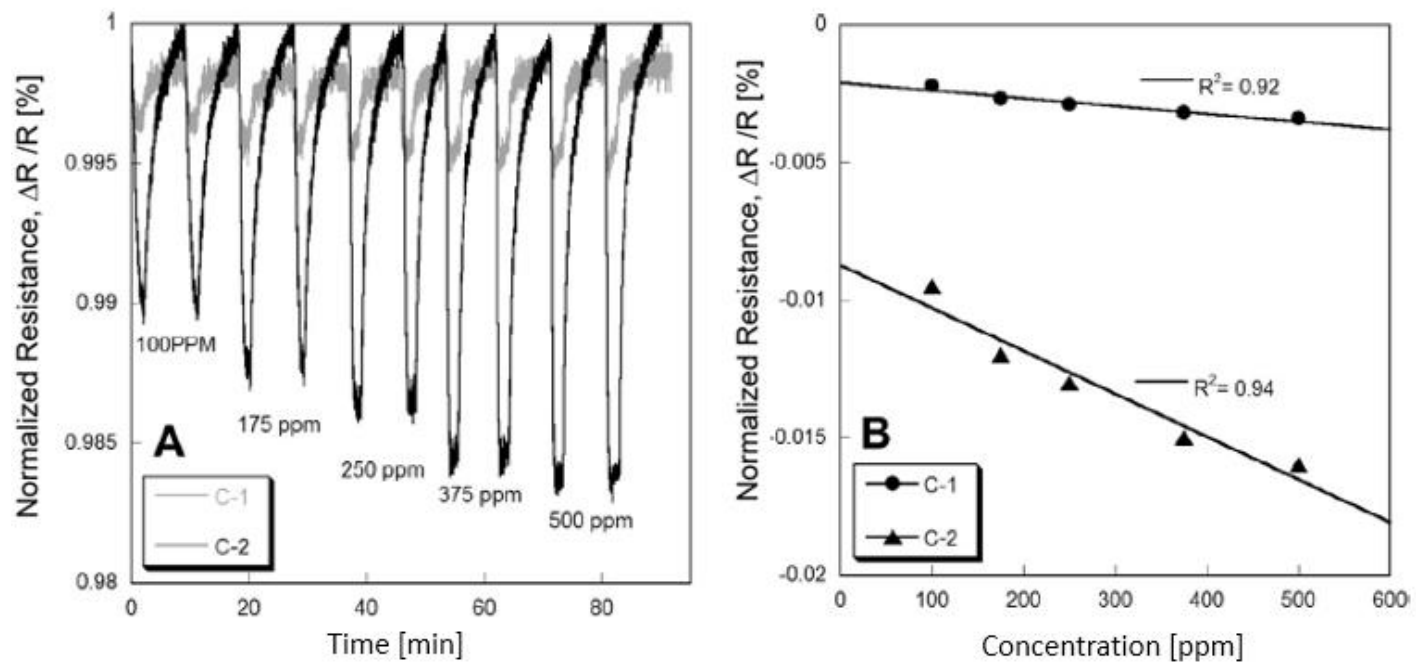

Figure 5.2. (A) Response curve for both carbons at various ammonia concentrations. (B) The dependence of the change in normalized resistance of the $\mathrm{C}-1$ and $\mathrm{C}-2$ carbons on the ammonia concentration in the challenge gas. ${ }^{84}$

\subsubsection{Reversible sensing capability of N-doped polymeric resin-derived carbons}

The reversible sensing capability of the $\mathrm{N}$-doped polymeric resin-derived carbons (PFM-AO, RFM-AO and PFU-AO) is illustrated in Figure 5.3. ${ }^{86}$ As seen, all carbons exhibit an excellent reversibility of the response upon their exposure to ammonia concentrations between 45-500 ppm. The response varies linearly with increasing gas concentrations (Figure 5.3D). Among the three carbons tested, PFU-AO exhibits the highest sensitivity (29\%), and PFM-AO - the lowest one (17\%), upon exposure to $500 \mathrm{ppm}$ of $\mathrm{NH}_{3}$. 

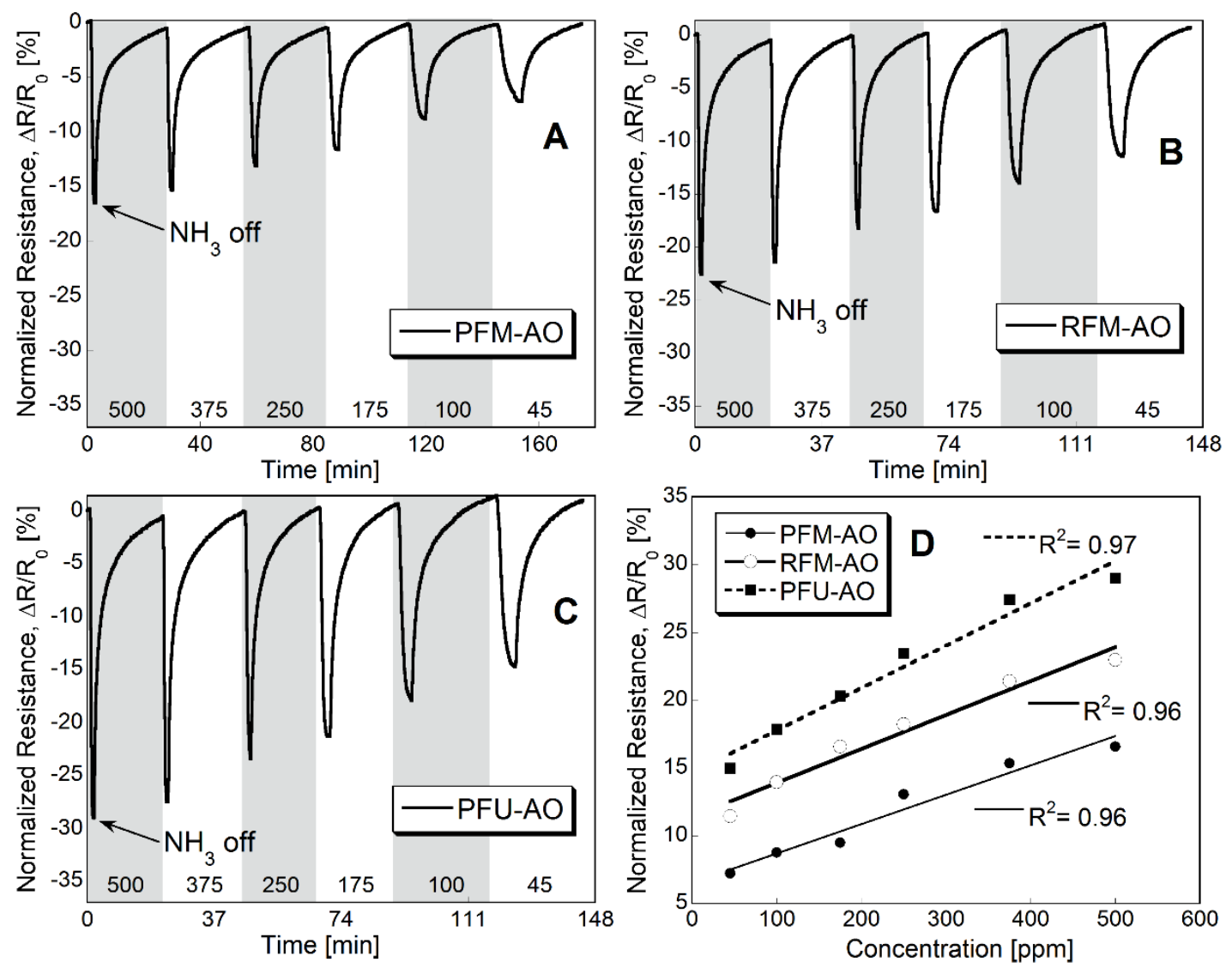

Figure 5.3. (A, B, C): Change in the normalized resistance for PFM-AO, RFM-AO and PFU-AO samples, upon testing their reversible sensing capability at $\mathrm{NH}_{3}$ concentrations varying between 45-500 ppm. (D): Dependence of $\Delta \mathrm{R} / \mathrm{R}_{\mathrm{o}}(\%)$ of the air-oxidized samples on various $\mathrm{NH}_{3}$ concentrations. $^{86}$

\subsubsection{Reversible sensing capability of S,N-co-doped carbons}

The results of the reversible sensing capability of the dual-doped S,N-containing carbons (C-AO and C-BO), are presented in Figure 5.4. ${ }^{85}$ As aforementioned these carbons were obtained by carbonization and further air oxidation of poly (4-ammonium styrene-sulfonic acid), and of a 1:1 mixture of 30\% solution of poly (4-ammonium styrene-sulfonic acid) and poly(4-styrenesulfonic acid-co-maleic acid) sodium salt, respectively. A good repeatability of the carbons' response is observed at each ammonia concentration. This means that when the carbons are exposed to 
repeated $\mathrm{NH}_{3} /$ air cycles, the response levels do not change, which indicates the stability of carbons. The response time of the sensors is fast and only $40 \mathrm{sec}$.

The reversible sensing capability of the carbons obtained from the initial polymer precursors (without applying further air-oxidation), was also examined. Figure 5.4A illustrates the reversible sensing on C-B, which is the carbon obtained from the 1:1 mixture of $30 \%$ solution of Poly (4ammonium styrene-sulfonic acid) and Poly(4-styrenesulfonic acid-co-maleic acid) sodium salt. ${ }^{85}$ Even though this sample exhibits reversible and consistent sensing upon exposure to continuous ammonia cycles, the electrical changes are too small for this carbon to be considered as a sensor with a satisfactory sensitivity. For C-A, on the other hand, which is the carbon obtained from poly (4-ammonium styrene-sulfonic acid), no changes at all in the electrical signal were measured upon exposure to ammonia ${ }^{85}$ Such differences in the electrical behavior of the carbons before and after air-oxidation, indicate the importance of the latter treatment stage (air-oxidation) for the development of efficient gas sensors. The reproducibility of the results on three different chips of $\mathrm{C}-\mathrm{AO}$ and $\mathrm{C}-\mathrm{BO}$ is illustrated in Figure 5.4C. Here, error bars represent the standard deviations upon exposure to various gas concentrations. The relative s (\% RSD) is $3.3 \pm 1.4 \%$ for C-AO and $7.2 \pm 1.3 \%$ for C-BO. 

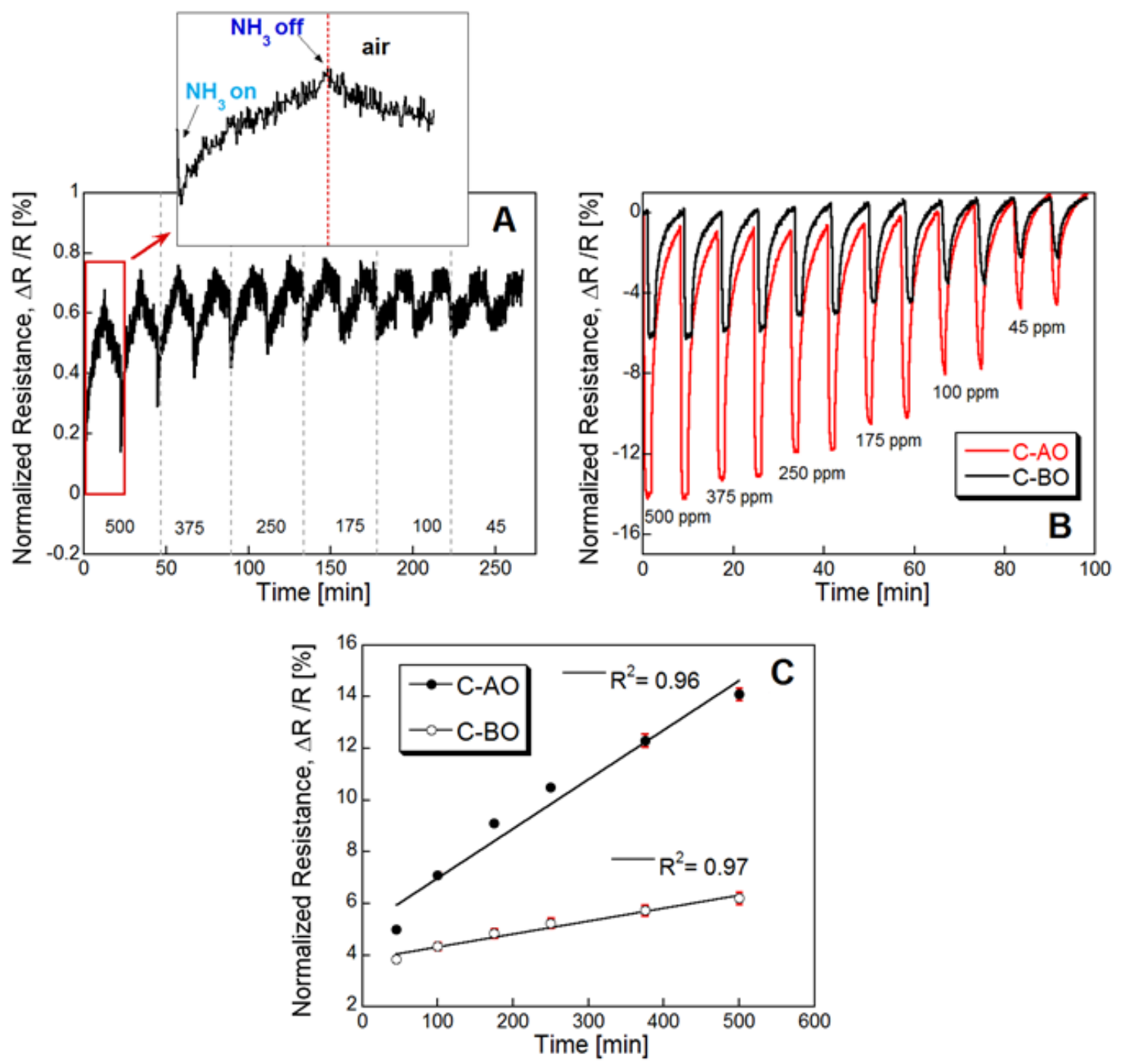

Figure 5.4. Response curves for $\mathrm{C}-\mathrm{B}(\mathrm{A}), \mathrm{C}-\mathrm{AO}$ and $\mathrm{C}-\mathrm{BO}(\mathrm{B})$ exposed to various ammonia concentrations. (C) Dependence of $\Delta \mathrm{R} / \mathrm{R}_{0}$ of the oxidized samples on $\mathrm{NH}_{3}$ concentration. The error bars are similar or smaller than the size of the data points used. ${ }^{85}$ 


\subsection{Morphological features affecting the carbon-sensor properties}

SEM and TEM images of the carbons tested provide valuable details about their morphological features. Figure 5.5 presents the SEM images of the S-containing carbon surfaces (C-1 and C-2) ${ }^{84}$ C-1 carbon exhibits a rather dense structure with a variety of pores of different sizes. ${ }^{84}$ In the morphology of C-2 carbon, on the other hand, the widening of the pores can be seen as a result of air oxidation at $350^{\circ} \mathrm{C}$, making micropores more accessible to adsorbates. This is one potential explanation of the greater sensitivity of C-2 compared to that of C-1 (Figure 5.2).
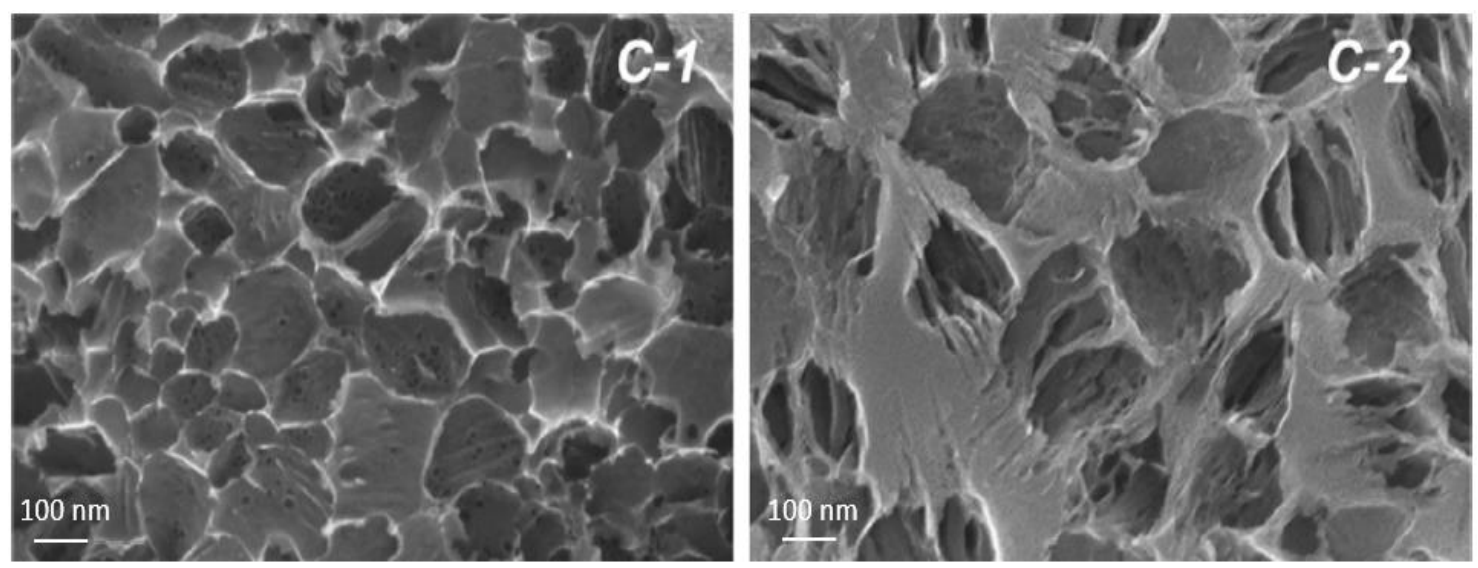

Figure 5.5. TEM images of C-1 and C-2 samples. ${ }^{84}$

Figure 5.6 presents the HR-TEM images of the S,N-dual doped nanoporous carbons (C-AO and C-BO) ${ }^{85}$ Both carbons show marked "dots" of $5-10 \mathrm{~nm}$ of graphitic domains. This high local level of graphitization is expected to affect their DC conductivity and suitability for redox reactions. 

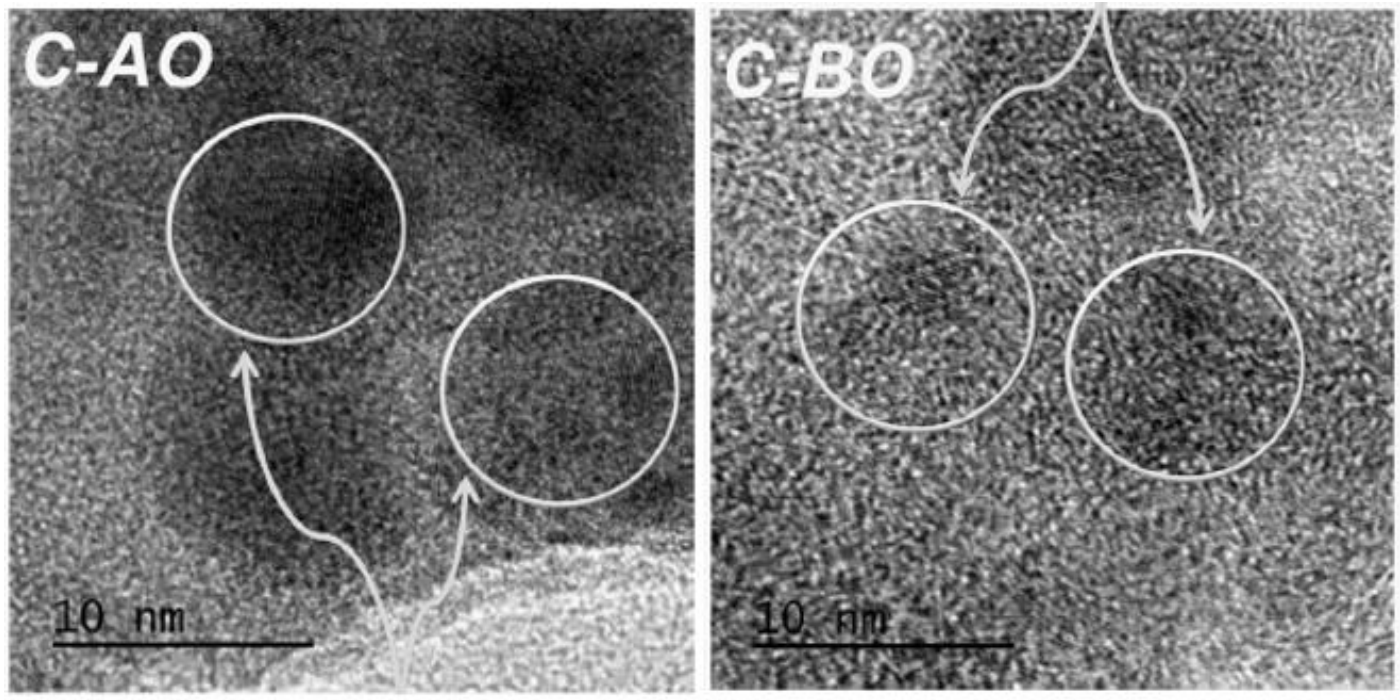

Figure 5.6. TEM images of C-AO and C-BO samples. Copyright 2017, with permission from Elsevier. $^{122}$

For the N-containing carbons, TEM images of the initial polymeric-resin derived carbons (before applying air-oxidation) were collected ( Figure 5.7). ${ }^{86}$ Interestingly, once again, RFM and especially PFU show some level of graphitization, which as above-mentioned should affect the electron transport properties of the carbon matrices. 

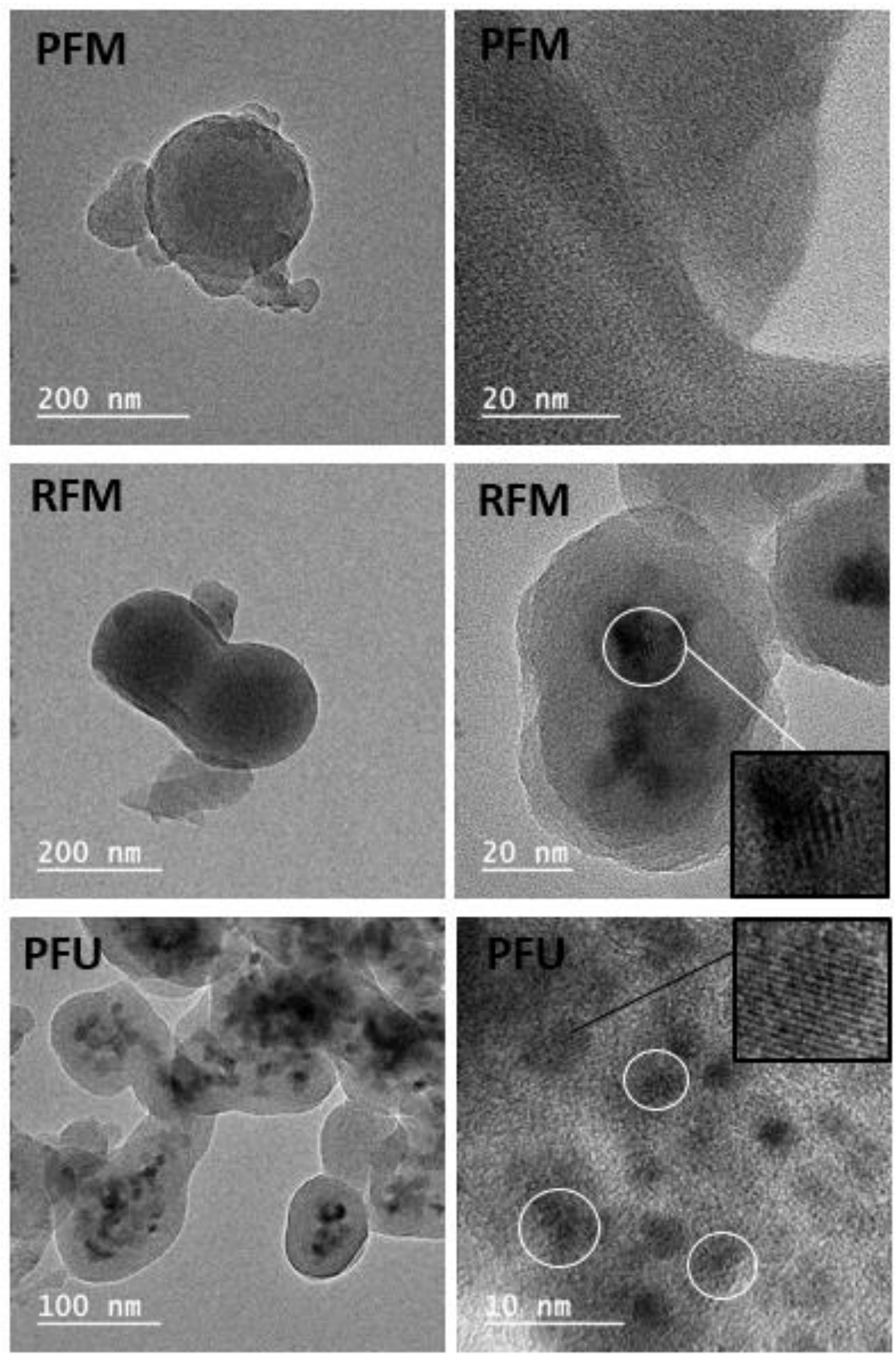

Figure 5.7. TEM images of the PFM, RFM and PFU samples. ${ }^{86}$ 


\subsection{Role of chemical heterogeneity in the carbons' electrical response}

\subsubsection{Role of sulfur as a carbon matrix heteroatom}

To comprehend the role of sulfur as a heteroatom in the carbon matrix and to examine the nature of specific functional groups on the carbons' surfaces, XPS analysis was carried out. This technique was applied to both the initial and exhausted carbons, after ammonia adsorption. The content of elements in atomic $\%$ and the results of the deconvolution of the $\mathrm{C} 1 s, \mathrm{O} 1 s$, and $\mathrm{S} 2 p$ core energy levels for C-1 and C-2 carbons are presented in Table 5.1 and Table 5.2, respectively. The deconvolution spectra are illustrated in Figures 5.8 and 5.9. Air oxidation led to a decrease in the total content of oxygen and sulfur (Table 5.1), which was the result of the decomposition of oxygen-containing sulfonic groups by heat treatment. ${ }^{84,97}$ After ammonia exposure, more nitrogen is detected on the surface of $\mathrm{C}-1$ than on $\mathrm{C}-2$, indicating the higher reactivity of the former carbon with the target gas. Interestingly, sulfur did not show marked differences before and after ammonia adsorption. This indicates that if it participates in chemical reactions with $\mathrm{NH}_{3}$, it must remain on the surface in the form of stable compounds. ${ }^{84}$

The deconvolution of the S $2 p$ core energy level spectra (Table 5.2 and Figure 5.8) indicates a higher content of sulfonic groups on $\mathrm{C}-1$ than on C-2. Air oxidation of C-1 sample led to a $~ 50 \%$ decrease in the amount of sulfoxides/sulfones, and an about $60 \%$ decrease in the amount of sulfonic acids (on C-2). Instead, carbonyl groups seem to predominate on the surface of C-2. These differences on the surface chemical features of the two carbons are important since they can partially explain the opposite trends in their electrical signals, during the initial sensor stabilization stage (Figures 5.1A and B). C-1 has a high content of highly acidic sulfonic/sulfuric acids and carboxylic acids which can interact with ammonia through acid-base reactions and form

ammonium ions $\left(\mathrm{NH}_{4}{ }^{+}\right)$. Such ions promote charge transport via ionic conductivity. ${ }^{84}$ Sulfuric acid 
can be formed by the oxidation of sulfonic groups by superoxide ions $\left(\mathrm{O}_{2}{ }^{-}\right)$, whose formation is enhanced on S-doped carbons owing to the band gap modification. ${ }^{84,12,124}$ For C-2 on the other hand, due to the predominance of carbonyl groups, the contribution of charge transport via ionic conductivity $\left(\mathrm{NH}_{4}{ }^{+}\right)$, as a result of the reactive ammonia adsorption, is minimal. This explains the resistance decrease of the chips upon ammonia exposure. Based on the deconvolution of the $\mathrm{N} 1_{\mathrm{s}}$ core energy level spectra (Figure 5.9), for the C-1E carbon, the majority of nitrogen in $\mathrm{C}-1 \mathrm{E}$ is in $\mathrm{NH}_{4}{ }^{+}$, amines, and hydrazine sulfates, while for $\mathrm{C}-2$, the majority of $\mathrm{N}$ is in hydrazine sulfates. This further verifies that chemisorption as an ammonia retention mechanism is more pronounced for $\mathrm{C}-1$ than for C-2. ${ }^{84}$ Finally, the deconvolution of the $\mathrm{S} 2 p$ core energy level spectra also indicates that for both carbons $\mathrm{NH}_{3}$ exposure led to a decrease in the contribution of sulfoxides and sulfones, with a simultaneous increase in the contribution of reduced sulfur species. Such a trend is related to the electron donating character of $\mathrm{NH}_{3}$. This reduction effect, however, seems to be more pronounced in the case of C-2 carbon.

Table 5.1. Content of elements on the surface (in at \%; from XPS analysis) for the initial and exhausted C-1 and C-2 carbons. ${ }^{84}$

\begin{tabular}{lcccc}
\hline Sample & C & O & N & S \\
\hline C-1 & 89.75 & 7.58 & & 2.67 \\
C-1-E & 88.08 & 8.02 & 0.93 & 2.97 \\
C-2 & 92.03 & 6.68 & & 1.37 \\
C-2-E & 90.36 & 8.08 & 0.15 & 1.40 \\
\hline
\end{tabular}

For the exhausted samples after ammonia adsorption, the suffix $-\mathrm{E}$ is added to their name. 
Table 5.2. The results of deconvolution of $\mathrm{C} 1 s, \mathrm{O} 1 s$ and $\mathrm{N} 1 s$ core energy levels for the initial and exhausted C-1 and C-2 carbons. ${ }^{84}$

\begin{tabular}{|c|c|c|c|c|c|}
\hline $\begin{array}{c}\text { Binding } \\
\text { energy, } \\
\text { eV }\end{array}$ & Bond assignment & $\mathrm{C}-1$ & C-1-ED & $\mathrm{C}-2$ & C-2-ED \\
\hline \multicolumn{6}{|l|}{$\mathrm{C} \mathrm{1s}$} \\
\hline 284.8 & $\begin{array}{l}\mathrm{C}-\mathrm{C}\left(\mathrm{sp}^{2} \text { carbon }\right) \text { or in nitro } \\
\text { compounds }\end{array}$ & 80.19 & 76.00 & 81.22 & 74.69 \\
\hline 286.2 & $\begin{array}{l}\mathrm{C}-\mathrm{O}, \mathrm{C}-\mathrm{H} \text { (phenolic, alcoholic, etheric) } \\
\text { or } \mathrm{C}-\mathrm{N}, \mathrm{C}-\mathrm{NH}_{2}\end{array}$ & 13.21 & 13.25 & 12.43 & 14.00 \\
\hline 287.3 & $\mathrm{C}=\mathrm{O}$ (carbonyl or quinone) or $\mathrm{C}=\mathrm{N}$ & 4.44 & 5.97 & 4.07 & 6.03 \\
\hline 289.0 & $\mathrm{O}-\mathrm{C}=\mathrm{O}$ (carboxyl or ester) & 2.15 & 3.26 & 2.28 & 3.63 \\
\hline 291.0 & $\pi-\pi^{*}$ & & 1.52 & & 1.64 \\
\hline \multicolumn{6}{|l|}{ O 1s } \\
\hline 531.7 & $\begin{array}{l}\mathrm{O}=\mathrm{C} / \mathrm{O}=\mathrm{S} \text { (in carboxyl/carbonyl or } \\
\text { sulfoxides/sulfones, sulfinyls) }\end{array}$ & 41.70 & 46.40 & 53.21 & 44.32 \\
\hline 533.3 & $\begin{array}{l}\text { O-C/ O-S (in phenol/epoxy or } \\
\text { thioeters/sulfonic) }\end{array}$ & 58.30 & 53.60 & 46.79 & 55.68 \\
\hline \multicolumn{6}{|l|}{$\mathbf{S} 2 p$} \\
\hline 164.1 & R-S-S-(bisulfides/thiols), -C-S-C- & 47.58 & 55.88 & 66.03 & 77.22 \\
\hline 165.9 & C-S-C/R-S - OR (sulfides/thioethers) & 13.98 & 11.09 & 15.75 & 9.53 \\
\hline 168.3 & $\mathrm{R}_{2}-\mathrm{S}=\mathrm{O} / \mathrm{R}-\mathrm{SO}_{2}-\mathrm{R}$ (sulfoxides/sulfones) & 20.97 & 12.30 & 11.31 & 4.77 \\
\hline 169.5 & $\mathrm{R}-\mathrm{SO}_{3}-\mathrm{H}$ (sulfonic acids) & 17.46 & 16.41 & 6.92 & 3.84 \\
\hline 170.6 & $\mathrm{SO}_{4}^{2-}$ & & 4.32 & & 4.64 \\
\hline \multicolumn{6}{|l|}{$\mathbf{N} 1 s$} \\
\hline 399.9 & NH amide & & 3.44 & & 20.72 \\
\hline 400.3 & $\mathrm{C}-\mathrm{NH}_{2}$ & & 38.10 & & 17.99 \\
\hline 401.4 & $\mathrm{~N}_{2} \mathrm{H}_{6} \mathrm{SO}_{4}$ hydrazine sulfate & & 33.18 & & 49.64 \\
\hline 402.5 & $\mathrm{NH}_{4}^{+}$ & & 25.28 & & 11.64 \\
\hline
\end{tabular}

For the exhausted samples after ammonia adsorption, the suffix $-\mathrm{E}$ is added to their name. 

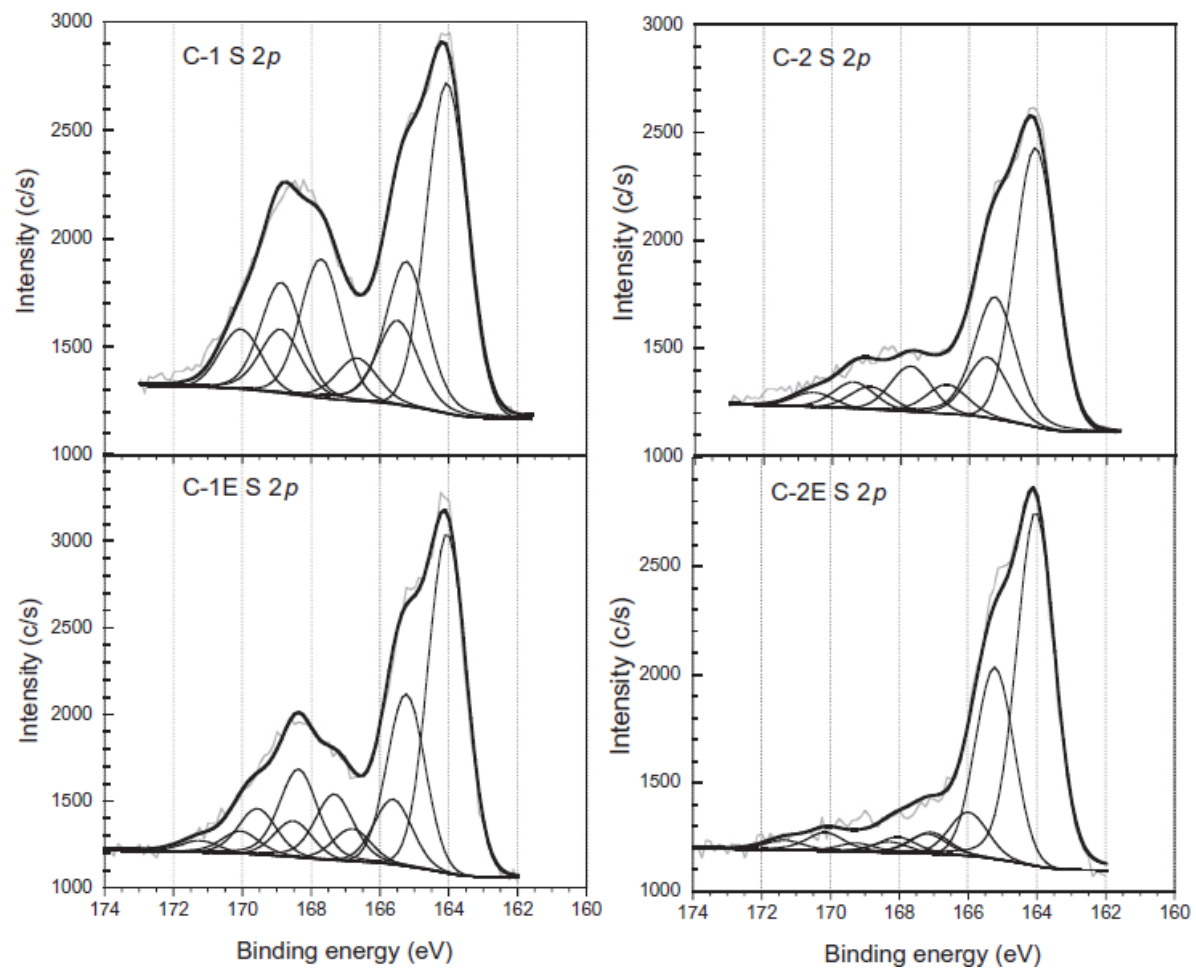

Figure 5.8. The deconvolution of $S 2 p$ core energy levels for the initial and exposed to ammonia C-1 and C-2 carbons. ${ }^{84}$
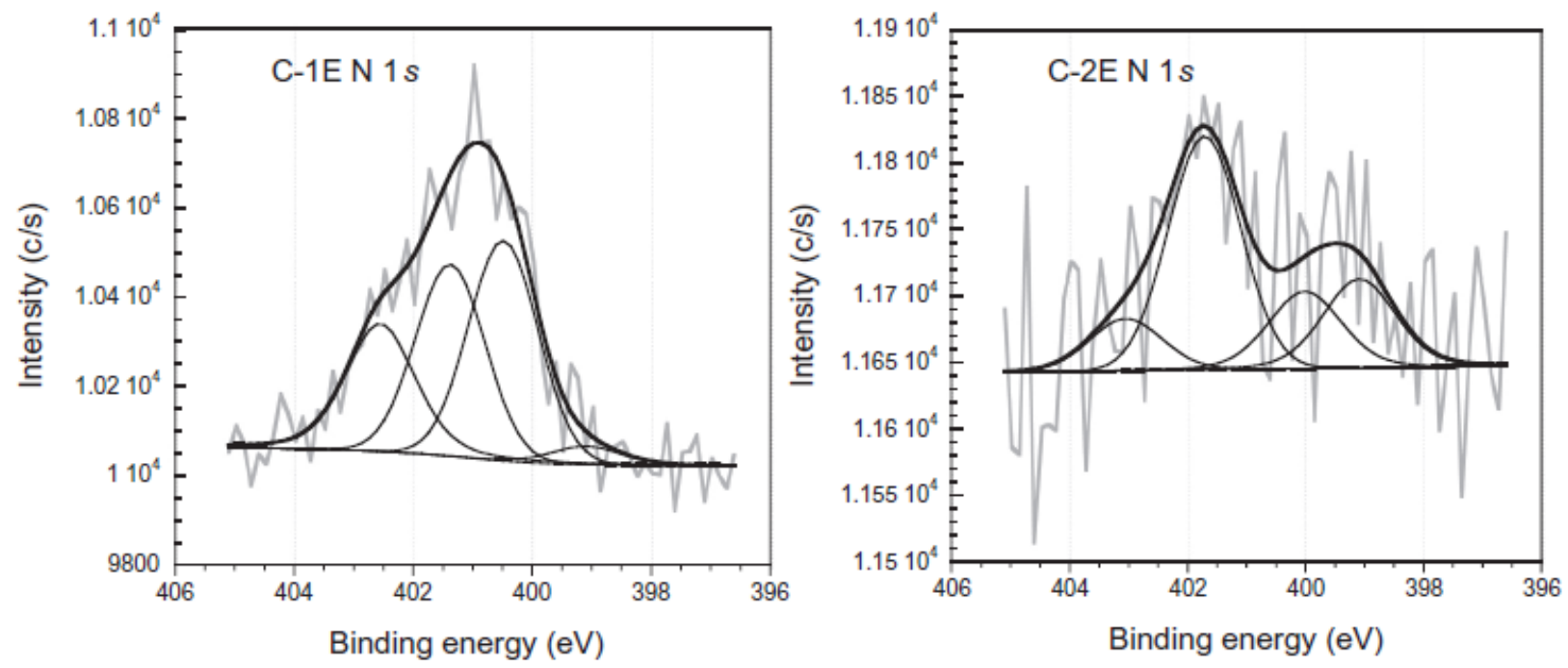

Figure 5.9. The deconvolution of $\mathrm{N} 1 \mathrm{~s}$ core energy levels for $\mathrm{C}-1$ and $\mathrm{C}-1$ carbons exposed to ammonia. $^{84}$ 
The formation of ammonium salts is further verified by the results obtained from Potentiomentric titration, which are illustrated in Figure 5.10. ${ }^{84}$ Considering that the peak at $\mathrm{pK}_{\mathrm{a}}$ 9-10 is assigned to $\mathrm{NH}_{4}+{ }^{97}$ its higher intensity for $\mathrm{C}-1 \mathrm{E}$ compared to that for $\mathrm{C}-2 \mathrm{E}$ suggests that the retention of ammonia on C-1 through the formation of ammonium salts is more pronounced than that on C-2. As aforementioned, such salts are formed in the chemical reaction of ammonia with surface acidic groups. Since the intensities of all peaks with $\mathrm{pK}_{\mathrm{a}} 4-7$ remain the same after the adsorption of $\mathrm{NH}_{3}$ (Figure 5.10), the formation of ammonium salts could be explained by the reaction of even more acidic groups, such as sulfonic, which cannot be detected by the potentiometric titration in the $\mathrm{pK}_{\mathrm{a}}$ range of $4-11$.

The combined results of the XPS analysis and those of the potentiometric titration suggest that ammonia adsorbs on C-1 mainly through its chemical reaction with the carbon's surface, while on C-2 it gets adsorbed mainly through weak physical interactions.
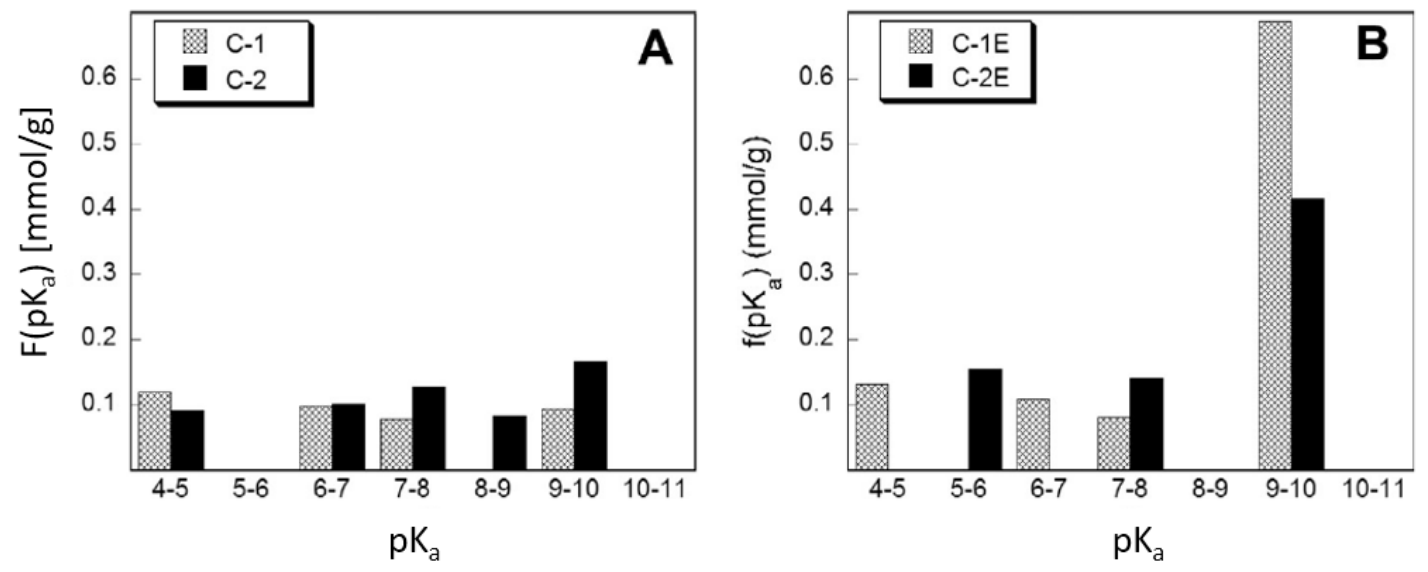

Figure 5.10. The distribution of the functional groups on C-1 and C-2, with $\mathrm{pK}_{\mathrm{a}}$ values between 4 and 11, determined from the potentiometric titration, before (A) and after (B) ammonia adsorption. For the exhausted samples after ammonia adsorption, the suffix $-\mathrm{E}$ is added to their names. ${ }^{84}$ 


\subsubsection{Role of nitrogen as a carbon matrix heteroatom}

To examine the role of nitrogen as a heteroatom and analyze its chemical state along with the chemical state of the other surface elements, XPS analysis was carried out. The samples tested for this purpose are the carbons derived by the carbonization and further air-oxidation of $\mathrm{N}$-containing polymeric resins. Table 5.3 presents the content of elements in atomic percentage (at \%), while the $\mathrm{C} 1 s, \mathrm{O} 1 s$, and $\mathrm{N} 1 s$ core energy level spectra are illustrated in Figure 5.10. ${ }^{86}$ More details are provided in Tables A5-A7 of Appendix. Table 5.3 shows an increase in the content of $-\mathrm{O}$ after $\mathrm{NH}_{3}$ adsorption, for all samples, suggesting that exposure to the target gas caused the oxidation of some surface functional groups. ${ }^{85}$ It is worth to notice that unlike PFM-AO-ED for which the $-\mathrm{N}$ content increased after $\mathrm{NH}_{3}$ exposure, RFM-AO-ED and PFU-AO-ED show a decrease in the content of this element.

Table 5.3. Content of elements on the surface (in at \%; from XPS analysis) for the initial and exhausted PFM-AO, RFM-AO, and PFU-AO. ${ }^{85}$

\begin{tabular}{l|lll}
\hline & \multicolumn{3}{|l}{ elemental content [at \%] } \\
\cline { 2 - 4 } Sample & $\mathrm{C}$ & $\mathrm{O}$ & $\mathrm{N}$ \\
\hline PFM-AO & 82.1 & 16.8 & 1.1 \\
PFM-AO-ED & 80.6 & 17.2 & 2.2 \\
RFM-AO & 80.7 & 15.8 & 3.5 \\
RFM-AO-ED & 82.0 & 15.3 & 2.7 \\
PFU-AO & 82.6 & 15.0 & 2.4 \\
PFU-AO-ED & 82.0 & 16.3 & 1.7 \\
\hline
\end{tabular}

For all initial air-oxidized samples (PFM-AO, RFM-AO and PFU-AO), the the $\mathrm{C} 1 s$ core energy level spectrum is deconvoluted into contributions at $284.8 \mathrm{eV}, 286.3 \mathrm{eV}, 287.6 \mathrm{eV}, 288.9 \mathrm{eV}$, and $290.5 \mathrm{eV}$ assigned to $\mathrm{sp}^{2} \mathrm{C}-\mathrm{C}, \mathrm{C}-\mathrm{O}$ (in phenols, epoxides), $\mathrm{C}=\mathrm{O}$ (in carbonyls), $\mathrm{O}-\mathrm{C}=\mathrm{O}$ (in 
carboxyls), and $\pi$-electrons in aromatic rings, respectively. Based on the deconvolution of the $\mathrm{O}$ $1 s$ core energy level spectra, all three samples exhibit contributions corresponding to oxygen in carbonyl/carboxyl groups (531-532 eV) and oxygen in phenols, epoxides, carboxyl groups or chemisorbed oxygen $(533.7 \mathrm{eV}) .{ }^{86}$ Among all three samples, however, PFU-AO exhibits the highest contribution of $\mathrm{C}=\mathrm{O}$ bonds in carboxylic groups. These groups, as mentioned above, can chemically react with ammonia leading to a decrease in the sensor resistance via ionic conduction.

The most interesting results are those of the analysis of the $\mathrm{N} 1 s$ core level spectra, which show componets at $398.5 \mathrm{eV}, 399.4-400.3 \mathrm{eV}$, and 400.7-401.3 eV. These binding energies correspond to pyridinic nitrpgen $(\mathrm{N}-1)$, nitrogen in amines/amides $(\mathrm{N}-2)$, and pyridine-N-oxides/quaternary $\mathrm{N}$ (N-3). In the case where melamine was used as the nitrogen source of carbons (PFM and RFM), $\mathrm{N}$ is retained in the carbon matrix in the form of amines/amides and quaternary $-\mathrm{N}$, after airoxidation. ${ }^{86}$ Due to the different phenolic sources used for the preparation of the polymeric resins (phenol for PFM, and resorcinol for RFM), and the thermal transformations during the heat treatment, N-2 nitorgen (amines/amides) predominates on the surface of PFM-AO, while N-3 nitrogen type (pyridine-N-oxides/quaternary $\mathrm{N}$ ) on that of RFM-AO. For PFU-AO, which performs best as a sensors, and where urea was the $-\mathrm{N}$ source, pyridine- $\mathrm{N}$-oxides/quaternary- $\mathrm{N}$ (N-3) and pyridinic nitrogen (N-1) (instead of amines/amides) are the predominant nitrogen species. $^{86}$

The results obtained by XPS analysis along with the sensing results of the carbons tested (Figure 5.10) suggest that urea as a nitrogen precursor leads to $-\mathrm{N}$ configurations that enhance the sensor response towards ammonia gas. Such configurations include $-\mathrm{N}$ incorporated in six-membered rings, in the form of pyridines, pyridine-N-oxides, and quaternary nitrogen. Amines and amides on the other hand, do not favor $\mathrm{NH}_{3}$ adsorption. This indicates that the adsorption capability of 
carbons strongly depends on the configuration of $-\mathrm{N}$ in their matrices. ${ }^{1}$ An enhanced ammonia adsorption on pyridines, quaternary nitrogen and pyridine-N-oxides, is in agreement with the results reported by Fujimoto and Saito, ${ }^{117}$ which showed that pyridine-type defects energetically favor ammonia adsorption. The importance of pyridines in ammonia sensing was also pointed out in Chapter 4, where the ammonia sensing capability of wood-based nanoporous carbons as $\mathrm{NH}_{3}$ sensors was tested. An enhanced ammonia adsorption on pyridines is related to an increase surface polarity induced by the these species. ${ }^{112,113}$ In the case of pyridine-N-oxides, ammonia adsorbs on the positively charged $\mathrm{N}$ of the $\mathrm{N}-\mathrm{O}$ moiety, due to its electron donating character. Positively charged quaternary nitrogen species located in central positions of the carbon lattice would show a similar effect. ${ }^{86,125}$ Ammonia on the other hand, shows the lowest affinity to adsorb on amines/amides, which predominate as $\mathrm{N}$-species on PFM-AO. This sample shows the smallest electrical sensitivity compared to the other two resin-derived carbons.

Overall, the results collected indicate that nitrogen located in the six-membered rings (pyridinic, quaternary, pyridine-N-oxides), rather than other peripheral $\mathrm{N}$-species (amines and amides), plays a more significant role in promoting the electron transport capability of $\mathrm{N}$-containing nanoporous upon $\mathrm{NH}_{3}$ exposure, and enhancing the ammonia adsorption affinity. ${ }^{86}$

For the exhausted RFM-AO and PFU-AO samples after ammonia exposure, based on the O1s core energy level spectra, chemisorbed oxygen species are detected,. As already mentioned in Chapter 4, such species can partially oxidize not only the carbon surface but also $\mathrm{NH}_{3}$ to $\mathrm{NO}_{2} .{ }^{85}$ The former oxidation is veryfied by the increased contribution of carbonyl and carboxyl groups on the surfaces of RFM-AO-ED and PFU-AO-ED. $\mathrm{NO}_{2}$ being a strong oxidant can also further oxidize the carbons' surfaces. ${ }^{107}$ Such a surface oxidation would lead to the removal of some functional groups, which explains the decreased content of $-\mathrm{N}$, and both $-\mathrm{N}$ and $-\mathrm{O}$ in the case of PFU-AO- 
ED and RFM-AO-ED, respectively. A considerable increase of the species with a binding energy of $286.3 \mathrm{eV}$ (C bonded to $\mathrm{O}, \mathrm{N}, \mathrm{H}$ ) in the case of the exhausted PFU-AO sample suggests that the chemical reaction of $\mathrm{NH}_{3}$ with epoxy groups is one potential pathway for the retention of the target gas on the carbon's surfaces. ${ }^{86}$ Such a reaction would form $-\mathrm{NH}_{2}$ and $-\mathrm{OH}$ groups due to the opening of the epoxide ring upon the reaction with ammonia, and is in agreement with the deconvolution of the $\mathrm{N} 1 s$ core energy level, which shows that the majority of $-\mathrm{N}$ on PFU-AO-ED exists in the form of amines/amides. An additional interesting finding is the detection of pyridines, also on the surface of the PFU-AO-ED sample, likely due to the reduction of pyridine-N-oxides during $\mathrm{NH}_{3}$ exposure. 

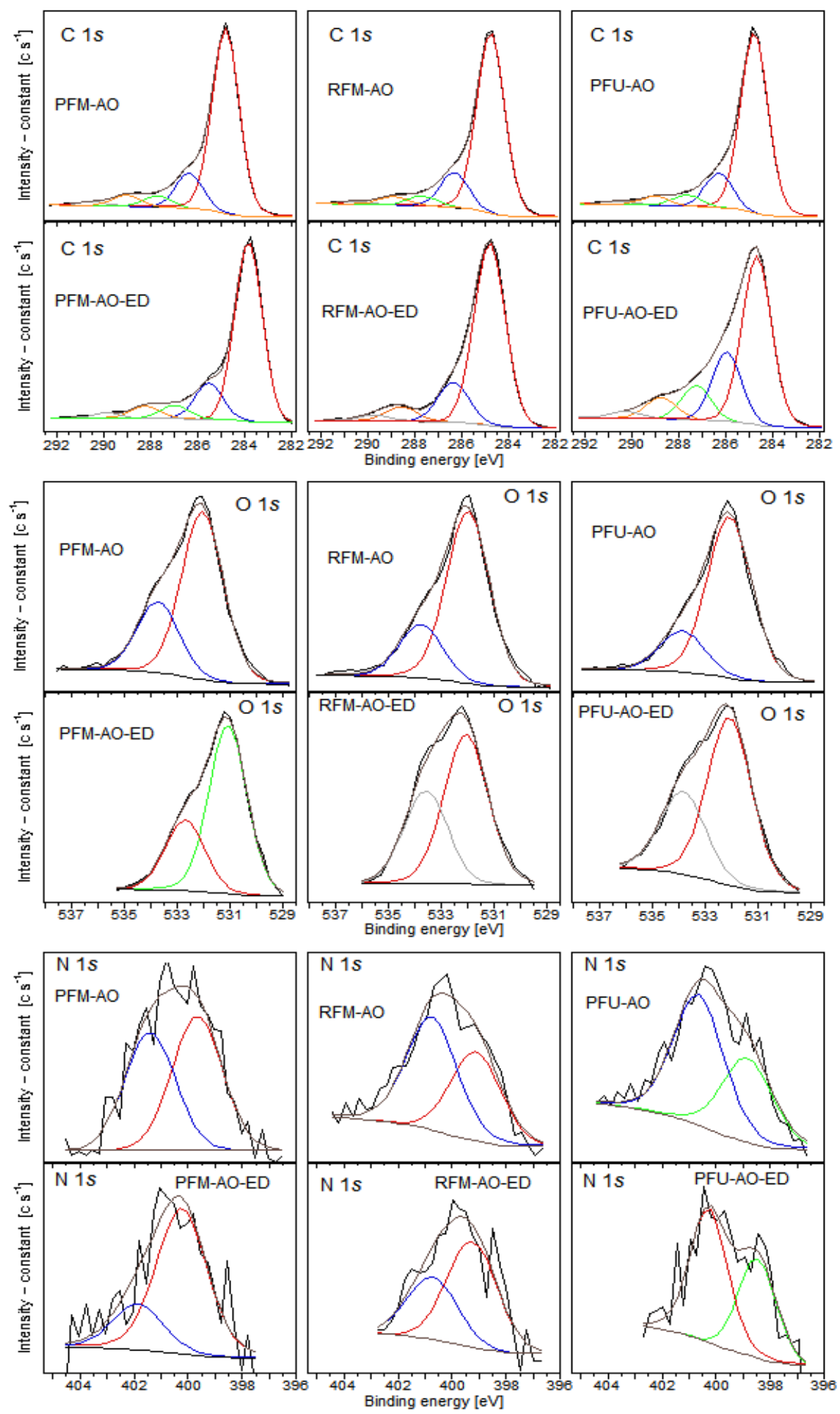

Figure 5.11. $\mathrm{C} 1 s, \mathrm{O} 1 s$, and $\mathrm{N} 1 s$ core energy level spectra for PFM-AO, RFM-AO, and PFU$\mathrm{AO}$, before and after ammonia exposure. ${ }^{85}$ 


\subsubsection{Role of sulfur and nitrogen as combined carbon matrix co-dopants}

The surface chemistry, and more precisely the role of $-\mathrm{S}$ and $-\mathrm{N}$ as co-dopants was analyzed using XPS. The samples tested for this purpose are the carbons derived by the carbonization and further air-oxidation of S- and N-containing polymer precursors (Poly (sodium 4-styrene sulfonate), Poly (4-ammonium styrene-sulfonic acid) and Poly (4-styrenesulfonic acid-co-maleic acid). The content of elements in atomic $\%$ and the results of the deconvolution of the $\mathrm{C} 1 s, \mathrm{O} 1 s, \mathrm{~N} 1 s$, and S $2 p$ core energy are summarized in Figure $5.11 .{ }^{85}$ Detailed results of the XPS analysis with an assignment of the specific functional groups are provided in Tables A8-A12 of Appendix. Once again, owing to the variety of $\mathrm{N}$-species existing at each one of the four distinguished energies in the $\mathrm{N}$ 1s core energy level spectra, the groups at $398.7 \mathrm{eV}, 400.1 \mathrm{eV}, 401.3 \mathrm{eV}$ and $402.5 \mathrm{eV}$ are referred to as $\mathrm{N} 1, \mathrm{~N} 2, \mathrm{~N} 3$ and $\mathrm{N} 4$, respectively. In N1 category we include pyridines, in N2pyrroles/pyridones, in N3-quaternary nitrogen and/or protonated amines and in N4-pyridine-Noxides and $\mathrm{C}-\mathrm{N}^{+} \mathrm{O}-\mathrm{C}, \mathrm{NO}_{2}$ species.

The results show that the S-containing groups detected on the surface of both air-oxidized carbons (C-AO and C-BO) include both oxidized S-species such as sulfoxides and sulfones, and reduced $\mathrm{S}$-species such as thiols. The $\mathrm{N}$-containing groups detected on the surface of both carbons, include positively charged pyridine-N-oxides and negatively charged pyridines. All these groups, by participating in weak interactions with ammonia (e.g. hydrogen bonding) contribute to the sensing response of the carbons. Other O-containing groups, which also participate in weak interactions with ammonia are phenols, alcohols and carboxylic groups. In the case of the latter groups, hydrogen bonding occurs both through the coordination of the $\mathrm{N}$-atom in $\mathrm{NH}_{3}$ to the hydrogen of the $-\mathrm{OH}$ group $\left(\mathrm{OH}^{\cdots \cdots} \mathrm{N}\right)$, and through the coordination of one of the three hydrogens of $\mathrm{NH}_{3}$ to the $-\mathrm{O}$ of the $-\mathrm{OH}$ groups $\left(\mathrm{NH}^{\cdots \cdots} \mathrm{O}\right)$. 
The analysis of the exhausted-S and $-\mathrm{N}$ dual-doped nanoporous carbons leads to interesting results. The new chemical groups formed in chemical reaction of $\mathrm{NH}_{3}$ with the carbons' surface (during the initial sensor stabilization) are in fact those that participate in the reversible sensing process. Thus, the chemistry of the exhausted samples is of great importance to comprehend the reversible sensing mechanism.

The deconvolution of the $\mathrm{O} 1$ s core energy level spectra shows that upon the exposure of the CAO and C-BO carbons to ammonia active oxygen species $\left(\mathrm{O}_{2}^{-}\right)$were formed. Such species are usually generated on the surface of heteroatom-containing carbons. ${ }^{124,126}$ As already mentioned in section 5.4.2, superoxide ions are able to partially oxidize $\mathrm{NH}_{3}$ to $\mathrm{NO}_{2}$, while the latter species can further oxidize the carbons' surface, and more precisely the reduced forms of $-\mathrm{S}$ and $-\mathrm{N}$ functional groups. ${ }^{107}$

Analysis of the results of the deconvolution of the S $2 p$ core energy level spectra shows that ammonia exposure causes a slight decrease in sulfonic acids on the surface of C-BO-ED. This effects is much more pronounced (100\% decrease) for C-AO-ED. This indicates that sulfonic acids show a great reactivity towards $\mathrm{NH}_{3}$ in the case of the C-AO sample and also play an important role on its sensing response. ${ }^{85}$ In the case of $\mathrm{C}-\mathrm{BO}$, on the other hand, carboxylic groups are more crucial in the reactivity of this sample with ammonia. Their contribution decreased by $38 \%$ after the exposure of the sample to the target gas. The number of carboxylic groups increased about $14 \%$ in $\mathrm{C}-\mathrm{AO}-\mathrm{ED}$ as a result of ammonia exposure and its oxidation to $\mathrm{NO}_{2}$, which can oxidize the carbon surface. ${ }^{85}$

Another interesting finding, based on the deconvolution of the $\mathrm{S} 2 \mathrm{p}$ core energy level spectra, is a decrease in the contribution of reduced S-species in the case of the exhausted C-B, C-AO and CBO samples. This decrease is accompanied by an increase in the contribution of oxidized $-\mathrm{S}$ 
species, and more precisely sulfones and sulfoxides, most likely as a result of the oxidation caused by both superoxide ions and $-\mathrm{NO}_{2}$. The activity of the latter species towards $\mathrm{N}$-containing functional groups is illustrated by an increase in the contribution of pyridine-N-oxides, especially for $\mathrm{CA}-\mathrm{O}$ and $\mathrm{C}-\mathrm{BO}$.

In summary, the XPS results show an enhanced generation of active oxygen species $\left(\mathrm{O}_{2}{ }^{-}\right)$in the case of the dual-doped nanoporous carbons compared to the carbons that are doped with solely $\mathrm{N}$ or $-\mathrm{S}$. A surface oxidation caused by such species leads to the formation of surface functional groups that can participate in weak interactions with the molecules of the target gas, and thus promote the charge transport across the carbon matrices. Moreover, oxidation of some $\mathrm{NH}_{3}$ molecules to $\mathrm{NO}_{2}$ is also expected to play an important role in the sensor response, due to the ability of the latter species to withdraw electrons. ${ }^{85}$ 

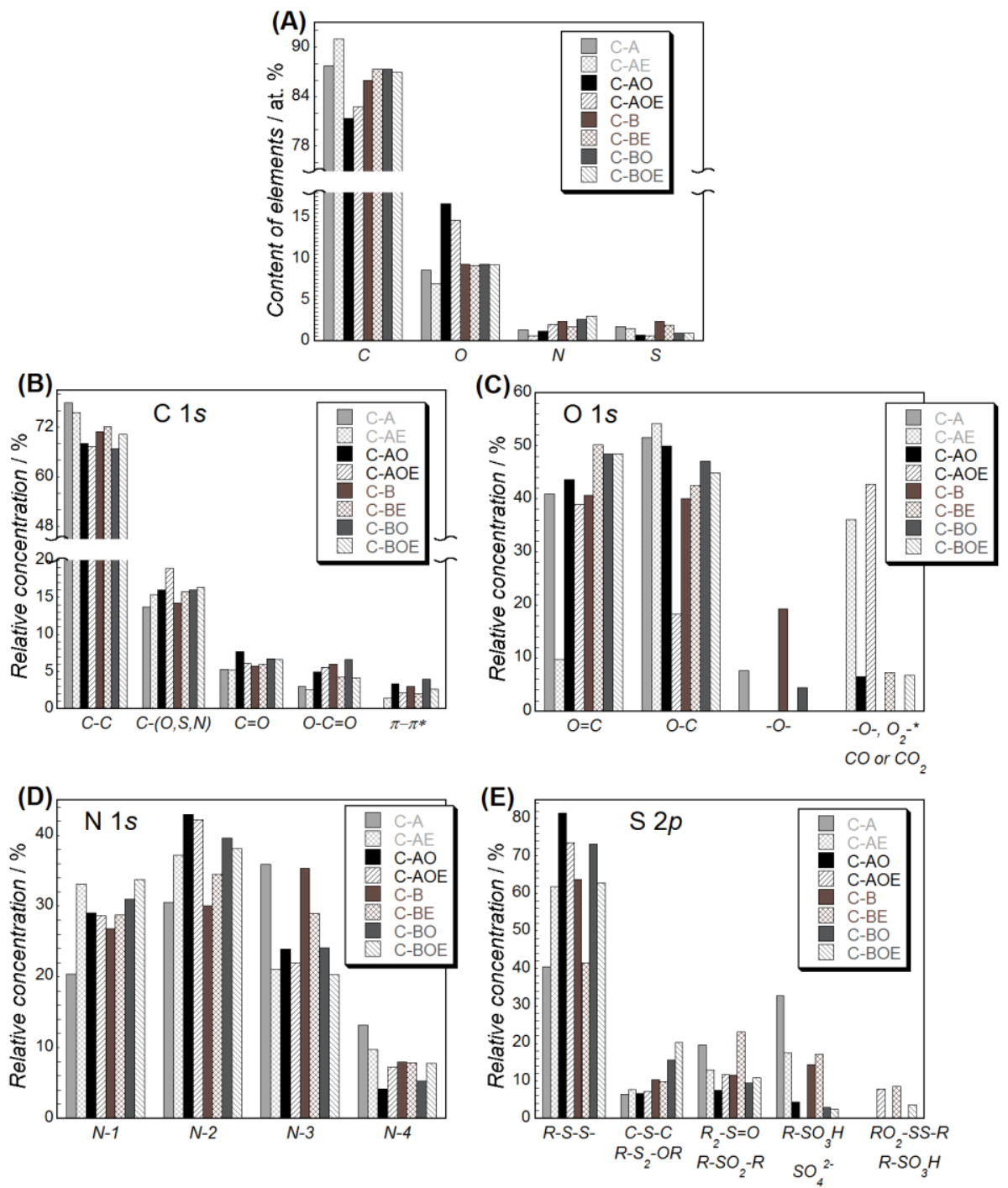

Figure 5.11. (A) Content of elements; (B-E) Surface concentration of the specific carbon, oxygen, nitrogen and sulfur groups on $\mathrm{C}-\mathrm{A}, \mathrm{C}-\mathrm{B}, \mathrm{C}-\mathrm{AO}$, and $\mathrm{C}-\mathrm{BO}$ before and after ammonia exposure. For the exhausted samples after ammonia adsorption, the suffix $-\mathrm{E}$ is added to their name. ${ }^{85}$ 


\subsection{Dependence of sensitivity on surface heterogeneity and porosity of nanoporous carbons}

Aiming to comprehend whether the chemical heterogeneity of nanoporous carbons or their porosity plays a more important role in their performance as sensitive gas sensors, the parameters of the porous structure of the carbons containing solely $-\mathrm{S}$ and those containing both $-\mathrm{S}$ and $-\mathrm{N}$ were analyzed (Table 5.4), and compared with the sensitivity of the same carbon chips (Figures 5.2 and 5.4).

Table 5.4 shows C-A as non-porous carbon with a very low surface area $\left(38 \mathrm{~m}^{2} / \mathrm{g}\right) .{ }^{85}$ When the sensing response of this sample was tested, no measurable signal changes were observed, even though the surface of this sample, based on XPS results, is rich in the functional groups that can interact with $\mathrm{NH}_{3}$ molecules and promote the charge transport. This observation clearly indicates that the porosity as a feature is a necessity for a carbon to operate as an ammonia sensor.

Comparison of the parameters of the pore structure of $\mathrm{C}-1$ and $\mathrm{C}-2$ shows that $\mathrm{C}-2$ that exhibits the highest volume of micropores and ultramicropores, also exhibits the highest sensitivity (Figure 5.2). Due to its small surface area, C-1 carbon exhibits a high density of bulky sulfonic groups, which "block" the entrance of ammonia molecules to the small pores. Thus, physical adsorption of ammonia that enhances the electron transport is limited. The C-2, on the other hand, having a more open pore structure (Figure 5.5), allows the access of $\mathrm{NH}_{3}$ molecules to its small pores, and thus promotes the electron transport across the pore network. As mentioned in Chapter 4, pores

with $\mathrm{V}_{<1 \mathrm{~nm}}$ play the most important role in the $\mathrm{NH}_{3}$ adsorption at ambient condistions, ${ }^{97}$ and therefore favor the electrical performance of the carbons. Furthermore, a smaller amount of bulky sulfonic groups on $\mathrm{C}-2$ compared to $\mathrm{C}-1$, allows the adsorbate molecules to reach the thermodynamically favorable positions in the pore system. All of these factors that are related to 
the porosity of the two samples and the existence/distribution of specific functional groups lead to a higher sensor response of the C-2 carbon.

Even though for C-1 and C-2 carbons there is a direct relationship between sensitivity of the chips and the volume of micro/ultramicropores, which govern $\mathrm{NH}_{3}$ retention, this is not the case for CAO with C-BO carbons. The results collected in Table 5.4 and Figure 5.4 indicate that the relationship between the sensor sensitivity and pore volume is indirect. C-AO carbon, for example, may show a higher sensitivity than C-BO, however, it has a smaller volume of micro/ultramicropores, which are the most crucial for ammonia sensing. ${ }^{91}$ The opposite is the trend for C-BO. Such results indicate that the surface chemical features of the dual-doped nanoporous carbons rather than their pore structure predominantly govern their electrical performance..$^{91}$ 
Table 5.4. Parameters of the porous structure for the initial and exhausted C-1, C-2, C-A, C-B, C-AO, and C-BO carbons, calculated from the nitrogen adsorption isotherms. ${ }^{85}$

\begin{tabular}{lcccccc}
\hline Sample & $\begin{array}{c}\mathrm{S}_{\text {BET }} \\
{\left[\mathrm{m}^{2} / \mathrm{g}\right]}\end{array}$ & $\begin{array}{c}\mathrm{V}_{\mathrm{t}} \\
{\left[\mathrm{cm}^{3} / \mathrm{g}\right]}\end{array}$ & $\begin{array}{c}\mathrm{V}_{\text {meso }} \\
{\left[\mathrm{cm}^{3} / \mathrm{g}\right]}\end{array}$ & $\begin{array}{c}\mathrm{V}_{\text {mic }} \\
{\left[\mathrm{cm}^{3} / \mathrm{g}\right]}\end{array}$ & $\begin{array}{c}\mathrm{V}_{<0.7 \mathrm{~nm}} \\
{\left[\mathrm{~cm}^{3} / \mathrm{g}\right]}\end{array}$ & $\begin{array}{c}\mathrm{V}_{<1 \mathrm{~nm}} \\
{\left[\mathrm{~cm}^{3} / \mathrm{g}\right]}\end{array}$ \\
\hline C-1 & 330 & 0.294 & 0.187 & 0.107 & 0.058 & 0.067 \\
C-1-ED & 263 & 0.277 & 0.192 & 0.085 & 0.037 & 0.049 \\
C-2 & 756 & 0.533 & 0.258 & 0.275 & 0.192 & 0.228 \\
C-2-ED & 749 & 0.520 & 0.246 & 0.274 & 0.192 & 0.229 \\
${ }^{\mathrm{a} C-A}$ & 38 & 0.022 & --- & --- & --- & --- \\
${ }^{\mathrm{a} C-A-E D}$ & 19 & 0.002 & --- & --- & --- & --- \\
${ }^{\mathrm{b}}$ C-B & 290 & 0.157 & 0.023 & 0.134 & 0.072 & 0.104 \\
C-B-ED & 174 & 0.109 & 0.031 & 0.078 & 0.035 & 0.053 \\
${ }^{\mathrm{b} C-A O}$ & 727 & 0.363 & 0.024 & 0.339 & 0.215 & 0.281 \\
C-AO-ED & 554 & 0.301 & 0.054 & 0.247 & 0.182 & 0.203 \\
${ }^{\mathrm{b}}$ C-BO & 847 & 0.458 & 0.060 & 0.398 & 0.266 & 0.339 \\
C-BO-ED & 823 & 0.453 & 0.075 & 0.378 & 0.273 & 0.320 \\
\hline
\end{tabular}

For the exhausted samples after ammonia adsorption, the suffix -ED is added to their name.

${ }^{\mathrm{a}, \mathrm{b}}$ Copyright 2017, with permission from Elsevier. ${ }^{122}$

Figure 5.12 presents a bar graph that compares the surface areas and changes in the normalized resistance of the S-containing carbon $\mathrm{C}-2$ with those of the S,N-dual-doped carbons $(\mathrm{C}-\mathrm{AO}$ and C-BO), when exposed to $500 \mathrm{ppm}$ of ammonia. Interestingly, even though all three samples exhibit similar surface areas, the dual-doped carbons and especially $\mathrm{C}-\mathrm{AO}$, exhibit much higher changes of their electrical signal compared to those for $\mathrm{C}-2$. These results indicate the key role of surface chemical heterogeneity on the response of nanoporous carbons. ${ }^{85,91}$ 


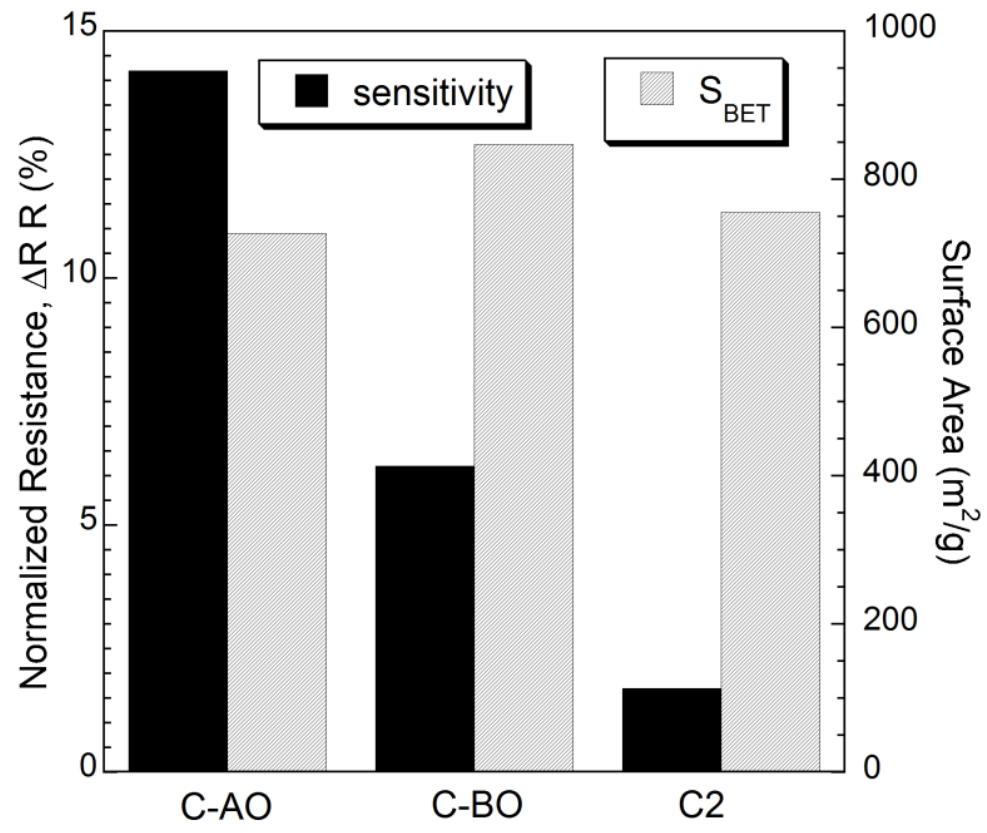

Figure 5.12. Comparative graph of the chip normalized resistance changes (\%) (at $500 \mathrm{ppm}$ of ammonia) and surface area of the nanoporous carbons addressed in this work and a previously studied S-doped nanoporous carbon. ${ }^{84,85}$

\subsection{Relationship between the sensitivity and the number of acidic groups}

The surface $\mathrm{pH}$ values and the amounts of strong acidic $\left(\mathrm{pK}_{\mathrm{a}}<7\right)$, weakly acidic $\left(\mathrm{pK}_{\mathrm{a}}>7\right)$ and total number of acidic groups for the air-oxidized polymeric resin-derived carbons (PFM-AO, RFM-AO, PFU-AO) are presented in Table 5.5. ${ }^{86}$ Even though no direct relationship between the sensitivity of the carbon chips (Figure 5.3) and the parameters of their pore structure (Table 5.4) was found, there is an indication that the sensitivity depends on the surface chemistry. More precisely, the results indicate that the sensing capability of the carbons is influenced by both the amount and the type of the surface functional groups. ${ }^{86}$ Figure 5.13 shows a linear correlation between the normalized resistance changes (sensitivity of the chips) and the total number of functional groups $\left(\mathrm{pK}_{\mathrm{a}}\right.$ 4-11). The correlation coefficients increases when the performance is linked to the amount of the weakly acidic groups $\left(\mathrm{pK}_{\mathrm{a}}<7\right){ }^{86}$ 
Table 5.5. The surface $\mathrm{pH}$ values and the amounts of strong acidic $\left(\mathrm{pK}_{\mathrm{a}}<7\right)$, weakly acidic $\left(\mathrm{pK}_{\mathrm{a}}\right.$ > 7) and total number of acidic groups, on PFM-AO, RFM-AO, and PFU-AO. ${ }^{86}$

\begin{tabular}{lllll}
\hline Sample & $\mathrm{pH}$ & $\begin{array}{l}\mathrm{pK}_{\mathrm{a}}<7 \\
{[\mathrm{mmol} / \mathrm{g}]}\end{array}$ & $\begin{array}{l}\mathrm{pK}_{\mathrm{a}}>7 \\
{[\mathrm{mmol} / \mathrm{g}]}\end{array}$ & Total \\
\hline PFM-AO & 3.6 & 0.413 & 0.510 & 0.923 \\
RFM-AO & 3.7 & 0.504 & 0.703 & 1.207 \\
PFU-AO & 3.7 & 0.495 & 0.744 & 1.239 \\
\hline
\end{tabular}

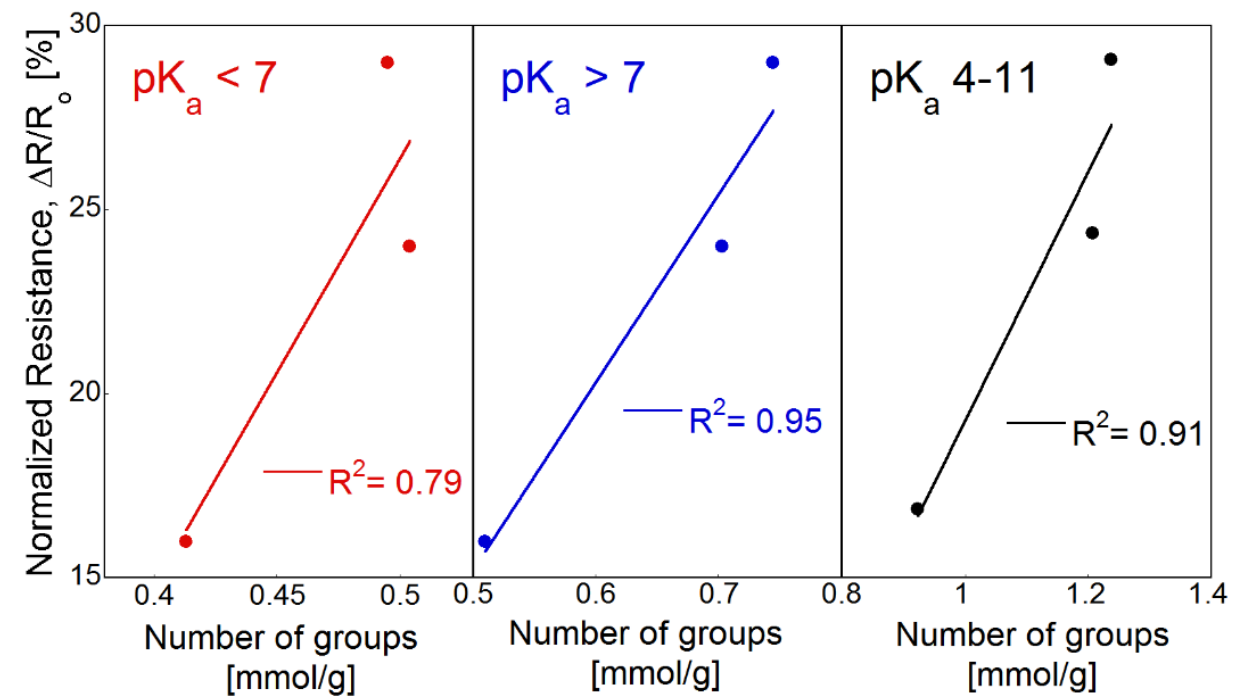

Figure 5.13. Dependence of $\Delta \mathrm{R} / \mathrm{R}_{\mathrm{o}}(\%)$ of the air-oxidized samples (PFM-AO, RFM-AO, and PFU-AO) on the number of strongly acidic groups $\left(\mathrm{pK}_{\mathrm{a}}<7\right)$, weakly acidic groups $\left(\mathrm{pK}_{\mathrm{a}}>7\right)$, and total number of functional groups. ${ }^{86}$ 


\subsection{Summary of the sensing mechanism}

\subsubsection{Pore filling and specific interactions}

The results analyzed indicate that physisorption is the main interaction type that is responsible for the reversibility of the sensor response. In physisorption, weak interactions of polar $\mathrm{NH}_{3}$ molecules with the charged functional groups located within the pores are of paramount importance. As mentioned in Chapter 4, the specific forces that govern the reversible sensing capability of the carbons involve weak interactions such as hydrogen bonding, and dipole-dipole interactions. ${ }^{82,84}$ Such interactions would lead to a decrease in the normalized resistance (or increase in the conductivity) as seen in Figures 5.2, 5.3 and 5.4, by providing alternate paths for current conduction across the micropores through charge hopping. ${ }^{120}$ This is supported by the fact that the volume of micropores, the pores that are the most active in the ammonia adsorption via the involvement of dispersive forces,

Even though, in general, the more porous, and especially microporous, carbon is the higher is its sensitivity (the case for C-1 and C-2 carbons), this may not always be the case (the case for C-AO and $\mathrm{C}-\mathrm{BO}$ ). Furthermore, we have not found a direct relationship between the magnitude of the signal and the surface parameters. This finding indicate that there are other factors affecting the electrical response of nanoporous carbons such as the specific configuration of the heteroatoms, their location in the carbon matrix, specific chemical entities in which they are engaged, and the size of the graphene layers that construct the porosity. A visualization of the working principles of nanoporous-carbon based sensors is provided in Figure 5.14. ${ }^{84}$ 


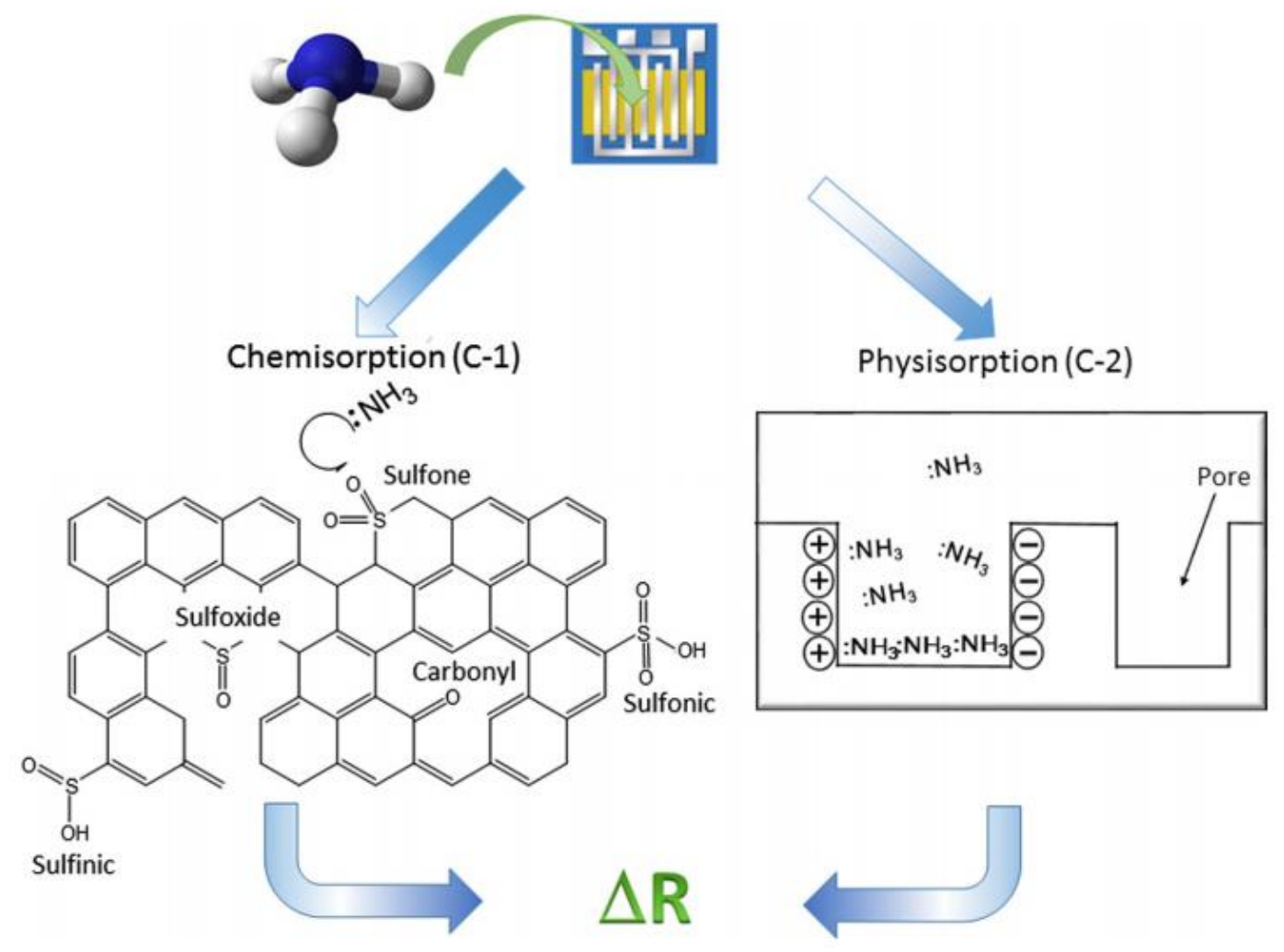

Figure 5.14. Visualization of the working principles of the nanoporous-carbon based sensor (only sulfur-containing groups active in adsorption of $\mathrm{NH}_{3}$ are present on the surface of the $\mathrm{C}-1$ carbon). ${ }^{84}$

\subsubsection{Hole depletion/accumulation in the matrix upon the contact with $\mathrm{NH}_{3}$ and/or $\mathrm{NO}_{2}$}

Another mechanism that is involved in the electrical response of the carbons is the depletion or accumulation of the positively charged carriers (holes) upon their exposure to the electron donating $\mathrm{NH}_{3}$ or electron withdrawing $\mathrm{NO}_{2}$, respectively. The $p$-type conduction of the carbons tested is illustrated in Figure A4 of the Appendix. ${ }^{85}$ For the carbons discussed in this chapter, the reversible sensing of all samples caused a decrease in the normalized resistance upon ammonia exposure (Figures 5.2, 5.3, and 5.4 ). Since this is not the trend observed in the case of typical $p$-type materials, pore filling and specific interactions discussed in section 5.7.1, rather than electron/hole conductivity, predominantly govern the electrical performance of our p-type carbons. 
Interestingly, in the case of $\mathrm{C}-\mathrm{AO}$ and $\mathrm{C}-\mathrm{BO}$, an additional unexpected phenomenon/process, which is related to electron/hole conductivity, is responsible for the decrease in the normalized resistance upon exposure to ammonia. ${ }^{85}$ The XPS analysis of these two samples suggested the partial oxidation of $\mathrm{NH}_{3}$ to $\mathrm{NO}_{2}$ by the superoxide ions $\left(\mathrm{O}_{2}{ }^{-}\right)$. Considering that $\mathrm{NO}_{2}$ has electron withdrawing properties, a conductivity increase observed for C-AO and C-BO upon $\mathrm{NH}_{3}$ exposure is related to an increased in the concentration of positively charged holes in the carbon matrix.

\subsubsection{Ionic conductivity}

A decrease in the normalized resistance can be also related to charge transfer through ionic conductivity. ${ }^{85}$ This mechanism is based on the formation of $\mathrm{NH}_{4}{ }^{+}$as a result of the acid-base reaction of ammonia with acidic groups (carboxylic/sulfonic acids) during the initial sensor stabilization stage. ${ }^{85}$ However, since the sensing tests addressed in this chapter have been conducted in dry conditions, such a mechanism should be limited.

\subsubsection{The effect of the Degree of graphitization/conductivity}

An additional parameter affecting the electronic properties of the carbons and thus their electrical response is the degree of the carbon graphitization. HRTEM images indicated a higher degree of graphitization in C-AO compared to that in C-BO (Figure 5.6). Similar results were also revealed by an earlier study where Raman spectroscopy indicated a narrower G-band for C-AO compared to that of $\mathrm{C}-\mathrm{BO} .{ }^{4} \mathrm{~A}$ high degree of the carbon graphitization enhances electron transport through the carbon matrix, leading to larger signal change for $\mathrm{C}-\mathrm{AO}$ compared to that for $\mathrm{C}-\mathrm{BO} .{ }^{85}$ 


\section{Chapter 6. Wood-based/polymer-derived nanoporous carbon composites}

This chapter describes the ammonia sensing capability of wood-based/polymer-derived nanoporous carbon composites. Two polymer precursors and a wood-based commercial activated carbon (BAX-1500) were used for the composite preparation. Composites having a polymerderived carbon content of 1, 5, 10 and $20 \%$ of the final material mass are referred to as: BAX-CS$\mathrm{X} \%$ and BAX-CSN-X\% (X: 1, 5, 10 and $25 \%$ of the polymer-derived carbon phase). CS and CSN refer to the carbons derived from the carbonization and subsequent air oxidation of (Poly (sodium 4-styrene sulfonate) and Poly (4-ammonium styrene-sulfonic acid), respectively. Details on the preparation of the carbon-composites are provided in Chapter 3. However, for the clarity of the discussion, a brief description of the treatments applied is illustrated below: ${ }^{127}$

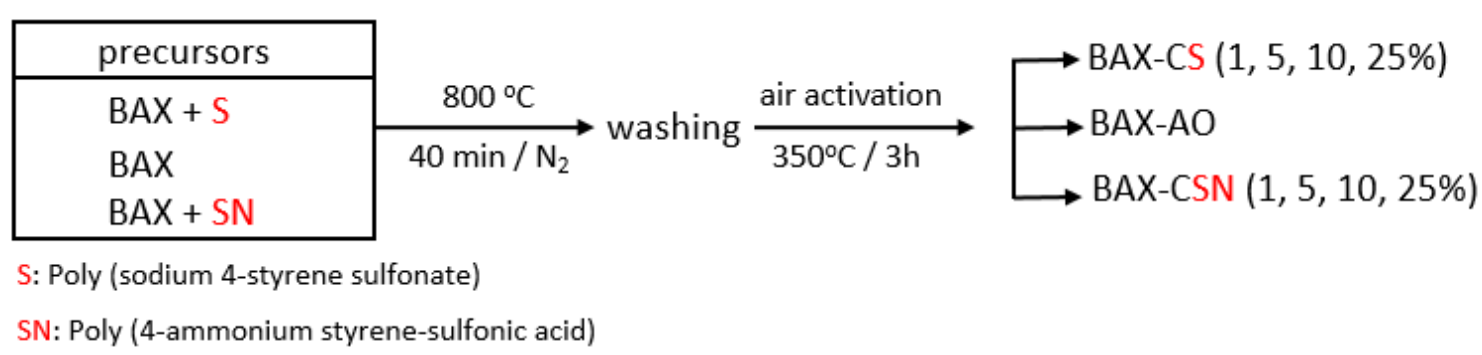

The chapter focuses on the role of the synergy between the components of the composites on their electrical response as gas sensors. It also examines whether the nature of the weak interactions between the various surface functional groups and ammonia or the electronic nature of the carbon matrix itself plays a more important role on the sensors' performance. Finally, it proposes a priority order of the various surface functional groups on the ammonia sensing capability of nanoporous carbons. 
Chapter 6 is a slightly revised version of the following article, with permission from Elsevier, Copyright 2017, reported in Reference 127:

Travlou, N. A.; Bandosz, T. J. Nanoporous Carbon-Composites as Gas Sensors: Importance of the Specific Adsorption Forces for Ammonia Sensing Mechanism. Carbon, 2017, 121, 114-126.

\subsection{Testing the reversible sensing capability of the sensors}

The reversible and repeatable sensing operation of the carbon composites was evaluated by exposing them to ammonia concentrations varying from $45-500 \mathrm{ppm}^{127}$ The electrical responses are illustrated in Figures 6.1A and 6.1B. Figure 6.1C indicates a linear dependence of the sensitivity of the two best performing composites (BAX-CS-1\% and BAX-CSN-1\%) on the ammonia concentration. Figure A5 of Appendix illustrates the electrical response of the three best performing samples (BAX-AO, BAX-CS-1\% and BAX-CSN-1\%), upon their initial stabilization to an $\mathrm{NH}_{3} /$ air cycle. ${ }^{127}$

The response time of both carbon series' chips upon their exposure to $500 \mathrm{ppm}$ of ammonia was only $40 \mathrm{sec}$. A relatively long recovery time (17 min.) was recorded, which in the case of nanoporous carbons should be related to their developed micro/ultramicroporous structure. ${ }^{127}$ Even though the latter feature (developed micro/ultramicropores) is responsible for the good sensitivity of the sensor, it is also responsible for the slow desorption of ammonia, and thus a slower recovery time, during the air purging stage. A shorter recovery time could had been achieved by purging the chamber with a higher air flow or by exposing the chips to the target gas for a shorter period of time. This however, would have a negative effect on a highly sensitive, repeatable, and stable sensor operation. This is mainly because a shorter recovery time would lead 
to small signal changes. Moreover, purging the chamber with a higher air flow would likely cause instabilities to the flow rate and thus to the stable sensor operation.

The response time of the carbon series at each gas concentration was also analyzed, and the results are illustrated in Figure 6.2A. Based on Figure 6.2A, with a decreasing concentration of ammonia, the response time of the sensors increases. ${ }^{127}$ This results from to the slower adsorption kinetics. The comparison of the response time of the two samples series (BAX-CS and BAX-CSN) (Figure 2B) indicates small but not significant differences. They are related to differences in the surface chemical and structural features of the two composite series, which differently affect their interactions with $\mathrm{NH}_{3}$. A stability test for the best performing carbon-composite (BAX-CS-1\%) was also conducted, by exposing the composite to repeatable $\mathrm{NH}_{3}(500 \mathrm{ppm}) /$ air cycles. The results are presented in Figure A6 the Appendix. 

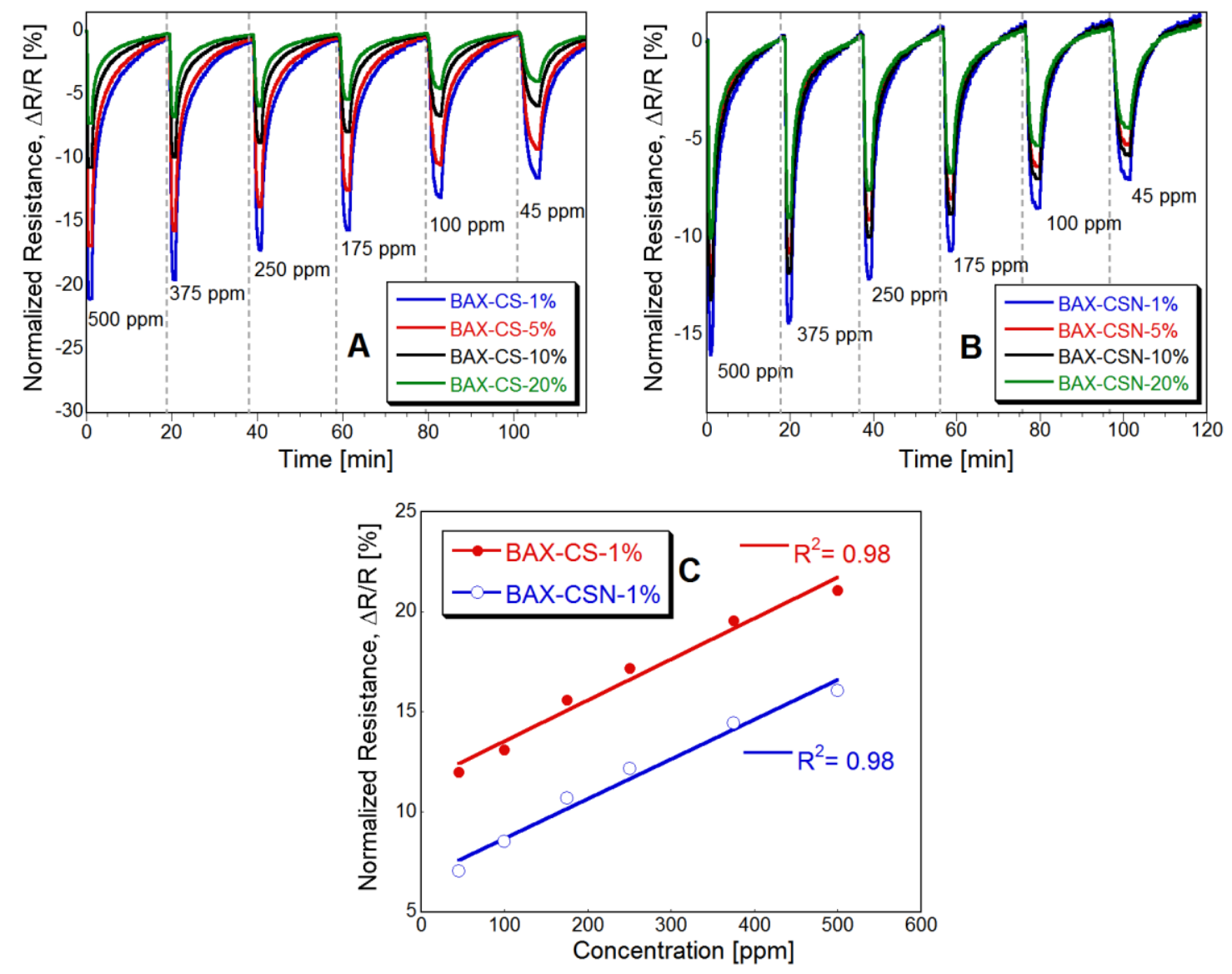

Figure 6.1. (A, B): Response curves for the BAX-CS and BAX-CSN composite series. (C): Dependence of $\Delta \mathrm{R} / \mathrm{R}_{\mathrm{o}}(\%)$ of the two best performing materials from each composite series, on various $\mathrm{NH}_{3}$ concentrations. ${ }^{127}$ 

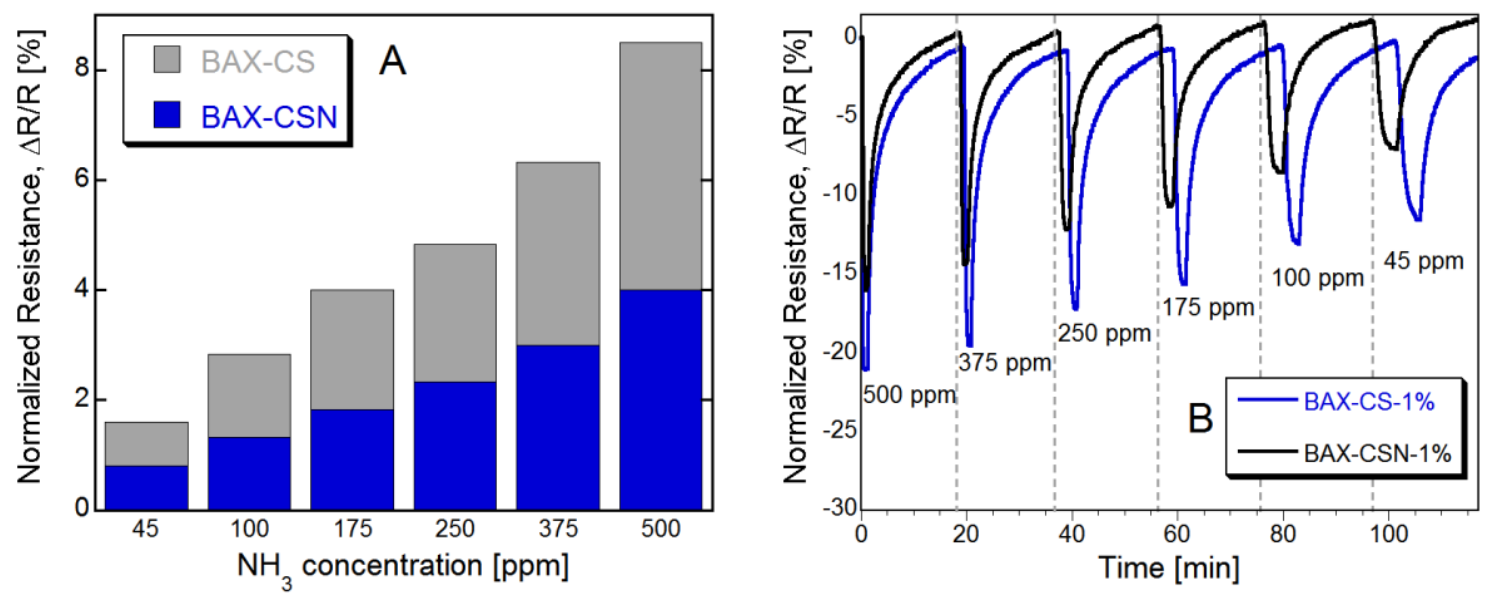

Figure 6.2. (A): Comparison of the response time required time for the electrical signal to reach the plateau of the two composite series upon the exposure to various ammonia concentrations, (B): Response curves for the BAX-CS-1\% and BAX-CSN-1\% composite series. ${ }^{127}$

\subsection{Effect of the polymer-derived carbon phase on the sensor sensitivity}

Figure 6.3 presents the absolute values of the normalized resistance changes (sensitivity) upon exposure of all samples to $500 \mathrm{ppm}$ of $\mathrm{NH}_{3} .{ }^{1} \mathrm{BAX}-\mathrm{AO}$ itself exhibits an $18 \%$ change in the normalized resistance upon exposure to $500 \mathrm{ppm}$. Interestingly, the introduction of only $1 \%$ of the S-containing polymer-derived carbon led to a $20 \%$ improvement in the chip sensitivity. The introduction of $1 \%$ of the S,N-containing polymer-derived carbon on the other hand, caused a 10 $\%$ sensitivity decrease. The decrease in the sensitivity was even more pronounced upon the addition of higher percentages of the polymer-based carbons.

The comparison of the sensitivity between the two series (Figure 6.3) shows that the composites consisting of $5 \%$ of the polymer-derived carbon (BAX-CS-5\% and BAX-CSN-5\%) exhibit the biggest variation in sensitivity. More precisely, BAX-CS shows a 17\% change in the normalized resistance upon $\mathrm{NH}_{3}$ exposure, while BAX-CSN shows a 12\% change in it (Figure 3). Summarizing, the sensitivities of all carbons tested upon exposure to $500 \mathrm{ppm}$ of $\mathrm{NH}_{3}$, are 18,21 , 
17, 10, and 7\% for BAX-O, BAX-CS-1\%, BAX-CS-5\%, BAX-CS-10\%, and BAC-CS-20\%, respectively, and 18, 16,12,13, and 10\% for BAX-O, BAX-CSN-1\%, BAX-CSN-5\%, BAX-CSN$10 \%$, and BAC-CSN-20\%, respectively.

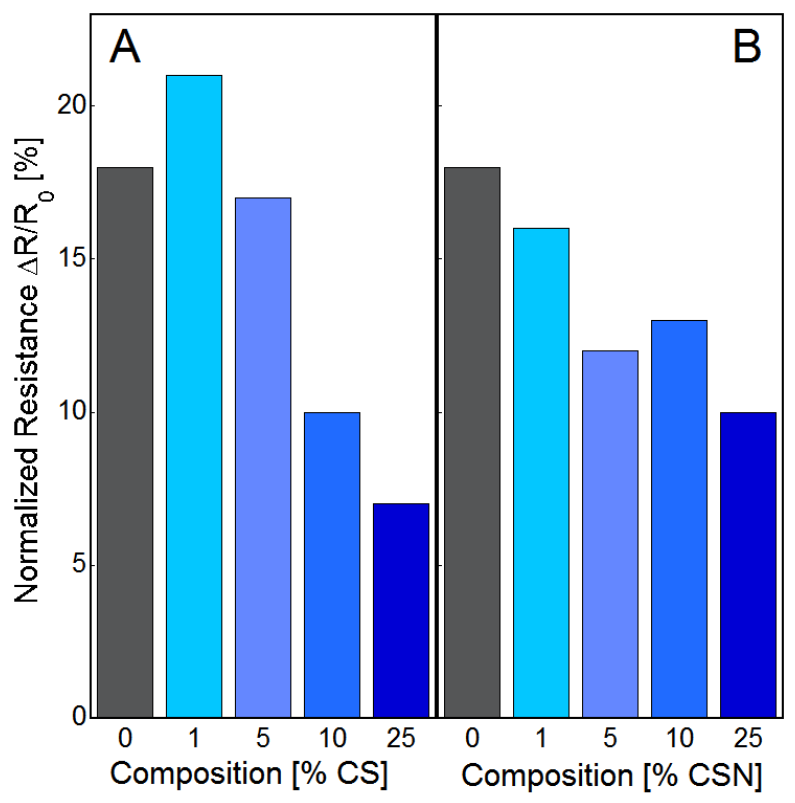

Figure 6.3. Comparison of the normalized resistance changes of BAX-CS and BAX-CSN composite series tested upon exposure to $500 \mathrm{ppm}$ of $\mathrm{NH}_{3 .}{ }^{127}$

\subsection{Synergistic effect on porosity affecting the electrical response of the carbon composites}

To clarify whether or not the synergistic effect on porosity affects the electrical response of the carbon composites, $\mathrm{NH}_{3}$ breakthrough tests were carried out, ${ }^{128}$ and the surface structural features of the initial and exhausted samples were analyzed. The parameters of the porous structure calculated from the $\mathrm{N}_{2}$ adsorption isotherms are presented in Table 6.1 and Figure 6.4, respectively. The Comparison of the data provided in Table 6.1 with the electrical response of the samples (Figure 6.1), indicates that there is no direct relationship between the sensitivity of the carbons and their surfaces areas. This is expected, since only the smallest pores (ultramicropores), 
and not all which contribute to the measured surface area, are predominantly involved in ammonia adsorption at ambient conditions. ${ }^{97}$ Table 6.1 shows that all samples exhibit similar volumes of mesopores, micropores, and especially ultramicropores $\left(\mathrm{V}_{<1 \mathrm{~nm}}\right)$.

The changes in the pore volumes after ammonia adsorption are indicative of the predominant interaction type. Thus, for BAX-AO-ED, a decrease of $~ 35 \%$ in the volume of ultramicropores, is linked to the contribution of the reactive ammonia adsorption. For the composites consisting of $1 \%$ and $5 \%$ of the polymer derived carbon phase, on the other hand, the unaltered volumes of meso-, micro- and ultramicropores are linked to physisorption being a predominant surface interaction type. ${ }^{127}$ 
Table 6.1. Parameters of the porous structure calculated from the nitrogen adsorption isotherms, for the BAX-CS and BAX-CSN composite series. ${ }^{127}$

\begin{tabular}{lllllll}
\hline Sample & $\begin{array}{l}\mathrm{S}_{\mathrm{NLDFT}} \\
\left(\mathrm{m}^{2} \mathrm{~g}^{-1}\right)\end{array}$ & $\begin{array}{l}\mathrm{V}_{\mathrm{t}} \\
\left(\mathrm{cm}^{3} \mathrm{~g}^{-1}\right)\end{array}$ & $\begin{array}{l}\mathrm{V}_{\text {meso }} \\
\left(\mathrm{cm}^{3} \mathrm{~g}^{-1}\right)\end{array}$ & $\begin{array}{l}\mathrm{V}_{\text {mic }} \\
\left(\mathrm{cm}^{3} \mathrm{~g}^{-1}\right)\end{array}$ & $\begin{array}{l}\mathrm{V}_{<0.7 \mathrm{~nm}} \\
\left(\mathrm{~cm}^{3} \mathrm{~g}^{-1}\right)\end{array}$ & $\begin{array}{l}\mathrm{V}_{<1 \mathrm{~nm}} \\
\left(\mathrm{~cm}^{3} \mathrm{~g}^{-1}\right)\end{array}$ \\
\hline BAX & 1549 & 1.373 & 0.756 & 0.617 & 0.086 & 0.225 \\
CS & 1080 & 0.533 & 0.200 & 0.333 & 0.279 & 0.298 \\
CSN & 942 & 0.363 & 0.037 & 0.326 & 0.224 & 0.260 \\
BAX-AO & 1374 & 1.049 & 0.486 & 0.563 & 0.112 & 0.283 \\
BAX-AO-ED & 1220 & 1.031 & 0.504 & 0.527 & 0.073 & 0.240 \\
BAX-CS-1\% & 1475 & 1.092 & 0.486 & 0.606 & 0.135 & 0.312 \\
BAX-CS-1\%-ED & 1436 & 1.067 & 0.479 & 0.588 & 0.129 & 0.301 \\
BAX-CS-5\% & 1472 & 1.078 & 0.488 & 0.590 & 0.137 & 0.311 \\
BAX-CS-5\%-ED & 1463 & 1.069 & 0.479 & 0.590 & 0.137 & 0.312 \\
BAX-CSN-1\% & 1479 & 1.112 & 0.505 & 0.607 & 0.122 & 0.308 \\
BAX-CSN-1\%-ED & 1460 & 1.102 & 0.501 & 0.601 & 0.126 & 0.301 \\
BAX-CSN-5\% & 1466 & 1.065 & 0.472 & 0.593 & 0.133 & 0.312 \\
BAX-CSN-5\%)-ED & 1438 & 1.050 & 0.470 & 0.580 & 0.129 & 0.301 \\
\hline BAX-CS-10\% & 1433 & 1.005 & 0.438 & 0.567 & 0.164 & 0.313 \\
BAX-CS-25\% & 1331 & 0.888 & 0.372 & 0.516 & 0.170 & 0.305 \\
BAX-CSN-10\% & 1347 & 0.993 & 0.449 & 0.544 & 0.125 & 0.281 \\
BAX-CSN-25\% & 1184 & 0.778 & 0.332 & 0.446 & 0.161 & 0.265 \\
\hline
\end{tabular}

Figure 6.4 presents the pore size distributions (PSDs) of the samples tested. Among all carbon composites, the ones consisting of 10 and $25 \%$ of the polymer derived carbon phase show the highest volumes of ultramicropores $\left(\mathrm{V}<_{0.7 \mathrm{~nm}}\right)$, and the smallest or in some cases unaltered volumes of micro- and mesopores. ${ }^{127}$ The composites consisting of 1 and $5 \%$ of the polymer derived carbon, on the other hand, show unaltered volumes in all pore size categories. 

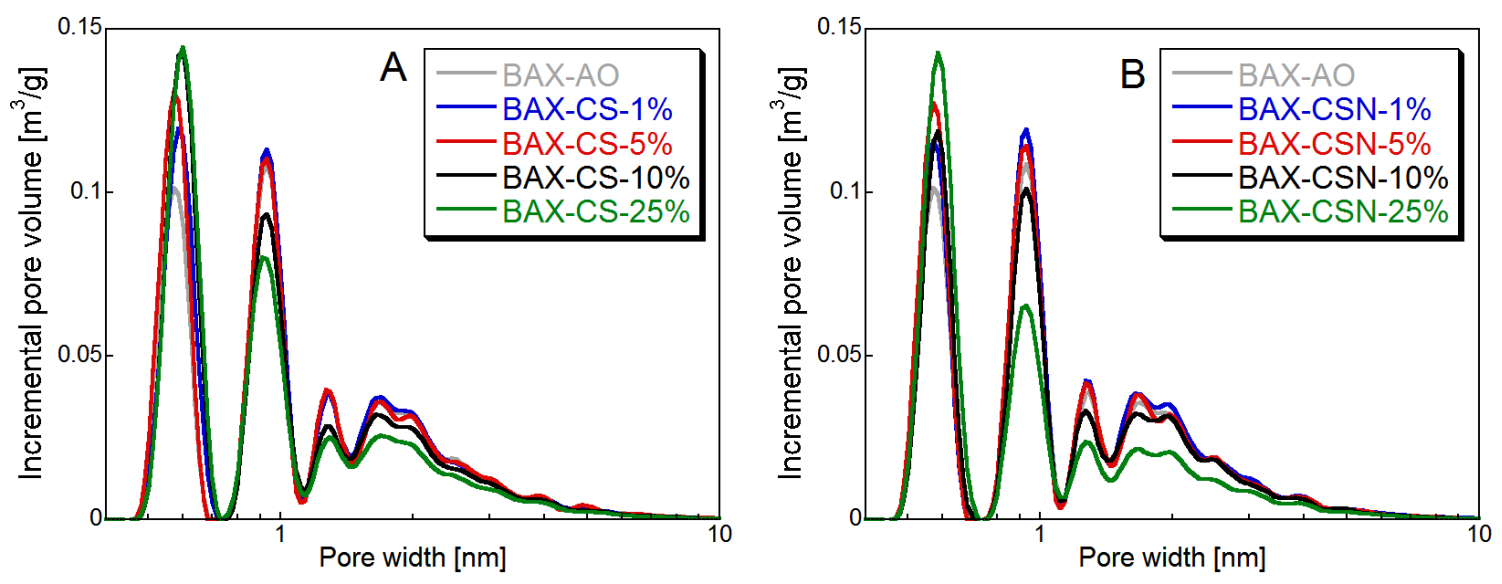

Figure 6.4. Pore size distributions for the BAX-CS and BAX-CSN composite series. ${ }^{127}$

To better comprehend the observed trends, and further clarify how the synergy on porosity affects the electrical performance of the composites, the hypothetical and experimental surface areas and volumes of mesopores, micropores, and ultramicropores $(\mathrm{V}<0.7 \mathrm{~nm})$ for the materials tested were analyzed (Figure 6.5). ${ }^{127}$ In this approach only the same counterparts of each series, showing the highest electrical sensitivity and biggest differences in sensitivity were chosen (BAX-CS-1\%, BAX-CS-5\%, BAX-CSN-1\%, and BAX-CSN-5\%). Thus, the higher than the hypothetical volumes of micro- and ultramicropores must be a consequence of the composite formation and interactions of the polymer with the BAX-AO carbon functional groups. The sample with the highest sensitivity (BAX-CS-1\%), exhibits the greatest deviation from the expected hypothetical volume of ultramicropores. The same sample also exhibits the highest ultramicroporosity. Thus, its superior electrical performance might be related to the developed ultramicroporosity that favors the adsorption and retention of the $\mathrm{NH}_{3}$ molecules in the carbon matrix. ${ }^{97}$ The morphological features of the composites consisting of the highest percentage of the polymer-derived carbon phase $(25 \%)$ are presented in Figure A7 of the Appendix. SEM images show two different phases originating either from the polymer (smooth) or commercial carbon (particles) 

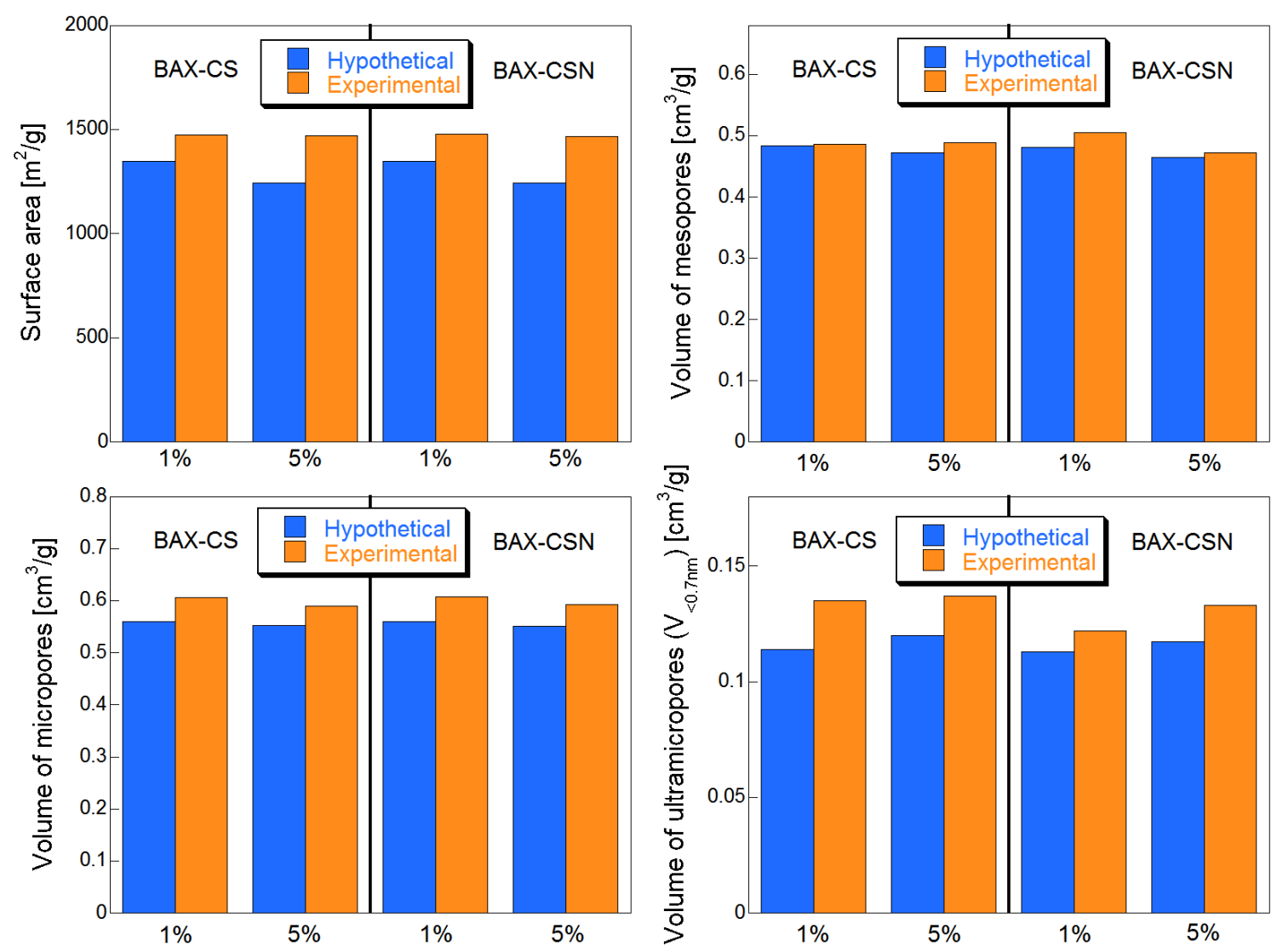

Figure 6.5. Comparison of the hypothetical and measured surface areas, volumes of mesopores, micropores and ultramicropores $(\mathrm{V}<0.7 \mathrm{~nm})$ for BAX-CS and BAX-CSN composite series (calculated using the NLDFT method). ${ }^{127}$

\subsection{Priority order of various chemical groups on the $\mathrm{NH}_{3}$ sensing capability of nanoporous carbons}

To clarify whether or not the synergistic effect on the surface chemical features affects the electrical response of the carbon composites, the initial and exhausted samples were analyzed using XPS analysis. ${ }^{127}$ The content of elements on the surface in atomic $\%$ and the results of the deconvolution of the $\mathrm{C} 1 s, \mathrm{O} 1 s, \mathrm{~N} 1 s$, and $\mathrm{S} 2 p$ core energy level spectra are summarized in Figure 6.6. Figures 6.7 and 6.8 illustrate the deconvolution of the $\mathrm{C} 1 s, \mathrm{O} 1 s$, and $\mathrm{N} 1 s$ core energy level 
spectra for the best performing carbons from each composite series (BAX-CS-1\% and BAX-CSN$1 \%$ ), along with the deconvolution of the S $2 p$ core energy level spectra of the composites with the $5 \%$ of the polymer drived carbon phase (BAX-CS-5\% and BAX-CSN-5\%), before and after ammonia exposure. Detailed results of XPS analyses with an assignment of the specific functional groups are provided in Tables A14-A18 of Appendix. As already mentioned in Chapter 4, the data obtained for the samples after $\mathrm{NH}_{3}$ exposure, from both XPS and $\mathrm{N}_{2}$ adsorption, are of a great importance to comprehend the reversible sensing mechanism. That reversible sensing depends on the new functional groups formed on the surface of the exhausted samples, as a result of the reactive ammonia adsorption during the stablization process. 

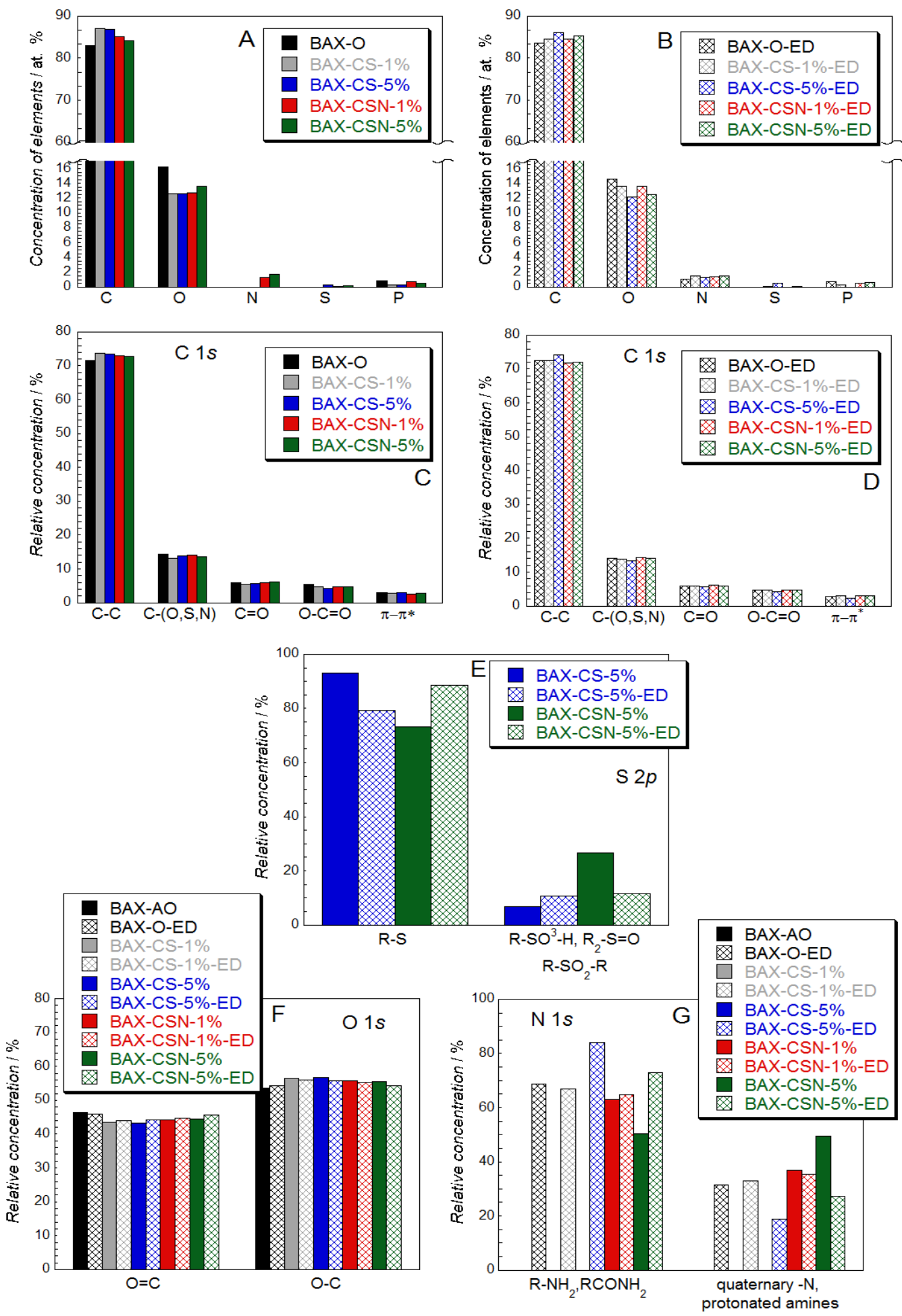

Figure 6.6. Content of elements and contributions of the specific carbon, oxygen, nitrogen and sulfur groups on the initial and exhausted BAX-AO, BAX-CS-1\%, BAX-CSN-1\%, BAX-CS-5\%, ans BAX-CSN-5\% . ${ }^{127}$ 
Among all samples tested, BAX-AO exhibits the highest content of oxygen (Figure 6.6A). Its content in the other samples tested remains practically the same (Figure 6.6A). While both BAX$\mathrm{CSN}-1 \%$ and BAX-CSN-5\% have nitrogen on their surfaces, the latter one along with BAX-CS$5 \%$ also have small amounts of S. On the surfaces of BAX-CS-1\% and BAX-CSN-1\% S was not detected. For the samples exposed to ammonia an increased content of $\mathrm{N}$ is due to the chemical reaction of ammonia with surface functional groups, and thus due to the formation of stable $\mathrm{N}$ containing surface compounds (Figures $6.6 \mathrm{G}$ and 6.7). ${ }^{127}$

The deconvolution of the deconvolution of the S $2 p$ core energy level spectra energy level spectra provides important information about the type of the S-containing groups that play the most important role in the sensing mechanism of our carbon composites. In BAX-CS-5\% and BAX$\mathrm{CSN}-5 \% \mathrm{~S}$ is incorporated to the carbon matrix mainly in its reduced forms (thiols and bisulfides) (Figure 6.6E and 6.8). ${ }^{127}$ Interestingly, these two samples show an opposite trend in the contribution of the reduced S-species upon ammonia exposure. More precisely, while $\mathrm{NH}_{3}$ exposure led to an increase in the contribution of reduced S-forms accompinied by a decrease in the contribution of the oxidized S-species (sulfoxides and sulfones) for BAX-CSN-5\%, for BAXCS-5\%, a decrease in the contribution of reduced S-species, followed by an increase in the contribution of oxidized S-specoes is observed for BAX-CS-5\%. These trends are oposite to the ones that have been found for S-doped and S, N- co-doped polymer-derived carbons ( Chapter 5). ${ }^{84,85}$ An increased contribution of reduced $\mathrm{S}$-forms upon $\mathrm{NH}_{3}$ exposure is likely related to its electron donating nature ( of $\mathrm{NH}_{3}$ ). The chemical reaction of ammonia with thioesters likely leads to their conversion to the corresponding thiols with a simultaneous formation of an amide group. ${ }^{129}$

Based on the deconvolutions of the $\mathrm{N} 1$ s core energy level spectra (Figures 6.6G and 6.7), exposure to $\mathrm{NH}_{3}$ led to an increase in the contribution of ammonium ions $\left(\mathrm{NH}_{4}^{+}\right)$. This species, 
as aforementioned in the previous Chapters, is formed by the acid-base reactions of $\mathrm{NH}_{3}$ with acidic O-containing groups. Such groups are carboxylic acids, which were detected on the surface of all carbons samples, and sulfonic acids which were detected on the surface of the composites consisting of $5 \%$ of the polymer derived carbon phase (BAX-CS-5\% and BAX-CSN-5\%).The deconvolution of the $\mathrm{N} 1 s$ core energy level spectra also indicates that BAX-CSN-1\% that exhibits a higher sensitivity to ammonia, also shows a higher contribution of amines and amides compared to the surface constitution of BAX-CSN-5\%.

After $\mathrm{NH}_{3}$ exposure, however, the increases in the contributions of amines/amides were more pronounced for BAX-CSN-5\% than those for BAX-CSN-1\%. Their appearance involves the chemical reaction of ammonia with carboxylic, epoxy, thioester and anhydride groups. When anhydrides reacted with ammonia, $-\mathrm{NH}_{2}$ and carboxyl groups were formed. This explains their increased contribution on the surface of the exhausted BAX-CSN-1\% and BAX-CSN-5\% carbon composites. 

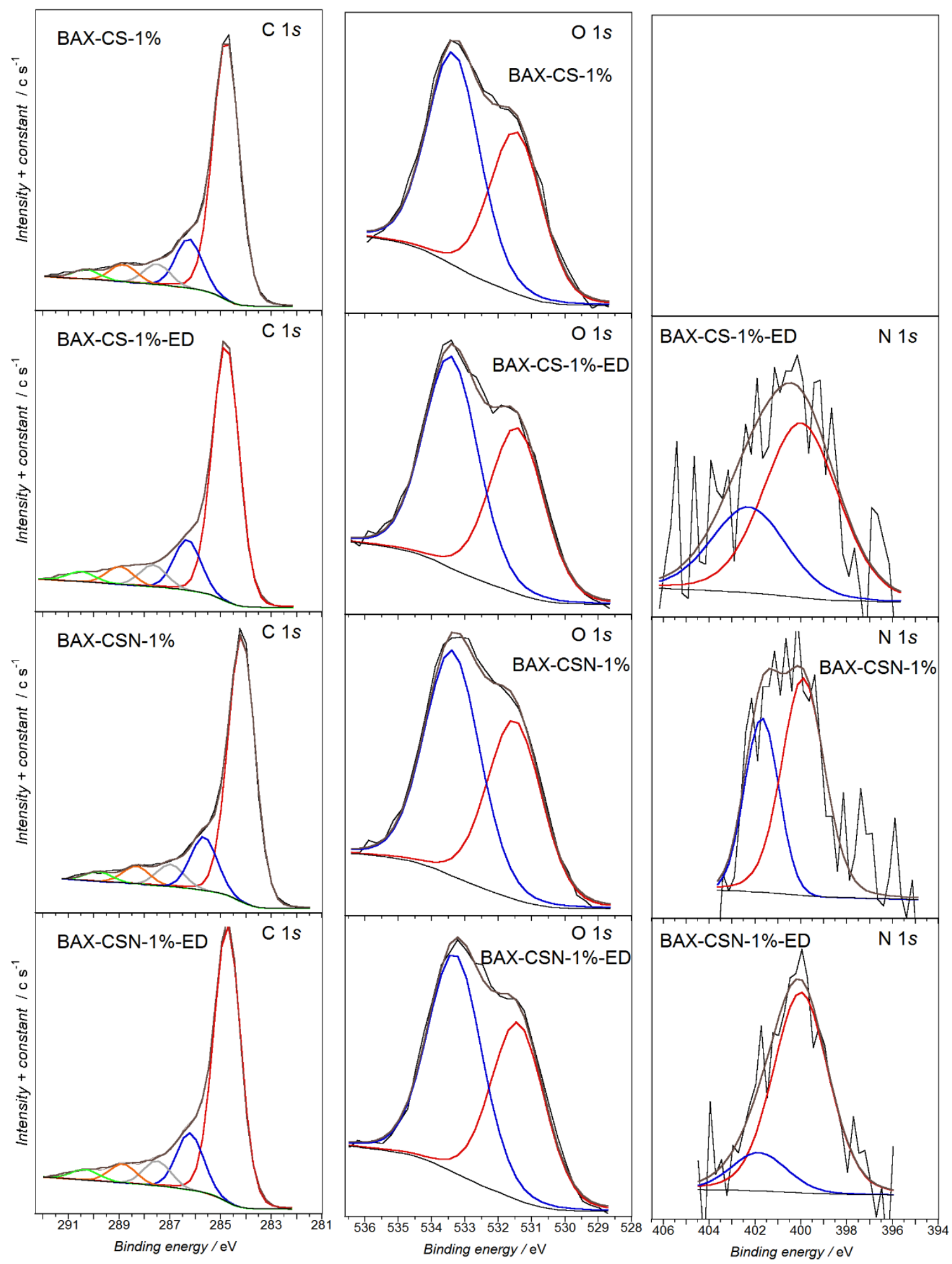

Figure 6.7. Deconvolutions $\mathrm{C} 1 s, \mathrm{O} 1 s$, and $\mathrm{N} 1 s$ core energy level spectra for BAX-CS-1\% and BAX-CSN-1\%, initial and exposed to ammonia. ${ }^{127}$ 


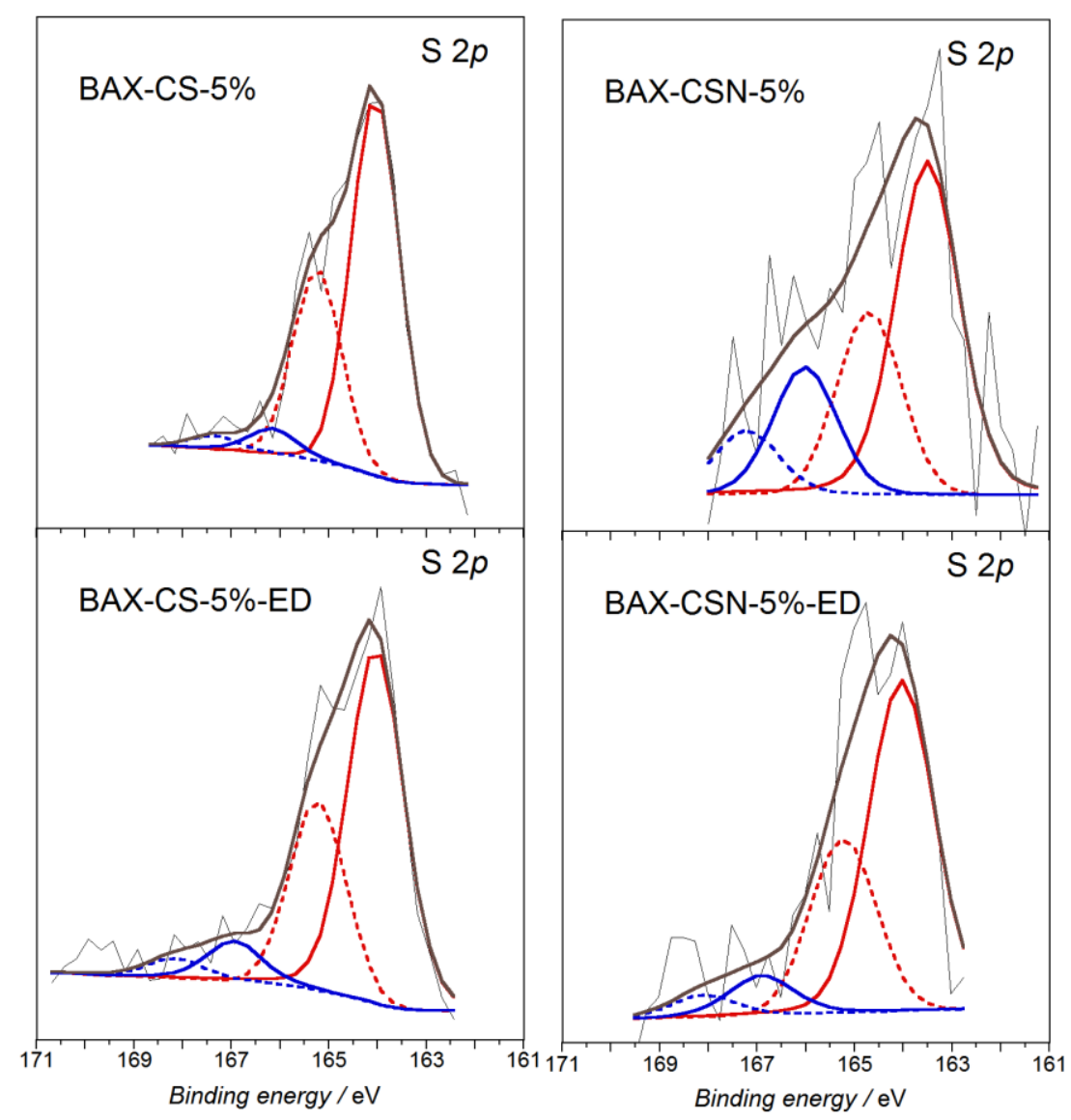

Figure 6.8. Deconvolutions S $2 p$ core energy level spectra for BAX-CS-5\% and BAX-CSN-5\%, initial and exposed to ammonia. ${ }^{127}$

The formation of ammonium ions was further verified by the results of the potentiometric titration (Figure 6.9), which show a peak at the $\mathrm{pK}_{\mathrm{a}} 9-10$ assigned to these species $\left(\mathrm{NH}_{4}{ }^{+}\right) .{ }^{127}$ Based on both XPS and potentiometric titration results, BAX-AO, BAX-CS-1\% and BAX-CSN-1\%, which are the samples that show the highest electrical sensitivity, also have the highest amounts of $\mathrm{NH}_{4}{ }^{+}$ species as a result of the reactive adsorption of ammonia on their surfaces (Figure 6.7). ${ }^{127}$ 

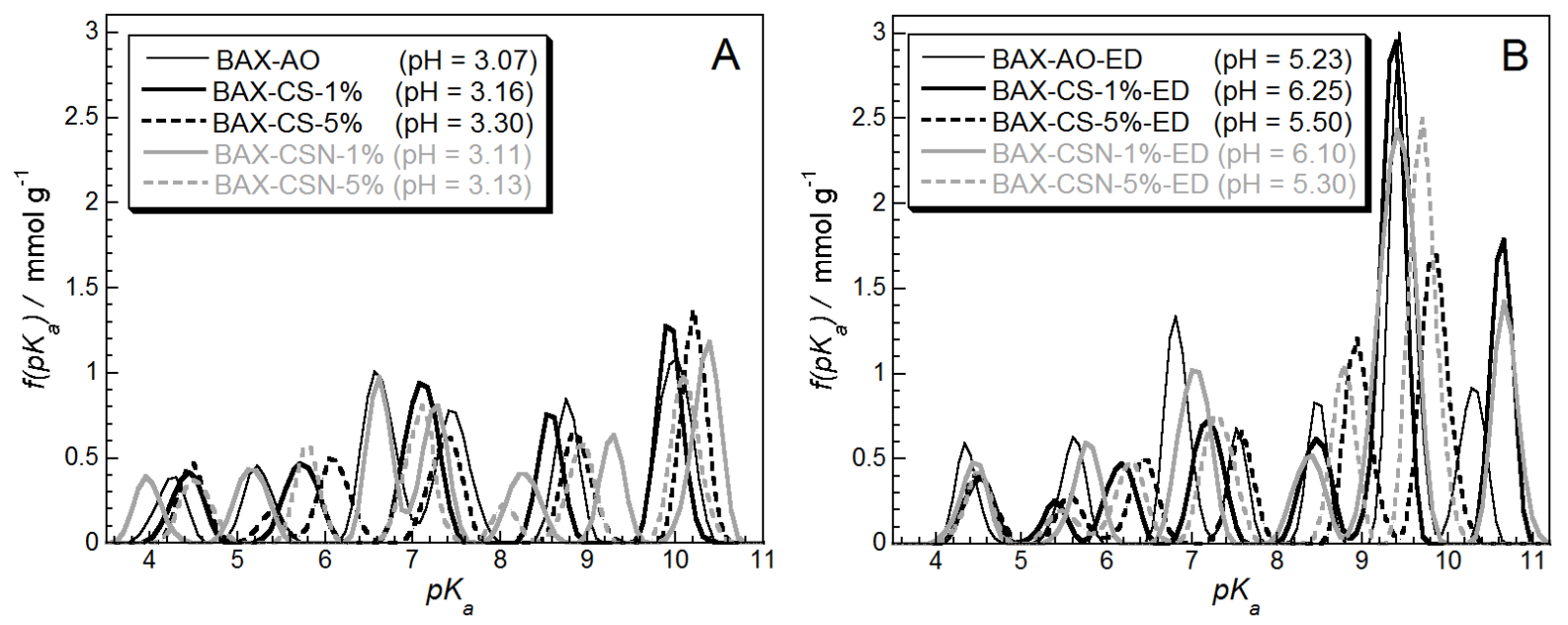

Figure 6.9. The distributions of the $\mathrm{pK}_{\mathrm{a}}$ for the species present on the surface of BAX-AO, BAXCS (1\% and 5\%) and BAX-CSN (1\% and 5\%), initial and exposed to ammonia. ${ }^{127}$

In overall, the chemical analyses results indicate that the BAX-CSN series has more carbonyl groups in ketones, aldehydes and amides than has the BAX-CS series. Such groups contribute to the reversible sensing through weak interactions with ammonia. On the surface of the exhausted BAX-CS series on the other hand, besides amines and hydroxyl groups, $\mathrm{NH}_{4}{ }^{+}$were also formed by the acid-base reaction of ammonia with acidic groups. This partially explains the greater signal changes measured for the BAX-CS composites.Furthermore, the comparison of the surface constitution of BAX-CSN-1\% and BAX-CSN-5\%, indicates that even though BAX-CSN-1\% shows a higher contribution of amines and amides compared to BAX-CSN-5\% as an initial sample, after $\mathrm{NH}_{3}$ exposure the contributions of quaternary-N and protonated amines increased. Considering that the reversible sensing strongly depends on surface chemistry of the exhausted/initally exposed samples, the above results suggest that quaternary- $\mathrm{N}$ rather than amines and amides play a more important role in sensing response. ${ }^{127}$

Sulfur in its reduced or oxidized forms is another heteroatom that affects the sensing performance of the carbons tested. Both oxidized and reduced (R-S) S-species can weakly interact with 
ammonia and thus contribute to the reversible sensing. Among the two carbon composites consisting of $5 \%$ of the polymer-derived carbon, BAX-CSN-5\% exhibits the highest contribution reduced S-species (Figure 6.6E and 6.8). BAX-CSN-5\% however shows a lower electrical sensitivity compared to BAX-CS-5\%. These results suggest that the oxidized S-configurations (such as sulfones and sulfonic acids) rather than the reduced ones (such as thiols and bisulfides) are more important in ammonia sensing. ${ }^{127}$

Unlike in the case of the S-doping, where on;y oxidized species play the most important role in sensing, $\mathrm{O}$ as a heteroatom plays an important role in its various configurations. Thus, highly acidic O-functionalities such as carboxyl and sulfonic groups, are able to participate in acid-base interactions with $\mathrm{NH}_{3}$ and thus promote the charge transport through ionic conductivity. The same groups can also form hydrogen bonds with $\mathrm{NH}_{3}$, which is an additional path for the promotion of charge transport. Carbonyl (ketones, aldehydes or $\mathrm{C}=\mathrm{O}$ of carboxylic groups) and epoxy groups can also react with $\mathrm{NH}_{3}$ and form $-\mathrm{OH},-\mathrm{NH}_{2}$ and $-\mathrm{CONH}_{2}$ groups, which in turn can also weakly interact with the molecules of the target gas. Finally, weakly acidic O-groups (phenols, alcohols) are the second most important $\mathrm{O}$-containing groups which can also weakly interact with $\mathrm{NH}_{3}$. BAX-CS-1\% that has the highest contribution of these species also exhibits the biggest changes in the normalized resistance (highest sensitivity). BAX-AO, which is the sample with the second highest sensitivity, shows the highest contribution of carboxyl groups and thus the highest surface acidity. The latter feature is very important for ammonia sensin, since the extent of $\mathrm{NH}_{3}$ adsorption on the carbons' surface strongly depends on it.

Based on extensive analysis of the surface chemical features of the samples tested and their electrical performances (Figure 6.3), a priority order of the most important specific surface groups for the ammonia sensing is proposed, which is the following: ${ }^{127}$ 
$-\mathrm{COOH} \approx-\mathrm{SO}_{3} \mathrm{H}>\mathrm{sp}^{2}-\mathrm{OH} \approx$ epoxy $>$ anhydrides $>\mathrm{sp}^{3}-\mathrm{OH}>$ carbonyl (in ketones, aldehydes) $>\mathrm{NH}_{4}{ }^{+}>-\mathrm{NH}_{2} \approx-\mathrm{CONH}_{2}>\mathrm{R}-\mathrm{S}-\mathrm{H} \approx \mathrm{R}-\mathrm{S}-\mathrm{S}-\mathrm{R}{ }^{\prime}$

\subsection{Sensing mechanism}

\subsubsection{Conduction type vs nature of weak interactions}

The Mott-Schottky approach ${ }^{92}$ was used to evaluate the conduction type of the carbon composites. ${ }^{1}$ For BAX-AO linear trends with similar positive and negative slopes are indicative of the coexistence of both $n$ - and $p$-conduction types, respectively (Figure 6.10A). This means that both negatively charged electrons $\left(e^{-}\right)$and positively charge holes $\left(h^{+}\right)$act as charge carriers. The addition of only $1 \%$ of the polymer-derived carbon was sufficient to alter the surface chemical features of the carbon matrices at such extent that the $p$-conduction type became predominant (Figures 6.10B and 6.10D). The groups that are responsible for a $p$-type conductivity are Ocontaining electron-withdrawing groups, such as $\mathrm{sp}^{3}$-bonded hydroxyl, carboxyl, carbonyl, ethers, and epoxides, while O-containing electron-donating groups such as $\mathrm{sp}^{2}$-bonded hydroxyl, ether and epoxide groups are responsible for an $n$-type conductivity. ${ }^{130}$

BAX-CS-1\% and BAX-CSN-1\% exhibit a higher contribution of $\mathrm{sp}^{3}-\mathrm{OH}$, ethers, and epoxy groups than does BAX-AO. Moreover, BAX-CSN-1\% was also found to exhibit quaternary Nspecies. All the above mentioned functional groups, being electron-withdrawing, are responsible for a predominantly $p$-type conductivity. In the case of the composite with $5 \%$ of the polymer derived carbon, $-\mathrm{SO}_{3} \mathrm{H}$ are additional groups acting as $p$-type doping impurities due to their strong electron withdrawing nature. ${ }^{131}$ The comparison of the series containing only S- (BAX-1\% and BAX-CS-5\%) with those containing both S- and N- (BAX-CSN-1\% and BAX-CSN-5\%), indicates that both series exhibit both conduction types, with $p$ - type being predominant. Based on 
the slopes of the linear trends corresponding to the $n$-type character (linear trends with positive slopes) however, the $n$-type conduction seems to be more pronounced for the BAX-CSN ones than the BAX-CS ones. This can be explained by a higher contribution of amines and -NHCOR groups on the surface of the latter composites (BAX-CSN), which acting as $n$-type doping impurities induce an $n$-type conductivity.
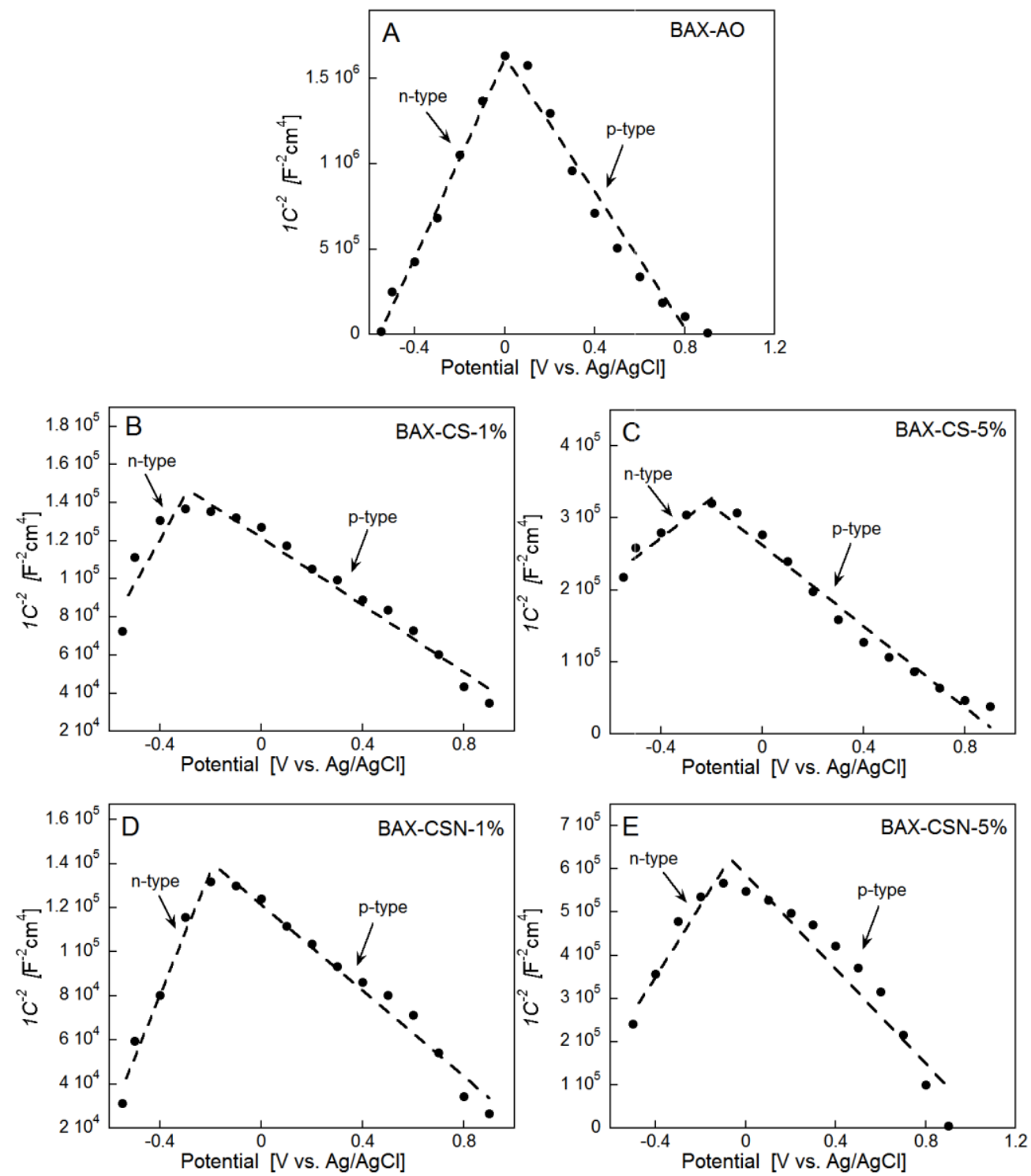

Figure 6.10. The Mott-Schottky plots for BAX-AO, BAX-CS-1\%, BAX-CSN-1\%, BAX-CS-5\%, and BAC-CSN-5\%. ${ }^{127}$ 
Based on the predominant $p$-conduction type of the materials tested, it would be expected that ammonia exposure causing a depletion in the concentration of the positively charged $h^{+}$, would lead to an increase in the normalized resistance. This is not however the observed trend (Figure 6.1). In Chapter 5, we have shown that such an opposite to the expected behavior of $p$-type materials (decrease instead of an expected increase in the normalized resistance) is usually linked to the partial oxidation of $\mathrm{NH}_{3}$ to $\mathrm{NO}_{2}$ by superoxide ions $\left(\mathrm{O}_{2}^{-}\right)^{85}$ that are generated on the surface of heteroatom-containing nanoporous carbons. ${ }^{124,126}$ The latter species $\left(\mathrm{NO}_{2}\right)$ being electron withdrawing cause an increase in the concentration of the positively charged $h^{+}$, which results in a decrease in the normalized resistance.

Here, XPS analysis does not support the formation of $\mathrm{O}_{2}{ }^{-}$, which would otherwise show a contribution at a high binding energy (at $536.9 \mathrm{eV}$ ), based on the deconvolution of the $\mathrm{O} 1 s$ core energy spectrum, and a contribution on $\mathrm{N} 1 s$ corresponding to $\mathrm{NO}_{\mathrm{x}}$ species $(402.5 \mathrm{eV})$. The latter species $\left(\mathrm{NO}_{\mathrm{x}}\right)$ would be formed from the partial ammonia oxidation by superoxide ions. The lack of these contributions suggests that the nature of the interactions between the surface functional groups and ammonia molecules, rather than the electronic configuration of the surface functional groups, and thus the conduction type, predominantly governs the electrical behavior of the carbons.

\subsubsection{Importance of surface features: Role of surface chemistry vs porosity}

The composites consisting of 1,5 and $10 \%$ of the polymer derived carbon show similar parameters of the porous structure (Table 6.1). Their ammonia detection sensitivities, however. differ (Figure 6.3). An indirect relationship between the sensitivity and porosity of the materials indicates that the differences in their electrical perfomance depend on their surface chemical features. The results suggest that altering the surface chemical features by introducing $\mathrm{O}, \mathrm{S}$ and $\mathrm{N}$ heteroatoms, we are 
able to control both the electronic nature of the carbon matrices (conduction type), and the nature of specific interactions with the target gas.

Interesting conclusions can be drawn when comparing the sensitivity and porosity of the composites consisting of 5\% of the polymer derived carbon phase (BAX-CS-5\% and BAX-CSN$5 \%$ ) with the 10 and $25 \%$ ones (BAX-CS-10 and -25, BAX-CSN-5 and -25). Even though the latter composites exhibit, in some cases, a slightly increasedultramicropore volumes, and a decreased micro- and especially mesopore volumes, compared to the former ones (Table 6.1 and Figure 6.4), they show less marked changes in their electrical response. This leads us to the following conclusions: a) when samples of similar porosity are compared, surfac echemistry is the feature that predominantly controls/determines the extent of their electrical signal changes; b) even though ultramicropores have been shown to be the most crucial pores for $\mathrm{NH}_{3}$ retention and thus play the most important role in ammonia sensing, here, mesopores also seems to play an important role. A higher volume of these pores leads to higher sensitivities, since more $\mathrm{NH}_{3}$ molecules can access the ultramicropores. Based on this, smaller mesopore volumes of the composites consisting of 10 and $25 \%$ of the polymer derived carbon phase (BAX-CS-10 and 25\%, BAX-CSN-5 and 25\%), compared to BAX-CS-5\% and BAX-CSN-5\%, partially explains their lower sensitivity.

\subsubsection{Importance of ionic conductivity as an ammonia sensing mechanism}

Chapters 4 and 5 presented that a specific surface chemistry plays an important role on ammonia sensing by promoting charge transport across the carbon matrix through the weak specific interactions of ammonia with the surfac efunctional groups. In this Chapter, an additional mechanism, which also plays a very important role on ammonia sensing, is extensively discussed; it is the charge transport via ionic conductivity. This mechanism involves the formation of ammonium ions that are formed by the acid-base reaction of $\mathrm{NH}_{3}$ with acidic $\mathrm{O}$ and $\mathrm{S}$-containing 
surface functional groups (carboxyl and sulfonic). Based on the results of the XPS nalysis, carboxylic acids were detected on the surface of all carbons samples, while sulfonic acids were detected on the surface of BAX-CS-5\% and BAX-CSN-5\%. Both XPS and potentiometric titration results show that the samples with the highest sensitivity (BAX-AO, BAX-CS-1\% and BAX-CSN-1\%) show the highest contribution of $\mathrm{NH}_{4}{ }^{+}$species, as a result of the reactive adsorption of ammonia on their surfaces. This indicates the crucial role of ionic conductivity as a mechanism governing the electrical response of our carbon chips. 


\section{Chapter 7. Role of water on the sensing performance of nanoporous carbons}

This chapter focuses on the influence of water on the $\mathrm{NH}_{3}$ sensing capability of nanoporous carbons. To investigate the role of humidity on the electrical performance of the carbon-based sensors, the sensing tests were carried out either using a flow of ammonia in moist air, or by performing a prehumidification step ( $1 \mathrm{~h}$ or $2 \mathrm{~h}$ ) prior to the sensing test. Two carbons series were used to test the sensing capability in humid conditions. These are; a) the S- and N-containing nanoporous carbons (C-AO and $\mathrm{C}-\mathrm{BO})$, tested in Chapter 5, and b) the wood-based/polymerderived nanoporous carbon-composites (BAX-CS-1\% and BAX-CSN-1\%), tested in Chapter 6.

Chapter 7 is a slightly revised version of the following article, with permission from Elsevier, Copyright 2016, reported in Reference 132:

Travlou, N. A.; Rodríguez-Castellón, E.; Bandosz, T. J. Sensing of $\mathrm{NH}_{3}$ on Heterogeneous Nanoporous Carbons in the Presence of Humidity. Carbon 2016, 100, 64-73. 


\subsection{Initial sensor stabilization in the presence of water}

The changes in the normalized resistance during the initial stabilization of C-AO and C-BO at 500 ppm of ammonia are illustrated in Figure 7.1. ${ }^{132}$ The samples were either exposed directly to a humid $\mathrm{NH}_{3}$ stream (C-AO-EM and C-BO-EM) or they underwent a $2 \mathrm{~h}$ prehumidification prior to their exposure to a moist stream of ammonia (C-AO-EPM and C-BO-EPM). Figure 7.1A shows that a direct exposure to a moist ammonia stream cause that, $\mathrm{C}$-AO sample shows an almost three times higher sensitivity than does $\mathrm{C}-\mathrm{BO}(50 \%$ for $\mathrm{C}-\mathrm{AO}$ vs $17.7 \%$ for $\mathrm{C}-\mathrm{BO}) .{ }^{132}$ The extent of physical or chemical ammonia adsorption was estimated based on the \% recovery of the normalized resistance, upon purging the carbon chips with moist air. Very small signal changes were recorded (1.5\% for $\mathrm{C}-\mathrm{AO}$ and $1.3 \%$ for $\mathrm{C}-\mathrm{BO}) .{ }^{132}$ Comparison of these values to those in dry conditions $(6.7 \%$ for $\mathrm{C}-\mathrm{AO}$ and $4.4 \%$ for $\mathrm{C}-\mathrm{BO}),{ }^{85}$ indicates that in the presence of water, chemisorption is the dominant interaction type.

The stabilization of the chips in ammonia was also conducted after applying a 2 hours prehumidification of the system, prior to their exposure to repeatable $\mathrm{NH}_{3} /$ air cycles. As indicated in Figures 7.1B and 7.1C, upon the exposure of both carbons to a moist gas stream, the normalized resistance increases about $225 \%$ for C-AO and about $160 \%$ for of C-BO. ${ }^{132}$ Interestingly, even though for the former sample it takes about $5 \mathrm{~h}$ for the electrical signal to reach the plateau upon exposure to a moist ammonia stream, for $\mathrm{C}-\mathrm{BO}$ the electrical signal does not stabilize even after $24 \mathrm{~h}$. 

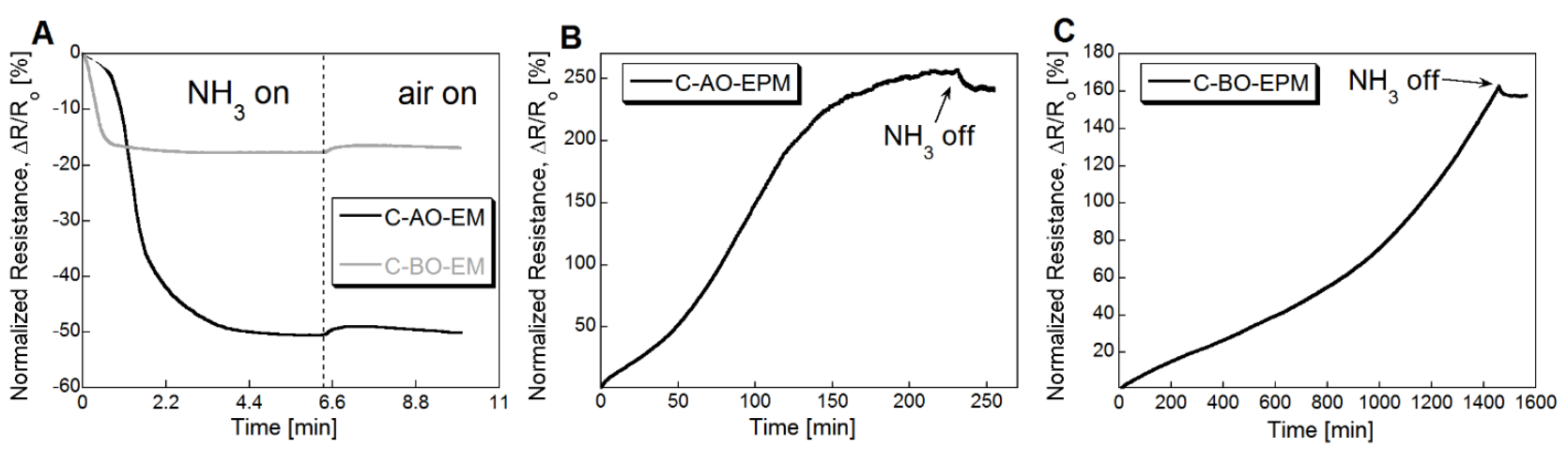

Figure 7.1. Normalized change in a resistance for $\mathrm{C}-\mathrm{AO}$ and $\mathrm{C}-\mathrm{BO}$ upon their initial exposure to a humid gas stream (A) and a humid gas stream with $2 \mathrm{~h}$ prehumidification (B and C). For the exhausted samples after ammonia adsorption, the suffix -EM is added when they were directly exposed to a humid $\mathrm{NH}_{3}$ stream, and the suffix -EPM is added after their prehumification. ${ }^{132}$

\subsection{Water as a factor enhancing ammonia sensing}

The results of the reversible sensing capability of $\mathrm{C}-\mathrm{AO}$ carbon upon its immediate exposure to moist $\mathrm{NH}_{3} /$ air cycles (without prehumidification) of various concentrations are illustrated in Figure 7.2A. The reproducibility of the sensing results under moist conditions is also included there. Comparison the signal change of $\mathrm{C}-\mathrm{AO}$ upon its exposure to $500 \mathrm{ppm}$ of ammonia in dry and moist conditions ( $14.1 \%$ in dry, Chapter 5 vs $\sim 34.9 \%$ in moist), indicates that moisture considerably enhances the sensitivity.

Figure 7.2B shows that the normalized resistance changes linearly with an increase in the concentrations of the target gas. Error bars were added to indicate the standard deviation. The relative $\sigma$ (standard deviation) (\% RSD) for C-AO was found to be between 4.6-7.5\%. The data presented are based on measurements on three different C-AO coated chips. ${ }^{132}$ 

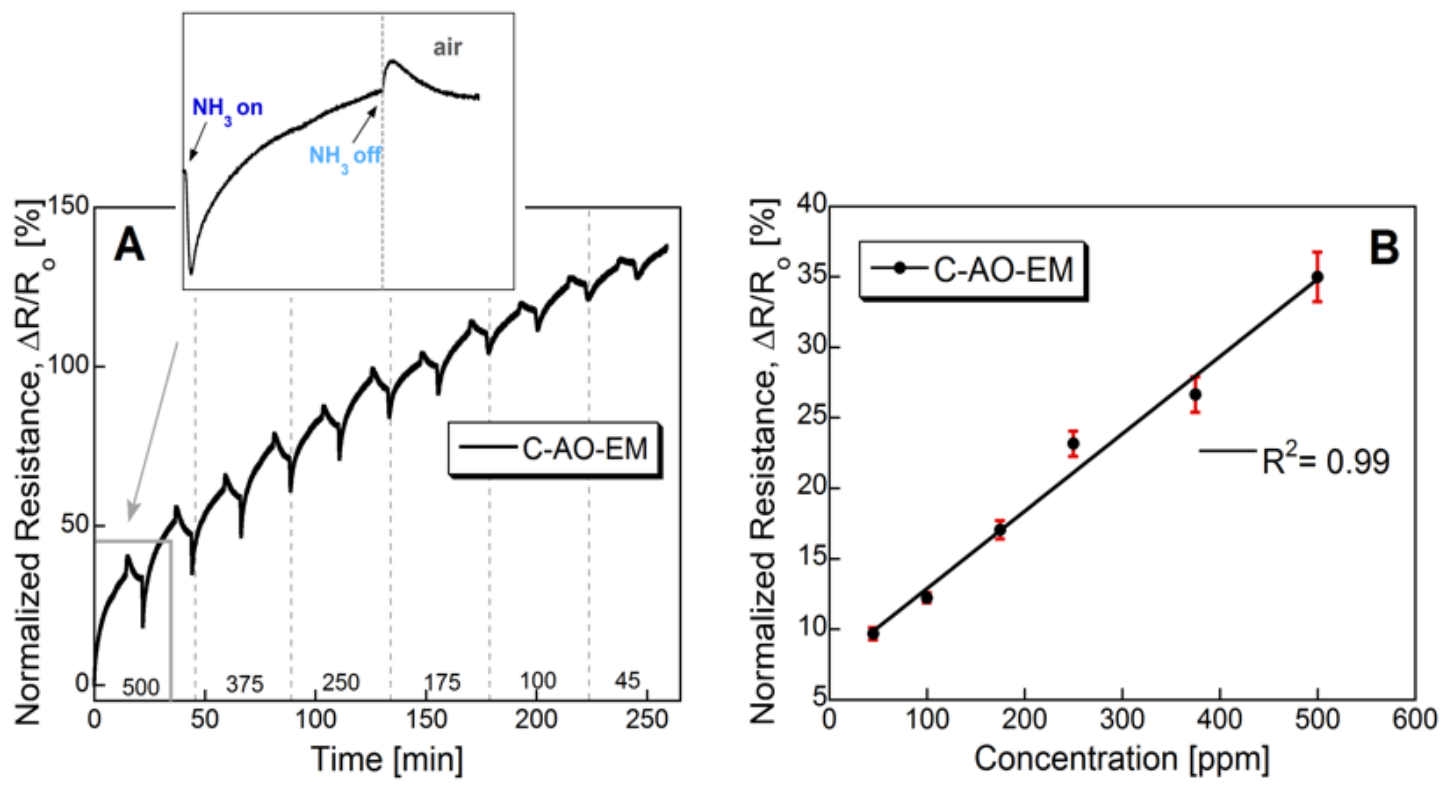

Figure 7.2. (A) Response curve for $\mathrm{C}-\mathrm{AO}$ upon the direct exposure to $\mathrm{NH}_{3} /$ moist air cycles, and (B) dependence of the normalized resistance change on the various ammonia concentrations. ${ }^{132}$

\subsection{Water as a neutral factor or obstacle for ammonia sensing}

Figure 7.3A presents the results of the reversible sensing capability of C-BO carbon upon its immediate exposure to moist $\mathrm{NH}_{3}$ /air cycles (without prehumidification). Even though water was found to have an enhancing effect on the electrical response of C-AO (Figure 7.2) upon its direct exposure to a moist ammonia stream, this is not the case for $\mathrm{C}-\mathrm{BO}$, where moisture didn't cause any change in the sensor response, compared to that in dry conditions. Thus it acted as a neutral factor ( $6.3 \%$ at moist vs. $6.2 \%$ at dry, for $500 \mathrm{ppm}$ of $\left.\mathrm{NH}_{3}\right)$.

The results of the electrical response for $\mathrm{C}-\mathrm{AO}$ and $\mathrm{C}-\mathrm{BO}$ upon the application of a 2-h prehumidification are illustrated in Figures 7.3B and 7.3C. As seen, when prehumidification is applied prior to the reversible sensing, smaller signal changes are recorded $(\sim 6.3 \%$ for $\mathrm{C}$-AO and $\sim 5.1 \%$ for C-BO) compared to those when the samples are directly exposed to a moist gas stream $(\sim 34.9 \%$ for $\mathrm{C}-\mathrm{AO}$ and $\sim 6.3 \%$ for $\mathrm{C}-\mathrm{BO})$ or when the sensing was run at dry conditions $(\sim 14.1 \%$ 
for $\mathrm{C}$-AO and $\sim 6 . \%$ for $\mathrm{C}$-BO) ${ }^{132}$ These results suggest that at higher humidity levels, water acts as an obstacle on the ammonia sensing capability of the carbons. Table 1 presents the changes in the normalized resistance for $\mathrm{C}-\mathrm{AO}$ and $\mathrm{C}-\mathrm{BO}$ upon their exposure to various concentrations of moist ammonia stream, either directly or after applying prehumidification of the carbon. The results collected clearly show the role of water as an enhancing, neutral or diminishing parameter on ammonia sensing.

The normalized resistance changes vary linearly with increasing ammonia concentrations (Figures 7.3D and 7.3E ). ${ }^{132}$ Moreover, the reproducibility of the sensing results is clearly seen. The collected data is based on measurements on three different chips for each sample, with error bars indicating the standard deviation. The relative $\sigma(\%$ RSD) was found to be between 3.9-9.7\% for the C-BO series. ${ }^{132}$
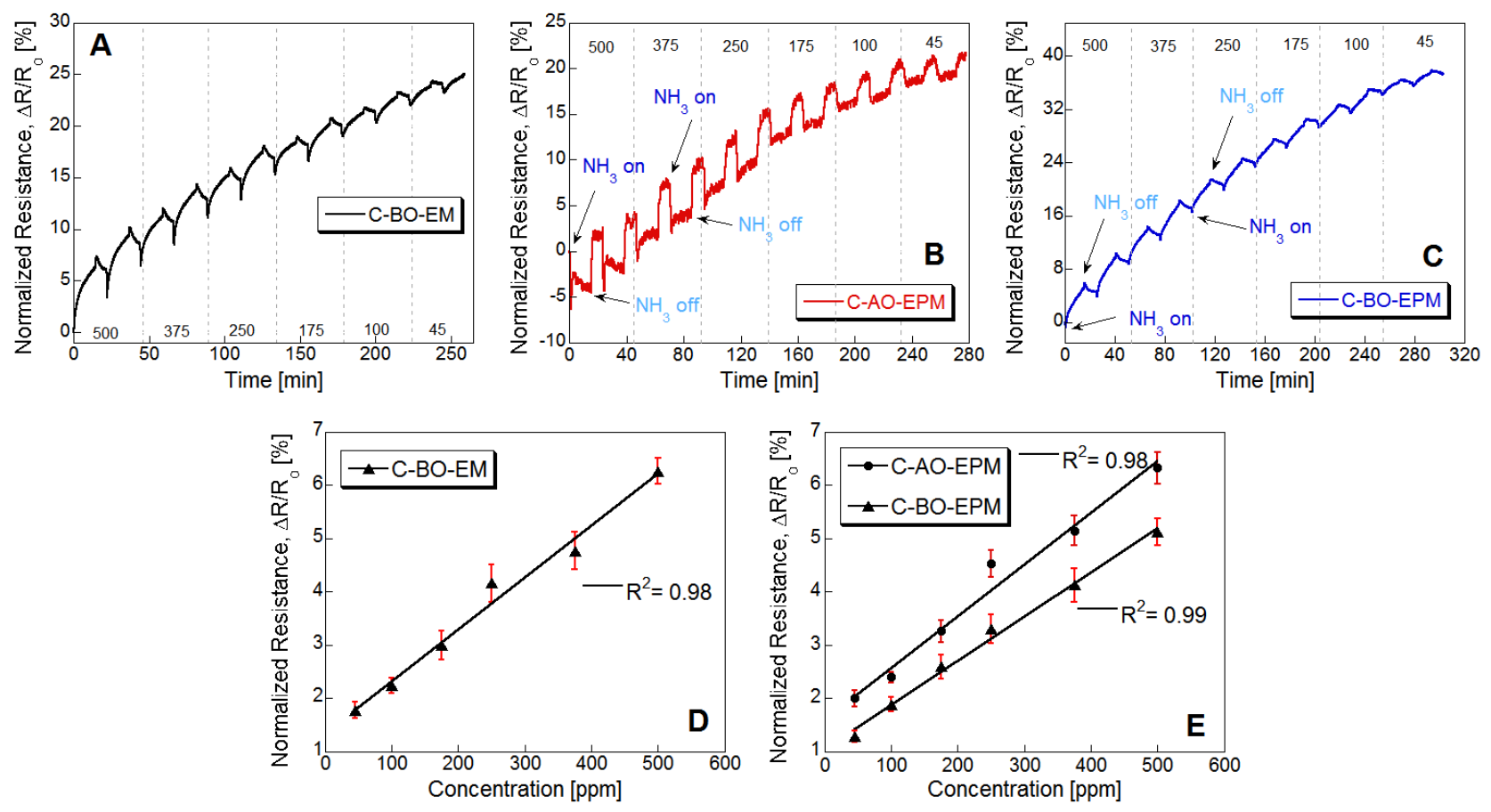

Figure 7.3. Response curve for (A): $\mathrm{C}-\mathrm{BO}$ upon the direct exposure to $\mathrm{NH}_{3} /$ moist air cycles, $(\mathrm{B}$, $\mathrm{C})$ : $\mathrm{C}-\mathrm{AO}$ and $\mathrm{C}-\mathrm{BO}$ after a $2 \mathrm{~h}$ prehumidification, and dependence of the normalized resistance 
change on the various ammonia concentrations for (D): C-BO without prehumidification, and (E): $\mathrm{C}-\mathrm{AO}$ and $\mathrm{C}-\mathrm{BO}$ with prehumidification. ${ }^{132}$

Table 7.1. Change of normalized resistance $\Delta R / R_{0}(\%)$ of the $C-A O$ and $C-B O$ carbon chips upon exposure to various ammonia concentrations in the moist conditions. ${ }^{132}$

\begin{tabular}{lrrrr}
\hline \multicolumn{5}{c}{$\begin{array}{c}\text { \% change of normalized } \\
\text { resistance }\left(\Delta \mathrm{R} / \mathrm{R}_{\mathrm{o}}\right)\end{array}$} \\
\hline Concentration $(\mathrm{ppm})$ & C-AO-EM & C-BO-EM & C-AO-EPM & C-BO-EPM \\
\hline 500 & 34.85 & 6.27 & 6.33 & 5.13 \\
375 & 26.60 & 4.77 & 5.15 & 4.13 \\
250 & 23.07 & 4.17 & 4.53 & 3.30 \\
175 & 17.02 & 3.00 & 3.26 & 2.60 \\
100 & 12.14 & 2.24 & 2.40 & 1.89 \\
45 & 9.52 & 1.78 & 2.00 & 1.28 \\
\hline
\end{tabular}

\subsection{Influence of moisture on the strength of ammonia adsorption}

The measured breakthrough curves of our carbons along with the desorption curves and ammonia breakthrough capacities are presented in Figure 7.4. For the breakthrough tests the carbons were either exposed directly to a wet $\mathrm{NH}_{3}$ stream ( $70 \%$ humidity) or they were exposed to moist air for $2 \mathrm{~h}$, before their exposure to a wet ammonia stream. The suffixes -EM and -EPM were added to the names of the exhausted carbon samples in both experiments, respectively.

For C-AO carbon water caused a slight improvement of ammonia retention when being preadsorbed on its surface (Figure 7.4). Water being present in the target gas, on the other hand, did not cause any enhancement in the ammonia retention. The neutral effect of water on the ammonia uptake is attributed to a competition between the two molecules (water and ammonia) 
for the same adsorption sites. ${ }^{132,133}$ Water seems to play an enhancing role in the $\mathrm{NH}_{3}$ adsorption on the surface of the C-BO carbon. This is linked to the effect of $\mathrm{H}_{2} \mathrm{O}$ on the sample's acidity, which favors the deprotonation of carboxylic groups. ${ }^{98}$ Such species can then chemically react with ammonium ions forming ammonium salts. When a $2 \mathrm{~h}$ prehumidification of the adsorbents was applied, gaps between the adsorption and desorption curves indicate the weak nature of interactions between ammonia and the carbon surfaces. As mentioned in Chapter 4, such gaps are due to the lack of data above the limit of the sensor that is $100 \mathrm{ppm}$ of ammonia.
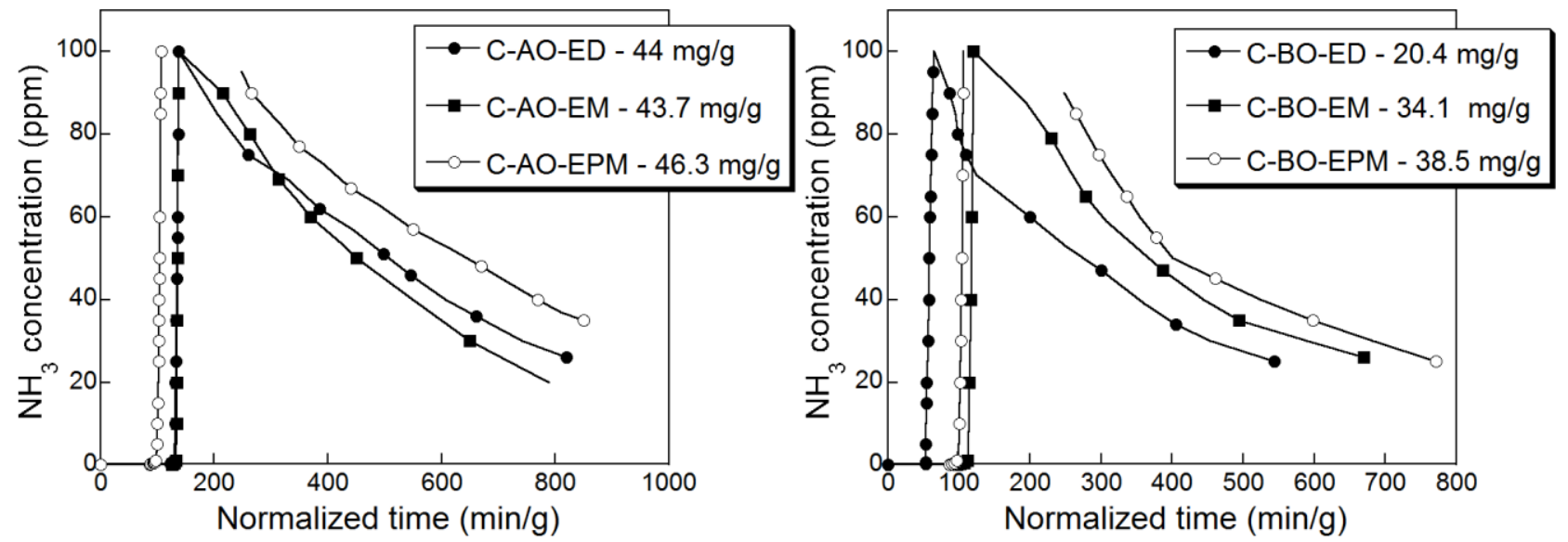

Figure 7.4. Ammonia breakthrough and desorption curves for C-AO and C-BO. ${ }^{132}$

\subsection{Changes in the porosity of the carbons upon exposure to water}

Water adsorption on activated carbons differs from that of other fluids $\left(\mathrm{CO}_{2}, \mathrm{~N}_{2}\right.$, hydrocarbons). Thus, unlike in the case of other fluids, in water adsorption, fluid-fluid interactions are much stronger than the interactions of water with the surface of the carbons'. Furthermore, water adsorption is predominantly controlled by the $\mathrm{H}$-bonding between its molecules $\left(\mathrm{H}_{2} \mathrm{O}\right.$ molecules $)$ and the O-containing surface functional groups. ${ }^{134}$ This suggests that the pore-filling mechanism in the case of water also differs compared to other fluids. Indeed, in the case of most other fluids, pore filling involves the formation of fluid monolayers on the surface of the carbon, followed by capillary condensation. Pore filling with water molecules on the other hand involves their 
adsorption on the oxygen containing groups of the carbon surface, where they act as nuclei for the formation of larger water clusters. The connection of these clusters across the pores causes their filling. ${ }^{134}$ Thus, the porosity of the carbons is a crucial parameter controlling ammonia sensing in moist conditions.

The parameters of the porous structure for $\mathrm{C}-\mathrm{AO}$ and $\mathrm{C}-\mathrm{BO}$ before and after ammonia adsorption, in moist conditions are presented in Table 7.2. ${ }^{132}$ Based on the results, the two exhausted carbon series, either when moisture was present in the challenging gas or water was preadsorbed on the adsorbents' surface, exhibit opposite changes in the volume of their pores, upon exposure to $\mathrm{NH}_{3}$. More precisely, for C-AO-EM and C-AO-EPM the volume of mesopores and micropores decreases likely as a result of the deposition of the formed reaction products on the entrances of their pores. For C-BO-EM and C-BO-EPM, on the other hand, the volume of mesopores increases, while changes in the ultramicropore volumes are almost negligible. Such an increase in the mesopores volume might be explained by the removal of bulky functional groups and/or carbon atoms from the walls of micropores. ${ }^{132}$

To be able to evaluate the observed changes in the porosity of the exhausted samples, the specific surface chemistry of the carbons, which affects their affinity to adsorb water was extensively analyzed. 
Table 7.2. Parameters of the porous structure calculated from the nitrogen adsorption isotherms, for $\mathrm{C}-\mathrm{AO}$ and $\mathrm{C}-\mathrm{BO}$ before and after ammonia exposure, in both dry and humid conditions. ${ }^{132}$

\begin{tabular}{lcccccccc}
\hline Sample & $\begin{array}{c}\mathrm{S}_{\text {BET }} \\
{\left[\mathrm{m}^{2} / \mathrm{g}\right]}\end{array}$ & $\begin{array}{c}\mathrm{S}_{\text {NLDFT }} \\
{\left[\mathrm{m}^{2} / \mathrm{g}\right]}\end{array}$ & $\begin{array}{c}\mathrm{V}_{\mathrm{t}} \\
{\left[\mathrm{cm}^{3} / \mathrm{g}\right]}\end{array}$ & $\begin{array}{c}\mathrm{V}_{\text {meso }} \\
{\left[\mathrm{cm}^{3} / \mathrm{g}\right]}\end{array}$ & $\begin{array}{c}\mathrm{V}_{\text {mic }} \\
{\left[\mathrm{cm}^{3} / \mathrm{g}\right]}\end{array}$ & $\begin{array}{c}\mathrm{V}_{<0.7 \mathrm{~nm}} \\
{\left[\mathrm{~cm}^{3} / \mathrm{g}\right]}\end{array}$ & $\begin{array}{c}\mathrm{V}_{<1 \mathrm{~nm}} \\
{\left[\mathrm{~cm}^{3} / \mathrm{g}\right]}\end{array}$ & $\mathrm{V}_{\text {mic }} / \mathrm{V}_{\mathrm{t}}$ \\
\hline${ }^{\mathrm{a} C-A O}$ & 727 & 995 & 0.363 & 0.024 & 0.339 & 0.215 & 0.281 & 0.93 \\
${ }^{\mathrm{b} C-A O-E D}$ & 554 & 761 & 0.301 & 0.054 & 0.247 & 0.182 & 0.203 & 0.82 \\
C-AO-EM & 543 & 792 & 0.272 & 0.014 & 0.258 & 0.191 & 0.218 & 0.95 \\
C-AO-EPM & 496 & 728 & 0.247 & 0.011 & 0.236 & 0.176 & 0.204 & 0.83 \\
${ }^{\mathrm{a} C-B O}$ & 847 & 1183 & 0.458 & 0.060 & 0.398 & 0.266 & 0.339 & 0.87 \\
${ }^{\mathrm{b}}$ C-BO-ED & 823 & 1143 & 0.453 & 0.075 & 0.378 & 0.273 & 0.320 & 0.83 \\
C-BO-EM & 852 & 1189 & 0.486 & 0.097 & 0.389 & 0.271 & 0.332 & 0.80 \\
C-BO-EPM & 859 & 1200 & 0.492 & 0.100 & 0.392 & 0.275 & 0.335 & 0.80 \\
\hline
\end{tabular}

$\overline{\mathrm{a}, \mathrm{b}}$ Data taken from Reference [122]. Copyright 2017, with permission from Elsevier [122].

\subsection{Influence of moisture on the surface chemical features of the carbons}

To understand how water can influence the surface chemical features of the carbons tested and thus their electrical behavior in moist conditions, the initial and exhausted samples after the $\mathrm{NH}_{3}$ breakthrough test were extensively characterized. To evaluate the role of moisture, the breakthrough test was performed with a flow of ammonia diluted in a moist air stream (70\% humidity). The ammonia breakthrough test same test was also performed after applying a $2 \mathrm{~h}$ prehumification of the carbons.

Figure 7.5 presents the results of the potentiometric titration experiments. The dissolution of ammonia in water and/or its acid-base reactions with acidic surface functional groups is supported by the presence of peaks at pKa 9-10, assigned to $\mathrm{NH}_{4}{ }^{+} \cdot{ }^{132}$ For C-AO-EPM the intensity of this 
peak is significantly smaller compared to that for CAO- EM. In the case of the C-BO exhausted carbon series, these peaks have the highest intensities than those for the C-BO-EM series.
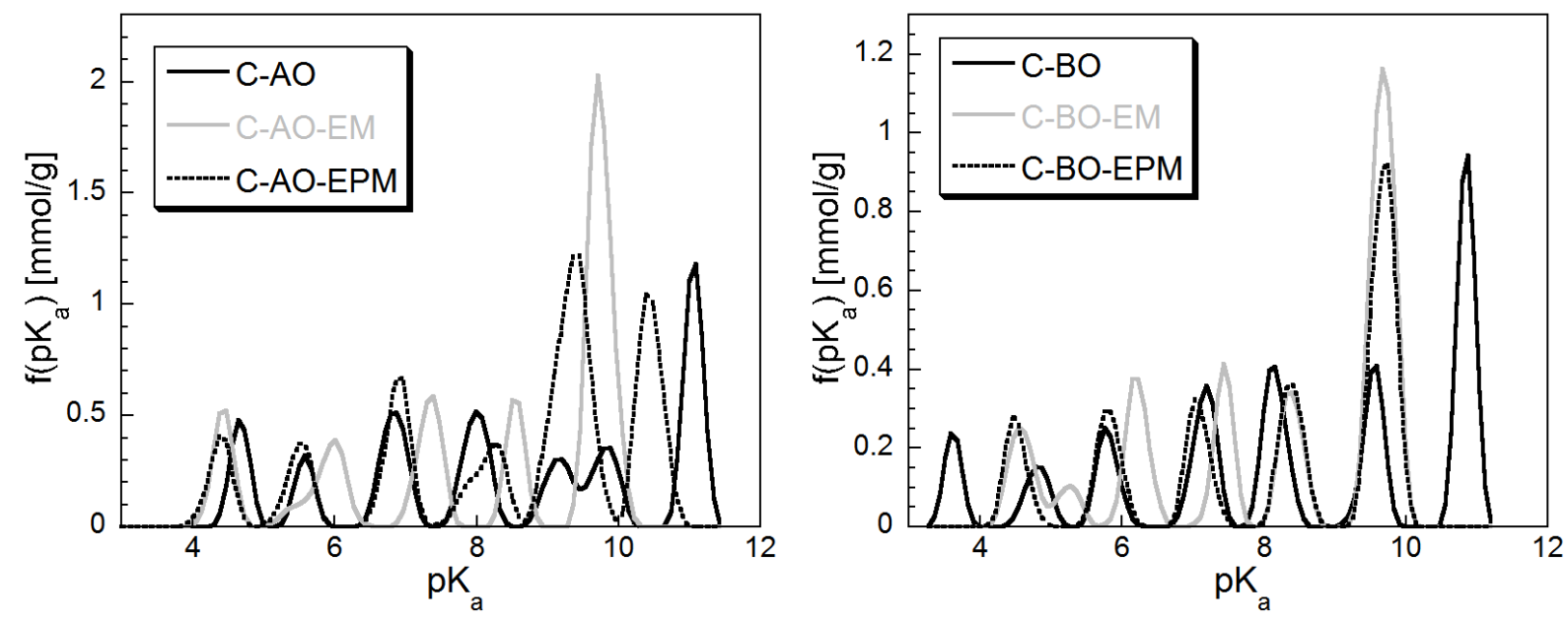

Figure 7.5. The $\mathrm{pK}_{\mathrm{a}}$ distributions of the species present on the surfaces of the initial and exhausted C-AO and C-BO carbons, in both dry and humid conditions. ${ }^{132}$

To account for differences in the species detected on the surfaces of the two sample series, the nature of the surface functional groups as well as the potential interactions between ammonia, water and the surface of the carbons were further analyzed.

The results of the XPS analyses, including the content of elements on the surface (in atomic \%), and the deconvolution results of the core energy level spectra are presented in Figure 7.6. ${ }^{132}$ Among all samples, C-BO-EM shows the most pronounced changes in the total content of O, N and S. More precisely, compared to C-BO it shows a fourfold increase in the total content of -N, and an almost threefold decrease in the total content of $-\mathrm{O}$ (Figure 7.6A). This indicates the high reactivity of this sample with $\mathrm{NH}_{3}$ through the oxygen-containing functional groups, which would lead to the incorporation of more nitrogen to its surface. 
The deconvolution results of the $\mathrm{S} 2 p$ core level spectra (Figure 7.6E) indicate an increased contribution of reduced sulfur species accompanied by a decreased contribution of $-\mathrm{S}$ in sulfones and sulfoxides, for C-AOEM, C-BO-EM and C-BO-EPM. For C-AOEPM, negligible changes in the relative concentration of sulfur in the reduced forms are observed. Knowing that this sample (C-AO-EPM) shows an increase in the contribution of superoxide ions $\left(\mathrm{O}_{2}{ }^{-}\right)$, based on the deconvolution of $\mathrm{O} 1 s$, the results suggest that it underwent some degree of surface oxidation. ${ }^{132}$

Due to the variety of species existing at each of the six distinguished energies in the $\mathrm{N} 1 s$ core energy level spectra, the species at $398.7 \mathrm{eV}, 400.1 \mathrm{eV}, 401.3 \mathrm{eV}$ and $402.5 \mathrm{eV}$ are referred to as $\mathrm{N}-1, \quad \mathrm{~N}-2, \quad \mathrm{~N}-3$ and $\mathrm{N}-4$, respectively. N-1 category includes pyridines, N-2 pyrroles/ammonia/amines/amides, N-3-quaternary nitrogen and/or protonated amines and N-4$\mathrm{NH}_{4}{ }^{+}$and/or $\mathrm{NO}_{2}$ species. An increase in the relative concentration of pyridines $(\mathrm{N}-1)$, pyrroles and amines (N-2) is observed in moist conditions, compared to dry ones (Figure 7.6D). N-1 and $\mathrm{N}-2$ type nitrogen functionalities are known to promote the formation of superoxide ions $\left(\mathrm{O}_{2}^{-}\right.$ ). ${ }^{123,126}$ This is related to the activation of the surface oxygen by electrons donated from the nitrogen atoms of these species. ${ }^{122,134}$ The reaction of $\mathrm{NH}_{3}$ with superoxide ions $\left(\mathrm{O}_{2}{ }^{-}\right)$may lead to the formation of $\mathrm{NO}$ and $\mathrm{N}_{2} \mathrm{O}$, as a result of ammonia partial oxidation. ${ }^{107,135-137} \mathrm{O}_{2}{ }^{-}$can also further transform the relatively unreactive $\mathrm{NO}$ to $\mathrm{NO}_{2}$, which is a strong oxidant. ${ }^{1}$ Thus, an increased contribution of $\mathrm{NO}_{\mathrm{x}}$ species in the case of the exhausted samples is likely attributed to the oxidizing activity of $\mathrm{O}_{2}^{-}$towards ammonia.

The deconvolution of the N $1 s$ core energy level spectra also shows that C-BO-EM exhibits the largest increase in the contribution of $\mathrm{NH}_{4}{ }^{+}(\mathrm{N}-4)$. As aforementioned, these species are the result of the acid-base reactions of ammonia with surface acidic functional groups, and their detection is in agreement with the results obtained from potentiometric titration for the same sample. Based on 
the deconvolutions of the $\mathrm{C} 1 s, \mathrm{O} 1 s$, and $\mathrm{S} 2 p$ core energy level spectra, such acidic groups are sulfonic and carboxylic acids, whose contribution decreases after ammonia adsorption. C-BOEPM also shows changes in the contribution of acidic groups, however, unlike C-BO-EM, it exhibits an increase rather than a decrease of sulfonic acids. In the case of this sample (where prehumidification was applied), the formation of ammonium ions is linked mainly to the dissolution of $\mathrm{NH}_{3}$ in the water preadsorbed on the carbon's surface, rather than to acid-base interactions.

Based on the deconvolution of $\mathrm{N} 1 s$, for both exhausted carbons in moist conditions $(\mathrm{C}-\mathrm{AO}$ and $\mathrm{C}-\mathrm{BO})$, the contribution of amines and pyrrolic groups $(\mathrm{N}-2)$, shows differences compared to the same carbons exposed to ammonia in dry conditions. More precisely, while the contributions of amines and pyrroles slightly decreased on the surface of C-AO-EM upon ammonia exposure, they increased in the case of C-AO-EPM, C-BO-EM and C-BO-EPM. This increase was about $27 \%$ for the two latter samples. This indicates that the interaction pathway of ammonia with the carbon matrices is different for each carbon series. Considering that both carbons exhibit similar surface functional groups, to account for these differences, the accessibility of water to the pore system of each carbon and the extent of $\mathrm{NH}_{3}$ dissolution are crucial matters that need to be considered. 

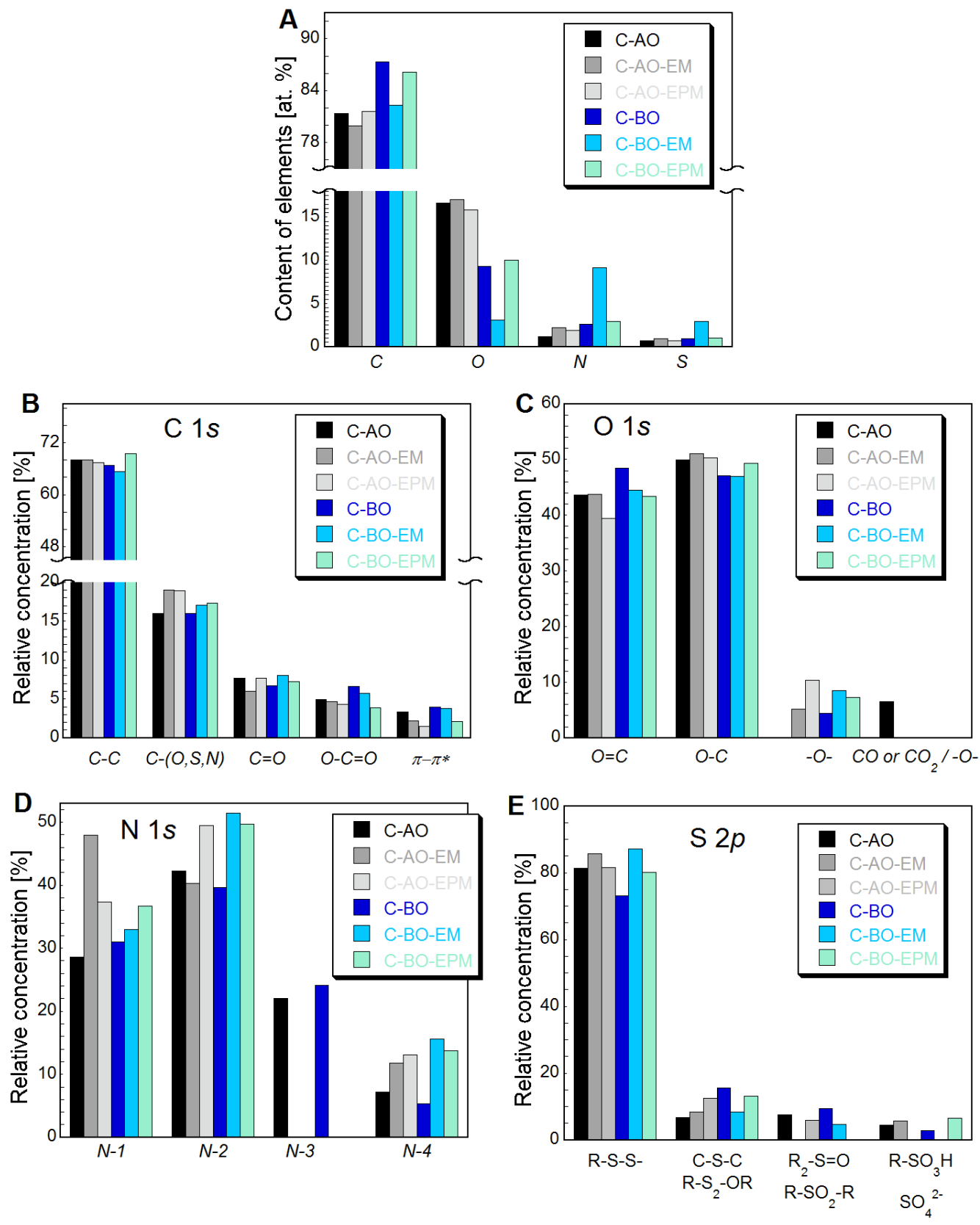

Figure. 7.6 A) Content of elements; B-E) Surface concentration of the specific carbon, oxygen, nitrogen and sulfur groups on the initial and exhausted $\mathrm{C}-\mathrm{AO}$ and $\mathrm{C}-\mathrm{BO}$ carbons, in both dry and humid conditions. Due to the complexity of the species, the components of the $\mathrm{N} 1 s$ core energy level spectra are referred to as $\mathrm{N}-1$ (pyridines), N-2 (pyrroles/ammonia/amines/amides), N-3 (quaternary nitrogen and/or protonated amines) and N-4 ( $\mathrm{NH}_{4}{ }^{+}$and/or $\mathrm{NO}_{\mathrm{x}}$ species). ${ }^{132}$ 


\subsection{Influence of water on the sensing mechanism}

\subsubsection{Competition between ammonia and water molecules}

Based on the electrical response of the carbon chips (Figures 7.2 and 7.3) and the extensive carbon surface characterization, a sensing mechanism is proposed. This mechanism is complex and includes several stages which are presented in Figure 7.7. ${ }^{132}$ Figure $7.7 \mathrm{~A}$ illustrates a typical sensing cycle for both $\mathrm{C}-\mathrm{AO}$ and $\mathrm{C}-\mathrm{BO}$ when moisture is present in the carrier gas without a prior prehumidification step. As seen from, upon the exposure of the carbon chips to ammonia, the normalized resistance slightly decreases (IA), which is followed by its well marked increase, (IIA). Upon purging the chamber with moist air an increase in the normalized resistance (IIIA), followed by a decrease in the same parameter (IVA)) is measured. As already mentioned earlier in this Chapter (section 7.4) for C-AO-EM and C-BO-EM carbons a competition between ammonia and water for the same adsorption sites occurs. More precisely, water molecules tend to occupy some of the carbon sites that would otherwise be available for interactions with $\mathrm{NH}_{3} .{ }^{132,133}$ Such sites consist of -O, $-\mathrm{S}$ and $\mathrm{N}$-containing surface functional groups, including sulfoxides, sulfones, thiols, phenols, alcohols, carboxylic groups, positively charged pyridine-N-oxides, and negatively charged pyridines. ${ }^{132}$ This competition is visible in the electrical behavior of the carbon chips in the parts of the cycle (Figure 7.7A) where normalized resistance decreases (IA and IVA). The same competition is also observed for the C-BO-EPM sample, which, based on Figure 7.3Cshowed a similar sensing response to that of $\mathrm{C}-\mathrm{AO}$ and $\mathrm{C}-\mathrm{BO}$ when water was directly supplied to the system as a part of the challenge gas. 

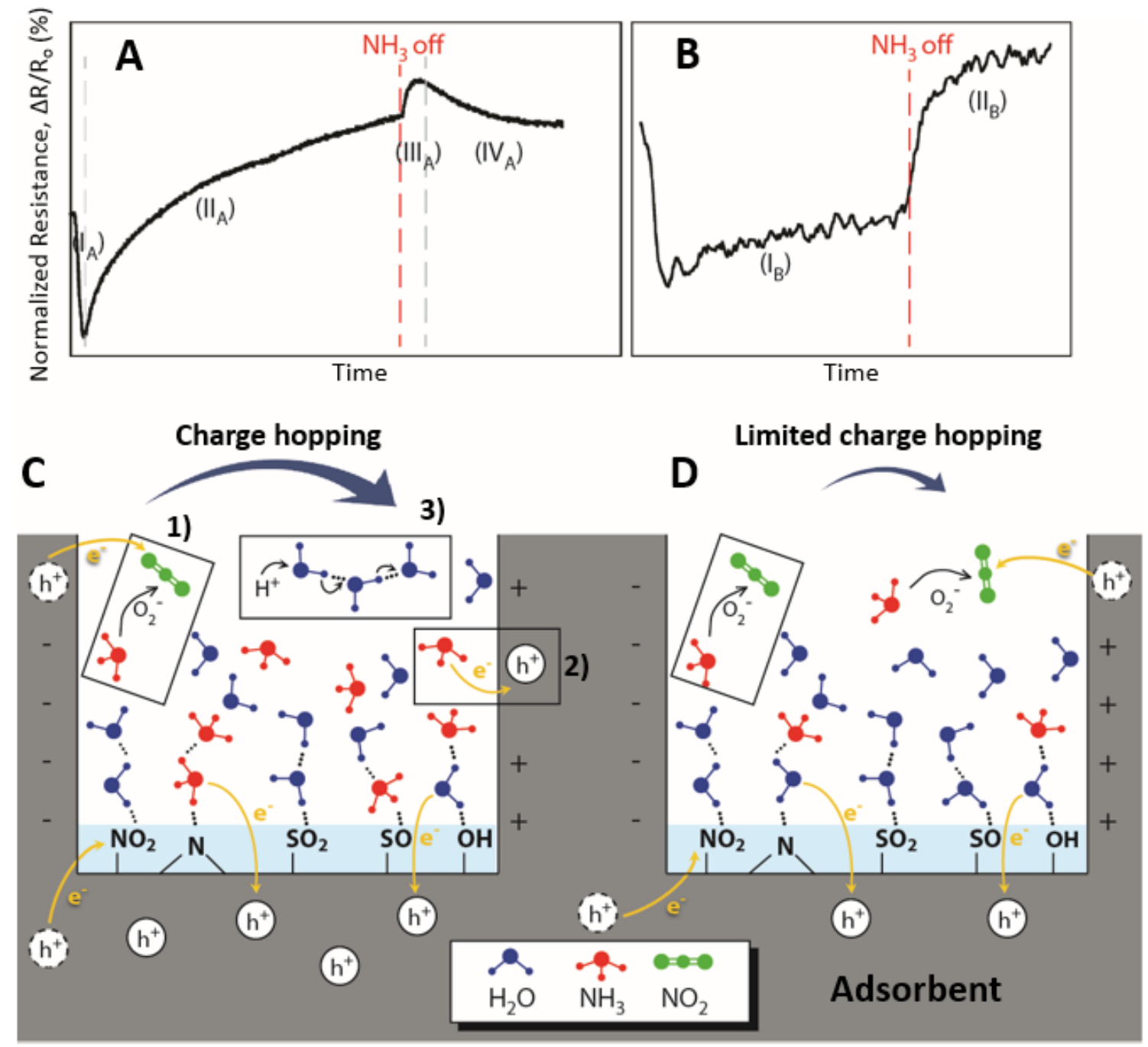

Figure 7.7. (A): Typical response curves for both carbons, during an $\mathrm{NH}_{3} /$ air cycle, without prehumidification (B): Typical response curve for $\mathrm{C}-\mathrm{AO}$, during an $\mathrm{NH}_{3} /$ air cycle, with water being preadsorbed on its surface. (C): Sensing mechanisms that correspond to the electrical outcome of Figure 6A. (6C-1: hole formation due to the electron withdrawing character of $\mathrm{NO}_{2}$, 6C-2: hole deletion by electrons donated by ammonia, 6C-3: proton transport mechanism) (D): Sensing mechanisms that corresponds to the electrical outcome of Figure $6 \mathrm{~B}-\mathrm{A}$ high surface coverage of water molecules "blocks" those sites on the carbon's surface, which would be otherwise available for weak interactions with ammonia, therefore leading to a limited charge hopping mechanism. ${ }^{132}$ 


\subsubsection{Ammonia diffusion and weak interactions}

Owing to their non-bonding electrons, ammonia and water can participate in weak physical interactions (specific and non-specific) with the surface functional groups. These interactions include hydrogen bonding, dipole/dipole interactions and dispersive forces. Oxygen-containing groups and particularly hydroxyl groups are known to favor a hydrogen bonding, but in our case other nitrogen and sulfur containing functionalities (e.g. sulfoxides, sulfones, thiols, phenols, $\mathrm{NO}_{2}$ ) can also participate in such interactions. ${ }^{132}$ They can take place when a moist gas stream is directly supplied to the system, and in the case when the prehumidification was carried out. Such weak interactions of the surface functional groups with ammonia molecules enable electron transport across the smaller pores of the carbon matrix, through charge hoping mechanisms. ${ }^{13}$ As a result, a decrease in the normalized resistance occurs. The above mentioned weak interactions by enabling electron transport across the smaller pores of the carbon matrix, through charge hoping mechanisms, ${ }^{120}$ result to a decrease in the normalized resistance. This resistance decrease is illustrated in stage $\mathrm{I}_{\mathrm{A}}$ and $\mathrm{I}_{\mathrm{B}}$ of Figure 7.7A that shows a typical sensing cycle for C-AO-EM, CBO-EM and C-BO-EPM, and Figure 7.7B which shows a typical response cycle of C-AO-EPM.

\subsubsection{Depletion of charge carriers by $\mathrm{NH}_{3} / \mathrm{H}_{2} \mathrm{O}$}

The ability of ammonia and water to donate electrons is another mechanism that governs the electrical response of $\mathrm{C}-\mathrm{AO}$ and $\mathrm{C}-\mathrm{BO}$ carbons. ${ }^{132}$ The conduction type of these carbons was addressed earlier in Chapter 5, and it was found that they both exhibit $p$-type conductivity. ${ }^{85}$ This means that positively charged holes $\left(\mathrm{h}^{+}\right)$are the predominant charge carriers. Figure $7.7 \mathrm{~A}-\mathrm{II}_{\mathrm{A}}$ shows that the initial resistance decrease upon ammonia exposure is followed by a slower process that causes the resistance to increase. At this stage the weak interactions, which initially caused the resistance of the carbon chips to decrease upon $\mathrm{NH}_{3}$ exposure (IA), are not involved in the 
electrical response any longer. Instead, this stage involves a diffusion process and the reequilibration of chemical species adsorbed or dissolved inside the pores. An increase in the normalized resistance (or decrease in the conductivity) is related to the ability of ammonia but also of water present in the gas stream to donate electrons, causing a depletion of the positively charged holes $\left(h^{+}\right)$. The depletion of the charge carriers is a mechanism that governs the electrical response of C-AO/C-BO as well as of C-AO-EPM, during the purging stage with moist air. This is illustrated in Figures 7.7A-stage $\mathrm{III}_{\mathrm{A}}$ and 7.7B-stage $\mathrm{II}_{\mathrm{B}}$, respectively. In this case electrons donated solely by water molecules are responsible for the increase in the normalized resistance. ${ }^{132}$

\subsubsection{Ammonia dissolution in water}

When C-AO and C-BO were tested as ammonia sensors in dry conditions (Chapter 5), it was found that exposure to $\mathrm{NH}_{3}$ caused a rapid decrease in the normalized resistance, followed by its increase upon air purging. ${ }^{85}$ Figure 7.7 indicates that when purging the system with a flow of ammonia diluted in moist air, unlike in the case of dry conditions, a resistance increase is found (Figure 7.7A- $\left.\mathrm{II}_{\mathrm{A}}\right)$. This resistance increase is caused by both hole depletion by electrons donated by $\mathrm{NH}_{3} / \mathrm{H}_{2} \mathrm{O}$, and the dissolution of $\mathrm{NH}_{3}$ in water. ${ }^{133}$ Since $\mathrm{NH}_{3}$ dissolved in water is weakly retained on the surface, it easily desorbs, together with water, upon purging the system with moist air. ${ }^{132}$ Such a process can occur in both cases whether moisture is part of the challenging gas or present on the carbons' surface (as a result of the $2 \mathrm{~h}$ prehumidification step). Ammonia dissolution in water is considered as a specific mechanism that is based on the hydrophilic nature of $\mathrm{NH}_{3}$, and thus is enhanced by the existence of surface functional groups that increase the hydrophilicity level of the adsorbents. Such groups favor the formation of weak physical interactions with the molecules of the ammonia (mainly hydrogen bonding or dipole-dipole interactions). ${ }^{133}$ Since ammonia dissolved in water is weakly retained on the carbons' surface, it can be easily released 
upon purging the system with moist air. The removal of $\mathrm{NH}_{3}$ molecules upon moist-air purging is illustrated by an increase in the normalized resistance in Figures 7.7A- $\mathrm{III}_{\mathrm{A}}$ and $7.7 \mathrm{~B}-\mathrm{II}_{\mathrm{B}}$.

\subsubsection{Ionic conductivity through proton transport}

Another mechanism that is involved in the electrical response of the carbon chips in moist conditions, involves ionic conductivity through proton transport, ${ }^{132}$ and is related to the presence of water in the system. During the purging stage of the sensors with moist air (Figure 7.7A-III and $7 \mathrm{~A}-\mathrm{IV}_{\mathrm{A}}$ ), or at high humidity levels, more water molecules enter the system. They are adsorbed on various $\mathrm{O}-, \mathrm{S}-$ and $\mathrm{N}$-containing surface functional groups, and in such positions they act as nuclei for the formation of larger water clusters, which connect either across the pore or along the surface..$^{5}$ This gradually leads to the pore filling and eventually to the formation of a water layer/film. ${ }^{5}$ Since the surface $\mathrm{pH}$ of $\mathrm{C}-\mathrm{AO}$ and $\mathrm{C}-\mathrm{BO}$ carbons is acidic ( $\mathrm{pH}$ of 3.53 and 4.03 for

C-AO and C-BO, respectively), ${ }^{85,122}$ the adsorbed water molecules get ionized forming hydronium ions $\left(\mathrm{H}_{3} \mathrm{O}^{+}\right)$, which become the main charge carriers. Hydronium ions get in turn hydrated into $\mathrm{H}^{+}$ and $\mathrm{H}_{2} \mathrm{O}$, and the acceptance of a $\mathrm{H}^{+}$from an adjacent $\mathrm{H}_{2} \mathrm{O}$ molecule occurs. This in turn releases another $\mathrm{H}^{+}$(Figure 7.7C-3). ${ }^{132}$ This mechanism that involves proton transport through ionic conductivity is the well-known Grotthuss reaction, ${ }^{138}$ and is responsible for the recorded resistance decrease (Figure 7.7A-IIIA).

\subsubsection{Hydrophilicity as an important factor}

When water is a part of the challenge gas CAO exhibits 5.5 times larger changes in the normalized resistance than does $\mathrm{C}-\mathrm{BO}$ (34.9\% for $\mathrm{C}-\mathrm{AO}$ vs 6.3\% for $\mathrm{C}-\mathrm{BO}$ ) (Figures 7.2 and 7.3A and Table 7.1). The differences in the sensitivity of these two carbons can be explained by the differences in the affinity of their surface to adsorb water, and thus by their hydrophilicity. Comparison of the amount of water adsorbed on the surface of each sample, (8.9\% on $\mathrm{C}-\mathrm{AO}$ and $3.8 \%$ on $\mathrm{C}-\mathrm{BO})$ 
indicates that $\mathrm{C}-\mathrm{AO}$ is more hydrophilic than is $\mathrm{C}-\mathrm{BO} .{ }^{132}$ This is in agreement with the XPS results, which indicated that at $\%$ of $\mathrm{O}$ of $\mathrm{C}-\mathrm{AO}$ is higher than that of $\mathrm{C}-\mathrm{BO}$ (Figure 7.6C). This means that the former sample likely has a higher content of oxygen-containing polar functional groups which enhance its affinity towards the adsorption of polar molecules (such as water or ammonia). A higher susceptibility of C-AO to water compared to that of C-BO allows a higher amount of $\mathrm{NH}_{3}$ to be retained on its surface through the dissolution process (in water). This in turn leads to enhanced signal changes for $\mathrm{C}-\mathrm{AO}$ compared to that of $\mathrm{C}-\mathrm{BO} .{ }^{132}$ Moreover, as expected, in the case of the most hydrophilic carbon (C-AO), an enhanced electrical response is also linked to the contribution of water to its sensing capability. As aforementioned, the water contribution would involve weak interactions, electron donation and ionic conductivity through the proton transport. Upon prehumidification of the system, both C-AO-EPM and C-BO-EPM show the suppressed signal changes (Figure 7.3 and Table 7.1). Moreover, the two samples show differences in the trend of their electrical signal changes (Figures 7.3B and 7.3C). More precisely, C-BO-EPM shows a sensing response similar to that when water was directly supplied to the system as a part of the challenge gas (C-AO-EM), and a competition between $\mathrm{NH}_{3}$ and $\mathrm{H}_{2} \mathrm{O}$ occurred. The C-AO-EPM sample, on the other hand, shows a different shape of the sensing curves (Figure 7.3B). A different hydrophilicity level of the carbons can offer a plausible explanation for these differences. For CBO a limited coverage of its surface by water molecules leaves available sites for the adsorption of ammonia molecules, which explains the observed competition of the two molecules for the same adsorption sites. In the case of the highly hydrophilic $\mathrm{C}$-AO carbon on the other hand, preadsorption of water on its surface led to strongly suppressed changes in the normalized resistance. This can be explained by the pore-filling by water molecules and the dissolution of ammonia in the formed water film. Considering that $\mathrm{H}_{2} \mathrm{O}$ molecules tend to first fill the small pores 
of an adsorbent and then the larger ones, ${ }^{133,134}$ more water is expected to be present in the larger pores when prehumidification is preformed than in the case of a direct exposure of the carbons to a moist gas stream. A high surface coverage by $\mathrm{H}_{2} \mathrm{O}$ molecules likely causes the "blocking" of those sites on the carbon's surface, which would otherwise be available to weakly interact with ammonia molecules. This surface coverage by water molecules is illustrated in Figure 7.7D. ${ }^{132}$

\subsection{Influence of different humidity levels}

The influence of different levels of relative humidity $(\mathrm{RH})$ on the ammonia sensing response of nanoporous carbons was further tested. For this purpose, the two best performing carbon composites, which were previously discussed in Chapter 6 (BAX-CS-1\% and BAX-CSN-1\%), were arbitrary chosen. ${ }^{15}$ To conduct the test, they were exposed to $500 \mathrm{ppm}$ ammonia at various humidity levels $(0 \%, 50-55 \%$ and $65-70 \% \mathrm{RH})$. An enhanced electrical response, compared to the dry conditions, is measured at RH 50-55\% (Figure 7.8). Such a behavior is expected since not only ammonia but also water molecules contribute to the electrical response of the carbons through their participation in weak interactions with the carbons' surface functional groups, their ability to donate electrons, and the ionization process.

At higher humidity levels $(65-70 \% \mathrm{RH})$, more water gets adsorbed on the carbon surfaces, and the electrical signals become suppressed, similar to the ones in dry conditions. A lower sensor response at higher humidity levels can be explained based on the pore-filling of the carbon matrices by water molecules and the dissolution of ammonia in the formed water films. As abovementioned, upon the coverage of the surface with $\mathrm{H}_{2} \mathrm{O}$ molecules, the sites on the carbons' surface, which would be otherwise available to participate in weak interactions with ammonia and contribute to the reversible sensing, get "blocked". This leads to a limited sensor operation through weak physical interactions/forces, and thus to the suppressed electrical signal changes. ${ }^{127}$ 


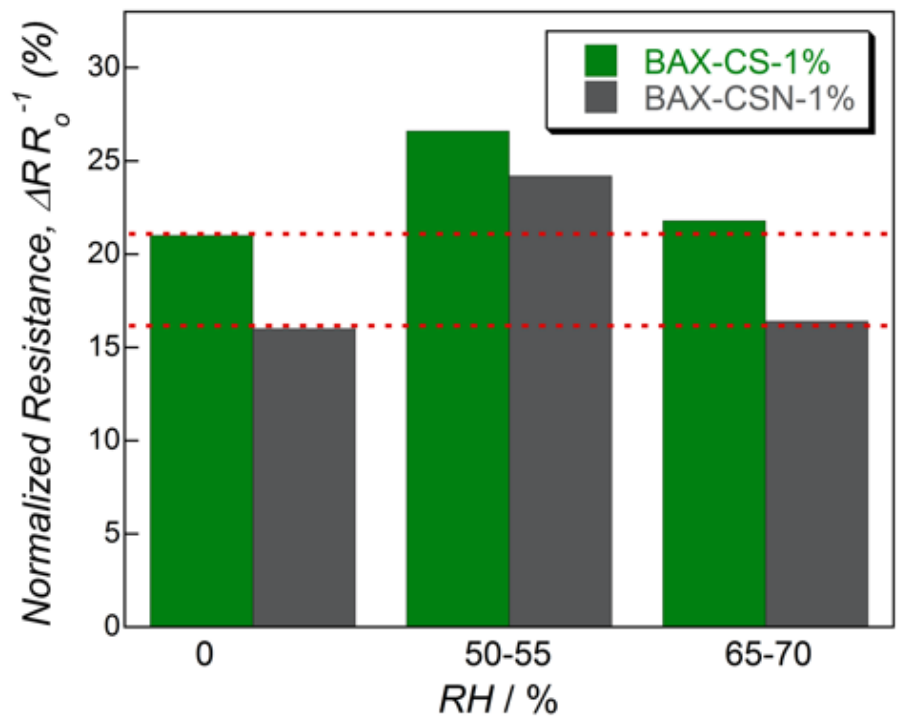

Figure 7.8. Changes in the normalized resistance for the best performing carbon-composite chips from both series tested (BAX-CS-1\% and BAX-CSN-1\%), upon exposure to $500 \mathrm{ppm}$ of ammonia, at different humidity levels. ${ }^{127}$ 


\section{Chapter 8. Summary of mechanisms that govern the ammonia sensing capability of nanoporous carbons and conclusions}

This Chapter summarizes the mechanisms that govern the overall sensing capability of nanoporous carbons and presents the conclusions of this research.

The results obtained indicate that the ammonia sensing capability of nanoporous carbons in dry conditions is governed by a complex mechanism that involves several processes, which affect its extent to various degrees. These processes depend on both, the surface chemical features and the structural properties (porosity) of the carbons. They are briefly described below:

a) Specific interactions of the gas molecules with surface functional groups.

b) Pore filling of a carbon matrix with the molecules of a target gas.

c) Hole-depletion or accumulation in the carbon matrix itself upon the contact with of electron donating $\mathrm{NH}_{3}$ and/or electron withdrawing $\mathrm{NO}_{2}$. As mentioned in Chapter $5, \mathrm{NO}_{2}$ is formed by the partial oxidation of ammonia by superoxide ions.

d) Increase in the DC conductivity due to the presence of liquid-like ammonia in the very small pores $\left(\mathrm{V}_{<1 \mathrm{~nm}}\right)$, which lack functional groups and thus specific interactions cannot occur.

e) Charge transport via ionic conductivity, owing to the formation of $\mathrm{NH}_{4}{ }^{+}$.

f) Finally, a carbon graphitization level is an additional parameter that enhances electron transport through the carbon matrix, and thus contributes to an increase in a sensor sensitivity.

The above-mentioned specific interactions, are weak in nature and include hydrogen bonding, dipole/dipole interactions, dispersive interactions, and fluid-fluid interactions between quasiliquid ammonia molecules physically adsorbed in the small pores via the pore filling mechanism. 
Such weak interactions provide alternate paths for the charge transport across the ultramicropores $(\mathrm{V}<1 \mathrm{~nm})$, through charge hopping mechanisms. This causes the conductivity of the chips to increase upon ammonia exposure. The O-species that can participate in such interactions are hydroxyl, phenol, and carboxylic groups. S-containing functional groups include both oxidized species such as sulfoxides and sulfones, and reduced sulfur species such as thiols. $\mathrm{N}$-containing functional groups are positively charged pyridine-N-oxides, negatively charged pyridines, amines, amides and $\mathrm{NO}_{\mathrm{x}}$ species.

Surface chemistry was found to be a crucial parameter that affects not only the nature of the specific interactions but also the type of the charge carriers, and thus the conduction type of the carbon matrix itself. Based on its specific surface chemistry (specific arrangement of heteroatoms) a carbon can be defined either as a predominantly $p$ - or predominantly $n$-type material. In the former case, where positively charged holes are the main charge carriers, an increase in the normalized resistance was observed upon exposure to ammonia that is an electron donating gas. In the case of $n$-type carbon samples, on the other hand, $e^{-}$are the main charge carriers, and thus an increase in their concentration upon ammonia exposure caused a decrease in the normalized resistance.

The incorporation of heteroatoms to the carbon matrix was an effective way to control the specific surface chemistry and thus surface acidity of the prepared carbons. The latter parameter (surface acidity) was found to play an important role in ammonia sensing by promoting the charge transport via ionic conductivity, due to the formation of $\mathrm{NH}_{4}{ }^{+}$. These species were formed by the acid-base reactions of ammonia with acidic surface functional groups (sulfones and carboxylic/sulfonic acids). The results of this research also indicated that the specific surface chemistry as a parameter affecting the surface acidity of carbons, needs to be controlled for a proper sensing performance. 
Thus, it was found that too strong surface oxidation may have a negative influence on sensing, by a) destroying the substrate/surface of the sensing chips, b) leading to highly resistive materials which lack the capability of providing measurable signal changes, and c) destroying the porosity of the carbons. In the latter case, the destruction of the pore structure was found to diminish the effect of porosity and thus of physical adsorption on sensing. Figure 8.1 illustrates a visualization of the specific interactions (hydrogen bonding, dipole/dipole interactions, dispersive interactions) which take place upon ammonia exposure. 


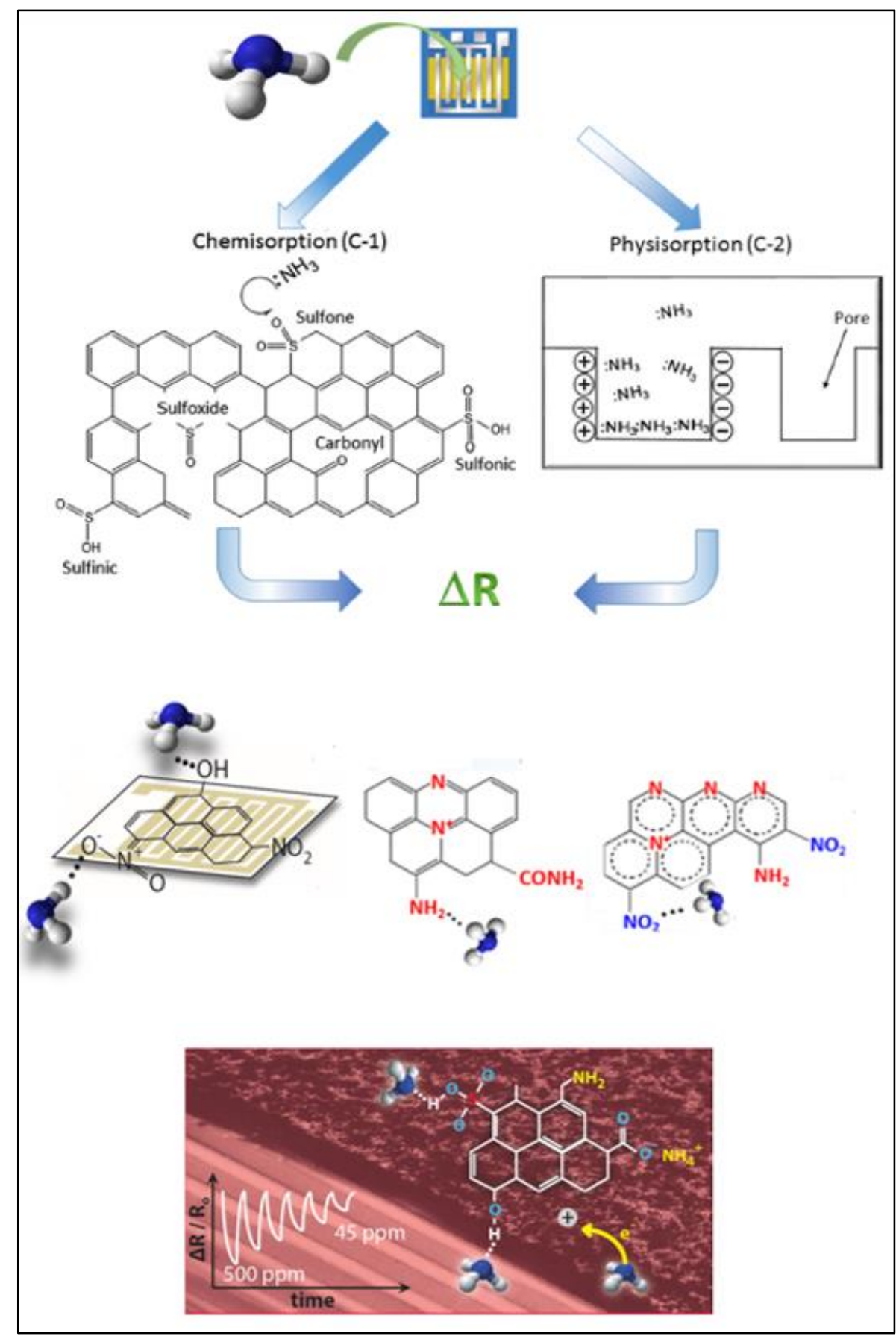

Figure 8.1. A visualization of the specific interactions (hydrogen bonding, dipole/dipole interactions, dispersive interactions) that take place upon ammonia exposure.

The results suggest that both surface chemistry and a porosity (especially micro- and ultramicroporosity) are crucial factors governing the sensing capability of nanoporous carbons. 
We have shown through this research that carbons functionalized with various surface groups but having a low porosity show a negligible ammonia sensing capability. This indicates that a developed pore structure, and especially a micropore structure, is a necessity in ammonia sensing. That is because micro- and ultramicropores function as "channels" promoting $e$ - transport through hopping mechanisms. The relationship, however, between the sensor sensitivity and the volume of micro/ultramicropores, can be either direct or indirect. This indicates that even though porosity is a necessity, it is a non-sufficient condition itself. In the case where sensitivity was not directly dependent on the porosity, and when samples of the similar porosities were compared, surface chemistry was a feature/parameter that predominantly determined the sensing response of the carbons. As above-mentioned, even in that case, however, the existence of a developed pore structure was a necessity. A lack of a porous structure diminished the effect of physisorption on sensing. Even though micropores were indicated as the most crucial pores in ammonia sensing, mesopores also played an important role. They allowed a better accessibility of ammonia molecules to micro/ultramicropores. Furthermore, the deposition of functional groups in mesopores was an additonal pathway for $e$ - transport across the carbon matrix, through their participation in specific interactions with $\mathrm{NH}_{3}$.

Based on the various parameters that influence the capability of nanoporous carbons to operate as ammonia gas senors, the mechanisms and factors that govern their electrical response are summarized in Figure 8.2. 


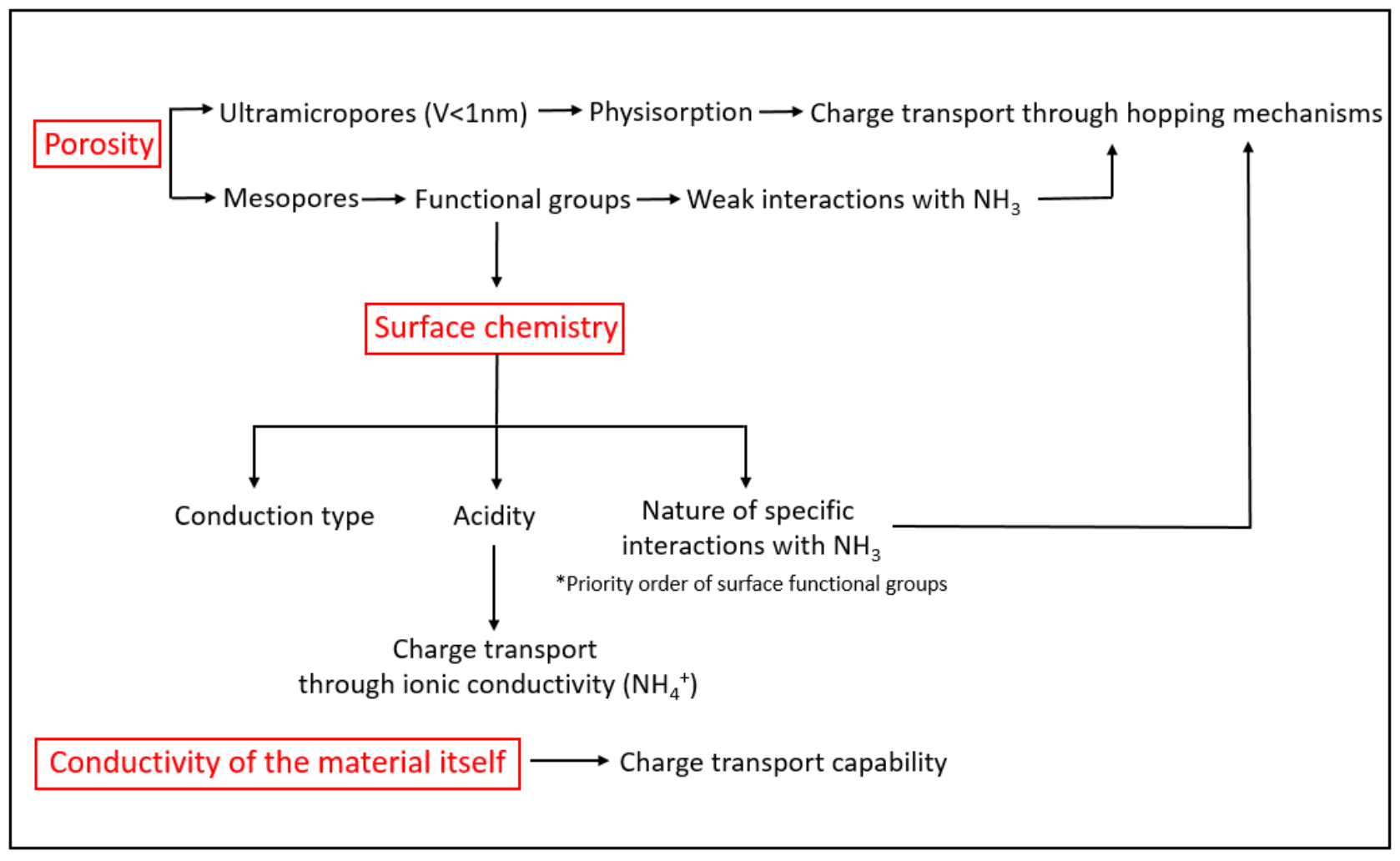

Figure 8.2. The factors that govern the electrical response of nanoporous carbons. ${ }^{127}$

In humid conditions, the sensing mechanism becomes even more complex since not only ammonia, but also water molecules contribute to the electrical response of the carbons. Both molecules compete for the same adsotpion sites on the carbons' surface. The involved mechanisms include the interaction of the ammonia and water molecules with the surface functional groups through weak specific forces, ionic conductivity through proton transport (Grotthuss reaction), and electron/hole conductivity due to the electron donating or withdrawing character of $\mathrm{NH}_{3} / \mathrm{H}_{2} \mathrm{O}$ and $\mathrm{NO}_{2}$, respectively. The latter species were formed by the partial oxidation of ammonia. Pore-filling with water molecules and $\mathrm{NH}_{3}$ dissolution in the formed water layer (or within the pores) was found to primarily govern the electrical response of the carbons in humid conditions. Therefore, the affinity of the carbons to adsorb water (hydrophilicity) is an important parameter to consider. At high levels of humidity (60-70\%), the 
electrical signal changes became suppressed. This was caused by a high surface coverage by water molecules, which limited the interactions of ammonia with the available surface functional groups.

Table 8.1 summarizes the changes in the normalized resistance (sensitivity) of the carbons tested in this research, when exposed to $500 \mathrm{ppm}$ of $\mathrm{NH}_{3}$, in dry conditions. The comparison of the sensitivities for the materials reported in this research (Table 8.1), with those summarized in Table 1.3 of Chapter 1 for modified graphene-based sensors, indicates that the performance of nanoporous carbon-based ammonia sensors is comparable, and in some cases even higher than that of other nanoforms of carbonaceous materials. 
Table 8.1. Changes in the normalized resistance (sensitivity), and response time of the carbons tested in this study, at $500 \mathrm{ppm}$ of $\mathrm{NH}_{3}$, in dry conditions.

\begin{tabular}{|c|c|c|c|}
\hline Carbon-samples & $\begin{array}{l}\text { Sensor sensitivity } \\
(\%)\end{array}$ & $\begin{array}{l}\text { Response time } \\
(\mathrm{sec})\end{array}$ & References \\
\hline \multicolumn{4}{|c|}{ Wood-based carbons } \\
\hline BAX & 19 & 900 & 82 \\
\hline BAX-O & 31 & 120 & 82 \\
\hline BAX-M & 6.1 & 360 & 83 \\
\hline BAX-MO1 & 13 & 120 & 83 \\
\hline BAX-MO1 & 17.4 & 120 & 83 \\
\hline BAX-O1-M & 8 & 480 & 83 \\
\hline BAX-O2-M & 5 & 480 & 83 \\
\hline BAX-O1-M[O1] & 29 & 120 & 83 \\
\hline BAX-O2-M[O1] & 17 & 120 & 83 \\
\hline \multicolumn{4}{|c|}{ Polymer-derived carbons } \\
\hline $\mathrm{C}-1$ & 0.6 & 35 & 84 \\
\hline $\mathrm{C}-2$ & 1.7 & 35 & 84 \\
\hline $\mathrm{C}-\mathrm{AO}$ & 14.1 & 40 & 85 \\
\hline $\mathrm{C}-\mathrm{BO}$ & 6.2 & 40 & 85 \\
\hline PFM-AO & 17 & 120 & 86 \\
\hline RFM-AO & 23 & 78 & 86 \\
\hline PFU-AO & 29 & 50 & 86 \\
\hline \multicolumn{4}{|c|}{ Wood-based/polymer derived-carbon composites } \\
\hline BAX-CS $(1,5,10,25 \%)$ & $21,17,10,7$ & 40 & 127 \\
\hline $\begin{array}{l}\text { BAX-CSN- }(1,5,10,25 \\
\%)\end{array}$ & $16,12,1310$ & 40 & 127 \\
\hline
\end{tabular}

In conclusion, it has been the first time that the ammonia detection on nanoporous carbons was studied. The results of our research allow us to determine the role of the surface chemical and structural features of nanoporous carbons on their conductive properties, and thus their ability to function as efficient ammonia gas sensors. The features that make nanoporous carbons superior to other carbon-based materials reported in the literature is their rich surface chemistry and their 
developed porosity (especially ultramicroporosity). The proper combination of these features is a tool to enhance the sensors' sensitivity. This can be done by controlling the nature of the specific interactions, the electrical conduction type of the carbon matrix itself, and the role of physisorption on sensing which is responsible for the reversible changes. Moreover, the rich and specific surface chemistry of nanoporous carbons offers a good sensor selectivity, allowing the discrimination of ammonia from other reducing gases ( $\operatorname{such}$ as $\mathrm{H}_{2} \mathrm{~S}$ ), without the need for costly metal/metal oxide doping processes. Chemical heterogeneity, and more precisely the synergistic effect between the heteroatoms was found to play a key role in the enhancement of the carbon chip sensitivity.

The novelty of this work in comparison to the state of the art in ammonia sensing is in presenting nanoporous carbos, which can be used as both sensitive/selective ammonia gas sensors and high capacity ammonia adsorbents. The latter feature is related to their developed pore structure, which results in high adsorption capabilities. Thus, ammonia sensors based on nanoporous carbons can both detect toxic gases and protect against their exposure. 


\section{Chapter 9. Outlook for future research to advance the sensing field}

The research presented in this thesis has extensively explored and established the ammonia sensing capability of various types of nanoporous carbons. Further improvements however are worth of investigation. This Chapter suggests an outlook for future research to advance the sensing field. Some concepts for the improvement of ammonia sensing on nanoporous carbons are proposed:

\section{Concept 1}

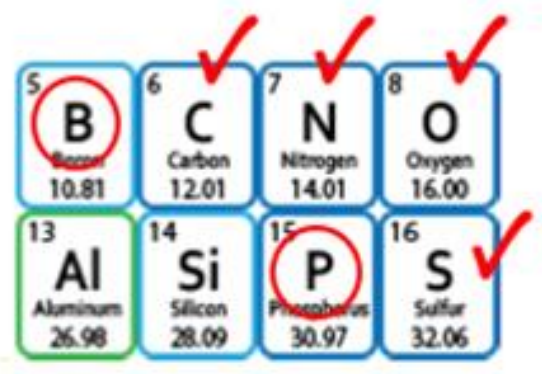

Figure 9.1 Possible dopantelements to examine
The influence of other heteroatoms than $\mathrm{S}, \mathrm{N}$, and $\mathrm{O}$ on the ammonia sensing capability of nanoporous carbons would be interesting to study. The introduction of nitrogen or boron for example would be an effective means to modify the surface chemical and electronic properties of nanoporous carbons, while simultaneously

controlling the surface reactivity with ammonia. This would provide a way to control the sensor sensitivity and selectivity. Phosphorus, being an $n$-type dopant is expected to have a similar to nitrogen effect on the electronic properties of the carbon matrix. Based on its specific configurations however, its incorporation to the carbon surface also offers an effective means to control the interactions with basic ammonia. Thus, $\mathrm{P}$ in its acidic forms is expected to increase the affinity towards ammonia adsorption, and thus increase the sensor selectivity when other acidic gasses are tested as the targets. Boron is an additional heteroatom worth of investigation, which is expected to induce a $p$-type conduction behavior.

Some preliminary results of ammonia sensing on P-doped nanoporous carbons are presented below: 


\section{Preparation of materials}

BAX was impregnated with solutions of phosphoric acid of various concentrations $(1,30,60$, and $85 \%)$. Phosphoric acid is a commonly used activating agent of carbons. It promotes the cleavage of the bonds in the carbon matrix and the formation of phosphate/polyphosphate bridges. ${ }^{139}$ The introduction of the heteroatom (-P) to the carbon matrix usually involves the polymerization of the carbonaceous precursor in the presence of the compounds including $-\mathrm{P}$. Thus, after stirring of BAX in $\mathrm{H}_{3} \mathrm{PO}_{4}$ solution, carbonization of the impregnated samples was carried out in a horizontal furnace, for $2 \mathrm{~h}$, at $600^{\circ} \mathrm{C}$. The obtained product was washed in a Soxhlet apparatus until constant $\mathrm{pH}$. The carbon was then objected to an air-oxidation treatment, by heating it in air for $3 \mathrm{~h}$, at $350^{\circ} \mathrm{C}$ (heating rate of $50{ }^{\circ} \mathrm{C} / \mathrm{min}$ ). The resulting materials are referred to as $\mathrm{BP}-\mathrm{C}-\mathrm{X} \%$ and $\mathrm{BP}-\mathrm{CAO}-\mathrm{X} \%$ where the $\mathrm{C}$ refers to carbonization, $\mathrm{AO}$ to air-oxidation, and $\mathrm{X}$-represents 1, 30, 60 and 85\% concentration of $\mathrm{H}_{3} \mathrm{PO}_{4}$.

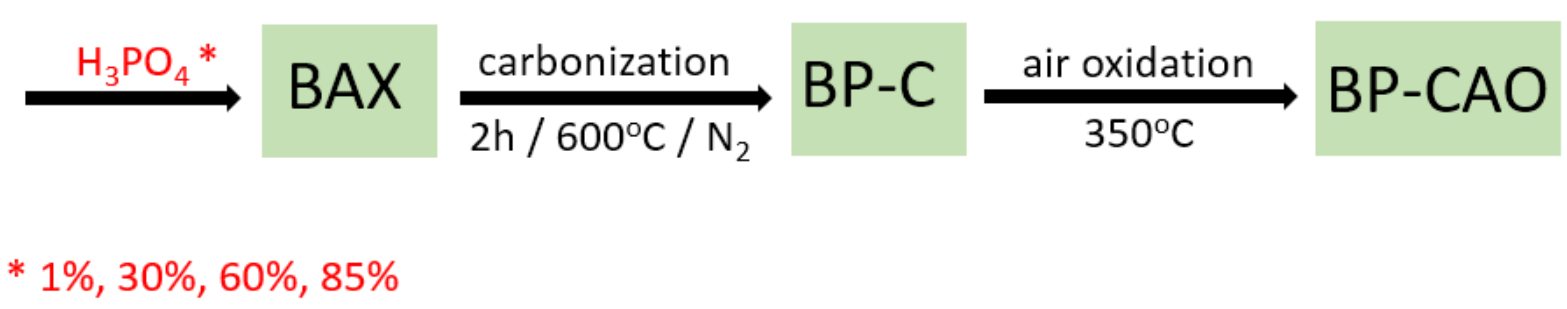

Electrical performance of P-doped nanoporous carbons as ammonia sensors

Table 9.1 summarizes the sensitivity results (changes in the normalized resistance) of the P-doped carbon samples before and after air-oxidation, upon their exposure to $500 \mathrm{ppm}$ of ammonia. Arrows indicate the direction of the electrical signal change (increase or decrease of normalized resistance) upon ammonia exposure. The initial resistivities of the materials are also provided in Table 9.1. As seen, all carbon series, except the ones treated with $1 \%$ of $\mathrm{H}_{3} \mathrm{PO}_{4}$, exhibit opposite trends in their signal before and after air-oxidation. More precisely, while BP-C-30, 60, and 85\% 
show a decrease in the normalized resistance when exposed to $500 \mathrm{ppm}$ of ammonia, an increase in resistance of these samples after air-oxidized at $350^{\circ} \mathrm{C}$ was measured. This indicates that airoxidation affected the surface chemical features of the samples and thus altered their electrical properties. This led to changes in the sensing mechanism. Differences in the configuration of $-\mathrm{O}$ and -P heteroatoms are responsible for differences in the predominant type of charge carriers, and thus the conduction-type of the carbon matrix. Interestingly, in the case of the carbon treated with $1 \%$ of $\mathrm{H}_{3} \mathrm{PO}_{4}$, the signal changes before and after air-oxidation follow the same trend, which is a decrease in the normalized resistance upon ammonia exposure. Moreover, among all carbons BPCAO-1 exhibits the highest sensitivity (35\%).

Table 9.1. Change in the normalized resistance $\left(\Delta R / R_{0}\right) * 100$ of the P-doped carbon samples before and after air-oxidation, upon their exposure to $500 \mathrm{ppm}$ of ammonia.

\begin{tabular}{|l|l|l|}
\hline \multicolumn{1}{|c|}{ Sample } & Sensitivity $\left(\Delta \mathrm{R} / \mathrm{R}_{\mathrm{o}}\right) * 100$ & Initial resistivity \\
\hline BP-C-1 & $30 \% \downarrow$ & $2.2 \mathrm{M} \Omega$ \\
\hline BP-CAO-1 & $\mathbf{3 5 \%} \downarrow$ & $1.9 \mathrm{M} \Omega$ \\
\hline BP-C-30 & $10.3 \uparrow$ & $0.22 \mathrm{k} \Omega$ \\
\hline BP-CAO-30 & $18 \% \downarrow$ & $23 \mathrm{k} \Omega$ \\
\hline BP-C-60 & $19.2 \% \uparrow$ & $56 \mathrm{k} \Omega$ \\
\hline BP-CAO-60 & $12 \% \downarrow$ & $4.5 \mathrm{k} \Omega$ \\
\hline BP-C-85 & $2.5 \% \downarrow 5 \% \uparrow$ & $135 \Omega$ \\
\hline BP-CAO-85 & $13 \% \downarrow$ & $4.6 \mathrm{k} \Omega$ \\
\hline
\end{tabular}

Figures 9.2 illustrates the sensing response of all carbons tested before and after air-oxidation. As expected, air oxidation affected the electrical properties of the samples. It is demonstrated by the opposite trends of the electrical signal changes before and after air-treatment for all samples except the one where $\mathrm{BAX}$ was treated with $1 \%$ of $\mathrm{H}_{3} \mathrm{PO}_{4}$. In the latter case, the signal changes before and after air-oxidation (for BP-C-1 and BP-CAO-1) follow the same trend. It is worth to notice that except of the trend in the electrical behavior of the carbons before and after air-oxidation, the 
differences are also seen, in the response time of the sensors. Thus for BP-C-30, BP-C-60, and BPC-85 it takes $\sim 15,10$ and 8 min for the electrical signal to reach the highest value of the normalized resistance upon ammonia exposure, while for the same samples after air-oxidation, the resistance reaches the maximum value within 1 minute. Figure 9.2B illustrates that for BP-CAO-1 which is the best performing carbon, the normalized resistance varies linearly with increasing the concentration of the target gas.

The greater sensitivity of the carbons after air-oxidation suggests that the formation of new surface chemical and structural features (as a results of air-oxidation) are likely responsible for the enhanced sensor response. As aforementioned in Chapter 5, such differences in the electrical behavior of the carbons before and after air-treatment, indicate the importance the air-oxidation for the development of efficient gas sensors. 

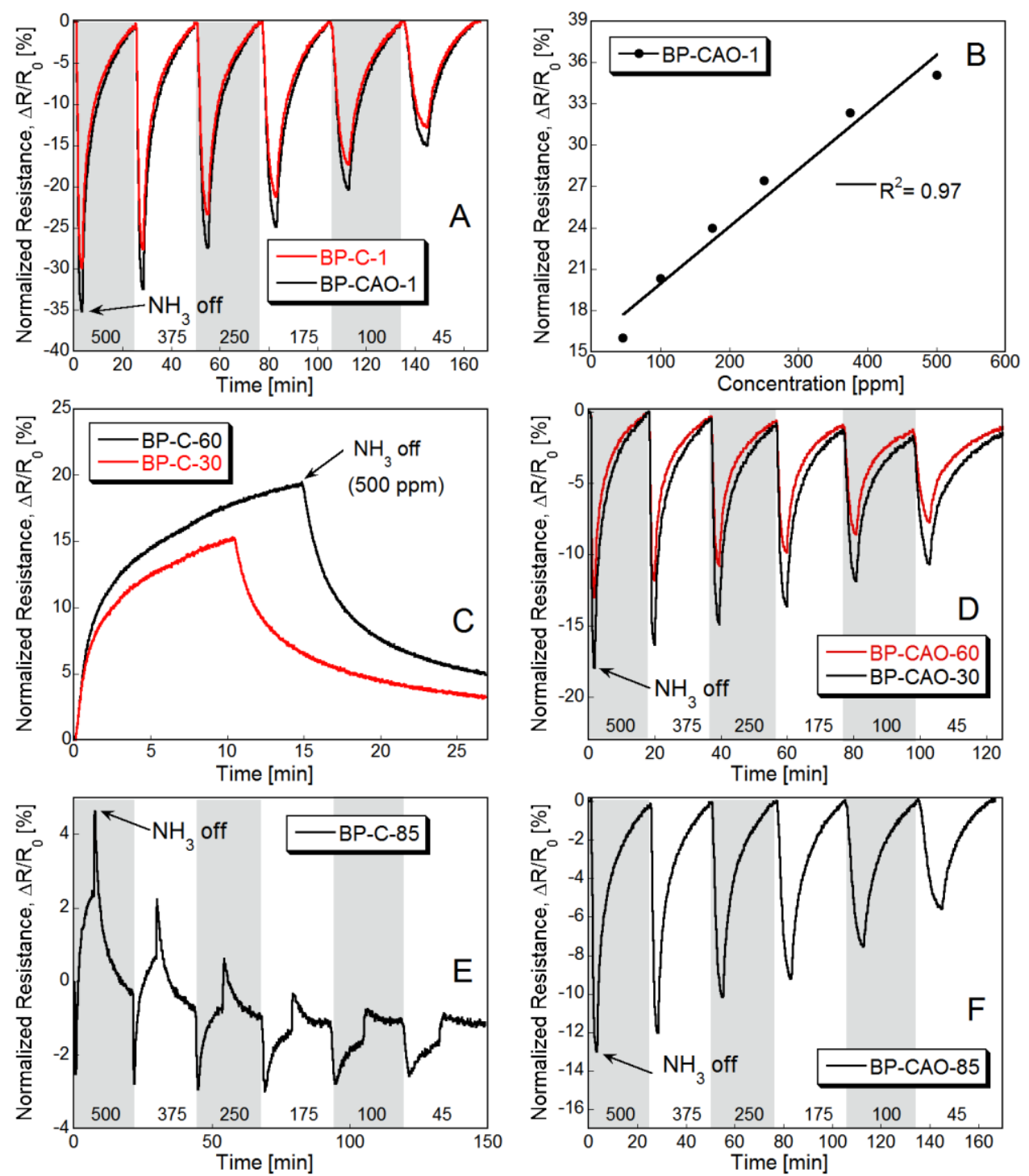

Figure 9.2. Changes in the normalized resistance for all P-modified samples before (BP-C-1, 30, $60,85 \%$ ) and after air-oxidation (BP-CAO-1, 30, 60, 85\%) upon exposure to $500 \mathrm{ppm}$ of ammonia, (B): linear response of the best performing carbon (BP-CAO-1).

To comprehend the role of $-\mathrm{P}$ as a heteroatom in the carbon matrix and to examine the nature of specific functional groups on the carbons' surfaces, the initial and exhausted samples after ammonia exposure need to be evaluated by various characterization methods. Figure 9.3 illustrates 
possible configurations of $-\mathrm{P}$ in the carbon matrix (phosphate-carbon complexes) as described in the literature. ${ }^{1}$

Thus, an additional concept for future research would be after examining the specific configurations of -P in the carbon matrix, to propose a priority order of the effect of various Pbased surface functional groups on ammonia sensing.

(a)

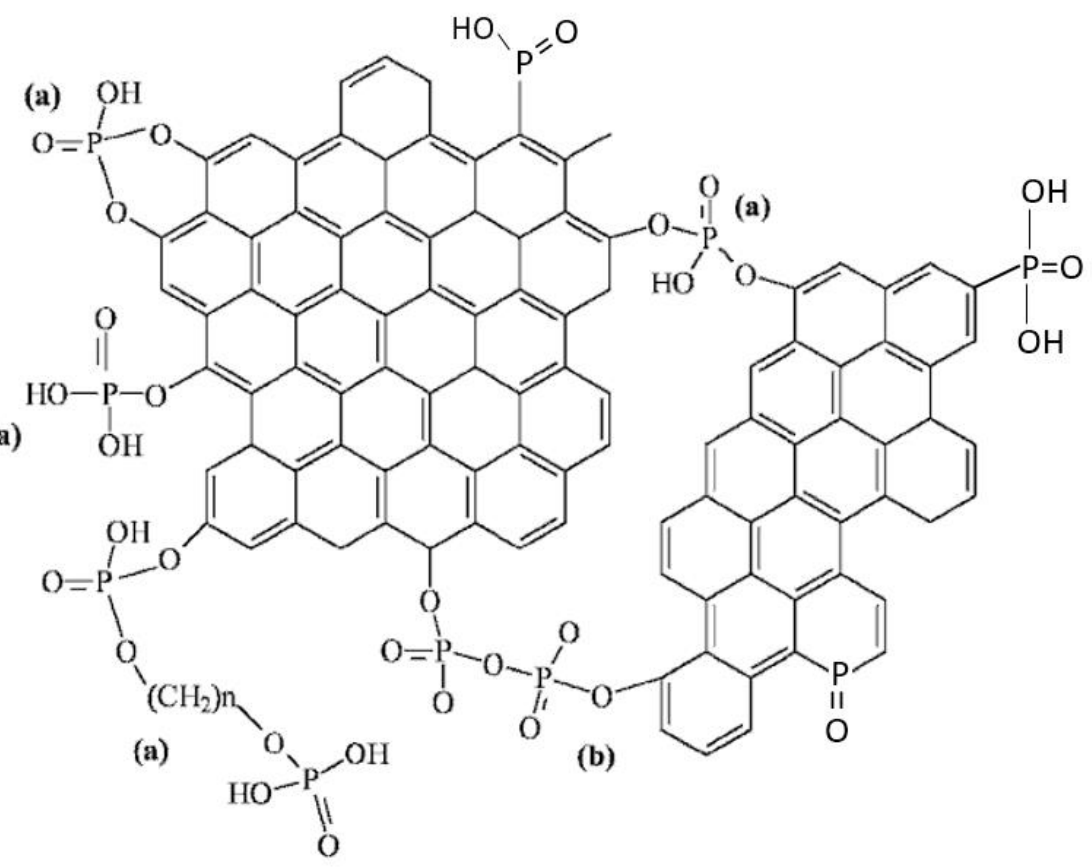

Figure 9.3. Possible configurations of $-\mathrm{P}$ in the carbon matrix (phosphate-carbon complexes) as described in the literature. ${ }^{139}$

\section{Concept 2}

The research summarized in this thesis focused on the toxic gas sensing capability of nanoporous carbons towards ammonia, while $\mathrm{H}_{2} \mathrm{~S}$ was also tested in some cases as a target gas, to conduct selectivity tests. Expanding the range of the toxic gas targets would be necessary aiming to improve the toxic gas sensing model on nanoporous carbonaceous materials. Potential toxic gases to examine would include nitrogen dioxide, benzene, ethylene, or carbon monoxide. An additional 
interesting improvement of the current study would be also the study of the sensing capability of nanoporous carbons towards ammonia in a mixture with other pollutants that can coexit, such as organic molecules. This would provide more information regarding the selective detection capability of the materials tested.

\section{Concept 3}

The research described in this thesis focuses on sensing tests which were conducted at ambient conditions (working temperature $\sim 23^{\circ} \mathrm{C}$ ). It would be therefore interesting to test the effect of temperature on the sensing capability of the materials in the range of $20-120^{\circ} \mathrm{C}$. It is possible that at higher temperatures a higher rate of ammonia adsorption/desorption mechanism would cause a rise on the sensor response. Thus, the influence of temperature needs to be taken into account when fabricating a reliable gas sensor.

\section{Concept 4}

The sustainability of a sensor surface is essential for its reusage and reproducibility of the results. Thus, regeneration or recycling of the active material is a crucial matter. The first approach involves a heat treatment or chemical extraction processes, aiming to remove the molecules of the target gas without altering the nature of the surface active sites. Considering however that during the initial stabilization stage of our sensors, ammonia chemically reacts with the carbon surface forming stable surface functional groups, regeneration is not suitable since it would alter both the structural and surface chemical features of the material. Recycling on the other hand, seems to be a more feasible/appropriate approach, considering that the reversible operation of a nanoporous carbon -based gas sensor relies on physisorption and thus on a developed pore structure. Even though the surface chemical features of the exhausted samples would differ from those of the initial/fresh adsorbents, a simple removal process of weakly retained adsorption products (such as 
air purging of the samples), would not affect their textural/structural features to a great extent, and thus the role of physisorption on sensing.

\section{Concept 5}

Even though nanoporous carbons seems to have a good performance on laboratory-scale applications, extensive research could be also carried out to study their usage as sophisticated "smart" sensors, in large-scale applications. This technology involves the integration of ammonia gas sensors into clothing; wearable apparatus which have the flexibility to adapt to changes in the body movements (such as masks, protective clothing, boots), and thus opens up new perspectives for the design of textile electronics.

\section{Concept 6}

Finally, improvements could be made in the design of the sensing device (e.g. gas chamber) and optimization of the sensing template aiming to achieve the optimal sensor sensitivity and selectivity. 


\section{Appendix}
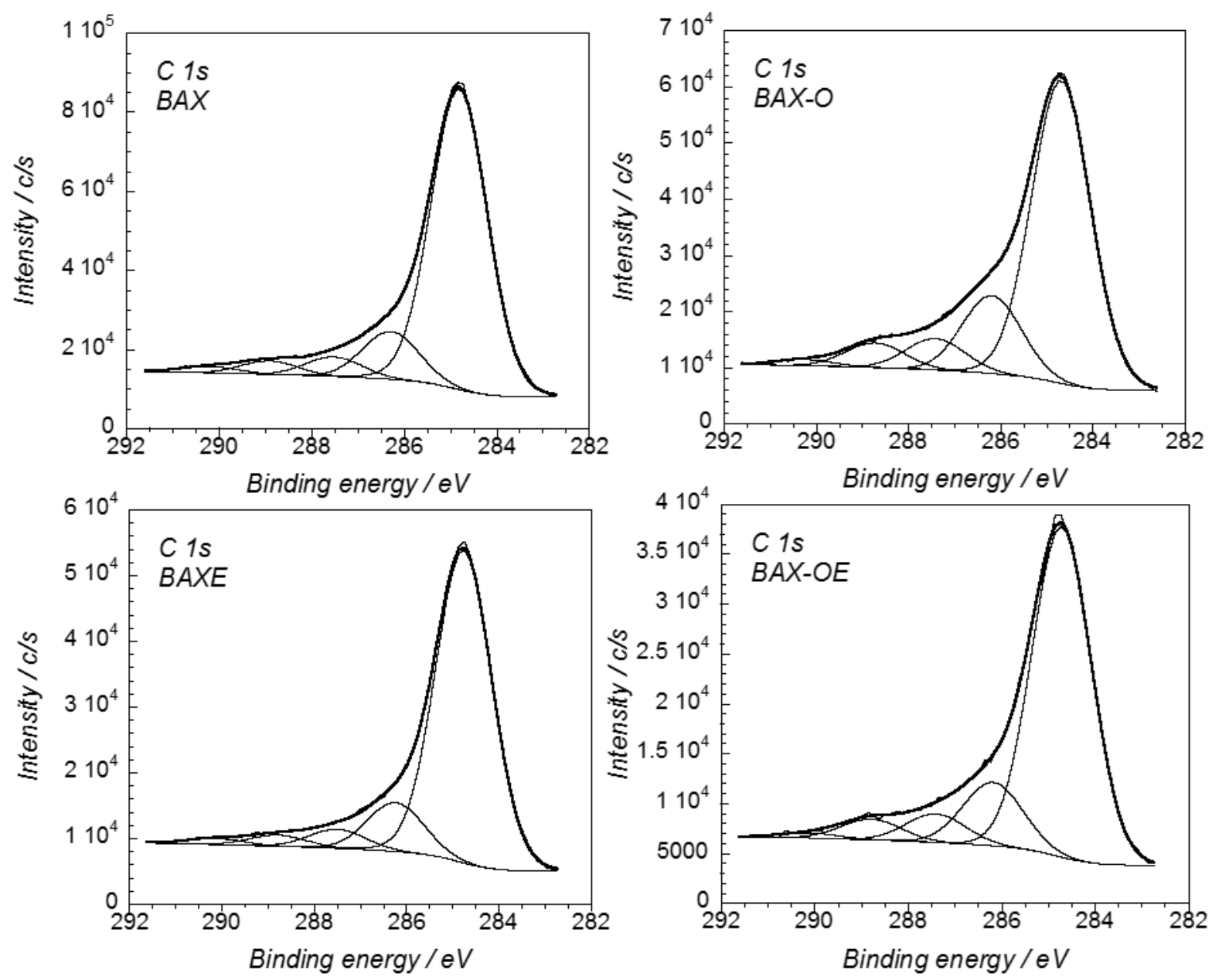

Figure A1. The deconvolution of C $1 s$ core energy levels for the initial and exposed to ammonia carbons. 

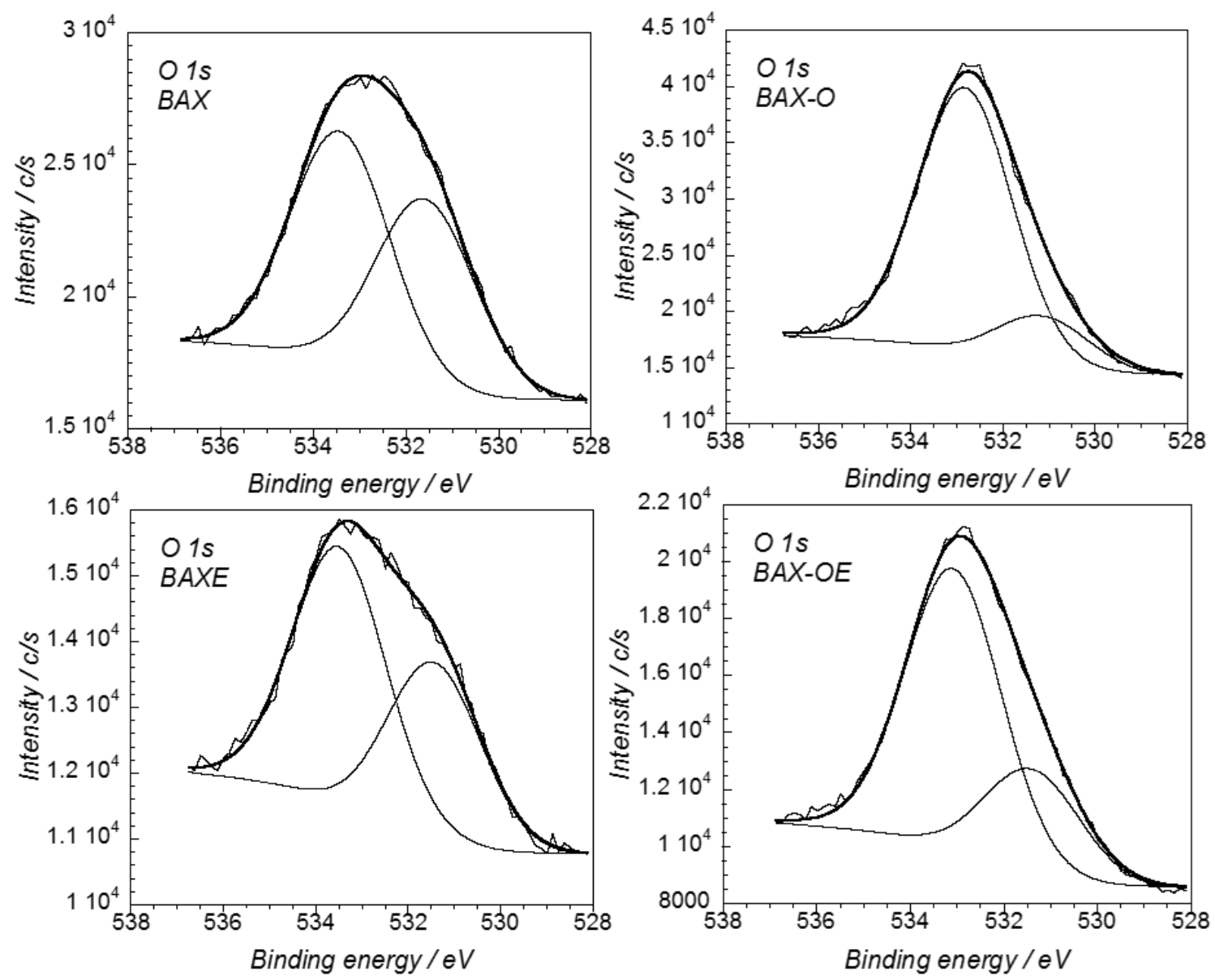

Figure A2. The deconvolution of O $1 s$ core energy levels for the initial and exposed to ammonia carbons.
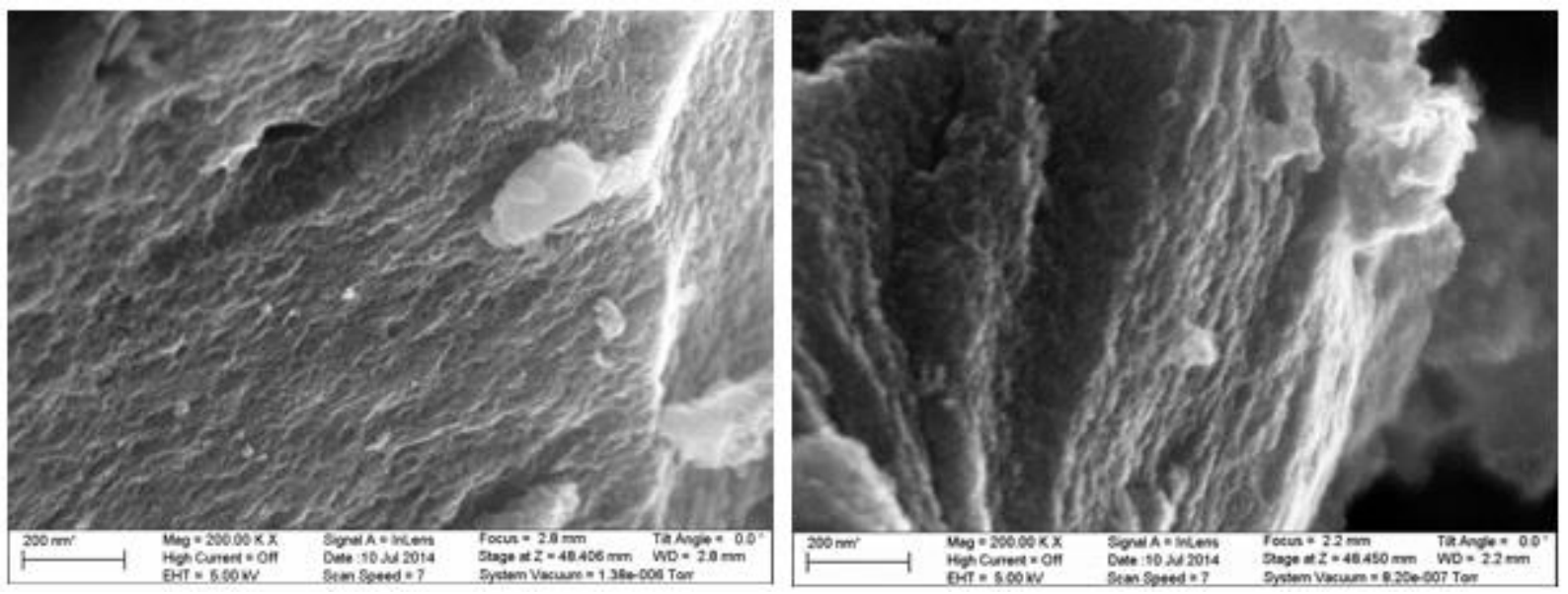

Figure A3. SEM images of BAX (A) and BAX-O (B) 

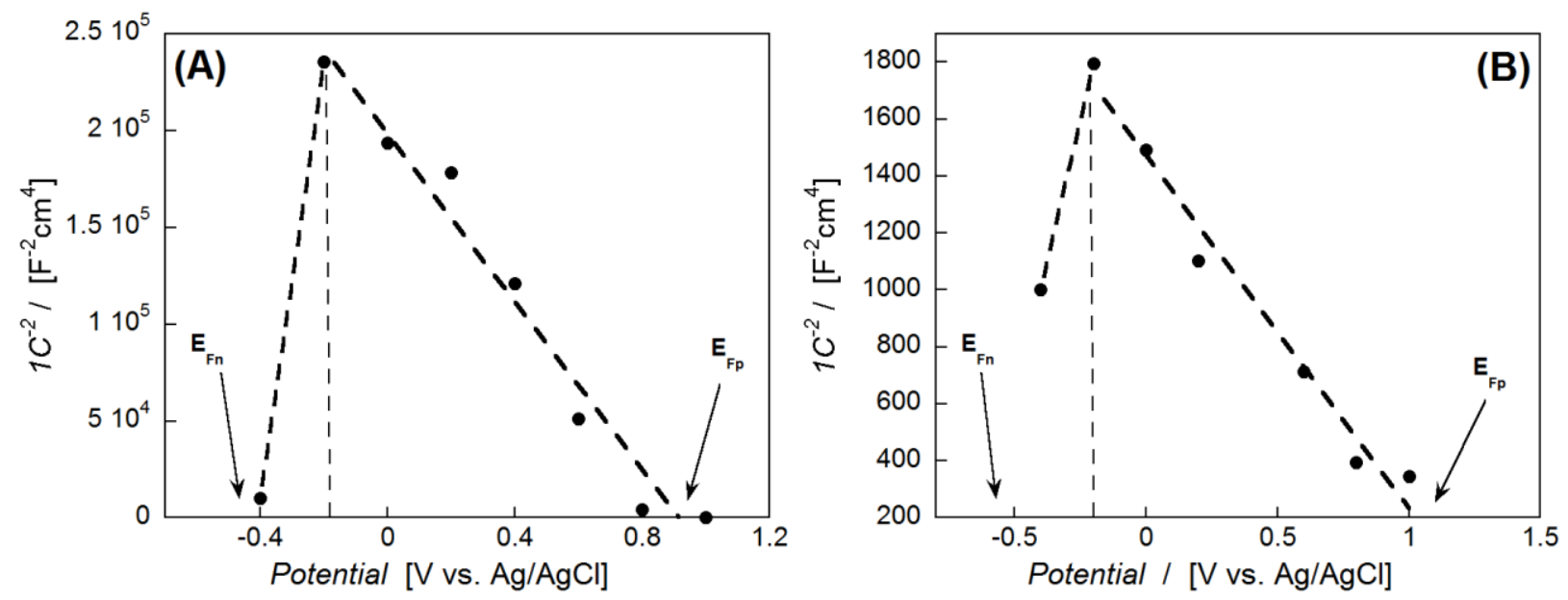

Figure A4. The Mott-Schottky plots for C-AO and C-BO. $E_{F n}$ and $E_{F p}$ represent the Fermi levels of $\mathrm{n}$ and $\mathrm{p}$ type materials.

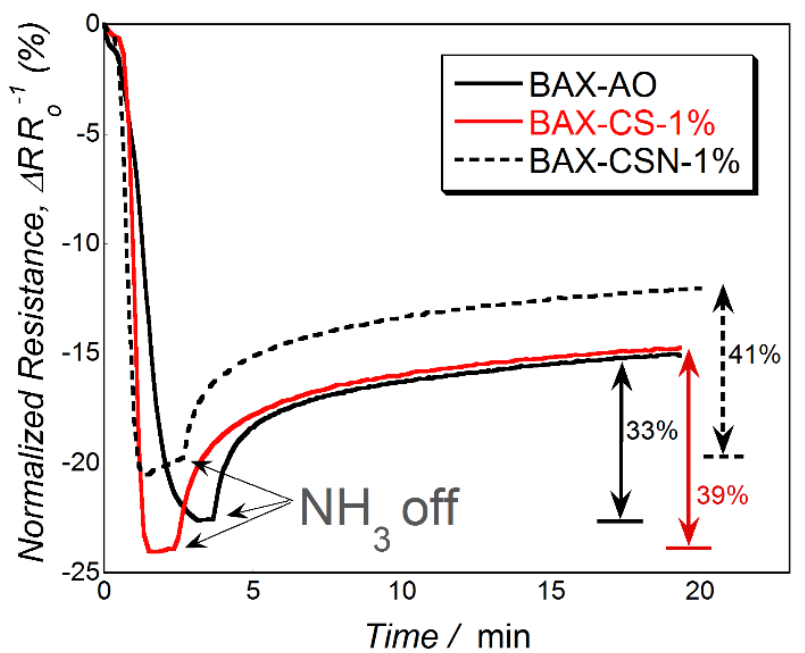

Figure A5. Changes in the normalized resistance for BAX-AO, BAX-CS-1\% and BAX-CSN-1\% carbon samples upon their initial exposure to $\mathrm{NH}_{3}$ and subsequent air purging (after the signal stabilization). 


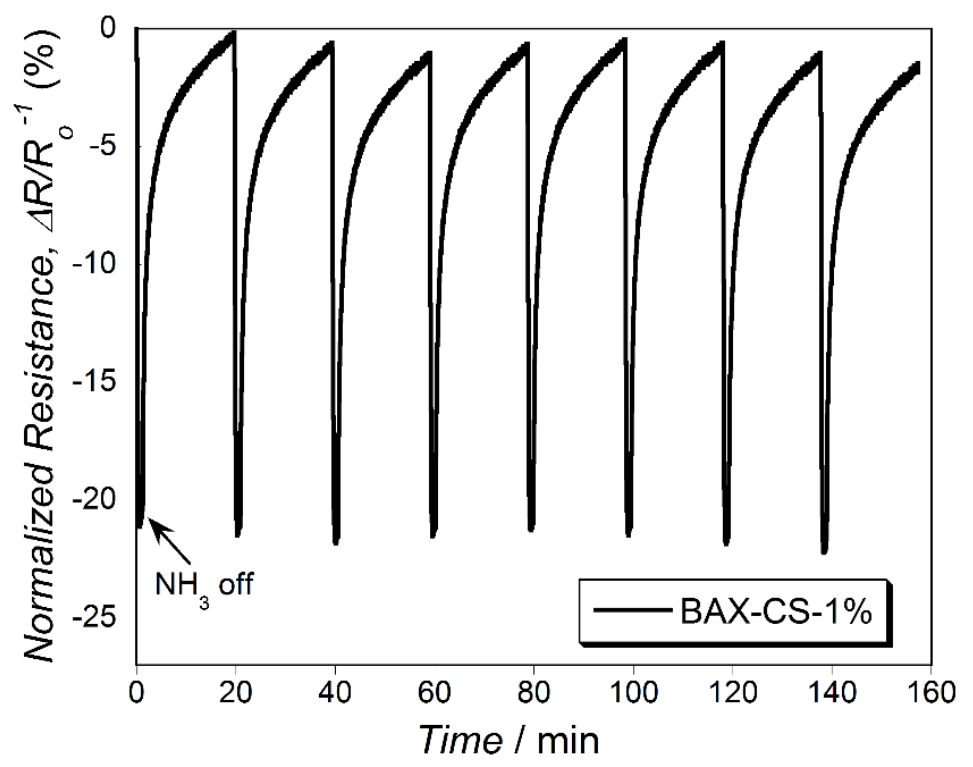

Figure A6. Response curves of BAX-CS-1\% upon exposure to various $\mathrm{NH}_{3} /$ air cycles, at 500 ppm of the target gas. 

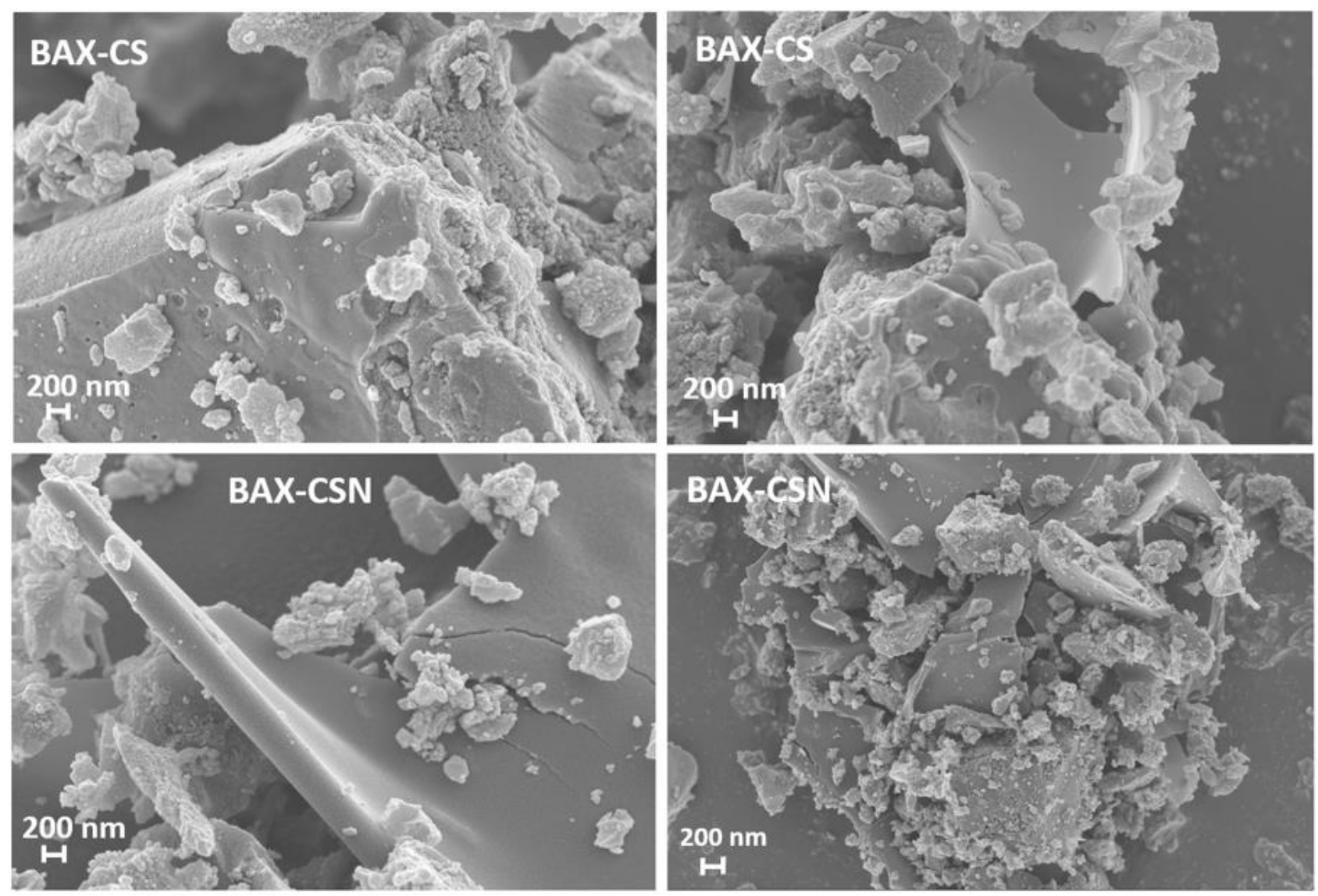

Figure A7. SEM images of BAX-CS-25\% and BAX-CSN-25\%. 
Table A1. Content of elements on the surface (in at. \% from XPS analysis). Copyright 2017, with permission from American Chemical Society. ${ }^{83}$

\begin{tabular}{lllll}
\hline Sample & $\mathrm{C}$ & $\mathrm{O}$ & $\mathrm{N}$ & $\mathrm{P}$ \\
\hline BAX-M & 86.8 & 4.6 & 8.2 & 0.3 \\
BAX-M-O1 & 84.8 & 8.3 & 6.9 & \\
BAX-M-O2 & 80.1 & 10.4 & 9.5 & \\
BAX-O1-M & 87.5 & 6.4 & 5.6 & 0.5 \\
BAX-O2-M & 83.7 & 5.6 & 10.6 & \\
BAX-O1-M[O1] & 83.6 & 11.2 & 5.3 & \\
BAX-O2-M[O1] & 81.0 & 8.8 & 10.2 & \\
\hline BAX-M-ED & 86.2 & 4.8 & 8.7 & 0.3 \\
BAX-M-O1-ED & 83.9 & 8.7 & 7.4 & \\
BAX-M-O2-ED & 80.7 & 11.0 & 8.2 & 0.14 \\
BAX-O1-M-ED & 88.0 & 6.1 & 5.7 & 0.2 \\
BAX-O2-M-ED & 83.5 & 5.0 & 11.5 & \\
BAX-O1-M[O1]-ED & 85.6 & 11.0 & 3.4 & \\
BAX-O2-M[O1]-ED & 80.9 & 8.6 & 10.5 & \\
\hline
\end{tabular}

Table A2. The results of deconvolution of C $1 s$ core energy level spectra. Copyright 2017, with permission from American Chemical Society. ${ }^{83}$

\begin{tabular}{lccccc}
\hline Sample & $284.8 \mathrm{eV}$ & $286.1 \mathrm{eV}$ & $287.0 \mathrm{eV}$ & $289.4 . \mathrm{eV}$ & $290.9 \mathrm{eV}$ \\
\hline BAX-M & 70.5 & 14.2 & 7.6 & 5.4 & 2.4 \\
BAX-M-O1 & 69.2 & 16.0 & 7.5 & 5.1 & 2.2 \\
BAX-M-O2 & 67.4 & 15.3 & 8.8 & 6.0 & 2.5 \\
BAX-O1-M & 70.2 & 15.1 & 7.3 & 4.7 & 2.7 \\
BAX-O2-M & 69.2 & 16.2 & 8.2 & 4.2 & 2.2 \\
BAX-O1-M[O1] & 66.5 & 15.7 & 8.6 & 6.0 & 3.2 \\
BAX-O2-M[O1] & 60.3 & 18.4 & 11.4 & 6.8 & 3.1 \\
\hline BAX-M-ED & 72.4 & 13.4 & 8.3 & 3.0 & 1.8 \\
BAX-M-O1-ED & 69.4 & 15.8 & 7.5 & 5.0 & 2.3 \\
BAX-M-O2-ED & 69.4 & 15.3 & 9.3 & 4.2 & 1.8 \\
BAX-O1-M-ED & 69.1 & 15.8 & 7.7 & 4.9 & 2.6 \\
BAX-O2-M-ED & 65.9 & 17.4 & 9.0 & 5.3 & 2.5 \\
BAX-O1-M[O1]-ED & 66.2 & 15.1 & 9.7 & 6.3 & 2.7 \\
BAX-O2-M[O1]-ED & 64.1 & 17.7 & 9.7 & 5.7 & 2.8 \\
\hline
\end{tabular}


Table A3. The results of deconvolution of O $1 s$ core energy level spectra. Copyright 2017, with permission from American Chemical Society. ${ }^{83}$

\begin{tabular}{llll}
\hline Sample & $531.3 \mathrm{eV}$ & $533.8 \mathrm{eV}$ & $536.4 \mathrm{eV}$ \\
\hline BAX-M & 38.3 & 61.7 & \\
BAX-M-O1 & 37.3 & 62.7 & \\
BAX-M-O2 & 34.7 & 58.6 & 6.7 \\
BAX-O1-M & 45.0 & 55.0 & \\
BAX-O2-M & 38.0 & 62.0 & \\
BAX-O1-M[O1] & 40.2 & 54.3 & 5.5 \\
BAX-O2-M[O1] & 37.6 & 49.0 & 13.4 \\
\hline BAX-M-ED & 43.0 & 57.0 & \\
BAX-M-O1-ED & 34.1 & 58.2 & 7.7 \\
BAX-M-O2-ED & 35.2 & 58.7 & 6.1 \\
BAX-O1-M-ED & 46.1 & 53.9 & \\
BAX-O2-M-ED & 47.9 & 52.1 & \\
BAX-O1-M[O1]-ED & 37.5 & 49.8 & 12.8 \\
BAX-O2-M[O1]-ED & 45.4 & 48.2 & 6.4 \\
\hline
\end{tabular}

Table A4. The results of deconvolution of N $1 s$ core energy level spectra. Copyright 2017, with permission from American Chemical Society. ${ }^{83}$

\begin{tabular}{llllll}
\hline Sample & $398.7 \mathrm{eV}$ & $400.2 \mathrm{eV}$ & $401.3 \mathrm{eV}$ & $402.6 \mathrm{eV}$ & $405.9 \mathrm{eV}$ \\
\hline BAX-M & 60.3 & 27.7 & 12.1 & & \\
BAX-M-O1 & 48.3 & 30.6 & & 6.3 & 14.9 \\
BAX-M-O2 & 46.2 & 23.8 & 14.5 & & 15.6 \\
BAX-O1-M & 26.9 & 70.1 & & 2.9 & \\
BAX-O2-M & 54.6 & 37.6 & 7.8 & & \\
BAX-O1-M[O1] & 45.6 & 54.4 & & & \\
BAX-O2-M[O1] & 58.9 & 41.1 & & & \\
\hline BAX-M-ED & 63.2 & 28.4 & & 4.6 & 3.8 \\
BAX-M-O1-ED & 48.9 & 30.0 & & 6.5 & 14.5 \\
BAX-M-O2-ED & 42.8 & 25.7 & 12.0 & & 18.5 \\
BAX-O1-M-ED & 47.6 & 46.4 & 6.1 & & \\
BAX-O2-M-ED & 55.5 & 36.8 & 7.8 & & \\
BAX-O1-M[O1]-ED & 48.5 & 51.5 & & & 18.1 \\
BAX-O2-M[O1]-ED & 45.8 & 36.2 & & & \\
\hline
\end{tabular}


Table A5. The results of deconvolution of C $1 s$ core energy level spectra.

\begin{tabular}{llllll}
\hline Sample & $284.8 \mathrm{eV}$ & $286.3 \mathrm{eV}$ & $287.6 \mathrm{eV}$ & $288.9 \mathrm{eV}$ & $290.5 \mathrm{eV}$ \\
\hline PFM-AO & 75.53 & 13.89 & 4.44 & 4.42 & 1.72 \\
RFM-AO & 76.54 & 14.42 & 4.06 & 3.68 & 1.29 \\
PFU-AO & 76.36 & 14.08 & 4.40 & 3.69 & 1.47 \\
\hline PFM-AO-ED & 72.20 & 14.72 & 5.36 & 5.58 & 2.14 \\
RFM-AO-ED & 74.08 & 16.99 & & 6.33 & 2.60 \\
PFU-AO-ED & 56.96 & 22.69 & 11.16 & 6.93 & 2.27 \\
\hline
\end{tabular}

$284.8 \mathrm{eV}-\mathrm{C}-\mathrm{C}$ in $\mathrm{sp}^{2}$ graphitic carbon

286.3-286.5 eV - C-(O, N, S, H) in phenolic, alcoholic, etheric

$287.6 \mathrm{eV}-\mathrm{C}=\mathrm{O}$ in carbonyl or quinone

$288.9-289.2 \mathrm{eV}-\mathrm{O}-\mathrm{C}=\mathrm{O}$ in carboxyl or ester

$290.4-291.0 \mathrm{eV}-\pi-\pi^{*}, \pi$-electrons in aromatic rings

Table A6. The results of deconvolution of O $1 s$ core energy level spectra.

\begin{tabular}{llll}
\hline Sample & $531.0 \mathrm{eV}$ & $532.0 \mathrm{eV}$ & $533.8 \mathrm{eV}$ \\
\hline PFM-AO & & 70.18 & 29.82 \\
RFM-AO & & 76.16 & 23.84 \\
PFU-AO & 79.57 & 20.43 \\
\hline PFM-AO-ED & 70.08 & 29.92 & \\
RFM-AO-ED & & 62.82 & 37.18 \\
PFU-AO-ED & & 65.77 & 34.23 \\
\hline
\end{tabular}

$531.3-532.1 \mathrm{eV}-\mathrm{C}=\mathrm{O}$ in carbonyl/quinone

$533.0 \mathrm{eV}-\mathrm{C}-\mathrm{O}$ in phenol/epoxy/carboxyl/ether or -O- chemisorbed oxygen species 
Table A7. The results of deconvolution of $\mathrm{N} 1 s$ core energy level spectra

\begin{tabular}{|c|c|c|c|}
\hline Sample & $\mathrm{N}-1$ & $\mathrm{~N}-2$ & $\mathrm{~N}-3$ \\
\hline PFM-AO & & $\begin{array}{c}53.29 \\
(399.7 \mathrm{eV})\end{array}$ & $\begin{array}{c}46.71 \\
(401.3 \mathrm{eV})\end{array}$ \\
\hline RFM-AO & & $\begin{array}{c}41.81 \\
(399.1 \mathrm{eV})\end{array}$ & $\begin{array}{c}58.19 \\
(400.7 \mathrm{eV})\end{array}$ \\
\hline PFU-AO & $\begin{array}{c}38.33 \\
(398.5 \mathrm{eV})\end{array}$ & & $\begin{array}{c}61.67 \\
(400.7 \mathrm{eV}) \\
\end{array}$ \\
\hline PFM-AO-ED & & $\begin{array}{c}23.91 \\
(400.1 \mathrm{eV})\end{array}$ & $\begin{array}{c}76.09 \\
(401.8 \mathrm{eV})\end{array}$ \\
\hline RFM-AO-ED & & $\begin{array}{c}63.01 \\
(399.3 \mathrm{eV})\end{array}$ & $\begin{array}{c}36.99 \\
(400.8 \mathrm{eV})\end{array}$ \\
\hline PFU-AO-ED & $\begin{array}{c}40.40 \\
(398.5 \mathrm{eV})\end{array}$ & $\begin{array}{c}59.60 \\
(400.3 \mathrm{eV})\end{array}$ & \\
\hline
\end{tabular}

$398.5 \mathrm{eV}-\mathrm{N}-1$ in pyridine

399.1-400.3 eV - N-2 in amides, amines

400.7-401.3 eV - N-3 in quaternary, pyridine-N-oxides

Table A8. Content of elements on the surface and the O/C ratio (in at. \% from XPS analysis).

\begin{tabular}{llllll}
\hline Sample & $\mathrm{C}$ & $\mathrm{O}$ & $\mathrm{N}$ & $\mathrm{S}$ & $\mathrm{O} / \mathrm{C}$ \\
\hline${ }^{\mathrm{a} C}$-A & 87.7 & 8.6 & 1.3 & 1.7 & 0.1 \\
${ }^{\mathrm{a}} \mathrm{C}-\mathrm{AO}$ & 81.4 & 16.6 & 1.2 & 0.7 & 0.2 \\
${ }^{\mathrm{a} C}$-B & 86.0 & 9.3 & 2.4 & 2.4 & 0.1 \\
${ }^{\mathrm{a}} \mathrm{C}-\mathrm{BO}$ & 87.3 & 9.3 & 2.6 & 0.9 & 0.1 \\
\hline $\mathrm{C}-\mathrm{AE}$ & 91.0 & 6.9 & 0.6 & 1.5 & 0.1 \\
$\mathrm{C}-\mathrm{AOE}$ & 82.8 & 14.6 & 2.0 & 0.6 & 0.2 \\
$\mathrm{C}-\mathrm{BE}$ & 87.3 & 9.1 & 1.7 & 1.9 & 0.1 \\
C-BOE & 86.9 & 9.2 & 3.0 & 0.9 & 0.1 \\
\hline
\end{tabular}

${ }^{a}$ XPS results for the initial polymer-derived carbons are reintroduced from literature [2].

Copyright 2017, with permission from Elsevier. 
Table A9. The results of deconvolution of C $1 s$ core energy level spectra.

\begin{tabular}{llllll}
\hline Sample & $284.8 \mathrm{eV}$ & $286.3 \mathrm{eV}$ & $287.6 \mathrm{eV}$ & $288.9 \mathrm{eV}$ & $290.4 \mathrm{eV}$ \\
\hline${ }^{\mathrm{a}} \mathrm{C}-\mathrm{A}$ & 77.9 & 13.7 & 5.3 & 3.0 & $\mathrm{ND}$ \\
${ }^{\mathrm{a}} \mathrm{C}-\mathrm{AO}$ & 68.0 & 16.0 & 7.7 & 4.9 & 3.3 \\
${ }^{\mathrm{a}} \mathrm{C}-\mathrm{B}$ & 71.0 & 14.2 & 5.7 & 6.0 & 3.0 \\
${ }^{\mathrm{a}} \mathrm{C}-\mathrm{BO}$ & 66.7 & 16.0 & 6.7 & 6.6 & 4.0 \\
\hline $\mathrm{C}-\mathrm{AE}$ & 75.5 & 15.4 & 5.2 & 2.5 & 1.4 \\
$\mathrm{C}-\mathrm{AOE}$ & 67.3 & 18.9 & 6.1 & 5.6 & 2.1 \\
$\mathrm{C}-\mathrm{BE}$ & 72.2 & 15.7 & 6.0 & 4.2 & 2.0 \\
$\mathrm{C}-\mathrm{BOE}$ & 70.3 & 16.4 & 6.6 & 4.1 & 2.6 \\
\hline
\end{tabular}

${ }^{a}$ XPS results for the initial polymer-derived carbon reintroduced from literature [122].

Copyright 2017, with permission from Elsevier [122].

$\mathrm{ND}$ - not detected

$284.8 \mathrm{eV}-\mathrm{C}-\mathrm{C}$ in $\mathrm{sp}^{2}$ graphitic carbon

286.3-286.5 eV - C-(O, N, S, H) in phenolic, alcoholic, etheric

$287.6 \mathrm{eV}-\mathrm{C}=\mathrm{O}$ in carbonyl or quinone

288.9-289.2 eV $-\mathrm{O}-\mathrm{C}=\mathrm{O}$ in carboxyl or ester

$290.4-291.0 \mathrm{eV}-\pi-\pi^{*}, \pi$-electrons in aromatic rings

Table A10. The results of deconvolution of O $1 s$ core energy level spectra.

\begin{tabular}{lllll}
\hline Sample & $531.4 \mathrm{eV}$ & $533.4 \mathrm{eV}$ & 534.7 & $536.9 \mathrm{eV}$ \\
\hline${ }^{\mathrm{a}} \mathrm{C}-\mathrm{A}$ & 40.9 & 51.5 & 7.6 & $\mathrm{ND}$ \\
${ }^{\mathrm{a}} \mathrm{C}-\mathrm{AO}$ & 43.6 & 49.9 & $\mathrm{ND}$ & 6.5 \\
${ }^{\mathrm{a}} \mathrm{C}-\mathrm{B}$ & 40.7 & 40.0 & 19.3 & $\mathrm{ND}$ \\
${ }^{\mathrm{a}} \mathrm{C}-\mathrm{BO}$ & 48.5 & 47.1 & 4.4 & $\mathrm{ND}$ \\
\hline $\mathrm{C}-\mathrm{AE}$ & 9.8 & 54.2 & & 36.1 \\
$\mathrm{C}-\mathrm{AOE}$ & 38.9 & 18.3 & & 42.8 \\
$\mathrm{C}-\mathrm{BE}$ & 50.1 & 42.5 & & 7.3 \\
$\mathrm{C}-\mathrm{BOE}$ & 48.4 & 44.8 & & 6.7 \\
\hline
\end{tabular}

${ }^{a} X P S$ results for the initial polymer-derived carbon reintroduced from literature [122].

Copyright 2017, with permission from Elsevier [122].

531.3-532.1 eV $-\mathrm{C}=\mathrm{O}$ in carbonyl/quinone or sulfoxides/sulfones

533.3-533.6 eV - C-O in phenol/epoxy, ether or thioethers/sulfonic

534.5-535.0 eV - -O- chemisorbed oxygen species

$536.9 \mathrm{eV}$ - - O- chemisorbed oxygen species, $\mathrm{C}=\mathrm{O}\left(\right.$ occluded $\mathrm{CO}$ or $\left.\mathrm{CO}_{2}\right)$ 
Table A11. The results of deconvolution of N $1 s$ core energy level spectra.

\begin{tabular}{lllll}
\hline Sample & $398.7 \mathrm{eV}$ & $400.1 \mathrm{eV}$ & 401.3 & 402.5 \\
\hline${ }^{\mathrm{a}} \mathrm{C}-\mathrm{A}$ & 20.4 & 30.5 & 35.9 & 13.2 \\
${ }^{\mathrm{a}} \mathrm{C}-\mathrm{AO}$ & 29.0 & 42.9 & 23.9 & 4.2 \\
${ }^{\mathrm{a}} \mathrm{C}-\mathrm{B}$ & 26.8 & 30.0 & 35.3 & 8.0 \\
${ }^{\mathrm{a}} \mathrm{C}-\mathrm{BO}$ & 31.0 & 39.6 & 24.1 & 5.3 \\
\hline $\mathrm{C}-\mathrm{AE}$ & 33.1 & 37.2 & 21.0 & 9.8 \\
$\mathrm{C}-\mathrm{AOE}$ & 28.6 & 42.2 & 22.0 & 7.2 \\
$\mathrm{C}-\mathrm{BE}$ & 28.7 & 34.5 & 28.9 & 7.9 \\
$\mathrm{C}-\mathrm{BOE}$ & 33.8 & 38.1 & 20.3 & 7.8 \\
\hline
\end{tabular}

${ }^{a}$ XPS results for the initial polymer-derived carbon reintroduced from literature [122].

Copyright 2017, with permission from Elsevier [122].

$398.7 \mathrm{eV}-\mathrm{N}-6$ in pyridine

$400.1 \mathrm{eV}-\mathrm{N}-5$ in pyrrolic/pyridone and azo nitrogen

$401.3 \mathrm{eV}-\mathrm{N}-\mathrm{Q}$ in quaternary and might be also from protonated amines

$402.5 \mathrm{eV}-\mathrm{N}-\mathrm{X}$ in pyridine-N-oxide, $\mathrm{C}-\mathrm{N}^{+} \mathrm{O}-\mathrm{C}, \mathrm{NO}_{2}$

Table A12. The results of deconvolution of $\mathrm{S} 2 p$ core energy level spectra.

\begin{tabular}{llllllll}
\hline Sample & $\begin{array}{l}164.1 \\
\mathrm{eV}\end{array}$ & $\begin{array}{l}165.2 \\
\mathrm{eV}\end{array}$ & $\begin{array}{l}166.8 \\
\mathrm{eV}\end{array}$ & $\begin{array}{l}167.2 \\
\mathrm{eV}\end{array}$ & $\begin{array}{l}167.7 \\
\mathrm{eV}\end{array}$ & $\begin{array}{l}168.8 \\
\mathrm{eV}\end{array}$ & $\begin{array}{l}169.2 \\
\mathrm{eV}\end{array}$ \\
\hline${ }^{\mathrm{a}} \mathrm{C}-\mathrm{A}$ & 40.4 & 6.4 & & 19.6 & & 32.7 & \\
${ }^{\mathrm{a}} \mathrm{C}-\mathrm{AO}$ & 81.4 & 6.7 & & 7.5 & & 4.4 & \\
${ }^{\mathrm{a}} \mathrm{C}-\mathrm{B}$ & 63.7 & 10.3 & & 11.6 & & 14.3 & \\
${ }^{\mathrm{a} C}-\mathrm{BO}$ & 73.2 & 15.6 & & 9.4 & & 2.9 & \\
\hline $\mathrm{C}-\mathrm{AE}$ & 61.9 & 7.6 & & & 12.9 & 17.6 & \\
$\mathrm{C}-\mathrm{AOE}$ & 73.6 & 7.1 & 11.6 & & & & 7.8 \\
$\mathrm{C}-\mathrm{BE}$ & 41.6 & 9.8 & & 23.0 & & 17.1 & 8.5 \\
C-BOE & 62.9 & 20.3 & & 10.8 & & 2.4 & 3.6 \\
\hline
\end{tabular}

${ }^{a} X P S$ results for the initial polymer-derived carbon reintroduced from literature [122].

Copyright 2017, with permission from Elsevier [122].

$164.1 \mathrm{eV}$ - R-S-S- in thiol, bisulfides configuration

$165.2 \mathrm{eV}-\mathrm{C}-\mathrm{S}-\mathrm{C} / \mathrm{R}-\mathrm{S}_{2}-\mathrm{OR}$ in sulfides and thioethers

166.8-167.7 eV $-\mathrm{R}_{2}-\mathrm{S}=\mathrm{O} / \mathrm{R}_{-} \mathrm{SO}_{2}-\mathrm{R}$ in sulfoxides, sulfones

$168.8 \mathrm{eV}-\mathrm{R}-\mathrm{SO}_{3} \mathrm{H}$ in sulfonic acids

$169.2 \mathrm{eV}-\mathrm{SO}_{4}{ }^{2-}$ in sulphate 
Table A13. Potentiometric titration results and surface $\mathrm{pH}$ of the carbons tested before and after exposure to ammonia.

\begin{tabular}{|c|c|c|c|c|c|c|c|c|c|}
\hline Sample & $\mathrm{pH}$ & $\mathrm{pK}_{\mathrm{a}} 4-5$ & $\mathrm{pK}_{\mathrm{a}} 5-6$ & $\mathrm{pK}_{\mathrm{a}} 6-7$ & $\mathrm{pK}_{\mathrm{a}} 7-8$ & $\mathrm{pK}_{\mathrm{a}} 8-9$ & $\mathrm{pK}_{\mathrm{a}} 9-10$ & $\mathrm{pK}_{\mathrm{a}} 10-11$ & All \\
\hline PFM-AO & 3.6 & $\begin{array}{c}4.39 \\
(0.122) \\
\end{array}$ & $\begin{array}{c}5.13 \\
(0.084) \\
\end{array}$ & $\begin{array}{c}6.23 \\
(0.207) \\
\end{array}$ & $\begin{array}{c}7.99 \\
(0.263) \\
\end{array}$ & & $\begin{array}{c}9.72 \\
(0.247) \\
\end{array}$ & & 0.923 \\
\hline $\begin{array}{l}\text { PFM-AO- } \\
\text { ED }\end{array}$ & 6.7 & $\begin{array}{c}4.33 \\
(0.133) \\
\end{array}$ & $\begin{array}{c}5.42 \\
(0.116) \\
\end{array}$ & $\begin{array}{c}6.33 \\
(0.129) \\
\end{array}$ & $\begin{array}{c}7.44 \\
(0.145) \\
\end{array}$ & $\begin{array}{c}8.60 \\
(0.215) \\
\end{array}$ & $\begin{array}{c}9.59 \\
(0.765) \\
\end{array}$ & & 1.503 \\
\hline RFM-AO & 3.7 & $\begin{array}{c}4.30 \\
(0.116)\end{array}$ & $\begin{array}{c}5.17 \\
(0.125)\end{array}$ & $\begin{array}{c}6.44 \\
(0.263)\end{array}$ & & $\begin{array}{c}8.24 \\
(0.284) \\
8.94 \\
(0.011)\end{array}$ & $\begin{array}{c}9.80 \\
(0.408)\end{array}$ & & 1.207 \\
\hline $\begin{array}{l}\text { RFM-AO- } \\
\text { ED }\end{array}$ & 6.3 & $\begin{array}{c}4.35 \\
(0.165)\end{array}$ & $\begin{array}{c}5.31 \\
(0.052)\end{array}$ & $\begin{array}{c}6.01 \\
(0.192)\end{array}$ & $\begin{array}{c}7.40 \\
(0.171)\end{array}$ & $\begin{array}{c}8.40 \\
(0.151)\end{array}$ & $\begin{array}{c}9.41 \\
(0.695)\end{array}$ & $\begin{array}{c}10.40 \\
(0.248)\end{array}$ & 1.674 \\
\hline PFU-AO & 3.7 & $\begin{array}{c}4.40 \\
(0.147)\end{array}$ & $\begin{array}{c}5.44 \\
(0.116)\end{array}$ & $\begin{array}{c}6.39 \\
(0.232)\end{array}$ & $\begin{array}{c}7.63 \\
(0.182)\end{array}$ & $\begin{array}{c}8.77 \\
(0.194)\end{array}$ & $\begin{array}{c}9.98 \\
(0.368)\end{array}$ & & 1.239 \\
\hline PFU-AO-ED & 6.1 & $\begin{array}{c}4.38 \\
(0.154)\end{array}$ & $\begin{array}{c}5.54 \\
(0.100)\end{array}$ & $\begin{array}{c}6.27 \\
(0.166)\end{array}$ & $\begin{array}{c}7.65 \\
(0.161)\end{array}$ & $\begin{array}{c}8.80 \\
(0.263)\end{array}$ & $\begin{array}{c}9.69 \\
(0.663)\end{array}$ & & 1.507 \\
\hline
\end{tabular}

Table A14. Content of elements on the surface (in at. \% from XPS analysis).

\begin{tabular}{lccccc}
\hline Sample & C & O & N & S & P \\
\hline BAX-AO & 83.0 & 16.2 & ND & ND & 0.8 \\
BAX-CSN-1\% & 85.2 & 12.7 & 1.3 & 0.1 & 0.7 \\
BAX-CSN-5\% & 84.1 & 13.6 & 1.6 & 0.2 & 0.5 \\
BAX-CS-1\% & 87.1 & 12.6 & ND & 0.0 & 0.3 \\
BAX-CS-5\% & 86.8 & 12.6 & ND & 0.3 & 0.3 \\
\hline BAX-AO-ED & 83.6 & 14.6 & 1.1 & ND & 0.7 \\
BAX-CSN-1\%-ED & 84.5 & 13.6 & 1.4 & ND & 0.5 \\
BAX-CSN-5\%-ED & 85.3 & 12.5 & 1.5 & 0.1 & 0.6 \\
BAX-CS-1\%-ED & 84.5 & 13.6 & 1.5 & 0.1 & 0.3 \\
BAX-CS-5\%-ED & 86.0 & 12.2 & 1.3 & 0.5 & 0.0 \\
\hline
\end{tabular}


Table A15. The results of deconvolution of $\mathrm{C} 1 s$ core energy level spectra.

\begin{tabular}{lcccccc}
\hline Sample & $284.2-$ & $286.3-$ & $287.0-$ & $288.3-$ & $289.8-$ & $\chi^{2}$ \\
& $284.8 \mathrm{eV}$ & $286.8 \mathrm{eV}$ & $287.7 \mathrm{eV}$ & $289.0 \mathrm{eV}$ & $290.7 \mathrm{eV}$ & \\
\hline BAX-AO & 71.57 & 14.33 & 5.82 & 5.35 & 2.94 & 19.82 \\
BAX-CSN-1\% & 72.97 & 14.05 & 5.85 & 4.60 & 2.53 & 21.52 \\
BAX-CSN-5\% & 72.78 & 13.53 & 6.23 & 4.74 & 2.71 & 10.91 \\
BAX-CS-1\% & 73.65 & 13.24 & 5.52 & 4.70 & 2.89 & 19.75 \\
BAX-CS-5\% & 73.39 & 13.84 & 5.65 & 4.18 & 2.95 & 17.29 \\
\hline BAX-AO-ED & 72.44 & 14.09 & 5.86 & 4.71 & 2.90 & 16.28 \\
BAX-CSN-1\%-ED & 71.89 & 14.24 & 6.20 & 4.71 & 2.96 & 14.46 \\
BAX-CSN-5\%-ED & 72.09 & 14.20 & 5.94 & 4.77 & 3.00 & 17.37 \\
BAX-CS-1\%-ED & 72.44 & 13.79 & 5.89 & 4.78 & 3.08 & 12.70 \\
BAX-CS-5\%-ED & 74.12 & 13.50 & 5.71 & 4.35 & 2.33 & 12.81 \\
\hline
\end{tabular}

284.2-284.8 eV - C-C in $\mathrm{sp}^{2}$ graphitic carbon 286.3-286.8 eV - C-(O, N, S, H) in phenolic, alcoholic, etheric $287.0-287.7 \mathrm{eV}-\mathrm{C}=\mathrm{O}$ in carbonyl or quinone 288.3-289.0 eV - O-C=O in carboxyl or ester $289.8-290.7 \mathrm{eV}-\pi-\pi^{*}, \pi$-electrons in aromatic rings

Table A16. The results of deconvolution of O $1 s$ core energy level spectra.

\begin{tabular}{lccc}
\hline Sample & $531.3-$ & $533.3-$ & $\chi^{2}$ \\
& $532.0 \mathrm{eV}$ & $533.6 \mathrm{eV}$ & \\
\hline BAX-AO & 46.37 & 53.63 & 4.20 \\
BAX-CSN-1\% & 44.29 & 55.71 & 3.00 \\
BAX-CSN-5\% & 44.49 & 55.51 & 1.82 \\
BAX-CS-1\% & 43.52 & 56.48 & 3.42 \\
BAX-CS-5\% & 43.22 & 56.78 & 3.85 \\
\hline BAX-AO-ED & 45.82 & 54.18 & 2.25 \\
BAX-CSN-1\%-ED & 44.72 & 55.28 & 3.34 \\
BAX-CSN-5\%-ED & 45.63 & 54.37 & 2.20 \\
BAX-CS-1\%-ED & 44.01 & 55.99 & 2.64 \\
BAX-CS-5\%-ED & 44.24 & 55.76 & 1.70 \\
\hline
\end{tabular}

531.3-532.1 eV $-\mathrm{C}=\mathrm{O}$ in carbonyl/quinone or sulfoxides/sulfones 533.3-533.6 eV - C-O in phenol/epoxy, ether or thioethers/sulfonic 
Table A17. The results of deconvolution of $\mathrm{N} 1 s$ core energy level spectra.

\begin{tabular}{lccc}
\hline Sample & $\begin{array}{c}399.5- \\
400.1 \mathrm{eV}\end{array}$ & $\begin{array}{c}401.5- \\
402.3 \mathrm{eV}\end{array}$ & $\chi^{2}$ \\
\hline BAX-AO & ND & ND & - \\
BAX-CSN-1\% & 63.09 & 36.91 & 0.58 \\
BAX-CSN-5\% & 50.35 & 49.65 & 1.21 \\
BAX-CS-1\% & ND & ND & - \\
BAX-CS-5\% & ND & ND & - \\
\hline BAX-AO-ED & 68.67 & 31.33 & 0.53 \\
BAX-CSN-1\%-ED & 64.74 & 35.26 & 0.63 \\
BAX-CSN-5\%-ED & 72.88 & 27.12 & 1.20 \\
BAX-CS-1\%-ED & 66.99 & 33.01 & 1.24 \\
BAX-CS-5\%-ED & 84.08 & 15.92 & 0.84 \\
\hline
\end{tabular}

399.5-400.1 eV - amines, amides

401.0-402.3 eV -quaternary $-\mathrm{N}$ and protonated amines

Table A18. The results of deconvolution of $\mathrm{S} 2 p$ core energy level spectra.

\begin{tabular}{lccc}
\hline Sample & $\begin{array}{c}163.5- \\
164.0 \mathrm{eV}\end{array}$ & $\begin{array}{c}166.0- \\
167.0 \mathrm{eV}\end{array}$ & $\chi^{2}$ \\
\hline BAX-AO & ND & ND & - \\
BAX-CSN-1\% & ND & ND & - \\
BAX-CSN-5\% & 73.28 & 26.72 & 2.18 \\
BAX-CS-1\% & ND & ND & - \\
BAX-CS-5\% & 93.17 & 6.83 & 2.19 \\
\hline BAX-AO-ED & ND & ND & - \\
BAX-CSN-1\%-ED & ND & ND & - \\
BAX-CSN-5\%-ED & 88.45 & 11.55 & 1.41 \\
BAX-CS-1\%-ED & ND & ND & - \\
BAX-CS-5\%-ED & 89.23 & 10.77 & 2.37 \\
\hline
\end{tabular}

163.5-164.0 eV - R-S-S- in thiol, bisulfides configuration

166.0-166.7 eV $-\mathrm{R}_{2}-\mathrm{S}=\mathrm{O} / \mathrm{R}-\mathrm{SO}_{2}-\mathrm{R}$ in sulfoxides, sulfones, sulfonic acid 


\section{Bibliography}

(1) Hanna, S. R.; Chang, J. C.; Strimaitis, D. G. Hazardous Gas Model Evaluation with Field Observations. Atmos. Environ. Part A. Gen. Top. 1993, 27, 2265-2285.

(2) Wales, D. J.; Grand, J.; Ting, V. P.; Burke, R. D.; Edler, K. J.; Bowen, C. R.; Mintova, S.; Burrows, A. D. Gas Sensing Using Porous Materials for Automotive Applications. Chem. Soc. Rev. 2015, 44, 4290-4321.

(3) Ryabtsev, S.; Shaposhnick, A.; Lukin, A.; Domashevskaya, E. Application of Semiconductor Gas Sensors for Medical Diagnostics. Sens. Actuators, B 1999, 59, 26-29.

(4) Publishing, I.; Yunusa, Z.; Hamidon, M. N.; Kaiser, A.; Awang, Z. Gas Sensors: A Review. Sensors and Transducers 2014, 168, 61-75.

(5) Korotcenkov, G. Introduction. In Handbook of Gas Sensor Materials; Potyrailo, R. A., Eds.; Springer: New York, 2006; pp 5-6.

(6) Potyrailo, R. A.; Leach, A.; Morris, W. G.; Gamage, S. K. Chemical Sensors Based on Micromachined Transducers with Integrated Piezoresistive Readout. Anal. Chem. 2006, $78,5633-5638$.

(7) Potyrailo, R. A. Polymeric Sensor Materials: Toward an Alliance of Combinatorial and Rational Design Tools? Angew. Chem. Int. Ed. 2006, 45, 702-723.

(8) Meyyappan, M. Carbon Nanotube-Based Chemical Sensors. Small 2016, 12, 2118-2129.

(9) Gautam, M. Development of Graphene Based Gas Sensors, Ph. D. Thesis, The University of Toledo, Ohio, USA, 2013.

(10) Varghese, S. S.; Lonkar, S.; Singh, K. K.; Swaminathan, S.; Abdala, A. Recent Advances in Graphene Based Gas Sensors. Sens. Actuators, B. 2015, 218, 160-183.

(11) Wang, C.; Yin, L.; Zhang, L.; Xiang, D.; Gao, R. Metal Oxide Gas Sensors: Sensitivity and Influencing Factors. Sensors 2010, 10, 2088-2106.

(12) Lundström, I. Approaches and Mechanisms to Solid State Based Sensing. Sens. Actuators, B 1996, 35, 11-19.

(13) Capone, S.; Forleo, A; Francioso, L.; Rella, R.; Siciliano, P.; Spadavecchia, J.; Presicce, D. S.; Taurino, A. M. Solid State Gas Sensors: State of the Art and Future Activities. $J$. Optoelectron. Adv. Mater. 2003, 5, 1335-1348.

(14) Krebs, P.; Grisel, A. Sens. Actuators, B. 1993, 14, 155-158. 
(15) Hodgkinson, J.; Tatam, R. P. Optical Gas Sensing: A Review. Meas. Sci. Technol. 2013, 24, 012004.

(16) Tan, Q.; Pei, X.; Zhu, S.; Sun, D.; Liu, J.; Xue, C.; Liang, T.; Zhang, W.; Xiong, J. Development of an Optical Gas Leak Sensor for Detecting Ethylene, Dimethyl Ether and Methane. Sensors 2013, 13, 4157-4169.

(17) Sutka, A.; Gross, K. A. Spinel Ferrite Oxide Semiconductor Gas Sensors. Sens. Actuators, $B$ 2016, 222, 95-105.

(18) Tricoli, A.; Righettoni, M.; Teleki, A. Semiconductor Gas Sensors: Dry Synthesis and Application. Angew. Chem. Int. Ed. Engl. 2010, 49, 7632-7659.

(19) Batzill, M. Surface Science Studies of Gas Sensing Materials: $\mathrm{SnO}_{2}$. Sensors 2006, 6, $1345-1366$.

(20) Chang, S. Oxygen Chemisorption on Tin Oxide: Correlation between Electrical Conductivity and EPR Measurements. J. Vac. Sci. Technol. 1980, 17, 366-369.

(21) Ogawa, H.; Nishikawa, M.; Abe, A. Hall Measurement Studies and an Electrical Conduction Model of Tin Oxide Ultrafine Particle Films. J. Appl. Phys. 1982, 53, 44484455.

(22) Feng, P.; Shao, F.; Shi, Y.; Wan, Q. Gas Sensors Based on Semiconducting Nanowire Field-Effect Transistors. Sensors 2014, 14, 17406-17429.

(23) Ferrari, V. ; Lucklum, R. Overview of Acoustic-Wave Microsensors. In Piezoelectric Transducers and Applications; Arnau, A., Eds.; Springer: Berlin, 2008; pp 39-59.

(24) Hoummady, M.; Campitelli, A.; Wlodarski, W. Acoustic Wave Sensors: Design, Sensing Mechanisms and Applications. Smart Mater. Struct. 1999, 6, 647-657.

(25) Liu, J.; Lu, Y. Response Mechanism for Surface Acoustic Wave Gas Sensors Based on Surface-Adsorption. Sensors 2014, 14, 6844-6853.

(26) Ballantine Jr, D. S.; Wohltjen, H. Surface Acoustic Wave Devices for Chemical Analysis. Anal. Chem. 1989, 61, 704A-715A.

(27) Benes, E.; Groschl, M.; Seifert, F.; Pohl, A. Comparison between BAW and SAW Sensor Principles. IEEE Trans. Ultrason. Ferroelectr. Freq. Control 1998, 45, 1314-1330.

(28) Nomura, T.; Takebayashi, R.; Saitoh, A. Chemical Sensor Based on Surface Acoustic Wave Resonator Using Langmuir-Blodgett Film. IEEE Trans. Ultrason. Ferroelectr. Freq. Control 1998, 45, 1261-1265. 
(29) Stradiotto, N. R.; Yamanaka, H.; Zanoni, M. V. B. Review Electrochemical Sensors : A Powerful Tool in Analytical Chemistry. J.Braz.Chem.Soc 2003, 14, 159-173.

(30) Xiong, L.; Compton, R. G. Amperometric Gas Detection: A Review. Int. J. Electrochem. Sci. 2014, 9, 7152-7181.

(31) Park, C. O.; Fergus, J. W.; Miura, N.; Park, J.; Choi, A. Solid-State Electrochemical Gas Sensors. Ionics 2009, 15, 261-284.

(32) Dunst, K.; Jasiński, G.; Jasiński, P. Potentiometric Oxygen Sensor With Solid State Reference Electrode. Metrol. Meas. Syst. 2014, 21, 205-216.

(33) Jaffrezic-Renault, N.; Dzyadevych, S. V. Conductometric Microbiosensors for Environmental Monitoring. Sensors 2008, 8, 2569-2588.

(34) Majoo, S.; Schwank, J. W. Fabrication of Conductometric Gas-Sensing Films by Selected Area Chemical-Vapor Deposition. Aiche Journal 1997, 43, 2760-2764.

(35) Soleimanpour, A. M. Synthesis, Fabrication and Surface Modification of Nanocrystalline Nickel Oxide for Electronic Gas Sensors. Ph. D. Thesis, The University of Toledo, Ohio, USA, 2013.

(36) Cuscó, O. M. Gas Sensors Based on Carbon Nanofibers: A Low Power Consumption Approach Gas Sensors Based on Carbon Nanofibers. Ph. D. Thesis, University of Barcelona, Barcelona, Spain, 2016.

(37) Arafat, M. M.; Dinan, B.; Akbar, S. A.; Haseeb, A. S. M. A. Gas Sensors Based on One Dimensional Nanostructured Metal-Oxides: A Review. Sensors 2012, 12, 7207-7258.

(38) Llobet, E. Gas Sensors Using Carbon Nanomaterials: A Review. Sens. Actuators, B 2013, $179,32-45$.

(39) Bai, H.; Shi, G. Gas Sensors Based on Conducting Polymers. Sensors 2007, 7, 267-307.

(40) Zhang, Y.; Kim, J. J.; Chen, D.; Tuller, H. L.; Rutledge, G. C. Electrospun Polyaniline Fibers as Highly Sensitive Room Temperature Chemiresistive Sensors for Ammonia and Nitrogen Dioxide Gases. Adv. Funct. Mater. 2014, 24, 4005-4014.

(41) Uh, K.; Kim, T.; Lee, C. W.; Kim, J. M. A Precursor Approach to Electrospun Polyaniline Nanofibers for Gas Sensors. Macromol. Mater. Eng. 2016, 301, 1320-1326.

(42) Liu, X.; Cheng, S.; Liu, H.; Hu, S.; Zhang, D.; Ning, H. A Survey on Gas Sensing Technology. Sensors 2012, 12, 9635-9665.

(43) Toxicological profile for ammonia, U.S. Department of health and human services, Public Health Service, Agency for Toxic Substances and Disease Registry, 2004. 
(44) Timmer, B.; Olthuis, W.; Berg, A. Van Den. Ammonia Sensors and Their Applications-a Review. Sens. Actuators, B 2005, 107, 666-677.

(45) Li, Y.; Schichtel, B. A; Walker, J. T.; Schwede, D. B.; Chen, X.; Lehmann, C. M. B.; Puchalski, M. A; Gay, D. A; Collett, J. L. Increasing Importance of Deposition of Reduced Nitrogen in the United States. Proc. Natl. Acad. Sci. U. S. A. 2016, 113, 5874-5879.

(46) Kowalchuk, G. A.; Stephen, J. R. Ammonia-Oxidizing Bacteria: A Model for Molecular Microbial Ecology. Annu. Rev. Microbiol. 2001, 55, 485-529.

(47) Yebo, N. A.; Sree, S. P.; Levrau, E.; Detavernier, C.; Hens, Z.; Martens, J. A.; Baets, R. Selective and Reversible Ammonia Gas Detection with Nanoporous Film Functionalized Silicon Photonic Micro-Ring Resonator. Opt. Express 2012, 20, 11855.

(48) Baek, B. H.; Aneja, V. P.; Tong, Q. Chemical Coupling between Ammonia, Acid Gases, and Fine Particles. Environ. Pollut. 2004, 129, 89-98.

(49) Webber, M. E.; MacDonald, T.; Pushkarsky, M. B.; Patel, C. K. N.; Zhao, Y.; Marcillac, N.; Mitloehner, F. M. Agricultural Ammonia Sensor Using Diode Lasers and Photoacoustic Spectroscopy. Meas. Sci. Technol. 2005, 16, 1547-1553.

(50) Pijolat, C.; Pupier, C.; Sauvan, M.; Tournier, G.; Lalauze, R. Gas Detection for Automotive Pollution Control. Sens. Actuators, B 1999, 59, 195-202.

(51) Wallin, M.; Karlsson, C. J.; Skoglundh, M.; Palmqvist, A. Selective Catalytic Reduction of NOx with $\mathrm{NH}_{3}$ over Zeolite H-ZSM-5: Influence of Transient Ammonia Supply. J. Catal. 2003, 218, 354-364.

(52) Koebel, M.; Elsener, M.; Kleemann, M. Urea-SCR: A Promising Technique to Reduce $\mathrm{NO}_{\mathrm{x}}$ Emissions from Automotive Diesel Engines. Catal. Today 2000, 59, 335-345.

(53) Buckley, S. G.; Damm, C. J.; Vitovec, W. M.; Sgro, L. A.; Sawyer, R. F.; Koshland, C. P.; Lucas, D. Ammonia Detection and Monitoring with Photofragmentation Fluorescence. Appl. Opt. 1998, 37, 8382-8391.

(54) Manchester, K. L. Man of Destiny: The Life and Work of Fritz Haber. Endeavour 2002, 26, 64-69.

(55) Colonna, P.; Gabrielli, S. Industrial Trigeneration Using Ammonia-Water Absorption Refrigeration Systems (AAR). Appl. Therm. Eng. 2003, 23, 381-396.

(56) Close, L. G.; Catlin, F. I.; Cohn, A. M. Acute and Chronic Effects of Ammonia Burns on the Respiratory Tract. Arch. Otolaryngol. 1980, 106, 151-158. 
(57) Leduc, D.; Gris, P.; Lheureux, P.; Gevenois, P. A; De Vuyst, P.; Yernault, J. C. Acute and Long Term Respiratory Damage Following Inhalation of Ammonia. Thorax 1992, 47, 755757.

(58) Brannelly, N. T.; Hamilton-Shield, J. P.; Killard, A. J. The Measurement of Ammonia in Human Breath and Its Potential in Clinical Diagnostics. Crit. Rev. Anal. Chem. 2016, 46, $1-12$.

(59) Hibbard, T.; Crowley, K.; Kelly, F.; Ward, F.; Holian, J.; Watson, A.; Killard, A. J. Point of Care Monitoring of Hemodialysis Patients with a Breath Ammonia Measurement Device Based on Printed Polyaniline Nanoparticle Sensors. Anal. Chem. 2013, 85, 1215812165.

(60) Zhang, T.; Nix, M. B.; Yoo, B. Y.; Deshusses, M. A.; Myung, N. V. Electrochemically Functionalized Single-Walled Carbon Nanotube Gas Sensor. Electroanalysis 2006, 18, $1153-1158$.

(61) Zhang, T.; Mubeen, S.; Bekyarova, E.; Yoo, B. Y.; Haddon, R. C.; Myung, N. V; Deshusses, M. A. Poly(m-Aminobenzene Sulfonic Acid) Functionalized Single-Walled Carbon Nanotubes Based Gas Sensor. Nanotechnology 2007, 18, 165504-165506.

(62) Kang, D.; Wang, B.; Wang, X.; Li, Y.; Chen, Z.; He, C.; Wu, Y. Stably Dispersed Metallophthalocyanine Noncovalently Bonded to Multiwalled Carbon Nanotubes for Ammonia Sensing at Room Temperature. Sensors Actuators, B 2017, 246, 262-270.

(63) Abdelhalim, A.; Abdellah, A.; Scarpa, G.; Lugli, P. Metallic Nanoparticles Functionalizing Carbon Nanotube Networks for Gas Sensing Applications. Nanotechnology 2014, 25, 055208-055217.

(64) Penza, M.; Cassano, G.; Rossi, R.; Alvisi, M.; Rizzo, A.; Signore, M. A.; Dikonimos, T.; Serra, E.; Giorgi, R. Enhancement of Sensitivity in Gas Chemiresistors Based on Carbon Nanotube Surface Functionalized with Noble Metal (Au, Pt) Nanoclusters. Appl. Phys. Lett. 2007, 90, 1-4.

(65) Tadjarodi, A.; Ferdowsi, S. M. The Novel Synthesis of Highly Water-Soluble Few-Layer Graphene Nanosheets by a Simple One-Pot Chemical Route and without Any Modification. Mater. Chem. Phys. 2016, 183, 297-305.

(66) Pei, S.; Cheng, H. M. The Reduction of Graphene Oxide. Carbon 2012, 50, 3210-3228.

(67) Mi, W.; Chiu, S.-W.; Xue, T.; Chen, Y.; Qi, H.; Yang, Y.; Tang, K.-T.; Ren, T.-L. Highly Sensitive and Portable Gas Sensing System Based on Reduced Graphene Oxide. Tsinghua Sci. Technol. 2016, 21, 435-441.

(68) Peng, Y.; Li, J. Ammonia Adsorption on Graphene and Graphene Oxide: A FirstPrinciples Study. Front. Environ. Sci. Eng. 2013, 7, 403-411. 
(69) Tang, S.; Cao, Z. Adsorption of Nitrogen Oxides on Graphene and Graphene Oxides: Insights from Density Functional Calculations. J. Chem. Phys. 2011, 134, 044710044724.

(70) Hu, N.; Yang, Z.; Wang, Y. Y.; Zhang, L.; Wang, Y. Y.; Huang, X.; Wei, H.; Wei, L.; Zhang, Y. Ultrafast and Sensitive Room Temperature $\mathrm{NH}_{3}$ Gas Sensors Based on Chemically Reduced Graphene Oxide. Nanotechnology 2014, 25, 025502-025510.

(71) Niu, F.; Tao, L. M.; Deng, Y. C.; Wang, Q. H.; Song, W. G. Phosphorus Doped Graphene Nanosheets for Room Temperature $\mathrm{NH}_{3}$ Sensing. New J. Chem. 2014, 38, 2269-2272.

(72) Seekaew, Y.; Lokavee, S.; Phokharatkul, D.; Wisitsoraat, A.; Kerdcharoen, T.; Wongchoosuk, C. Low-Cost and Flexible Printed Graphene-PEDOT:PSS Gas Sensor for Ammonia Detection. Organic Electronics 2014, 15, 2971-2981.

(73) Huang, X.; Hu, N.; Gao, R.; Yu, Y.; Wang, Y.; Yang, Z.; Siu-Wai Kong, E.; Wei, H.; Zhang, Y. Reduced Graphene Oxide-polyaniline Hybrid: Preparation, Characterization and Its Applications for Ammonia Gas Sensing. J. Mater. Chem. 2012, 22, 22488-22495.

(74) Wang, Y. Y.; Zhang, L.; Hu, N.; Wang, Y. Y.; Zhang, Y.; Zhou, Z.; Liu, Y.; Shen, S.; Peng, C. Ammonia Gas Sensors Based on Chemically Reduced Graphene Oxide Sheets Self-Assembled on Au Electrodes. Nanoscale Res. Lett. 2014, 9, 251.

(75) Xiang, C.; Jiang, D.; Zou, Y.; Chu, H.; Qiu, S.; Zhang, H.; Xu, F.; Sun, L.; Zheng, L. Ammonia Sensor Based on Polypyrrole-graphene Nanocomposite Decorated with Titania Nanoparticles. Ceram. Int. 2015, 41, 6432-6438.

(76) Teerapanich, P.; Myint, M. T. Z.; Joseph, C. M.; Hornyak, G. L.; Dutta, J. Development and Improvement of Carbon Nanotube-Based Ammonia Gas Sensors Using Ink-Jet Printed Interdigitated Electrodes. IEEE Trans. Nanotechnol. 2013, 12, 255-262.

(77) Cui, S.; Pu, H.; Lu, G.; Wen, Z.; Mattson, E. C.; Hirschmugl, C.; GajdardziskaJosifovska, M.; Weinert, M.; Chen, J. Fast and Selective Room-Temperature Ammonia Sensors Using Silver Nanocrystal-Functionalized Carbon Nanotubes. ACS Appl. Mater. Interfaces 2012, 4, 4898-4904.

(78) Majzlíková, P.; Sedláček, J.; Práek, J.; Pekárek, J.; Svatoš, V.; Bannov, A.; Jašek, O.; Synek, P.; Eliáš, M.; Zajíčková, L.; et al. Sensing Properties of Multiwalled Carbon Nanotubes Grown in MW Plasma Torch: Electronic and Electrochemical Behavior, Gas Sensing, Field Emission, IR Absorption. Sensors 2015, 15, 2644-2661.

(79) Gautam, M.; Jayatissa, A. H. Adsorption Kinetics of Ammonia Sensing by Graphene Films Decorated with Platinum Nanoparticles Adsorption Kinetics of Ammonia Sensing by Graphene Films Decorated with Platinum Nanoparticles. 2012, 111, 094317-094129. 
(80) Lin, Q.; Li, Y.; Yang, M. Tin Oxide/graphene Composite Fabricated via a Hydrothermal Method for Gas Sensors Working at Room Temperature. Sensors Actuators, B 2012, $173,139-147$.

(81) H Göpel, W.; Schierbaum K.-D; Zemel, J.N. Sensors A Comprehensive Survey. In Specific Molecular Interactions and Detection Principles, Göpel, W.; Jones, T.A; Kleitz, M.; Lundström, J.; Seiyama, T., Eds.; VCH: Weinheim, 1991; pp 137-145.

(82) Travlou, N. A.; Seredych, M.; Rodríguez-Castellón, E.; Bandosz, T. J. Activated CarbonBased Gas Sensors: Effects of Surface Features on the Sensing Mechanism. J. Mater. Chem. A 2015, 3, 3821-3831.

(83) Travlou, N. A.; Ushay, C.; Seredych, M.; Rodríguez-Castellón, E.; Bandosz, T. J. Nitrogen-Doped Activated Carbon-Based Ammonia Sensors: Effect of Specific Surface Functional Groups on Carbon Electronic Properties. ACS Sensors 2016, 1, 591-599.

(84) Singh, K.; Travlou, N. A.; Bashkova, S.; Rodríguez-Castellón, E.; Bandosz, T. J. Nanoporous Carbons as Gas Sensors: Exploring the Surface Sensitivity. Carbon 2014, 80, 183-192.

(85) Travlou, N. A.; Seredych, M.; Rodríguez-Castellón, E.; Bandosz, T. J. Insight into Ammonia Sensing on Heterogeneous S- and N-Co-Doped Nanoporous Carbons. Carbon 2016, 96, 1014-1021.

(86) Travlou, N. A.; Bandosz, T. J. N-Doped Polymeric Resin-Derived Porous Carbons as Efficient Ammonia Removal and Detection Media. Carbon 2017, 117, 228-239.

(87) Jagiello, J.; Olivier, J. P. Carbon Slit Pore Model Incorporating Surface Energetical Heterogeneity and Geometrical Corrugation. Adsorption 2013, 19, 777-783.

(88) Jagiello, J.; Olivier, J. P. 2D-NLDFT Adsorption Models for Carbon Slit-Shaped Pores with Surface Energetical Heterogeneity and Geometrical Corrugation. Carbon 2013, 55, $70-80$.

(89) Jagiellot, J. Stable Numerical Solution of the Adsorption Integral Equation Using Splines. Langmuir 1994, 10, 2778-2785.

(90) Jagiello, J.; Bandosz, T. J.; Schwarz, J. A. Carbon Surface Characterization in Terms of Its Acidity Constant Distribution. Carbon 1994, 32, 1026-1028.

(91) Travlou, N. A.; Bandosz, T. J. Toxic Gas Sensing on Nanoporous Carbons. Adsorption 2017, 23, 271-280.

(92) Ferreira, M. G. S.; Engineering, G. Semiconducting Properties of Oxide and Passive Films Formed on AISI 304 Stainless Steel and Alloy 600. J. Braz. Chem. Soc. 2002, 13, 1-14.

(93) Wang, Y. C.; Chang, C.-Y.; Yeh, T. F.; Lee, Y. L.; Teng, H. Formation of Internal p-n Junctions in $\mathrm{Ta}_{3} \mathrm{~N}_{5}$ Photoanodes for Water Splitting. J. Mater. Chem. A 2014, 2, 20570 20577. 
(94) Qi, X.; She, G.; Huang, X.; Zhang, T.; Wang, H.; Mua, L.; Shi, W. High-Performance N$\mathrm{Si} / \alpha-\mathrm{Fe}_{2} \mathrm{O}_{3}$ Core/Shell Nanowire Array Photoanode towards Photoelectrochemical Water Splitting. Nanoscale 2014, 6, 3182-3189.

http://krohne.com/en/services/dielectric-constants/, accessed April 2017

(96) Seredych, M.; Petit, C.; Tamashausky, A. V.; Bandosz, T. J. Role of Graphite Precursor in the Performance of Graphite Oxides as Ammonia Adsorbents. Carbon 2009, 47, 445456.

(97) Petit, C.; Kante, K.; Bandosz, T. J. The Role of Sulfur-Containing Groups in Ammonia Retention on Activated Carbons. Carbon 2010, 48, 654-667.

(98) Le Leuch, L. M.; Bandosz, T. J. The Role of Water and Surface Acidity on the Reactive Adsorption of Ammonia on Modified Activated Carbons. Carbon 2007, 45, 568-578.

(11) Usachov, D. Y.; Fedorov, A. V; Vilkov, O. Y.; Senkovskiy, B. V; Adamchuk, V. K.; Andryushechkin, B. V; Vyalikh, D. V. Synthesis and Electronic Structure of NitrogenDoped Graphene. Phys. Solid State 2013, 55, 1325-1332.

(100) Fujimoto, Y.; Saito, S. Energetics and Electronic Structures of Pyridine-Type Defects in Nitrogen-Doped Carbon Nanotubes. Phys. E Low-Dimensional Syst. Nanostructures 2011, 43, 677-680.

(101) Fujimoto, Y.; Saito, S. Formation, Stabilities, and Electronic Properties of Nitrogen Defects in Graphene. Phys. Rev. B - Condens. Matter Mater. Phys. 2011, 84, 1-7.

(102) Usachov, D.; Vilkov, O.; Grüneis, A.; Haberer, D.; Fedorov, A; Adamchuk, V. K.; Preobrajenski, A. B.; Dudin, P.; Barinov, A.; Oehzelt, M.; et al. Nitrogen-Doped Graphene: Efficient Growth, Structure, and Electronic Properties. Nano Lett. 2011, 11, 5401-5407.

(103) Ni, S.; Li, Z. Y.; Yang, J. L. Oxygen Molecule Dissociation on Carbon Nanostructures with Different Types of Nitrogen Doping. Nanoscale 2012, 4, 1184-1189.

(104) Sheng, Z. H.; Shao, L.; Chen, J. J.; Bao, W. J.; Wang, F. B.; Xia, X. H. Catalyst-Free Synthesis of Nitrogen-Doped Graphene via Thermal Annealing Graphite Oxide with Melamine and Its Excellent Electrocatalysis. ACS Nano 2011, 5, 4350-4358.

(105) Zhou, J.; Zhang, Z.; Xing, W.; Yu, J.; Han, G.; Si, W.; Zhuo, S. Nitrogen-Doped Hierarchical Porous Carbon Materials Prepared from Meta-Aminophenol Formaldehyde Resin for Supercapacitor with High Rate Performance. Electrochim. Acta 2015, 153, 6875.

(106) Scardamaglia, M.; Struzzi, C.; Aparicio Rebollo, F. J.; De Marco, P.; Mudimela, P. R.; Colomer, J.-F.; Amati, M.; Gregoratti, L.; Petaccia, L.; Snyders, R.; Bittencourt.; C. 
Tuning Electronic Properties of Carbon Nanotubes by Nitrogen Grafting: Chemistry and Chemical Stability. Carbon 2015, 83, 118-127.

(107) Conte, M. L.; Carroll, K. S. The chemistry of thiol oxidation and detection. In Oxidative Stress and Redox Regulation; Jakob, U., Reichmann, D., Eds.; Springer: Dordrecht, The Netherlands, 2013.

(108) Gonçalves, M.; Sánchez-García, L.; Oliveira Jardim, E. De; Silvestre-Albero, J.; Rodríguez-Reinoso, F. Ammonia Removal Using Activated Carbons: Effect of the Surface Chemistry in Dry and Moist Conditions. Environ. Sci. Technol. 2011, 45, 1060510610.

(109) Huang, C. C.; Li, H. S.; Chen, C. H. Effect of Surface Acidic Oxides of Activated Carbon on Adsorption of Ammonia. J. Hazard. Mater. 2008, 159, 523-527.

(110) Seredych, M.; Hulicova-Jurcakova, D.; Lu, G. Q.; Bandosz, T. J. Surface Functional Groups of Carbons and the Effects of Their Chemical Character, Density and Accessibility to Ions on Electrochemical Performance. Carbon 2008, 46, 1475-1488.

(111) Seredych, M.; Bandosz, T. J. Desulfurization of Digester Gas on Wood-based Activated Carbons Modified with Nitrogen: Importance of Surface Chemistry. Energy Fuels 2008, $22,850-859$.

(112) Bandosz, T. J. On the Adsorption/Oxidation of Hydrogen Sulfide on Activated Carbons at Ambient Temperatures. J. Colloid Interface Sci. 2002, 246, 1-20.

(113) Lahaye, J.; Nansé, G.; Bagreev, A.; Strelko, V. Porous Structure and Surface Chemistry of Nitrogen Containing Carbons from Polymers. Carbon 1999, 37, 585-590.

(114) Bagreev, A.; Bashkova, S.; Bandosz, T.; Menendez, A.; Dukhno, I.; Tarasenko, Y. Nitrogen Enriched Activated Carbons as Adsorbents and Catalysts in Desulfurization Technologies. ACS Div. Fuel Chem. Prepr. 2004, 49, 920-922.

(115) Jeong, H. K.; Yang, C.; Kim, B. S.; Kim, K. Valence Band of Graphite Oxide. Europhys. Lett. 2010, 92, 37005.

(116) Liu, C.C.; Walters A. B.; Vannice, M. A. Measurement of Electrical Properties of a Carbon Black. Carbon 1995, 33, 1699-1708.

(117) Fujimoto, Y.; Saito, S. Adsorption of Molecules on Nitrogen-Doped Graphene : A FirstPrinciples Study. JPS Conference Proceedings 2015, 4, 012002.

(118) Fujimoto, Y.; Saito, S. Hydrogen Adsorption and Anomalous Electronic Properties of Nitrogen-Doped Graphene. J. Appl. Phys. 2014, 115, 1-6. 
(119) Fujimoto, Y.; Saito, S. Structure and Stability of Hydrogen Atom Adsorbed on NitrogenDoped Carbon Nanotubes. J. Phys. Conf. Ser. 2011, 302, 012006.

(120) Im, J. S.; Kang, S. C.; Lee, S. H.; Lee, Y. S. Improved Gas Sensing of Electrospun Carbon Fibers Based on Pore Structure, Conductivity and Surface Modification. Carbon 2010, $48,2573-2581$

(121) Weast, R. C.; Astle, M. J. CRC Handbook of Chemistry and Physics, 62nd ed.; CRC Press: Boca Raton, FL, 1981.

(122) Seredych, M.; Rodríguez-Castellón, E.; Biggs, M. J.; Skinner, W.; Bandosz, T. J. Effect of Visible Light and Electrode Wetting on the Capacitive Performance of S- and N-Doped Nanoporous Carbons: Importance of Surface Chemistry. Carbon 2014, 78, 540-558.

(123) Strelko, V. V; Kuts, V. S.; Thrower, P. A. On the Mechanism of Possible Influence of Heteroatoms of Nitrogen, Boron and Phosphorus in a Carbon Matrix on the Catalytic Activity of Carbons in Electron Transfer Reactions. Carbon 2000, 38, 1499-1503.

(124) Stöhr, B.; Boehm, H. P.; Schlögl, R. Enhancement of the Catalytic Activity of Activated Carbons in Oxidation Reactions by Thermal Treatment with Ammonia or Hydrogen Cyanide and Observation of a Superoxide Species as a Possible Intermediate. Carbon 1991, 29, 707-720.

(125) Kondo, T.; Casolo, S.; Suzuki, T.; Shikano, T. Atomic Scale Characterization of NitrogenDoped Graphite: Effects of the Dopant Nitrogen on the Electronic Structure of the Surrounding Carbon Atoms. Phys Rev B 2012, 86, 1-37.

(126) Strelko, V. V.; Kartel, N. T.; Dukhno, I. N.; Kuts, V. S.; Clarkson, R. B.; Odintsov, B. M. Mechanism of Reductive Oxygen Adsorption on Active Carbons with Various Surface Chemistry. Surf. Sci. 2004, 548, 281-290.

(127) Travlou, N. A.; Bandosz, T. J. Nanoporous Carbon-Composites as Gas Sensors: Importance of the Specific Adsorption Forces for Ammonia Sensing Mechanism. Carbon, 2017, 121, 114-126.

(128) Bandosz, T. J.; Petit, C. On the Reactive Adsorption of Ammonia on Activated Carbons Modified by Impregnation with Inorganic Compounds. J. Colloid Interface Sci. 2009, 338, 329-345.

(129) Otomo, I.; Kuroda, C. Effect of the Position of Reaction-Site in Amphipathic-Type Thioester in Aqueous Amidation Reaction. Adv. Chem. Eng. Sci. 2015, 5, 311-316.

(130) Tu, N. D. K.; Choi, J.; Park, C. R.; Kim, H. Remarkable Conversion between N- and PType Reduced Graphene Oxide on Varying the Thermal Annealing Temperature. Chem. Mater. 2015, 27, 7362-7369. 
(131) Yamamoto, Т.; Koizumi, Т. A. Synthesis of П-Conjugated Polymers Bearing Electronic and Optical Functionalities by Organometallic Polycondensations and Their Chemical Properties. Polymer 2007, 48, 5449-5472.

(132) Travlou, N. A.; Rodríguez-Castellón, E.; Bandosz, T. J. Sensing of $\mathrm{NH}_{3}$ on Heterogeneous Nanoporous Carbons in the Presence of Humidity. Carbon 2016, 100, 64-73.

(133) Petit, C., Factors Affecting the Removal of Ammonia from Air on Carbonaceous Materials. In: Role of water, Springer Theses, Springer: Boston, 2012, pp 83-87.

(134) McCallum, C. L.; Bandosz, T. J.; McGrother, S. C.; Müller, E. A.; Gubbins, K. E. A Molecular Model for Adsorption of Water on Activated Carbon: Comparison of Simulation and Experiment. Langmuir 1999, 15, 533-544.

(135) Jimenez, I.; Vila, A. M.; Calveras, A. C.; Morante, J. R. Gas-Sensing Properties of Catalytically Modified $\mathrm{WO}_{3}$ with Copper and Vanadium for $\mathrm{NH}_{3}$ Detection. IEEE Sens. J. 2005, 5, 385-391.

(136) Latif, U.; Dickert, F. Graphene Hybrid Materials in Gas Sensing Applications. Sensors 2015, 15, 30504-30524.

(137) Chmielarz, L.; Jabloska, M. Advances in Selective Catalytic Oxidation of Ammonia to Dinitrogen: A Review. RSC Adv. 2015, 5, 43408-43431.

(138) Agmon, N. The Grotthuss Mechanism. Chem. Phys. Lett. 1995, 244, 456-462.

(139) Bandosz, T. J.; Ania, C. O. Surface chemistry of activated carbons and its characterization. In Activated Carbon Surfaces in Environmental Remediation; Bandosz, T. J., Eds.; Elsevier: New York, 2013. 